Universidade de Brasília

Instituto de Biologia

Departamento de Botânica

Programa de Pós-Graduação em Botânica

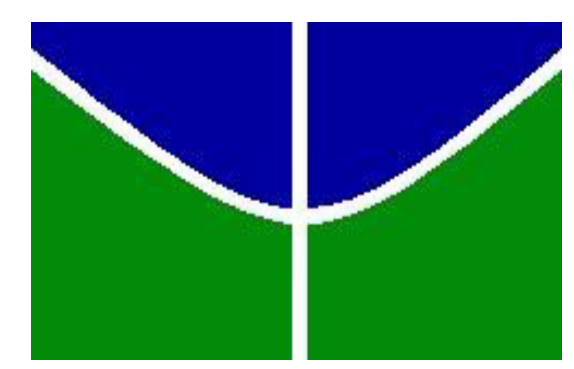

\title{
A Família Thuidiaceae Schimp. no Brasil, um estudo taxonômico, filogenético e morfológico.
}

ABEL EUSTÁQUIO ROCHA SOARES

Brasília - DF

Maio, 2015 
Universidade de Brasília

Instituto de Biologia

Departamento de Botânica

Programa de Pós-Graduação em Botânica

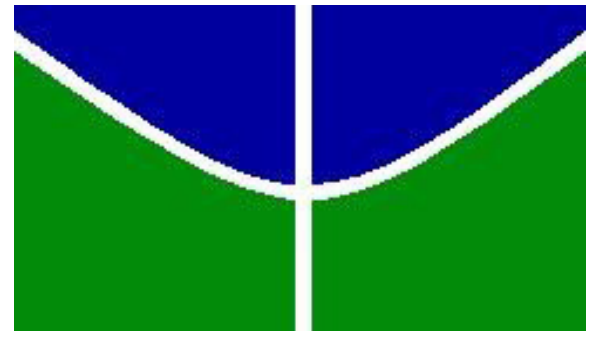

\section{A Família Thuidiaceae Schimp. no Brasil, um estudo taxonômico, filogenético e morfológico.}

\section{ABEL EUSTÁQUIO ROCHA SOARES}

Tese apresentada ao Programa de Pós-Graduação em Botânica da Universidade de Brasília, como parte dos requisitos necessários para a obtenção do título de DOUTOR EM BOTÂNICA.

Orientador: Dr. Paulo Eduardo A. S. CÂMara 
Ficha catalográfica elaborada automaticamente, com os dados fornecidos pelo(a) autor(a)

Soares, Abel Eustáquio Rocha

A Família Thuidiaceae Schimp. no Brasil, um estudo taxonômico, filogenético e morfológico. / Abel Eustáquio Rocha Soares; orientador Paulo Eduardo Aguiar Saraiva Câmara. -- Brasília, 2015. $202 \mathrm{p}$.

Tese (Doutorado - Doutorado em Botânica) -Universidade de Brasília, 2015.

1. Thuidiaceae. 2. Bryophyta. 3. Thuidium. 4. Pelekium. 5. Filogenia. I. Câmara, Paulo Eduardo Aguiar Saraiva, orient. II. Título. 


\section{A Família Thuidiaceae Schimp. no Brasil, um estudo taxonômico, filogenético e morfológico.}

Tese apresentada e aprovada em 29 de maio de 2015.

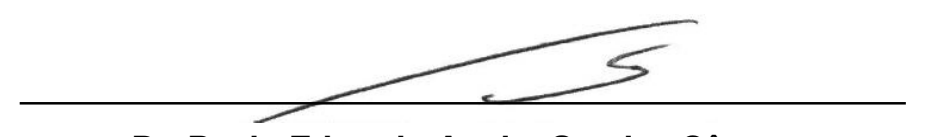

Dr. Paulo Eduardo Aguiar Saraiva Câmara

Orientador e Presidente da Banca

Universidade de Brasília

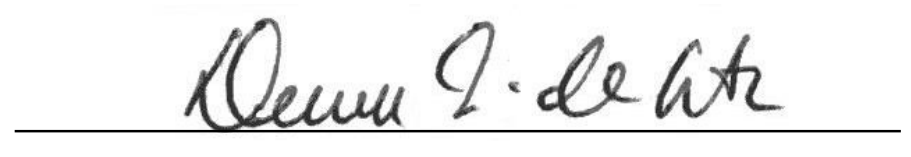

Dra. Denise Pinheiro da Costa

Membro Titular

Instituto de Pesquisa Jardim Botânico do Rio de Janeiro

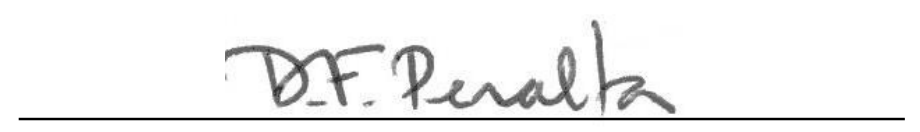

Dr. Denílson Fernandes Peralta

Membro titular

Instituto de Botânica de São Paulo

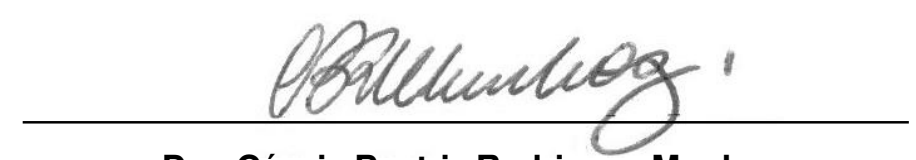

Dra. Cássia Beatriz Rodrigues Munhoz

Membro titular

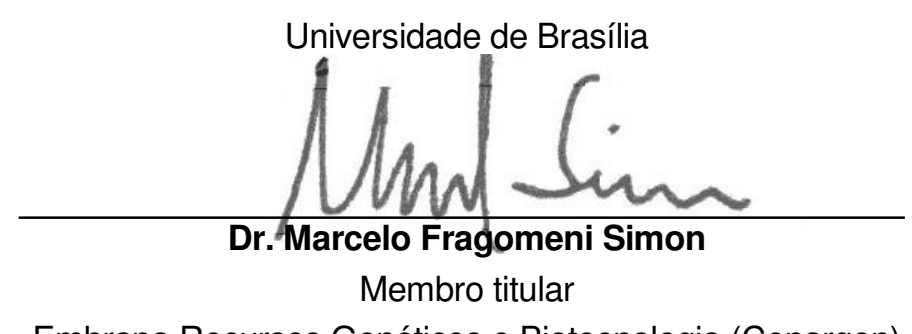

Embrapa Recursos Genéticos e Biotecnologia (Cenargen)

\footnotetext{
Dr. Diego Knop Henriques

Suplente

Universidade de Brasília
}

Brasília - DF

Maio, 2015 
Com muito carinho e gratidão, aos meus queridos pais Manoel e Ana, pela oportunidade de tentar e por sempre acreditar no meu potencial. Ao meu filho Gabriel, fonte eterna de força e inspiração.

Dedico 
"As nuvens mudam sempre de posição, mas são sempre nuvens no céu. Assim devemos ser todos os dias, mutantes, porém leais com o que pensamos e sonhamos; lembre-se, tudo se desmancha no ar, menos os pensamentos". (Paulo Beleki). 


\section{AGRADECIMENTOS}

Ao Programa de Pós-Graduação em Botânica da Universidade de Brasília, que possibilitou a realização desta tese.

Ao CNPq pela concessão da bolsa de doutorado e a CAPES pela concessão da bolsa de doutorado sanduíche no Jardim Botânico de Nova lorque.

A minha família e amigos que abdicaram de tantos momentos para tornar este sonho realidade, especialmente ao meu filho Gabriel, fonte de inspiração e alegria e de onde retiro todas as forças para me levantar pela manhã e continuar trabalhando. Aos meus pais onde eu sempre encontro colo, alento e amor, que proporcionaram todas as condições necessárias para que eu pudesse realizar da melhor maneira possível este trabalho e sempre acreditaram no meu potencial, me apoiando em todos os momentos.

Ao meu orientador e amigo Paulo Câmara. Obrigado pelo carinho de sempre e a total confiança depositada em mim desde o início. Até aqui foram seis anos juntos compartilhando alegrias, desafios, sorrisos, conquistas e novas descobertas. Foi um grande orgulho trabalhar com você e ter contribuído para o crescimento e desenvolvimento do laboratório e do herbário de briófitas da UnB.

À Dra. Micheline, pela contínua disponibilidade e amizade que tornaram a realização deste trabalho mais tranqüila e prazerosa.

Ao corpo docente do Programa de Pós-Graduação em Botânica da UnB pelos ensinamentos transmitidos.

A todos os funcionários do herbário que de alguma forma contribuíram para a realização deste trabalho.

Aos curadores dos herbários citados, que gentilmente emprestaram material dos acervos ou que, juntamente com os funcionários, me receberam sempre muito bem.

Ao New York Botanical Garden (NYBG) e ao Bill Buck por terem me recebido durante meu período de doutorado sanduíche em Nova lorque. A Stella Sylva por ter me recebido em sua residência durante meus primeiros meses em NY e por ter facilitado ao máximo minha estadia no NYBG.

Aos amigos da pós-graduação pela amizade, ajuda nos rabalhos de campo, inclusão do material no herbário, pelos importantes momentos de trabalho e descon- 
tração, almoços, butecos, conselhos, por terem compartilhado ótimos momentos que ficarão para sempre guardados em minha lembrança.

A todos os amigos e companheiros do Laboratório de Criptógamas e do NUBRIOCO (Núcleo de Briológos do Centro-Oeste) pelos vários momentos de discussão, aprendizagem, apoio e descontração. Sem vocês esse caminho teria sido muito mais difícil.

A todos que, direta ou indiretamente contribuíram para a realização deste trabalho e que, embora não citados aqui, não deixaram de ter meu profundo agradecimento, pois uma tese deve-se ao trabalho muitas vezes oculto de diversas pessoas que de uma forma ou de outra colaboraram para o sucesso deste trabalho. 


\section{SUMÁRIO}

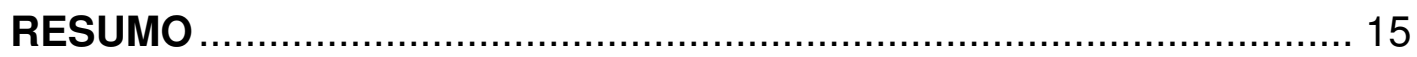

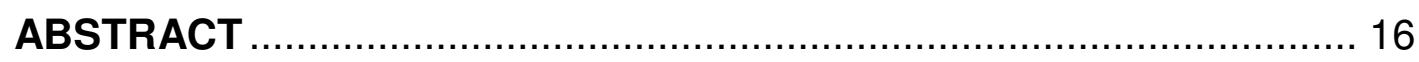

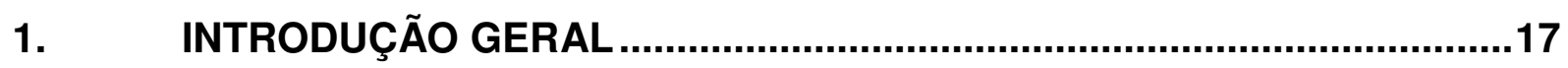

1.1 Visão Geral ....................................................................................17

1.2 Caracterização da Família...................................................................

1.2.1 Resumo da história taxonômica da família Thuidiaceae ..........................................19

1.2.2 O estudo da família Thuidiaceae na América Latina e no Brasil ...............................24

1.3 Principais características de importância taxonômica em

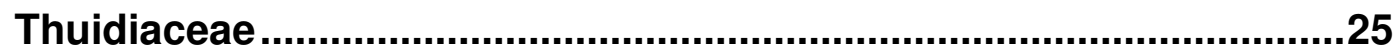

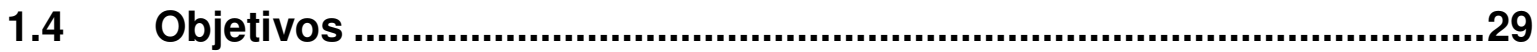

1.5 Modelo de organização da tese...........................................................29

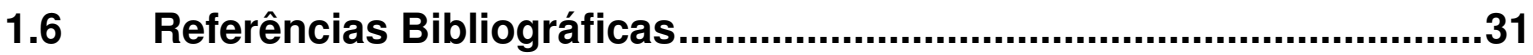

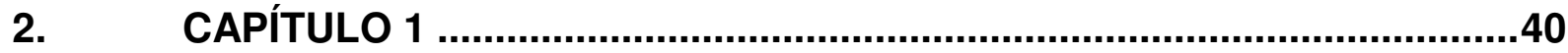

Filogenia molecular da família Thuidiaceae, baseada em marcadores de mitocôndria, cloroplasto e núcleo. .............................................. 40

Resumo

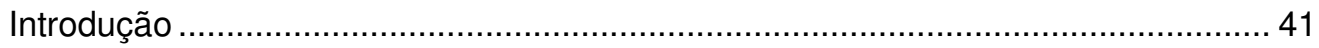

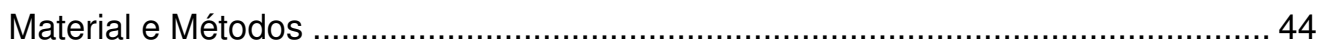

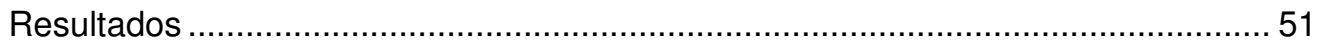

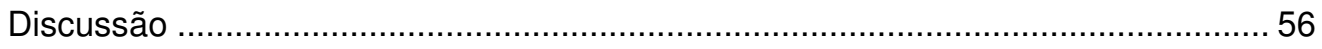

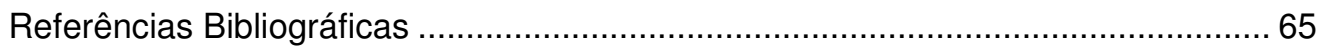

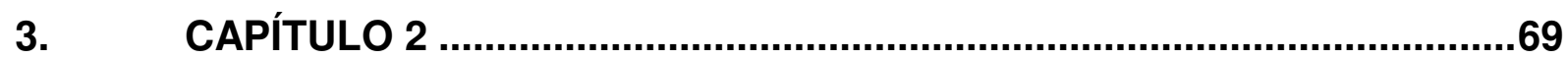

Novo arranjo taxonômico dos gêneros Pelekium e Thuidiopsis

baseado em marcadores de mitocôndria, cloroplasto e núcleo e em

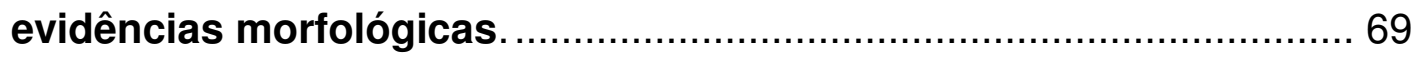

Resumo

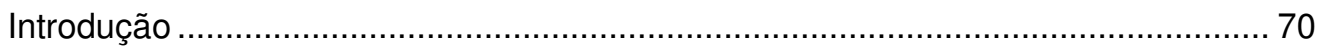

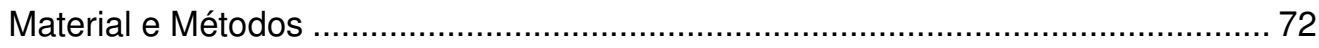

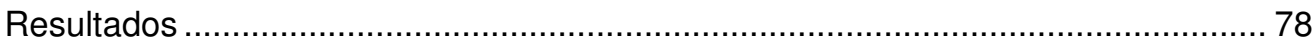




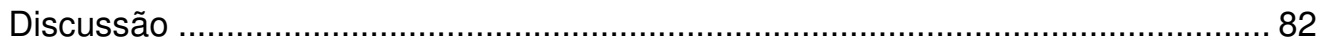

Referências Bibliográficas ........................................................................... 93

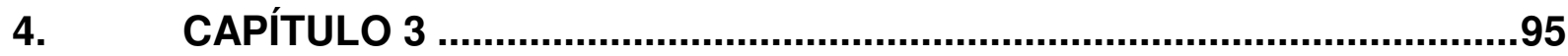

A new species of Thuidium (Thuidiaceae) from Brazil and a Key to the

Brazilian species of the genus. ........................................................ 95

Abstract

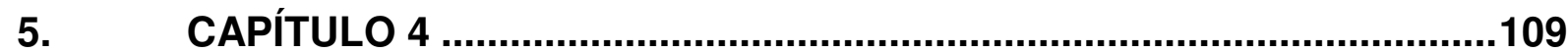

A Família Thuidiaceae Schimp. (Bryophyta) no Brasil ...................... 109

Resumo

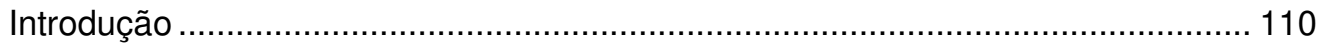

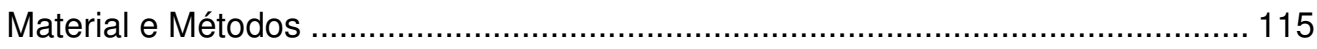

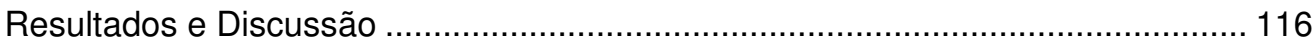

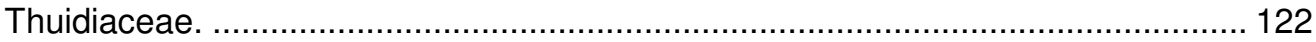

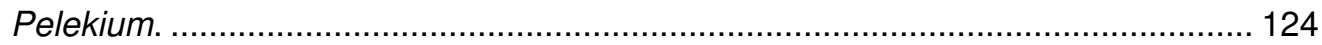

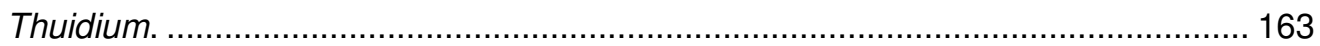

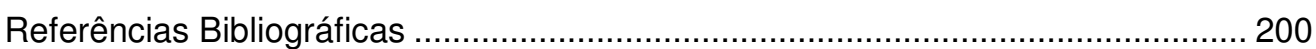




\section{ÍNDICE DE TABELAS}

Tabela 1: Histórico dos principais sistemas de classificação de Thuidiaceae.

\section{Capítulo 1}

Tabela 1: Primers e temperaturas de anelamento utilizados no estudo 45

Tabela 2: Táxons utilizados no estudo, localidade de coleta, coletor e número de coleta, herbário onde está depositado e número de acesso no GenBank. * Sequências do GenBank 46

Tabela 3: Estatísticas individuais para cada marcador utilizado e da análise compartilhada. $\mathrm{Cl}=$ índice de consistência; $\mathrm{Rl}=$ índice de retenção 52

\section{Capítulo 2}

Tabela 1: Primers e temperaturas de anelamento utilizados no estudo 73

Tabela 2: Táxons utilizados no estudo, localidade de coleta, coletor e número de coleta, herbário onde está depositado e número de acesso no GenBank. * Sequências do GenBank 74

Tabela 3: Estatísticas individuais para cada marcador utilizado e da análise compartilhada. $\mathrm{Cl}=$ índice de consistência; $\mathrm{Rl}=$ índice de retenção 78 


\section{ÍNDICE DE FIGURAS}

\section{Capítulo 1}

Figura 1: Cladograma de consenso obtido por análise bayesiana com a matriz combinada (rps4+26s+nad5). Os valores sobre os ramos correspondem aos valores de bootstrap de parcimônia, verossimilhança e probabilidades posteriores da análise Bayesiana respectivamente. Valores abaixo de $50 \%$ para bootstrap e 0,5 para probabilidades posteriores foram descartados no cladograma. 58

Figura 2: Cladograma (bayesiana) obtido com a matriz combinada (rps4+26s+nad5). Os valores sobre os ramos correspondem aos valores de bootstrap de parcimônia e verossimilhança, e probabilidades posteriores da análise Bayesiana. 1 = Seta papilosa/rugosa. 2 e 3 = Seta lisa ... 60

Figura 3: Cladograma (bayesiana) obtido com a matriz combinada (rps4+26s+nad5). Os valores sobre os ramos correspondem aos valores de bootstrap de parcimônia e verossimilhança, e probabilidades posteriores da análise Bayesiana. 1 = pluripapilosa com as papilas na periferia do lúmen, 2 = unipapilosa, 3 = unipapilosa com papila baixa, 4 = unipapilosa com papila alta, $5=$ pluripapilosa com as papilas no centro do lúmen, 6 = unipapilosa bífida, 7 = unipapilosa com papila curvada e mediana, 8 = unipapilosa com papila mediana e $9=$ unipapilosa com papila alta 61

\section{Capítulo 2}

Figura 1: Cladograma de consenso obtido por análise bayesiana com a matriz combinada (rps4+26s+nad5). Os valores sobre os ramos correspondem aos valores de bootstrap de parcimônia, verossimilhança e probabilidades posteriores da análise Bayesiana respectivamente. Valores abaixo de $50 \%$ para bootstrap e 0,5 para probabilidades posteriores foram descartados no cladograma.

Figura 2: Cladograma (bayesiana) obtido com a matriz combinada (rps4+26s+nad5). Os valores sobre os ramos correspondem aos valores de bootstrap de parcimônia e verossimilhança, e probabilidades posteriores da análise Bayesiana. $A, B$ e $C=$ Paráfilo ramificado típico do gênero Thuidium. D, E e F = Paráfilo simples típico de Thuidiopsis e Pelekium. 81

Figura 3: Paráfilo simples em Pelekium. $A$ e $B$ = visão geral do caulídio e paráfilos em Pelekium siphotheca. C e E = Paráfilo com ápice agudo em Pelekium siphotheca. D e F = Paráfilo com ápice truncado em Pelekium scabrosulum.

Figura 4: Paráfilo simples em Thuidiopsis. A = visão geral do caulídio e paráfilos em Thuidiopsis furfurosa. $\mathrm{B}=$ Paráfilos em Thuidiopsis furfurosa. C, D, E e F = Paráfilo simples em Thuidiopsis sparsa 85

Figura 5: Paráfilo simples, não ramificado típico do gênero do Pelekium 86 
Figura 6: Paráfilo simples, não ramificado típico do gênero Thuidiopsis.

86

Figura 7: Paráfilo ramificado em Thuidium. A e B = Caulídio e paráfilos em Thuidium brasiliense. $\mathrm{C}$ e $\mathrm{D}=T$. delicatulum. $\mathrm{E}$ e $\mathrm{F}=T$. brasiliense $\mathrm{G}=$ Paráfilos com papilas em $T$. pseudoprotensum $\mathrm{H}$ = Paráfilo com papilas em $T$. brasiliense .

Figura 8: Paráfilo ramificado típico do gênero Thuidium. 88

Figura 9: Células unipapilosas com papilas típicas de Pelekium e Thuidiopsis. $\mathrm{A}=$ Pelekium muricatulum. $\mathrm{B}$ e $\mathrm{C}=$ Pelekium siphotheca $\mathrm{D}=$ Thuidiopsis furfurosa. 88

Figura 10: Células unipapilosas com papilas típicas de Pelekium e Thuidiopsis. A = Pelekium muricatulum. $\mathrm{B}=$ Thuidiopsis furfurosa. 89

Figura 11: Células pluripapilosas com papilas típicas de Pelekium e Thuidiopsis. A e B = Pelekium scabrosulum. C e D = Thuidiopsis sparsa 89

Figura 12: Células pluripapilosas com papilas típicas de Pelekium e Thuidiopsis. A e B = Pelekium scabrosulum. C e D = Thuidiopsis sparsa. 90

Figura 13: Células unipapilosas com papilas típicas de Thuidium. A e B = Thuidium delicatulum. $\mathrm{C}$ e $\mathrm{D}=$ Thuidium brasiliense 90

Figura 14: Células unipapilosas com papilas típicas de Thuidium. $\mathrm{A}=$ Thuidium brasiliense. $\mathrm{B}=$ Thuidium delicatulum 91

Figura 15: Células pluripapilosas com papilas típicas de Thuidium, localizadas no centro do lúmen celular. A e B = Thuidium tomentosum 91

Figura 16: Células pluripapilosas com papilas típicas de Thuidium tomentosum, localizadas no centro do lúmen celular 91

\section{Capítulo 3}

Figure 1: Comparison of the morphological differences between Thuidium bifidum and $\mathrm{T}$. tomentosum. A. Gametophyte of T. bifidum. B. Gametophyte of T. tomentosum. C. T. bifidum paraphyllia with 2-4 papillae per cell. D. T. tomentosum paraphyllia with 1-2 papillae per cell. E. T. bifidum stem leaf with narrow base. F. T. tomentosum stem leaf with wide base. G. T. bifidum branch leaf. H. T. tomentosum branch leaf. 102

Figure 2: Comparison of the morphological differences between T. bifidum and T. tomentosum. A: Bifid papillae on T. bifidum (observed under scanning electronmicroscopy). B: Pluripapillose on $T$. tomentosum (observed under scanning electron microscopy) 103

Figure 3: Comparison of the morphological differences between $T$. bifidum and $T$. tomentosum. A: Bifid papillae on T. bifidum. B: Pluripapillose cells on T. tomentosum. 103

Figure 4: Known geographical distribution of Thuidium bifidum in Brazil, highlighting its occurrence area within the Atlantic Forest and Cerrado 105 


\section{Capítulo 4}

Figura 1: Locais, Estados e Biomas de ocorrência do gênero Pelekium no Brasil ......................119

Figura 2: Locais, Estados e Biomas de ocorrência do gênero Thuidium no Brasil ......................120

Figura 3: Variação altitudinal do gênero Pelekium no Brasil .................................................... 121

Figura 4: Variação altitudinal do gênero Thuidium no Brasil .................................................. 121

Figura 5: Mapa de distribuição de Pelekium involvens no Brasil................................................131

Figura 6: Pelekium involvens. A: Gametófito. B: Paráfilo. C: Filídio do caulídio. D: Filídio da ramificação. E: Células pluripapilosas da região mediana. F: Seta rugosa ................................132

Figura 7: Mapa de distribuição de Pelekium minutulum no Brasil ..............................................135

Figura 8: Pelekium minutulum. A: Gametófito. B: Paráfilo. C: Filídio do caulídio. D: Filídio da segunda ramificação. E: Células pluripapilosas da região mediana. F: Seta lisa .......................137

Figura 9: Mapa de distribuição de Pelekium muricatulum no Brasil ........................................... 140

Figura 10: Pelekium muricatulum. A e B: Gametófito. C: Paráfilo. D: Filídio do caulídio. E: Filídio da segunda ramificação. F: Células unipapilosas do filídio da ramificação..................................141

Figura 11: Mapa de distribuição de Pelekium scabrosulum no Brasil ........................................144

Figura 12: Pelekium scabrosulum. A: Gametófito. B e C: Paráfilo. D: Filídio do caulídio. E: Filídios da última ramificação. F: Ápice do filídio da ramificação. G: Células pluripapilosas do filídio da

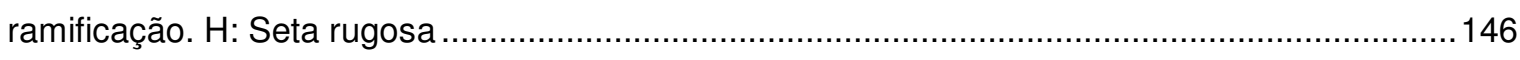

Figura 13: Mapa de distribuição de Pelekium schistocalyx no Brasil .........................................148

Figura 14: Pelekium schistocalyx. A: Gametófito. B e C: Paráfilo. D: Filídio do caulídio. E: Filídio ramificação secundária. F: Ápice do filídio da ramificação. G: Células pluripapilosas do filídio da ramificação. H: Seta rugosa. 150

Figura 15: Mapa de distribuição de Pelekium siphotheca no Brasil. 153

Figura 16: Pelekium siphotheca. A: Gametófito. B: Paráfilo. C: Filídio do caulídio. D: Filídio da ramificação. E: Células unipapilosas do filídio da ramificação. F: Seta lisa ..... 154

Figura 17: Mapa de distribuição de Pelekium sparsum no Brasil 157

Figura 18: Pelekium sparsum. A: Gametófito. B e C: Paráfilo. D: Filídio falcado do caulídio. E: Filídio da ramificação. F: Ápice do filídio do caulídio. G: Células pluripapilosas. H: Margem do filídio. 159

Figura 19: Mapa de distribuição de Pelekium subpinnatum no Brasil 161

Figura 20: Pelekium subpinnatum. A: Gametófito. B e C: Paráfilo. D: Filídio do caulídio. E: Filídios da ramificação. F: Células unipapilosas. G: Seta lisa. H: Cápsula 162

Figura 21: Mapa de distribuição de Thuidium assimile no Brasil 168 
Figura 22: Thuidium assimile. A: Gametófito. B: Paráfilo. C: Filídio do caulídio. D: Filídio da ramificação. E: Ápice do filídio. F: Células do ápice do filídio. G: Células unipapilosas do filídio do caulídio. H: Células unipapilosas do filídio do ramo. 169

Figura 23: Mapa de distribuição de Thuidium bifidum no Brasil 172

Figura 24: Thuidium bifidum. A: Gametófito. B: Paráfilo. C: Paráfilo, em detalhe células quadradas e papilas. D: Filídio do caulídio. E: Filídio da ramificação. F: Células unipapilosas bifídas 173

Figura 25: Mapa de distribuição de Thuidium brasiliense no Brasil. 175

Figura 26: Thuidium brasiliense. A: Gametófito. B e C: Paráfilo. D: Filídio do caulídio. E: Filídio da ramificação. F: Ápice do filídio do caulídio. G: Células unipapilosas do filídio do caulídio e H: Células unipapilosas do filídio da ramificação 176

Figura 27: Mapa de distribuição de Thuidium delicatulum no Brasil..... 179

Figura 28: Thuidium delicatulum. A: Gametófito. B e C: Paráfilo. D: Filídio do caulídio. E: Filídio da ramificação. F: Ápice do filídio do caulídio. G: Células unipapilosas do filídio do caulídio. H: Células unipapilosas do filídio do ramo. 181

Figura 29: Mapa de distribuição de Thuidium pseudoprotensum no Brasil. 183

Figura 30: Thuidium pseudoprotensum. A: Gametófito. B e C: Paráfilo. D: Filídio do caulídio. E: Filídio da ramificação. F: Células unipapilosas do filídio do ramo 185

Figura 31: Mapa de distribuição de Thuidium tamariscinum no Brasil 187

Figura 32: Thuidium tamariscinum. A: Gametófito. B e C: Paráfilo. D: Filídio do caulídio. E: Filídio da ramificação. F: Ápice e célula apical aguda do filídio da ramificação. G: Células unipapilosas do filídio do caulídio. H: Células unipapilosas do filídio do ramo 189

Figura 33: Mapa de distribuição de Thuidium tomentosum no Brasil 192

Figura 34: Thuidium tomentosum. A: Gametófito. B e C: Paráfilo. D: Filídio do caulídio. E: Filídio da ramificação. F: Células pluripapilosas do filídio do ramo. 194

Figura 35: Mapa de distribuição de Thuidium urceolatum no Brasil 196

Figura 36: Thuidium urceolatum. A: Gametófito. B e C: Paráfilo. D: Filídio do caulídio. E: Filídio da ramificação. F: Ápice do filídio do caulídio preenchendo o ápice. G: Células unipapilosas do filídio do ramo. H: Células unipapilosas do filídio do caulídio 197 
A família Thuidiaceae pertence ao grupo dos musgos pleurocárpicos e a ordem das Hypnales. É uma família cosmopolita que coloniza substratos diversos e muitos de seus representantes exercem um papel ecológico importante. Estima-se que a família seja composta mundialmente por 72 espécies e 16 gêneros, distribuídas em regiões tropicais e temperadas do mundo. $O$ objetivo deste trabalho é realizar uma revisão taxonômica da família Thuidiaceae para o Brasil; apresentar uma filogenia molecular e construir uma hipótese filogenética com uso de marcadores moleculares para Thuidiaceae a nível mundial e determinar quais caracteres morfológicos informativos para separar os gêneros e espécies de Thuidiaceae. Para tanto a tese está subdividida em quatro capítulos. O primeiro aborda a filogenia molecular da família Thuidiaceae baseada em marcadores de mitocôndria, cloroplasto e núcleo. Neste capítulo foram selecionadas 47 espécies para a extração de DNA. Foram utilizadas três regiões do genoma: rps4, nad5 e 26s. Em todas as análises foi possível observar a monofilia da família Thuidiaceae composta somente pelos gêneros Pelekium, Thuidiopsis e Thuidium e a polifilia de Leskeaceae e demais gêneros antes tradicionalmente agrupados em Thuidiaceae. O segundo capítulo refere-se ao novo arranjo taxonômico dos gêneros Pelekium e Thuidiopsis baseado em marcadores de mitocôndria, cloroplasto e núcleo e em evidências morfológicas. Foram selecionadas 26 espécies de Thuidiaceae para as análises filogenéticas e morfológicas. Marcadores de três regiões diferentes do genoma foram utilizados (rps4, 26S e nad5). Os gêneros Pelekium e Thuidiopsis formam um clado monofilético bem suportado, sugerindo a grande proximidade entre estes dois gêneros e a necessidade de uma nova circunscrição que está sendo apresentada neste estudo baseada em evidências filogenéticas e morfológicas. O terceiro capítulo traz a descrição de uma nova espécie de Thuidium endêmica do Brasil. O quatro é o último capítulo refere-se a revisão taxônomica da família Thuidiaceae no Brasil. Neste último capítulo foram estudadas exsicatas provenientes de diversos herbários nacionais e internacionais e o material-tipo de todas as espécies com registro de ocorrência no Brasil. Neste capítulo estão sendo tratadas 16 espécies e dois gêneros de Thuidiaceae para o Brasil. Duas novas ocorrências para o Brasil e uma nova espécie são apresentadas. 
The Thuidiaceae family belongs to the pleurocarpous mosses and the Hypnales Order. It is a cosmopolitan family that colonizes a large tips of substrates, having an important ecological function in their enviroment. 72 species from 16 genus are worldwide estimated for the family distributed in tropical and temperate regions. This work objective is to realize a taxonomic revision of the Thuidiaceae family for Brazil; present a molecular phylogeny build a phylogenetic hypothesis by using molecular markers for the Thuidiaceae in a worldwide level and determine wich informative morphological characters to separate the genus and species of Thuidiaceae. The thesis is divide in four chapters. The first one is about a molecular phylogeny of Thuidiaceae family based on mitochondrial, nucleus and chloroplast markers. 47 species were selected for DNA extraction. Three genome regions were used: rps4, nad5 and 26s. In all the analyzes was possible to identify the monophyly of the Thuidiaceae family compose only by the Pelekium, Thuidiopsis and Thuidium genus and the polyphyly of the Leskeaceae and the traditional genus agrouped in Thuidiaceae. The second chapter refers to new taxonomical arrengement of the Pelekium and Thuidiopsis genus, based in mitochondrial, nucleus and chloroplast markers and in morphological evidences. 26 species from Thuidiaceae were selected for the phylogenetic and morphological analisys. Three regions markers were selected from the genome (rps4,26S and nad5). The Pelekium and Thuidiopsis genus forms a monophyletic clade well suported, sugesting a great proximity between these two genus making necessary a new circunscript that is beeing introduce in this study, using phylogenetical and morphological evidences. The third chapter presents the description of a new Thuidium specie endemic to Brazil. The last and the fourth one refers to a taxonomic review of the Thuidiaceae family in Brazil. In this last chapter, we studied exsiccatae from several national and international herbaria and the type material of all species with occurrence in Brazil. In this chapter we analyze 16 species and two genus of brazilian Thuidiaceae. Two new records of Thuidiceae were found to Brazil and a new specie were discovered and described. 


\section{INTRODUÇÃO GERAL}

\subsection{Visão Geral}

Briófitas são um grupo de plantas altamente diversificado, com ampla distribuição, capazes de colonizar todos os ecossistemas terrestres. As Briófitas latu sensu constituem o segundo maior grupo de plantas terrestres (Buck \& Goffinet 2000), perdendo em número de espécies apenas para as Angiospermas. Formam um grupo parafilético que pode ser dividido em três divisões: Anthocerotophyta (Antóceros), Marchantiophyta (Hepáticas) e Bryophyta (Musgos) (Buck \& Goffinet 2000).

As briófitas possuem muitas funções ecológicas, sendo importantes bioindicadores da qualidade do ar e água (Ando \& Matsuo 1984; Fernández \& Serrano 2009) e embora seu papel ecológico ainda não tenha sido suficientemente estudado, sabe-se que diversas espécies animais, tais como tardígrados, vivem exclusivamente sobre musgos durante toda sua vida (Welch 1948; Ando \& Matsuo 1984). Briófitas também possuem atividade anticancerígena, anti-inflamatória, alelopática e são produtoras de antibióticos e antivirais (Welch 1948, Fernández \& Serrano 2009). Têm sido muito utilizadas também como organismos modelos em estudos de desenvolvimento celular em biologia molecular (Cuming 2009).

Estudos recentes sobre as taxas de evolução molecular em briófitas indicam que em algumas linhagens estas taxas são substancialmente mais lentas do que nas outras linhagens de embriófitas (Stoeinin 2008). Estas diferenças nas taxas de evolução molecular e de evolução morfológica, juntamente com um registro fóssil muito antigo que remonta ao Devoniano tardio (Schofield 2001) e a evidência de padrões filogenéticos correlacionados com as vicariâncias associadas à fragmentação dos supercontinentes Gondwana (McDaniel \& Shaw 2003) e Laurasia (Vanderpoorten et al. 2008), sugerem que as briófitas constituem um grupo modelo com grande potencial para estudos biogeográficos em geral.

A divisão Bryophyta que inclui apenas os musgos, filogeneticamente é considerada descendente direta das antigas divisões de plantas-terrestres e são funcionalmente importantes em muitos ecossistemas terrestres (Rydin 2009).

Os musgos podem ser divididos em três grupos com base na posição do periquécio (La-Farge-England 1996): Acrocárpico, Cladocárpico e Pleurocárpico. 
Os musgos pleurocárpicos são um grupo monofilético (De Luna et al. 2000; Newton et al. 2000) que inclui as ordens Hookeriales, Hypnales e Ptychomniales, e constituem uma linhagem altamente diversificada com aproximadamente $42 \%$ das espécies de musgos (Newton et al. 2000). A ordem Hypnales é a maior e mais importante, sendo constituída por 42 famílias, 408 gêneros e 4.400 espécies (Goffinet et al. 2009), o que compreende aproximadamente $80 \%$ das espécies de musgos pleurocárpicos (Câmara \& Shaw 2013). Possui seu centro de diversidade em áreas tropicais (Buck 1998), com seus representantes ocorrendo principalmente em áreas florestais. Para o Brasil, estima-se 25 famílias, 92 gêneros e 236 espécies amplamente distribuídas (Costa et al. 2011).

\subsection{Caracterização da Família}

A família Thuidiaceae pertence ao grupo dos musgos pleurocárpicos e a ordem das Hypnales. É uma família cosmopolita que coloniza substratos diversos e muitos de seus representantes exercem um importante papel, pois formam tapetes no chão de florestas, contribuindo para a retenção da água, servindo como substrato para a germinação de sementes e como microhabitat para muitas espécies de artrópodes (García-Avila et al. 2009). A família, de acordo com García-Avila et al. (2009) que realizou um estudo filogenético com Thuidiaceae e Leskeaceae, é um grupo parafilético. No entanto, esses mesmos autores chegaram a conclusão de que seria necessária uma análise mais ampla sobre as famílias Thuidiaceae e Leskeaceae a afim de se esclarecer os verdadeiros limites dentro destas famílias.

A família Thuidiaceae, tal como definida por Buck \& Crum (1990) e Touw (2001), é caracterizada por uma ampla combinação de caracteres: crescimento prostrado; ramificação pinada; em secção transversal sem hialoderme e com uma pequena camada de células pequenas de parede espessa, bordeadas por células largas de parede delgada; filídios da última ramificação marcadamente diferenciados dos filídios dos caulídios nas espécies 2-3 pinadas; células uni- a pluripapilosas; caulídios primários cobertos por paráfilos, paráfilos simples a ramificados, papilosos e esporófito do tipo "hypnóide" (com exostômio e endostômio alterno e bem definidos). Em termos de substratos, algumas espécies são terrestres e outras são epífitas e/ou saxícolas. 
Estima-se que a família seja composta por aproximadamente 72 espécies e 16 gêneros (Touw 2001), distribuídas em regiões tropicais e temperadas do mundo; no neotrópico cerca de 30 espécies (Gradstein et al. 2001). Ocorrem principalmente na Ásia, América do Sul e Central e Oceania, sendo a região tropical asiática o seu centro de diversidade. Na Europa e América do Norte, devido a ocorrência de poucas espécies, as mesmas são bem estudadas e conhecidas (Gier 1980).

Para o Brasil, os números sobre a quantidade de gêneros e espécies divergem bastante. De acordo com o checklist dos musgos brasileiros (Costa et al. 2011), ocorrem no país três gêneros e 19 espécies, sendo cinco endêmicas, ocorrendo no Cerrado, Amazônia, Pantanal e principalmente na Mata Atlântica, habitando o interior de matas e florestas úmidas. Já o catálogo dos musgos brasileiros (Yano 2011) cita a ocorrência de quatro gêneros e 27 espécies. Por fim, a listagem mais atual (Costa \& Soares 2015), cita a ocorrência de três gêneros e 16 espécies.

\subsubsection{Resumo da história taxonômica da família Thuidiaceae}

A circunscrição da família é controversa devido ao seu parentesco conflitante com Leskeaceae, o que gerou diversas classificações diferentes ao longo de sua história, pois durante anos foi extremamente comum a transferência de gêneros entre estas duas famílias. Durante a maior parte do século $X X$, a circunscrição adotada por Fleischer (1922) e Brotherus (1925) para a classificação da família (Touw 2001a) foi a mais aceita.

Schimper (1852) foi o primeiro a reconhecer as diferenças taxonômicas do grupo, propondo o estabelecimento do gênero Thuidium Bruch \& Schimp., inicialmente com cinco espécies. Schimper também foi o primeiro a descrever Thuidiaceae (Schimper 1860, 1876), reconhecendo a mesma como uma subfamília de Leskeaceae.

O primeiro a reconhecer Thuidiaceae como família foi Kindberg (1897), elevando a subfamília Thuidieae proposta por Schimper (1876) ao status de família (Thuidiaceae) e transferindo alguns gêneros de Leskeaceae para Thuidiaceae. A família ficou dividida em cinco gêneros: Heterocladium Bruch \& Schimp., Myurella Bruch \& Schimp., Pseudoleskeella Kindb., Pseudoleskea Bruch \& Schimp. e Thuidium. 
Brotherus (1908) adotou a proposta de Schimper (1876) e reconheceu apenas a família Leskeaceae, que foi dividida em cinco subfamílias e 23 gêneros. Brotherus também incluiu 158 espécies em Thuidium e o subdividiu em cinco subgêneros: Thuidiella Schimp., Thuidiopsis Broth., Tetrastichium Mitt., Euthuidium Lindb., e Abietinella (Mull. Hal.) Broth.

Posteriormente, Fleischer (1922) elevou novamente Thuidiaceae a categoria de família, organizando a mesma em quatro subfamílias e 18 gêneros. Reconhecendo o trabalho de Fleischer (1922), Brotherus (1925) fez algumas pequenas modificações a nível genérico, mantendo a essência da classificação, com Thuidiaceae dividida em quatro subfamílias e 17 gêneros. Os gêneros foram classificados principalmente de acordo com o tamanho do gametófito, sexualidade, padrão de ramificação, formato dos filídios periqueciais, peristômio e orientação da seta.

Durante um longo período o trabalho de Brotherus (1925) serviu como referência para diversos trabalhos a respeito da classificação e dos limites da família Thuidiaceae. Porém, no início dos anos 90, Buck \& Crum (1990) na tentativa de solucionar e clarificar os limites entre Thuidiaceae e Leskeaceae especularam sobre as relações filogenéticas entre ambas. Os referidos autores dividiram Leskeaceae em 18 gêneros e Thuidiaceae em duas subfamílias e sete gêneros: Cyrtohypnoideae (Boulaya Cardot, Cyrto-hypnum (Hampe) Hampe \& Lorentz, Lorentzia Hampe e Rauiella Reimers) e Thuidioideae (Abietinella, Thuidiopsis e Thuidium) e transferiram os gêneros Hylocomiopsis Cardot e Actinothuidium Broth. antes em Thuidiaceae para Hylocomiaceae. Eles também transferiram as antigas espécies agrupadas dentro do subgênero Microthuidium (Limpr.) Warnst. I Thuidiella Reimers, pertencente a Thuidium subfamília Thuidioideae para o gênero Cyrto-Hypnum subfamília Cyrtohypnoideae.

Realizando uma revisão taxonômica e um realinhamento dos táxons acomodados em Thuidiaceae, Touw (2001a) limitou a família a 16 gêneros e 72 espécies e dividiu a mesma em três grupos informais: "Combinado", "Helodioideo" e "Thuidioideo". Também propôs dois novos gêneros (Aequatoriella Touw e Indothuidium Touw), novas combinações transferindo os representantes de Cyrtohypnum para Pelekium e considerou que as características morfológicas entre Thuidiaceae e Leskeaceae são bastantes distintivas para mantê-las separadas. 
Por fim, García-Avila et al. (2009) realizou um estudo filogenético com Thuidiaceae e Leskeaceae e concluiu que ambas as famílias são polifiléticas se entendidas conforme o conceito adotado até então. Também demonstrou a existência de um grupo monofilético constituído pelas espécies do grupo "Thuidioideo" (Aequatoriella, Bryochenea C. Gao \& G.C. Zhang, Indothuidium, Orthothuidium D.H. Norris \& T.J. Kop., Pelekium, Thuidium e Thuidiopsis) proposto por Touw (2001a).

A tabela 1 apresenta o resumo do histórico dos principais sistemas de classificação já utilizados em Thuidiaceae.

Tabela 1: Histórico dos principais sistemas de classificação de Thuidiaceae.

\begin{tabular}{|c|c|c|c|c|}
\hline Autor / Ano & Família & Subfamília & Gêneros & subgêneros \\
\hline $\begin{array}{c}\text { Schimper, } \\
1852\end{array}$ & Hypnaceae & & Thuidium & \\
\hline $\begin{array}{l}\text { Schimper, } \\
1860,1876\end{array}$ & Leskeaceae & Thuidieae & $\begin{array}{l}\text { Heterocladium } \\
\text { Thuidium }\end{array}$ & \\
\hline $\begin{array}{c}\text { Kindberg, } \\
1897\end{array}$ & Thuidiaceae & - & $\begin{array}{c}\text { Heterocladium } \\
\text { Myurella } \\
\text { Pseudoleskeella } \\
\text { Pseudoleskea } \\
\text { Thuidium }\end{array}$ & \\
\hline $\begin{array}{c}\text { Brotherus, } \\
1908\end{array}$ & Leskeaceae & Thuidieae & $\begin{array}{l}\text { Actinothuidium } \\
\text { Claopodium } \\
\text { Duthiella } \\
\text { Haplocladium } \\
\text { Helodium } \\
\text { Pelekium } \\
\text { Rauia } \\
\text { Thuidium }\end{array}$ & $\begin{array}{c}\text { Thuidiella } \\
\text { Thuidiopsis } \\
\text { Tetrastichium } \\
\text { Euthuidium } \\
\text { Abietinella }\end{array}$ \\
\hline
\end{tabular}

Fleischer, Thuidiaceae Anomodontoideae

Anomodon 1922

Claopodium 


\begin{tabular}{|c|c|c|c|c|}
\hline \multirow[t]{2}{*}{ Autor / Ano } & Família & Subfamília & Gêneros & subgêneros \\
\hline & \multicolumn{4}{|c|}{ Haplocladium } \\
\hline \multicolumn{5}{|c|}{ Haplohymeniu, } \\
\hline \multicolumn{5}{|c|}{ Herpetineuron } \\
\hline \multicolumn{5}{|c|}{ Miyabea } \\
\hline \multicolumn{5}{|c|}{ Euthuidiodeae } \\
\hline \multicolumn{5}{|c|}{ Boulaya } \\
\hline \multicolumn{5}{|c|}{ Pelekium } \\
\hline \multicolumn{5}{|c|}{ Rauia } \\
\hline \multicolumn{5}{|c|}{ Thuidiopsis } \\
\hline & & & \multirow[t]{2}{*}{ Thuidium } & Thuidiella \\
\hline & & & & Euthuidium \\
\hline & & \multicolumn{3}{|c|}{ Actinothuidium } \\
\hline & & \multicolumn{3}{|l|}{ Helodioideae } \\
\hline & & \multicolumn{3}{|c|}{ Hylocomiopsis } \\
\hline & & \multicolumn{3}{|c|}{ Tetrastichum } \\
\hline & & \multicolumn{3}{|l|}{ Heterocladiodeae } \\
\hline & & \multicolumn{3}{|c|}{ Leptopteryginandrum } \\
\hline Brotherus, & Thuidiaceae & \multicolumn{3}{|l|}{ Anomodontoideae } \\
\hline \multicolumn{5}{|c|}{ Claopodium } \\
\hline \multicolumn{5}{|c|}{ Haplocladium } \\
\hline \multicolumn{5}{|c|}{ Haplohymenium } \\
\hline \multicolumn{5}{|c|}{ Herpetineuron } \\
\hline \multicolumn{5}{|c|}{ Miyabea } \\
\hline \multicolumn{5}{|c|}{ Euthuidiodeae } \\
\hline \multicolumn{5}{|c|}{ Boulaya } \\
\hline \multicolumn{5}{|c|}{ Pelekium } \\
\hline \multicolumn{5}{|c|}{ Rauia } \\
\hline & & & \multicolumn{2}{|l|}{ Thuidiopsis } \\
\hline & & & \multirow[t]{2}{*}{ Thuidium } & Euthuidium \\
\hline & & & & Thuidiella \\
\hline & & Helodioideae & Actinothuidium & \\
\hline & & & Helodium & \\
\hline & & & Hylocomiopsis & \\
\hline & & & Tetrastichum & \\
\hline
\end{tabular}




\begin{tabular}{|c|c|c|c|c|}
\hline \multirow[t]{3}{*}{ Autor / Ano } & Família & Subfamília & Gêneros & subgêneros \\
\hline & & Heterocladiodeae & Heterocladium & \\
\hline & & & Leptopteryginandrum & \\
\hline \multirow{4}{*}{$\begin{array}{l}\text { Grout, } \\
1932\end{array}$} & Leskeaceae & Thuidioideae & Claopodium & \\
\hline & & & Helodium & \\
\hline & & & Heterocladium & \\
\hline & & & Thuidium & \\
\hline \multirow{17}{*}{$\begin{array}{c}\text { Watanabe, } \\
1972\end{array}$} & Thuidiaceae & Anomodontoideae & Anomodon & \\
\hline & & & Haplohymenium & \\
\hline & & & Herpetineuron & \\
\hline & & & Miyabea & \\
\hline & & Heterocladioideae & Heterocladium & \\
\hline & & & Leptopterygynandrum & \\
\hline & & & Abietinella & \\
\hline & & & Actinothuidium & \\
\hline & & & Boulaya & \\
\hline & & & Bryonoguchia & \\
\hline & & Thuidioideae & Claopodium & \\
\hline & & & Haplocladium & \\
\hline & & & Helodium & \\
\hline & & & Hylocomiopsis & \\
\hline & & & Pelekium & \\
\hline & & & Rauiella & \\
\hline & & & Thuidium & \\
\hline \multirow{7}{*}{$\begin{array}{c}\text { Crum \& } \\
\text { Anderson, } \\
1981\end{array}$} & Thuidiaceae & & Haplocladium & \\
\hline & & & Helodium & \\
\hline & & & Heterocladium & \\
\hline & & & Myurella & \\
\hline & & & Pseudoleskea & \\
\hline & & & Pseudoleskeella & \\
\hline & & & Thuidium & \\
\hline \multirow{5}{*}{$\begin{array}{c}\text { Buck \& } \\
\text { Crum, } \\
1990\end{array}$} & Thuidiaceae & Cyrtohypnoideae & Boulaya & \\
\hline & & & Cyrto-hypnum & \\
\hline & & & Lorentzia & \\
\hline & & & Rauiella & \\
\hline & & & Abietinella, & \\
\hline
\end{tabular}




\begin{tabular}{|c|c|c|c|c|}
\hline Autor / Ano & Família & Subfamília & Gêneros & subgêneros \\
\hline & & Thuidioideae & Thuidiopsis & \\
\hline & & & Thuidium & \\
\hline \multirow{16}{*}{$\begin{array}{l}\text { Touw, } \\
2001\end{array}$} & Thuidiaceae & "Combinado" & Abietinella & \\
\hline & & & Boulaya & \\
\hline & & & Haplocladium & \\
\hline & & & Rauiella & \\
\hline & & & Actinothuidium & \\
\hline & & & Bryonoguchia & \\
\hline & & Helodioideo & Echinophyllum & \\
\hline & & & Helodium & \\
\hline & & & Hylocomiopsis & \\
\hline & & & Aequatoriella & \\
\hline & & & Bryochenea & \\
\hline & & & Indothuidium & \\
\hline & & Thuidioideo & Orthothuidium & \\
\hline & & & Pelekium & \\
\hline & & & Thuidium & \\
\hline & & & Thuidiopsis & \\
\hline
\end{tabular}

\subsubsection{0 estudo da família Thuidiaceae na América Latina e no Brasil}

Os primeiros relatos sobre a ocorrência de espécies de Thuidiaceae na América Latina datam de 1867 e foram publicados em uma lista de musgos coletados em uma viagem transcontinental pelo vale do Amazonas e Montanhas Andinas da América do Sul (Spruce 1867). Posteriormente, Mitten (1869) relatou 24 espécies de Thuidium para a América Latina e outras 30 espécies que poderiam ser Thuidiaceae.

Gier (1980) foi o primeiro e único a propor um estudo sobre as Thuidiaceae da América Latina. Em seu trabalho ele estudou amostras provenientes de diversos herbários da América e Europa, o que resultou na identificação de 10 gêneros e 96 espécies. Outros pesquisadores que estudaram musgos na América Latina e fizeram referências a Thuidiaceae são: Bescherelle (1871), Jaeger (1870, 1879), Brotherus (1891), Kindberg (1897), Muller (1901), Cardot (1909), Herzog (1910), Cardot \& Brotherus (1923), Williams (1927), Bartram (1928), Williams (1930), Herzog (1942), Steere (1948), Crum (1950), Bartram (1964), Robinson (1967), Steere (1967), 
Crosby (1969), Pursell (1973), Bowers (1974), Hegewald \& Hegewald (1975, 1976), Robinson (1975), Hermann (1976), Sehnem (1976), Churchill \& Linares (1995), Buck (1998), Churchill et. al (2000) e Schiavone \& Suarez (2007).

No Brasil os primeiros relatos de Thuidiaceae ocorreram a partir da publicação de Brotherus (1891). Neste trabalho foram realizadas coletas nos estados de Minas Gerais e Rio de Janeiro, onde foram amostradas 97 espécies de Briófitas, dentre as quais apenas três eram Thuidiaceae. A partir de Brotherus, alguns trabalhos fazem referências a ocorrência de Thuidiaceae em alguns estados brasileiros: Sehnem (1976), Lisboa \& Ilkiu-Borges (1997), Costa (2003), Santos \& Lisboa (2003), Câmara \& Vital (2004), Yano (2004), Yano \& Bastos (2004), Yano \& Câmara (2004), Yano \& Peralta (2004), Câmara et. al (2005), Costa \& Lima (2005), Peralta \& Yano (2005), Souza \& Lisboa (2005), Visnadi (2005), Câmara \& Vital (2006), Genevro et al. (2006), Moraes \& Lisboa (2006), Peralta \& Yano (2006), Yano \& Peralta (2006), Câmara (2008), Peralta et al. (2008), Peralta \& Filho (2008), Peralta \& Yano (2008), Santos \& Lisboa (2008), Yano \& Peralta (2008a, 2008b), Bôas-Bastos \& Bastos (2009), Bordin \& Yano (2009), Valente et al. (2009), Yano et al. (2009), Bordin \& Yano (2010), Câmara \& Soares (2010), Sousa et al. (2010), Visnadi (2011), Yano (2010), Costa et al. (2011), Yano (2011) e Pinheiro \& Câmara (2012).

\subsection{Principais características de importância taxonômica em}

\section{Thuidiaceae}

Muitas espécies de Thuidiaceae possuem características que não são continuas, larga variação intraespecifica e sobreposição de caracteres que dificultam o delineamento dos seus gêneros e espécies (Touw 2001).

\section{a) Arquitetura}

As Thuidiaceae são atrativas visualmente devido ao seu padrão de ramificação. Seus caulídios são geralmente 2 ou 3-pinados. Este padrão de pinação pode ser utilizado para diferenciar algumas espécies e gêneros, como é o caso de Thuidium que sempre apresenta ramificação do tipo 2-3-pinada, nunca 1-pinada. A ramificação geralmente consiste de uma primeira pina constituída de uma parte basal ascendente, uma segunda pina na parte mediana orientada paralelamente ao substrato e uma terceira pina mais delgada que as demais, perpendicular a segunda. Plantas que crescem em condições desfavoráveis (ambientes secos e com 
baixa umidade) geralmente apresentam um padrão de ramificação menos regular e mais fracamente ramificado do que plantas que crescem em ambientes favoráveis (Touw 2001). As ramificações estão situadas em um único plano e inseridas lateralmente, mas não exatamente em duas fileiras.

\section{b) Pêlos Axilares}

Estão inseridos no caulídio e situados na axila dos filídios. A maneira mais fácil de observá-los é dissecando as partes vegetativas próximas a axila de inserção dos filídios. São numerosos nas axilas dos filídios jovens (Touw 2001). Os pêlos axilares podem ser constituídos de 1-2 células basais e 1-5 células distais (Touw 2001) e apresentam pequenas diferenças morfológicas entre os gêneros.

\section{c) Rizóides}

Agrupamentos de rizóides estão inseridos abaixo da inserção dos filídios no caulídio. Rizóides são marrons, laranja-marrom ou avermelhado-marrom, variando de simples a ramificados, lisos ou finamente papilosos. Por causa destas variações que podem ser encontradas dentro da mesma espécie, rizóides não podem ser usados para diferenciação de gêneros e espécies (Touw 2001).

\section{d) Paráfilo e Pseudoparáfilo}

Estão presentes em todos os gêneros (Touw 2001), sendo os pseudoparáfilos estruturas geralmente inconspícuas de difícil visualização e que durante muito tempo teve sua presença ignorada em Thuidiaceae. Não existem diferenças significativas entre os pseudoparáfilos encontrados nos gêneros e espécies de Thuidiaceae.

Os paráfilos estão dispersos sobre a superfície do caulídio e são originados da camada de células mais externa do caulídio, ao passo que pseudoparáfilos são encontrados nas axilas das ramificações e nos primórdios das bases das ramificações e são originados dos primórdios da ramificação (Akiyama 1990; Touw 2001).

O paráfilo freqüentemente forma uma densa cobertura sobre o caulídio, podendo ser escasso em algumas espécies de Pelekium. O paráfilo da ramificação é similar ao paráfilo do caulídio e freqüentemente apresenta-se em menor número e tamanho (Touw 2001). Os paráfilos variam em distribuição, tamanho e forma. Eles geralmente são formados por uma célula basal, células intermediárias e uma célula apical que pode variar sua estrutura, podendo ser uma característica taxonômica importante para a diferenciação de espécies. 
Paráfilos simples e unisseriados são encontrados em Pelekium e Thuidiopsis, enquanto paráfilos ramificados e plurisseriados são encontrados em Thuidium.

\section{e) Filídios}

Nas espécies de Thuidiaceae que apresentam ramificação 1-pinada, os filídios são monomórficos. As espécies com ramificação 2-pinada e 3-pinada possuem os filídios do caulídio e da ramificação (em especial os filídios da última ramificação) diferenciados em tamanho e forma. Os filídios da primeira ramificação (intermediária) freqüentemente apresentam características intermediárias entre os filídios do caulídio e da última ramificação (Touw 2001).

Geralmente a forma mais comum dos filídios é a deltóide (triangular) ou ovadodeltóide, podendo também ocorrer como cordado ou ovado. Suas margens são quase sempre recurvadas próximas a inserção dos filídios e plana na porção superior. O tamanho dos filídos varia de 0,3-3mm de comprimento nos caulídios e de 0,2-1,2mm nas ramificações.

Sempre apresenta costa bem definida, forte, terminando próxima ao ápice (ou no ápice). Ocasionalmente a costa apresenta apêndices clorofilados na base (filídios do caulídio), que podem ser referidos na literatura como paráfilos.

A presença de células papilosas nos filídios é uma das características que definem o grupo (Buck \& Crum 1990). As papilas são definidas por Magill (1990) como ornamentações celulares vistas ao microscópio como "sólidas protuberâncias". Em alguns casos, o lúmen celular aparece em cima da projeção, dando um formato de mamilo as células e recebendo a denominação de mamilosas. Em outros casos as células são denominadas prorulosas, pois ocorre a projeção do ápice da célula, dando a impressão de ser tratar de uma papila. De acordo Buck \& Goffinet (2000), embora agrupadas com um único nome, estas ornamentações celulares são consideradas como assembléias heterogêneas de projeções celulares e provavelmente estão relacionadas a adaptação a ambientes secos.

Todas as espécies de Thuidiaceae apresentam filídios papilosos, seja na face abaxial, adaxial ou em ambas, variando de unipapilosa a pluripapilosa. Em muitas espécies do gênero Thuidium a ornamentação adaxial é inconspícua ou ausente. A ornamentação das células (papilas) dos filídios é um tema muito delicado e necessita de estudos mais detalhados e aprofundados para elucidar sua verdadeira função. 
As células dos filídios geralmente são isodiamétricas a retangulares nos caulídios e isodiamétricas/arredondadas nas ramificações, com as papilas situadas acima do lúmen, ao centro ou na periferia. Seu tamanho varia de $5-45 \mu \mathrm{m}$ de comprimento. Todas as espécies com células alongadas são unipapilosas e geralmente possuem papilas altas situadas ao centro (Touw 2001). Geralmente as papilas são mais pronunciadas nas células dos filídios da ramificação. Freqüentemente as células do ápice são lisas ou fracamente papilosas em relação às demais.

\section{f) Periquécio}

Os filídios periqueciais estão situados na parte basal e mediana do caulídio. Seu formato é geralmente lanceolado, plicado ou liso, com a presença ou ausência de cílios na margem. A ornamentação da margem (cílios) é um caractere importante para a separação de algumas espécies de Thuidium (Watanabe 1972; Touw 2001a). Seu tamanho também varia bastante, sendo menor nas espécies monóicas de Pelekium (1-1,8mm) e maior nas espécies dioicas de Thuidium (3-5mm).

De acordo com Touw (2001), as espécies dióicas de Thuidiaceae ocasionalmente produzem esporogônios, sendo extremamente difícil a visualização destas estruturas.

\section{g) Seta}

A seta é geralmente longa (> $1 \mathrm{~cm}$ ) e sua ornamentação é importante para a separação de algumas espécies e gêneros. A seta pode ser lisa (Thuidium, Thuidiopsis e Pelekium) ou rugosa/papilosa (Pelekium). De acordo com Touw (2001) a seta inteiramente rugosa/papilosa é uma característica de todas as espécies tropicais de terras baixas. No Brasil as espécies de Pelekium com seta rugosa/papilosa ocorrem com maior frequência na Amazônia. A ornamentação consiste da projeção de células que se assemelham a espinhos e podem variar de tamanho de acordo com a espécie (Touw 2001).

\section{h) Cápsula}

Podem ser simétricas ou assimétricas, ovóides ou cilíndricas, inclinadas ou horizontais. As células do exotécio possuem uma variação significativa dentro da própria espécie, não sendo usadas como uma característica importante para a separação de grupos e espécies (Touw 2001). Seu tamanho geralmente varia de 1$3 \mathrm{~mm}$. 
As paredes do exotécio podem ser delgadas ou incrassadas. Os ânulos apresentam pouca diferenciação. O opérculo geralmente é rostrado, mas ocasionalmente pode se apresentar como cônico.

\section{i) Peristômio}

A família possui um peristômio do tipo "hypnóide" perfeito, com os dentes do exostômio bem desenvolvidos. A coloração varia de avermelhado, alaranjadomarrom a amarelado-marrom. Os exostômios são amarelados ou alaranjados, lanceolados, com ombros, bordeados, estriados abaixo, papilosos acima, trabeculados. Os endostômios são lanceolados, papilosos, quilhados, com as membranas basais altas; cílios presentes, em grupos de 1-3. O peristômio não exibe variações significativas, não sendo utilizado como uma caracteristica para a separação de gêneros e espécies.

\section{j) Caliptra}

A grande maioria apresenta caliptra cuculada, exceto algumas poucas espécies de Pelekium que podem apresentar caliptra campanulada (Watanabe 1972).

\subsection{Objetivos}

Realizar uma revisão taxonômica da família Thuidiaceae para o Brasil;

Apresentar uma filogenia molecular e construir uma hipótese filogenética com uso de marcadores moleculares para Thuidiaceae a nível mundial;

Determinar quais caracteres morfológicos informativos para separar os gêneros e espécies de Thuidiaceae.

\subsection{Modelo de organização da tese}

De acordo com as diretrizes estabelecidas pelo Programa de Pós Graduação em Botânica / UnB e devido às facilidades deste modelo, optou-se pela apresentação da tese em um formato misto, dividida em formato clássico de dissertação e em artigos divididos em quatro capítulos, cada um correspondendo a uma publicação em revista cientifica: 
Capítulo 1: Filogenia molecular da família Thuidiaceae, baseada em marcadores de mitocôndria, cloroplasto e núcleo.

Capítulo 2: Novo arranjo taxonômico dos gêneros Pelekium e Thuidiopsis baseado em evidências filogenéticas.

Capítulo 3: A new species of Thuidium (Thuidiaceae) from Brazil and a Key to the Brazilian species of the genus.

Capítulo 4: A Família Thuidiaceae Schimp. (Bryophyta) no Brasil. 


\subsection{Referências Bibliográficas}

Akiyama, H. 1990. A morphological study of branch development in mosses with special reference to pseudoparaphyllia. The Botanical Magazine 103: 269282.

Ando, H. \& A. Matsuo. 1984. Applied Bryology. Advances in Bryology 2: 133-224.

Bartram, E. B. 1928. Costa Rican mosses collected by Paul C. Standley in 19241926. Contributions from the United States National Herbarium 26: 106.

Bartram, E. B. 1964. Mosses of Cerro Antisana, Ecuadorian Andes. Revue Bryologique et Lichénologique 33: 1-14.

Bescherelle, E. 1871. Prodomus bryologiae mexicanae. Mémoires de la Société des Sciences Naturelles de Cherbourg 15: 90-93.

Bôas-Bastos, S. B. V. \& C. J. P. Bastos. 2009. Musgos pleurocárpicos dos fragmentos de Mata Atlântica da Reserva Ecológica da Michelin, município de Igrapiúna, BA, Brasil. II - Hypnales (Bryophyta: Bryopsida). Acta Botanica Brasilica 23(3): 630-643.

Bordin, J. \& O. Yano. 2009. Briófitas do centro urbano de Caxias do Sul, Rio Grande do Sul, Brasil. Hoehnea 36 (1): 7-71.

Bordin, J. \& O. Yano. 2010. Lista das Briófitas (Anthocerotophyta, Bryophyta, Marchantiophyta) do Rio Grande do Sul, Brasil. Pesquisa Botânica 61: 39170.

Bowers, F. D. 1974. The Mosses Reported from Costa Rica. The Bryologist 77: 150177.

Brotherus, V. F. 1891. Contribution à la Flore bryologique du Brasil. Acta Societatis Scientiarum Fennicae 19 (5): 27.

Brotherus, V. F. 1908. Bryales. Pp. 977-1019. In: A. Engler \& K. Prantl (eds.), Die naturlichen Pflanzenfamilien Part I(3). Engelmann, Leipzig.

Brotherus, V. F. 1925. Musci (Laubmoose). 2. Halfte. In: A. Engler (ed.), Die naturlichen Pflanzenfamilien, Zweite Auflage. 11. Duncker \& Humblot, Berlin.

Buck, W. R. 1998. Pleurocarpous mosses of the West Indies. Memoirs of The New York Botanical Garden 82: 1-400. 
Buck, W. R. \& B. Goffinet. 2000. Morphology and classification of mosses. Pp. 71123. In: A. J. Shaw \& B. Goffinet (eds.), Bryophyte Biology. Cambridge University Press, Cambridge.

Buck, W. R. \& H. Crum. 1990. An evaluation of familial limits among the genera traditionally aligned with the Thuidiaceae and Leskeaceae. Contributions of the University of Michigan Herbarium 17: 55-69.

Câmara, P. E. A. S. 2008. Musgos pleurocárpicos das matas de galeria da Reserva Ecológica do IBGE, RECOR, Distrito Federal, Brasil. Acta Botanica Brasilica 22(2): 573-581.

Câmara, P. E. A. S. \& D. M. Vital. 2004. Briófitas do Município de Poconé, Pantanal de Mato Grosso, MT, Brasil. Acta Botanica Brasilica 18(4): 881-886.

Câmara, P. E. A. S., J. R. P. M. Oliveira \& M. M. M. Santiago. 2005. A Checklist of the bryophytes of Distrito Federal (Brasília, Brazil). Tropical Bryology 26: 133140.

Câmara, P. E. A. S. \& D. M. Vital. 2006. Briófitos de Cáceres, Pantanal de Matogrosso, Brasil, con nuevos registros para el estado y el País. Tropical Bryology 27: 1-8.

Câmara, P. E. A. S. \& A. E. R. Soares. 2010. A new and updated bryophyte checklist for Distrito Federal (Brasília, Brazil). Tropical Bryology 31: 165-168.

Câmara, P. E. A. S., J. Shaw. 2013. A Molecular Phylogeny of the Moss Genus Taxithelium (Pylaisiadelphaceae) Based on Plastid, Mitochondrial and Nuclear Markers. Systematic Botany 38(4): 861-868.

Cardot, J. 1909. Diagnoses préliminaires de mousses mexicaines. Revue Bryologique 36: 105-115.

Cardot, J. \& V. F. Brotherus. 1923. Botanische Ergebnisse der schwedischen Expedition nach Patagonien und dem Feuerlande 1907-1909. X. Les mousses. Kongliga Svenska Vetenskaps Academiens Handlingar 63(10): 62.

Churchill, S. P. \& E. L. Linares. 1995. Prodromus bryologiae Novo-Granatensis: Introducción a la flora de musgos de Colombia. Parte 2: Grimmiaceae a Trachypodaceae. Biblioteca José Jerónimo Triana 12(2): 831-843.

Churchill, S. P., D. Griffin, J. Muñoz. 2000. A checklist of the mosses of the tropical Andean countries. Ruizia 17: 137-139. 
Costa, D. P. 2003. Florisitic composition and diversity of amazonian rainforest bryophytes in the state of Acre, Brazil. Acta Amazonica 33(3): 399-414.

Costa, D. P. \& F. M. Lima. 2005. Moss diversity in the tropical rainforests of Rio de Janeiro, southeastern Brazil. Revista Brasileira de Botânica 28(4): 671-685.

Costa, D. P., K. C. Pôrto, A. P. Luizi-Ponzo, A. L. Ilkiu-Borges, C. J. P. Bastos, P. E. A. S. Câmara, D. F. Peralta, S. B. V. Bôas-Bastos, C .A. A. Imbassahy, D. K. Henriques, H. C. S. Gomes, L. M. Rocha, N. D. Santos, T. S. Siviero, T. F. Vaz-Imbassahy \& S. P. Churchill. 2011. Synopsis of the Brazilian moss flora: checklist, distribution and conservation. Nova Hedwigia 93(3-4): 277-334.

Costa, D. P. \& A. E. R. Soares. Thuidiaceae. In: Lista de Espécies da Flora do Brasil. Jardim Botânico do Rio de Janeiro. Disponível em: <http://www.floradobrasil.jbrj.gov.br/jabot/floradobrasil>. Accesso: 10 de Janeiro de 2015.

Crosby, M. R. 1969. The mosses reported from Panama. The Bryologist 72: 511-521.

Crum, H. A. 1950. Mosses from Honduras. The Bryologist 53: 292-295.

Crum, H. A. \& L. E. Anderson. 1981. Mosses of Eastern North America. 1. Columbia University Press, New York.

Cuming, A. C. 2009. Mosses as model organisms for developmental, cellular and molecular biology. Pp. 199-236. In: B. Goffinet \& A. J. Shaw (eds.), Bryophyte Biology. ed. 2. Cambridge University Press, Cambridge.

De Luna, E., W. R. Buck, H. Akiyama, T. Arikawa, H. Tsubota, A. E. Newton \& A. J. Shaw. 2000. Ordinal phylogeny within the hypnobryalean pleurocarpous mosses inferred from cladistic analyses of three chloroplast DNA sequence data sets: trnL-F, rps4 and rbcL. The Bryologist 103: 242-256.

Fernández, E. G \& A. M. V. Serrano. 2009. Atividades Biológicas das Briófitas. Âmbito cultural, Rio de Janeiro.

Fleischer, M. 1922. Thuidiaceae. Die Musci der Flora von Buitenzorg 4: 1494-1533.

García-Avila, D., E. De Luna \& A. E. Newton. 2009. Phylogenetic relationships of the Thuidiaceae and the non-monophyly of the Thuidiaceae and the Leskeaceae based on rbcL, rps4 and the rps4-trnS intergenic spacer. The Bryologist 112(1): 80-93. 
Genevro, J. A., F. P. A. Filho \& D. F. Peralta. 2006. Briófitas de mata de galeria no Parque Municipal Mário Viana, Nova Xavantina, Mato Grosso, Brasil. Boletim do Instituto de Botânica 18: 149-157.

Gier, L. J. 1980. A preliminary study of the Thuidiaceae (Musci) of Latin America. Journal of Bryology 11: 253-309.

Goffinet, B., W. R. Buck \& A. J. Shaw. 2009. Morphology and classification of the Bryophyta. pp. 55-138. In: B. Goffinet \& A. J. Shaw (eds.), Bryophyte Biology 2 ed. Cambridg University Press, Cambridge.

Gradstein, S. R., S. P. Churchill, \& N. Salazar-Allen. 2001. Guide to the Bryophytes of Tropical America. Memoirs of The New York Botanical Garden 86: 1-577.

Grout, A. J. 1932. Leskea and Pseudoleskea. pp. 185-196. In: A. J. Grout (ed.), Moss Flora of North America v. 3. Newfane, Vermont.

Hampe, G. E. L. \& Geheeb, A. 1881. Additamenta ad Enumerationem hactenus in provinciis Brasiliensibus Rio de Janeiro et São Paulo detectroum. Flora 64: 369-381.

Hedenãs, L. 1997. An Evaluation of Phylogenetic Relationships among the Thuidiaceae, the Amblystegiaceae, and the Temperate Members of the Hypnaceae. Lindbergia 22(3): 101-133.

Hegewald, P. \& E. Hegewald. 1975. Verzeichnis der Laubmoose von Peru nach Literatureangaben. Journal of the Hattori Botanical Laboratory 39: 39-66.

Hegewald, E. \& P. Hegewald. 1976. Eine Moossammlung aus Peru. I. Nova Hedwigia 28: 731-758.

Hermann, F. J. 1976. Recopilacion de los musgos de Bolivia. The Bryologist 79: 125171.

Herzog, T. 1910. Weitere Beiträge zur Laubmoosflora von Bolivia. Beihefte zum Botanischen Centralblatt 27(2): 352.

Herzog, T. 1942. Beiträge zur Kenntnis neotropischen Bryophyten. Beihefte zum Botanischen Centralblatt 61b: 559-590.

Jaeger, A. 1870. Adumbratio flore muscorum totius orbis terrarum. Part 1. Bericht über die Thätigkeit der St. Gallischen Naturwissenschaftlichen Gesellschaft. 1869-1870: 436. 
Jaeger, A. 1879. Adumbratio flore muscorum totius orbis terrarum. Part 9. Bericht über die Thätigkeit der St. Gallischen Naturwissenschaftlichen Gesellschaft. 1877-1878: 257-514.

Kindberg, N. C. 1897. Laubmoose aus dem Umanakdistrickt. Bibliotheca Botanica 87(A): 64-68.

La-Farge-England, C. 1996. Grouth form, branching pattern, and perichaetial position in mosses: cladocarpy and pleurocarpy redifined. The Bryologist 99:170-186.

Lisboa, R. C. L. \& A. L. Ilkiu-Borges. 1997. Novas ocorrências de Bryophyta (Musgos) para o Estado do Pará, Brasil. Acta Amazonica 22(2): 81-102.

Magill, R. E. 1990. Glossarium polyglottum bryologiae: a multilingual glossary for bryology. Monographs in Systematic Botany from the Missouri Botanical Garden 33: 1- 297.

McDaniel, S. F. \& A. J. Shaw. 2003. Phylogeographic structure and cryptic speciation in the trans-Antarctic moss Pyrrhobryum mnioides. Evolution 57:205-215.

Mitten, W. 1869. Musci austro-americana. Journal of the Linnean Society, Botany. 12: $1-659$.

Moraes, E. N. R. \& R. C. L. Lisboa. 2006. Musgos (Bryophyta) da Serra dos Carajás, Estado do Pará, Brasil. Boletim Museu Paraense Emílio Goeldi, Ciências Naturais 1(1): 39-68.

Müller, C. 1901. Symbolae ad bryologiam Brasiliae et regionum vicinarum. Hedwigia 40: 55-99.

Newton, A. E., C .J. Cox, J. G. Duckett, J. A. Wheeler, B. Goffinet, T. A. J. Hedderson \& B. D. Mishler. 2000. Evolution of the Major Moss Lineages: Phylogenetic Analyses Based on Multiple Gene Sequence and Morphology. The Bryologist 103(2):187-211.

Peralta, D. F. \& O. Yano. 2005. Briófitas de mata paludosa, município de Zacarias, noroeste do Estado de São Paulo, Brasil. Acta Botanica Brasilica 19(4): 963977.

Peralta, D. F. \& O. Yano. 2006. Novas ocorrências de musgos (Bryophyta) para o Estado de São Paulo, Brasil. Revista Brasileira de Botânica 29(1): 49-65. 
Peralta, D. F. \& O. Yano. 2008. Briófitas do Parque Estadual da llha Anchieta, Ubatuba, estado de São Paulo, Brasil. Iheringia, Série Botânica 63(1): 101127.

Peralta, D. F., J. Bordin \& O. Yano. 2008. New mosses records (Bryophyta) for Goiás and Tocantins states, Brazil. Acta Botanica Brasilica 22(3): 834-844.

Peralta, D. F. \& F. P. A. Filho. 2008. Briófitas corticícolas de mata ciliar ao longo do Rio Uruguai, antes do alagamento da área pela Barragem de Itá, entre Santa Catarina e Rio Grande do Sul, Brasil. Hoehnea 35(3): 411-418.

Pinheiro, E. M. L. \& P. E. A. S. Câmara. 2012. Musgos Pleurocárpicos de Capões de Mata no Parque Nacional da Chapada dos Veadeiros, Goiás, Brasil. Heringeriana 6(2): 54-65.

Pursell, R. A. 1973. Un censo de los musgos de Venezuela. The Bryologist 76: 473500 .

Robinson, H. 1967. Preliminary studies on the bryophytes of Colombia. The Bryologist 70: 1-61.

Robinson, H. 1975. The mosses of Juan Fernandez Islands. Smithsonian Contributions to Botany 27: 1-88.

Rydin, H. 2009. Population and community ecology of bryophytes. Pp. $393-444$. In: B. Goffinet \& A. J. Shaw (eds.), Bryophyte biology, 2 ed. Cambridge University Press, Cambridge.

Santos, R. C. P. \& R. C. L. Lisboa. 2003. Musgos (Bryophyta) do nordeste paraense, Brasil - 1. Zona Bragantina, microrregião do Salgado e município de Viseu. Acta amazonica 33(3): 415-422.

Santos, R. C. P. \& R. C. L. Lisboa. 2008. Musgos (Bryophyta) da microrregião do Salgado Paraense e sua utilização como possíveis indicadores de ambientes perturbados. Rodriguesia 59(2): 361-368.

Schiavone, M. M. \& Suárez, G. M. 2007. Las Thuidiaceae en el noroeste de Argentina. Boletín de la Sociedad Argentina de Botánica 42: 211-230.

Schimper, W.P. 1852. Thedenia, Anisodon, Pseudoleskea, Heterocladium, Thuidium, Hylocomium, Thamnium, Rhynchostegium. Bryologia Europaea 49-51.

Schimper, W.P. 1860. Synopsis muscorum europaeorum. E. Schweizerbart, Stuttgart. 
Schimper, W.P. 1876. Synopsis muscorum europaeorum praemissa introductione de elementis bryologicis tractante. Ed. 2. E. Schweizerbart, Stuttgart.

Schofield W.B. 2001. Introduction to Bryology. The Blackburn Press, Caldwell.

Sehnem, A. 1976. Musgos Sul-Brasileiros IV. Pesquisas 30: 52.

Sousa, M. A. R., V. L. Gomes-Klein \& O. Yano. 2010. Musgos (Bryophyta) do Parque Estadual da Serra dos Pireneus, Goiás, Brasil. Revista de Biologia Neotropical 7(1): 7-26.

Souza, A. P. S. \& R. C. L. Lisboa. 2005. Musgos (Bryophyta) na Ilha Trambioca, Barcarena, PA, Brasil. Acta Botanica Brasilica 19(3): 487-492.

Spruce, R. 1867. Catalogus muscorum fere omnium quos in terris Amazonicis et Andinis legit Ricardius Sprucus per annos 1849-1860. London.

Steere, W. C. 1948. Contribution of the bryogeography of Ecuador. I. A review of the species of Musci previously reported. The Bryologist 51: 65-167.

Steere, W. C. 1967. The Bryology of Brazil: a preliminary bibliography. Atlas do Simpósio sobre a Biota Amazônica 4: 259-267.

Stoeinin, H. K. 2008. Slow molecular evolution in 18S rDNA, rbcL and nad5 genes of mosses compared with higher plants. Journal of Evolutionary Biology 21:566571.

Touw, A. 2001. A review of Thuidiaceae (Musci) and a realignment of taxa traditionally accommodated in Thuidium sensu amplo (Thuidium Schimp., Thuidiopsis (Broth.) M. Fleisch, and Pelekium Mitt.) including Aequatoriella gen. nov. and Indothuidium gen. nov. Journal of the Hattori Botanical Laboratory 90: 167-209.

Valente, E. B., K. Pôrto, S. B. V. Bôas-Bastos \& C. J. P. Bastos. 2009. Musgos (Bryophyta) de um fragmento de Mata Atlântica na Serra da Jibóia, município de Santa Terezinha, BA, Brasil. Acta Botanica Brasilica 23(2): 369-375.

Vanderpoorten, A., N. Devos, B. Goffinet, O. J. Hardy \& A. J. Shaw. 2008. The barriers to oceanic island radiation in bryophytes: insights from the phylogeography of the moss Grimmia montana. Journal of Biogeography 35: 654-663.

Visnadi, S. R. 2005. Brioflora da Mata Atlântica do estado de São Paulo: região norte. Hoehnea 32(2): 215-231. 
Visnadi, S. R. 2011. Briófitas dos picos do Cuscuzeiro e do Cardoso, estado de São Paulo, Brasil. Boletim Museu Paraense Emílio Goeldi, Ciências Naturais 6(3): 307-317.

Warnstorf, C. 1905. Kryptogamenflora der Mark Brandenburg, Laubmoose 5. Gebrüder Borntraeger, Leipzig.

Watanabe, R. 1972. A revision of the family Thuidiaceae in Japan and adjacent areas. Journal of the Hattori Botanical Laboratory 36: 171-320.

Welch, W. H. 1948. Mosses and their uses. Procedings Indiana Academy of Science 58: 31-46.

Williams, R. S. 1927. Mosses from Peru collected by the Captain Marshall Field Peruvian Expedition, 1923. Publications of the Field Museum of Natural History, Botanical Series 4(5): 125-139.

Williams, R. S. 1930. Haitian mosses collected by E. C. Leonard. Journal of the Washington Academy of Sciences 20(10): 177.

Yano, O. 2004. Novas ocorrências de briófitas para vários estados do Brasil. Acta Amazonica 34(4): 559-576.

Yano, O. \& C. J. P. Basto. 2004. Adições à flora de briófitas de Mato Grosso do Sul, Brasil. Acta Botanica Brasilica 18(3): 437-458.

Yano, O. \& D. F. Peralta. 2004. Musgos (Bryophyta) de Mato Grosso, Brasil. Hoehnea 31(3): 251-292.

Yano, O. \& P. E. A. S. Câmara. 2004. Briófitas de Manaus, Amazonas, Brasil. Acta Amazonica 34(3): 445 - 457.

Yano, O. \& D. F. Peralta. 2006. Novas Ocorrências de Briófitas para os Estados de Alagoas e Sergipe, Brasil. Arquivos do Museu Nacional 64(4): 287-297.

Yano, O. \& D. F. Peralta. 2008a. Briófitas do Espírito Santo existentes no Herbário Científico do Estado "Maria Eneyda P. Kauffmann Fidalgo", Instituto de Botânica, São Paulo, Brasil. Boletim do Museu Biológico Mello Leitão 24: 5100.

Yano, O. \& D. F. Peralta. 2008b. Briófitas da llhabela, Estado de São Paulo, Brasil. Hoehnea 35(1): 111-121.

Yano, O., J. Bordin \& D. F. Peralta. 2009. Briófitas dos estados do Ceará, Maranhão, Paraíba, Piauí e Rio Grande do Norte (Brasil). Hoehnea 36(3): 387-415. 
Yano, O. 2010. Levantamento de novas ocorrências de Briófitas brasileiras. Instituto de Botânica de São Paulo, São Paulo.

Yano, O. 2011. Catálogo de musgos brasileiros: literatura original, basiônimo, localidade-tipo e distribuição geográfica. Instituto de Botânica de São Paulo, São Paulo. 


\title{
2. CAPÍTULO 1
}

A ser submetido para a revista Systematic Botany

\section{Filogenia molecular da família Thuidiaceae, baseada em marcadores de mitocôndria, cloroplasto e núcleo.}

\author{
Abel Eustáquio R. Soares ${ }^{1}$ \& Paulo E.A.S. Câmara ${ }^{1}$ \\ ${ }^{1}$ Universidade de Brasília, UnB, Depto. de Botânica. Campus Universitário Darcy Ribeiro, Asa \\ Norte, Brasília, DF. Brazil.
}

\section{Resumo}

A família Thuidiaceae pertence ao grupo dos musgos pleurocárpicos e a ordem Hypnales. Possuem características pouco comuns a maioria dos pleurocárpicos, como a presença de paráfilos com papilas e gametófito com padrão de pinação característico (1-3 pinada). Mundialmente é representada por 16 gêneros e ca. de 72 espécies distribuídas pelas regiões temperadas e principalmente nas regiões tropicais. A circunscrição da família sempre foi controversa, principalmente devido às similaridades e parentesco conflitante com Leskeaceae. Desta forma, o objetivo foi apresentar uma filogenia molecular e construir uma hipótese filogenética com uso de marcadores moleculares para Thuidiaceae a nível mundial. Foram selecionadas 47 espécies para a extração de DNA. Material para extração foi obtido durante as coletas de campo e material de herbário. Foram utilizadas três regiões do genoma: rps4, nad5 e 26s. Os resultados aqui apresentados não suportam a atual divisão da família baseada em caracteres morfológicos. Podemos confirmar a monofilia da família Thuidiaceae constituída somente pelos gêneros Pelekium, Thuidium e Thuidiopsis e também a polifilia de Leskeaceae e demais gêneros antes tradicionalmente agrupados em Thuidiaceae. A proximidade entre Thuidiopsis e Pelekium sugere um forte parentesco entre estes dois gêneros e a necessidade da revisão dos sistemas de classificações atuais.

Palavras Chaves: Monofilétilo, Thuidium, Pelekium. 


\section{Introdução}

A divisão Bryophyta, que inclui apenas os musgos, com aproximadamente 12.000 espécies (Crosby et al. 2004), pode ser dividida em três importantes grupos com base na posição do periquécio (La-Farge-England 1996): Acrocárpico, Cladocárpico e Pleurocárpico.

Os musgos pleurocárpicos são tipicamente encontrados em florestas tropicais e respondem por aproximadamente $50 \%$ de todas as espécies de musgos (Bryophyta) conhecidas (Shaw \& Renzaglia 2004). São um grupo monofilético (De Luna et al. 1999; Newton et al. 2000) com uma linhagem altamente diversificada (Newton et al. 2007) que inclui as ordens Hookeriales, Hypnales e Ptychomniales. A radiação dos pleurocárpicos é datada em aproximadamente 165-131 milhões de anos, coincidindo com o aparecimento das complexas florestas de angiospermas no cretáceo (Newton et al. 2007), portanto são um grupo altamente derivado.

A ordem Hypnales é a maior e mais diversificada dentro dos pleurocárpicos, com aproximadamente 4.200 espécies, o que significa um terço de todas as espécies de Bryophyta (Goffinet et al. 2009).

A família Thuidiaceae pertence a ordem Hypnales. Colonizam diferentes substratos, ocorrendo sobre rochas, solos e troncos, em especial no interior de florestas. Muitos representantes da família tem um papel ecológico importante, formando carpetes sobre o solo das florestas, contribuindo para a retenção da umidade e manutenção do microclima, servindo como um ótimo substrato para a germinação de sementes e micro-habitat para diversos artrópodes (García-Avila et al. 2009).

Mundialmente é representada por 16 gêneros e ca. de 72 espécies distribuídas nas regiões temperadas e principalmente nas regiões tropicais (Touw 2001a). Seu centro de diversidade florística é na região Sino-Japonesa, o que sugere sua origem na Laurasia (Buck \& Vitt 1986). É amplamente distribuída em todos os continentes com exceção da Antártida, ocorrendo das florestas tropicais as florestas temperadas, do nível do mar a altas altitudes, como por exemplo Himalaia e Cordilheira dos Andes. Muitos gêneros e espécies são endêmicos da Ásia e da América do Sul, sendo estes os locais de maior diversidade (Touw 2001a). Espécies de Thuidiaceae crescem geralmente na camada inferior de ambientes mésicos ou florestas úmidas (Touw 2001a), poucas espécies são encontradas em ambientes secos. 
A família pode ser caracterizada por uma larga combinação de caracteres: ramificação regularmente pinada (1-3 pinada); paráfilos nos caulídios, na maioria das espécies abundantes; filídio do caulídio frequentemente deltóide ou deltóide-ovado, ápice acuminado ou longo-acuminado; costa simples; células papilosas; filídios da ramificação, nas espécies 2-3 pinadas, conspicuamente diferentes dos filídios dos caulídios e peristômio tipicamente hypnóide (Touw 2001b).

A circunscrição da família sempre foi controversa, principalmente devido às similaridades e parentesco conflitante com Leskeaceae. Estas controvérsias geraram diversas classificações diferentes ao longo de sua história. Durante muitos anos a circunscrição proposta por Brotherus (1908), com Thuidiaceae sendo considerada subfamília de Leskeaceae foi a mais aceita.

Porém, a partir da década de 90 duas propostas (Buck \& Crum 1990; Touw 2001) surgem para explicar as relações de parentesco entre Leskeaceae e Thuidiaceae e dentro desta última família. Buck \& Crum (1990) dividiram Thuidiaceae em duas subfamílias: Cyrtohypnoideae (Boulaya Cardot, Cyrto-hypnum (Hampe) Hampe \& Lorentz, Lorentzia Hampe e Rauiella Reimers) e Thuidioideae (Abietinella Müll. Hal., Thuidiopsis (Broth.) M. Fleisch. e Thuidium Bruch \& Schimp.) e transferiram os gêneros Hylocomiopsis Cardot. e Actinothuidium Broth. antes em Thuidiaceae para Hylocomiaceae.

No inicio do século 21 surge o conceito mais aceito e utilizado nos dias de hoje. Touw (2001a), baseado em múltiplos caracteres, dividiu a família em 16 gêneros e 72 espécies organizadas em três grupos informais: Combinado (Abietinella, Boulaya, Haplocladium (Müll. Hal.) Müll. Hal. e Rauiella), Helodioideo (Actinothuidium, Bryonoguchia Z. Iwats. \& Inoue, Echinophyllum T.J. O'Brien, Helodium Warnst. e Hylocomiopsis) e Thuidioideo (Aequatoriella Touw, Bryochenea C. Gao \& G.C. Zhang, Indothuidium Touw, Orthothuidium D.H. Norris \& T.J. Kop., Pelekium Mitt., Thuidium e Thuidiopsis).

Desta forma, surge a eminente necessidade de resolver as relações filogenéticas dentro de Thuidiaceae e entre Thuidiaceae e Leskeaceae. Muitos trabalhos a respeito da filogenia de Hypnales utilizaram representante de Thuidiaceae em suas análises (De Luna et al. 1999, 2000; Buck et al. 2000; Goffinet et al. 2001; Goffinet \& Buck 2004; Tsubota et al. 2004) e todos indicaram que Thuidiaceae pertence ao grupo das Hypnales e é um grupo irmão de Leskeaceae. 
Gardiner et al. (2005), indicou que a família Thuidiaceae estava relacionada com Leskea Hedw. (gênero tipo de Leskeaceae) e Haplocladium (Müll. Hal.) Müll. Hal. mais do que qualquer outro grupo. As espécies do gênero Thuidium apresentaram-se como monofiléticas, porém, as outras espécies tradicionalmente agrupadas em Thuidiaceae apresentaram-se como polifiléticas. Nas análises de Gardiner et al. (2005), foi possível observar a formação de um grupo monofilético composto pelas três espécies de Thuidium utilizados no estudo (Thuidium delicatulum (Hedw.) Schimp., Thuidium philibertii Limpr. e Thuidium tamariscinum (Hedw.) Schimp.), mais algumas espécies de Leskeaceae, incluindo a espécie-tipo (Leskea polycarpa Hedw.), evidenciando a proximidade deste grupo e a necessidade de estudos mais aprofundados para solucionar a verdadeira circunscrição de Thuidiaceae e Leskeaceae.

Cox et al. (2010) em estudo a respeito da filogenia molecular de musgos, confirmou a existência de um grupo monofilético bem suportado composto por Thuidium, Cyrto-hypnum (Pelekium) e Thuidiopsis. Toda via, sua análise agrupou dentro de Thuidiaceae representantes de Helodiaceae e Leskeaceae.

A não monofilia de Thuidiaceae e Leskeaceae foi citada por Ignatov (2007). No seu trabalho representantes de Thuidium aparecem dentro do clado formado por Leskea e Haplocladium formando um grupo monofilético.

O primeiro trabalho exclusivo a respeito da filogenia molecular de Thuidiaceae foi realizado por García-Avila et al. (2009). Os autores realizaram um estudo filogenético com Thuidiaceae e Leskeaceae utilizando somente marcadores de cloroplasto ( $r b c L$, rps4 e rps4-trnS) e parcimônia. Os autores demonstraram a grande proximidade entre Leskeaceae e Thuidiaceae, bem como a confirmação da existência de um grupo monofilético composto somente por alguns representantes do agrupamento "Thuidioideo" proposto por Touw (2001a), sendo eles Pelekium, Thuidiopsis e Thuidium, ou seja, somente estes gêneros poderiam ser considerados Thuidiaceae. Também concluíram que Thuidiaceae e Leskeaceae não são grupos monofiléticos e que seria necessária uma análise mais ampla, incluindo mais representantes de ambas as famílias, além da inclusão de mais marcadores para tornar seus resultados mais conclusivos.

Desta forma, o objetivo deste trabalho é apresentar uma filogenia molecular e construir uma hipótese filogenética com uso de marcadores moleculares para Thuidiaceae a nível mundial, resolvendo o parentesco filogenético de Thuidiaceae e 
Leskeaceae, bem como sua monofilia e delimitando os verdadeiros limites da família e dos seus gêneros. A hipótese filogenética foi construída utilizando dados de diferentes regiões do genoma como cloroplasto, mitocôndria e núcleo. De acordo com Kuzoff et al. (1998), hipóteses filogenéticas baseadas somente em um único gene não representam a verdadeira história de parentesco dos organismos. Sendo assim, o uso de diferentes regiões do genoma permite uma maior confiança nos resultados, uma vez que não estão sujeitos a transferência lateral ao mesmo tempo.

\section{Material e Métodos}

Amostragem - Foram selecionadas 47 espécies, sendo 10 gêneros e 33 espécies tradicionalmente agrupadas por Touw (2001a) em Thuidiaceae (Abietinella, Actinothuidium, Boulaya, Haplocladium, Helodium, Hylocomiopsis, Pelekium, Rauiella, Thuidiopsis e Thuidium); um gênero e duas espécies de Rigodiaceae (Rigodium Kunze ex Schwägr.); seis gêneros e sete espécies de Leskeaceae (Claopodium (Lesq. \& James) Renauld \& Cardot, Lescuraea Schimp., Leskea, Lindbergia Kindb., Pseudoleskea Bruch \& Schimp., Pseudoleskeella Kindb.); dois gêneros e duas espécies de Pterigynandraceae (Heterocladium Bruch \& Schimp. e Myurella Schimp.) e uma espécies de Theliaceae (Fauriella Besch.). Também foram selecionadas duas espécies de Hypnaceae (Ectropothecium Mitt. e Vesicularia (Müll. Hal.) Müll. Hal.) como grupo externo (Tabela 2). A escolha do grupo externo (outgroup) se baseou no trabalho de Cox et al. (2010). As espécies foram selecionadas para refletirem a variação morfológica e geográfica do grupo. Assim sendo, espécies de diferentes continentes foram utilizadas, tais como: América do Sul, América do Norte, Europa e Ásia.

A classificação das espécies agrupadas dentro de Thuidiaceae seguiu o conceito de Touw (2001a). Para as demais adotou-se o conceito de Goffinet et al. (2009).

Extração de DNA e amplificação - O DNA genômico foi extraído do material fresco obtido durante as coletas de campo em diversas regiões do Brasil e do material proveniente dos herbários quando disponível, viável e autorizado, utilizando as dependências do Laboratório de Biologia Molecular do Departamento de Botânica da Universidade de Brasília. 
As espécies selecionadas para a extração foram limpas em água com auxilio de um pincel visando a retirada da terra, restos de substratos e outras espécies que ocasionalmente crescem em associação com o material selecionado.

O DNA foi obtido utilizando o protocolo mini-CTAB (Doyle \& Doyle 1987). Foram utilizados marcadores de três regiões diferentes do genoma (Tab. 1). Para o cloroplasto foi utilizada a proteína ribossomal 4 (rps4); para o genoma mitocondrial foi utilizado o $\mathrm{NADH}$ - desidrogenase subunidade 5 (nad5) e para o genoma nuclear foi utilizado sequência parcial do DNA ribossomal 26s. Também foram utilizadas sequências do GenBank - NCBI quando as sequências obtidas não eram de qualidade aceitável e para aumentar a matriz de dados.

Uma única amplificação foi produzida para os marcadores rps4 e 26s. O nad5 foi amplificado em dois fragmentos sobrepostos: nad5K - nad5Li e nad5Ki - nad5Le (Bell \& Newton 2005)

Tabela 1: Primers e temperaturas de anelamento utilizados no estudo.

\begin{tabular}{ccc}
\hline Marcador & Referência & $\begin{array}{c}\text { Temperatura de } \\
\text { anelamento } \mathbf{C}^{\circ}\end{array}$ \\
rps4 F & Nadot et al. 1994 & $51-54$ \\
rps4 R & Nadot et al. 1994 & $51-54$ \\
nad5K & Beckert et al. 1999 & $52-54$ \\
nad5Li & Beckert et al. 1999 & $52-54$ \\
nad5Ki & Beckert et al. 1999 & $58-60$ \\
nad5Le & Beckert et al. 1999 & $58-60$ \\
26s R - LSOF & Shaw 2000 & $50-52$ \\
26s F - LS12R & Shaw 2000 & $50-52$ \\
\hline
\end{tabular}

A tabela 2 lista todos os táxons utilizados neste estudo, com o respectivo voucher de todas as espécies, com coletor e número de coleta, localidade e herbário, bem como o número de acesso no GenBank. 
Tabela 2: Táxons utilizados no estudo, localidade de coleta, coletor e número de coleta, herbário onde está depositado e número de acesso no GenBank. * Sequências do GenBank.

\begin{tabular}{|c|c|c|c|c|c|}
\hline \multirow[b]{2}{*}{ Espécie } & \multirow[b]{2}{*}{ Voucher } & \multirow[b]{2}{*}{ Origem } & \multicolumn{3}{|c|}{ GenBank } \\
\hline & & & RPS4 & $26 S$ & NAD5 \\
\hline Abietinella abietina (Hedw.) M. Fleisch. & Jia 8640 (MO) & China & & & \\
\hline Actinothuidium hookeri (Mitt.) Broth. & Shevock 35187 (MO) & China & & & \\
\hline Boulaya mittenii (Broth.) Cardot & Tanaka 327 (MO) & Japão & & & \\
\hline Ectropothecium leptochaeton (Schwägr.) W.R. Buck * & Whittemore 5594 (MO) & Belize & AY908558.1 & HM751405.1 & AY908405.1 \\
\hline Fauriella tenuis (Mitt.) Cardot * & He \& Song 327 (MO) & Coreia do Sul & AY908233.1 & HM751394.1 & AY908545.1 \\
\hline Haplocladium angustifolium (Hampe \& Müll.) Broth. & Allen 27907 (MO) & USA & & & \\
\hline Lescuraea radicosa (Mitt.) Mönk. & Whittemore 5372 (NY) & USA & & & \\
\hline Leskea nervosa (Brid.) Myrin & Shevock 32344 (MO) & China & & & \\
\hline Leskea polycarpa Hedw. & Allen 28958 (MO) & USA & & & \\
\hline
\end{tabular}




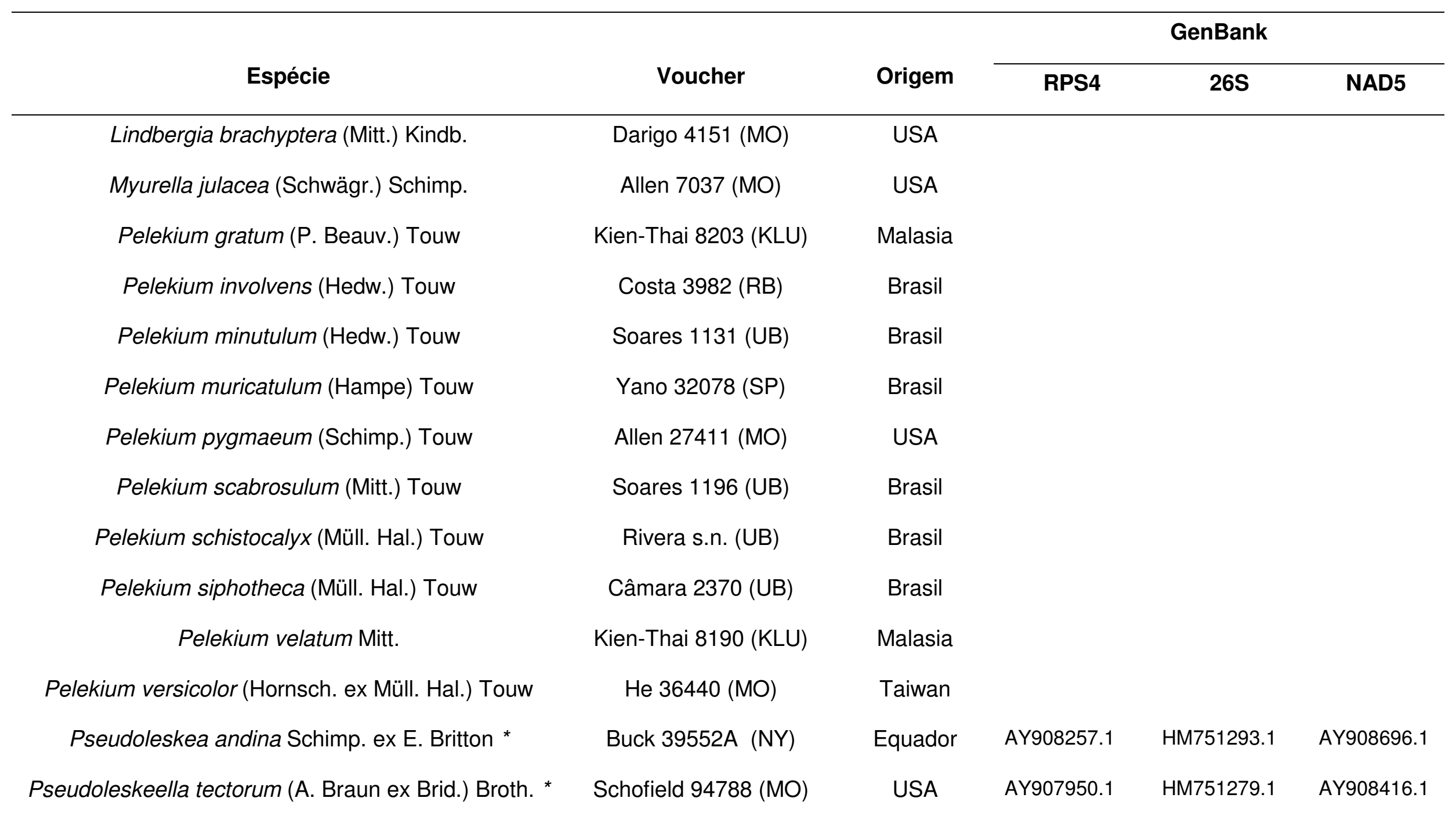




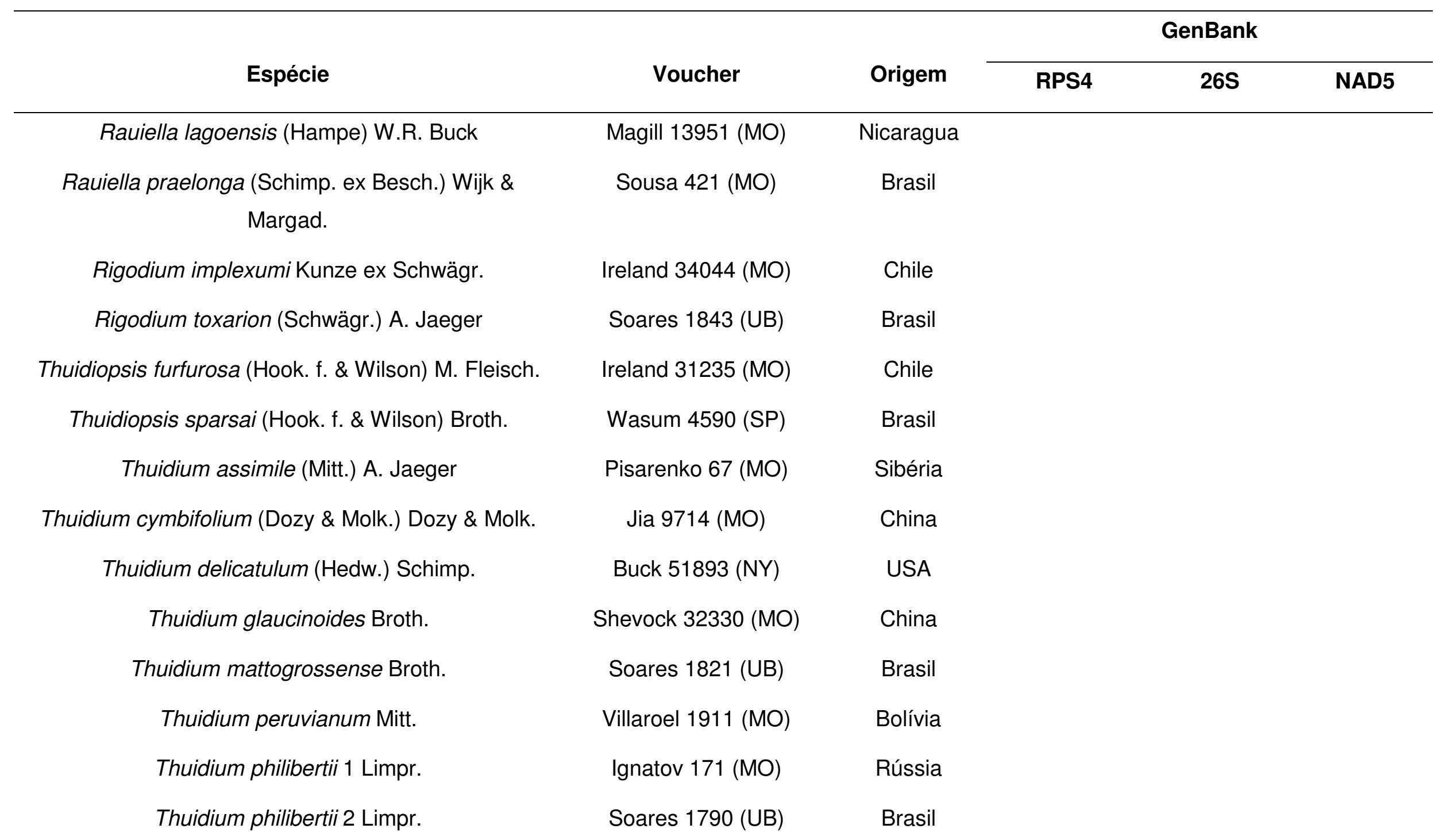




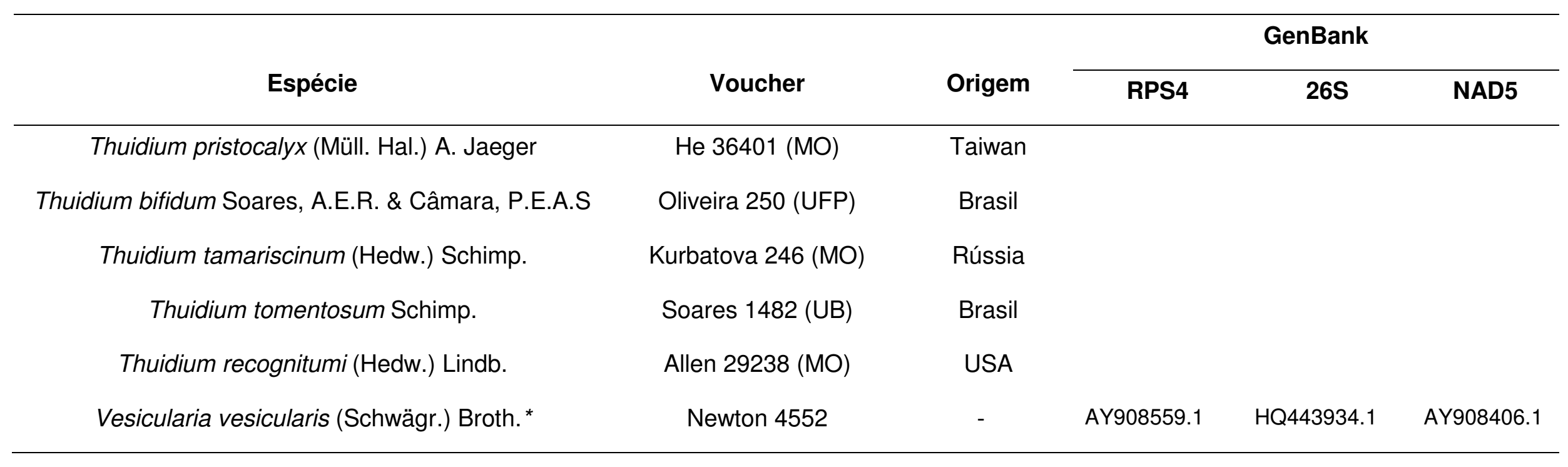


A amplificação foi feita utilizando-se a técnica de reação em cadeia da polimerase (PCR), utilizando um volume final de $20 \mu \mathrm{l}$, sendo $2 \mu \mathrm{l}$ de

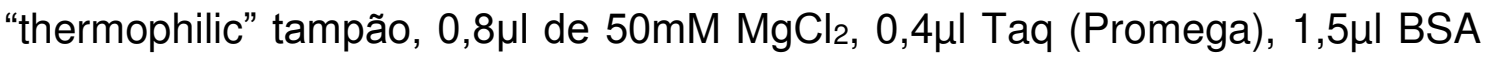
$(10 \mathrm{mg} / \mathrm{ml}), 3,2 \mu \mathrm{l} 1 \mathrm{mM}$ dNTP, $1 \mu \mathrm{l}$ de cada primer $(10 \mathrm{mM}), 3 \mu \mathrm{l}$ de DNA, completados com $7,1 \mu$ l de água Milli-q. O DNA genômico utilizado foi diluído na proporção de 1:10 antes do uso. As condições de amplificação foram as seguintes para todos os primers, com diferenças apenas nas temperaturas de anelamento (tabela 1) de acordo com a especificidade de cada primer e espécie: $94^{\circ} \mathrm{C}-1 \min$ (desnaturação), $50-60^{\circ} \mathrm{C}-1 \min$ (anelamento), $72^{\circ} \mathrm{C}-$ $1 \mathrm{~min}$, repetidos durante 35 ciclos, sempre precedidos de um passo inicial de 2 minutos a $94^{\circ} \mathrm{C}$ e uma extensão final de 7 minutos a $72^{\circ} \mathrm{C}$.

Sequenciamento e análise dos dados - a limpeza da reação de PCR e o sequenciamento (sem clonagem) foram terceirizados e realizados pela MACROGEN Inc. (Seoul, Korea). A montagem das sequências (Contigs) foi feita utilizando o software CodonCode Aligner (versão 4.2.7; CodonCode Corporation, MA, USA). Todas as sequências serão submetidas ao GenBank (tabela 2).

Inicialmente o alinhamento foi realizado utilizando o software ClustalX (Higgins \& Sharp 1988), e então ajustados e checados manualmente utilizando o software Phyde (versão 0.9971; Phylogenetic Data Editor).

A análise dos dados e a reconstrução filogenética foram feitas por meio dos critérios da parcimônia, verossimilhança e análise bayesiana.

Para a análise de máxima parcimônia foi utilizado o software PAUP versão 4.0b10 para Macintosh (Swofford 2002). Busca heurística foi realizada com 100 replicações randômicas e TBR (tree-bisection reconnection) com no máximo 10.000 árvores. Todos os caracteres foram desordenados $\mathrm{e}$ igualmente ponderados, gaps foram tratados como ausência de dados. O bootstrap foi calculado como parâmetro de suporte para os clados (Felsenstein 1985), com 1.000 replicações. Valores de bootstrap superiores a 75 são considerados confiáveis e aceitáveis.

As análises de Verossimilhança foram realizadas no software RaxML. (Stamatakis 2014). O modelo de evolução ideal para cada locus foi calculado utilizando o software jModeltest 2.1.3 (Darriba et al. 2012). O suporte para os 
clados foi calculado utilizando bootstrap (Felsenstein 1985), com 1.000 replicações.

As inferências Bayesianas foram feitas no software Mr. Bayes v.3.2.2 (Ronquist \& Huelsenbeck 2003). O modelo de evolução ideal para cada locus foi calculado utilizando o software jModeltest 2.1.3 (Darriba et al. 2012). Quatro corridas, cada uma com quatro cadeias MCMC (Markov Chain Monte Carlo Chain) foram executadas para 5.000.000 gerações, amostradas a cada 1.000 gerações, em corridas paralelas. O suporte para os nós foi calculado por meio das probabilidades posteriores. Os valores das probabilidades posteriores variam entre 0 e 1 , sendo que valores abaixo de 0,95 foram considerados não confiáveis. O software Tracer 1.5 (Rambaut \& Drummond 2013) foi utilizado para determinar quando a amostragem das árvores estava estabilizada. Os primeiros $25 \%$ das árvores foram descartados (burn-in). Uma árvore de consenso foi construída a partir das demais árvores resultantes para estimar as probabilidades posteriores.

As árvores obtidas foram editadas utilizando o software FigTree 1.4.2 (Rambaut 2009).

Para cada método de reconstrução filogenética (parcimônia, verossimilhança e bayesiana), foram utilizadas uma matriz de dados concatenada com os três marcadores (rps $4+26 s+$ nad5), bem como uma matriz de dados individual para cada marcador.

\section{Resultados}

Foram utilizados 47 táxons neste estudo, resultando em 183 novas sequências obtidas e disponibilizadas no GenBank.

Todas as árvores obtidas individualmente para cada marcador apresentaram a mesma topologia, diferindo somente no grau de resolução dos nós, demonstrando a consistência dos dados e das análises realizadas. Os poucos conflitos observados na topologia referem-se aos agrupamentos com baixo valor de suporte e as politomias. Como não houve incongruência nas análises individuais para cada marcador, as matrizes foram concatenadas para 
a obtenção de uma matriz única e mais robusta, que também apresentou a mesma topologia das matrizes individuais.

O alinhamento das 47 sequências geradas resultou em uma matriz compartilhada (rps4 + 26s + nad5) com 3.170 caracteres, sendo 2.748 constantes, 240 variáveis e 232 informativos (Tab. 3). Dentre todas as árvores obtidas individualmente para cada marcador e para a análise compartilhada (rps4 $+26 s+$ nad5), os resultados provenientes da análise compartilhada obtiveram os valores mais elevados de índice de confiança (bootstrap e probabilidades posteriores) e a topologia da árvore foi a mais consistente.

Tabela 3: Estatísticas individuais dos marcadores rps4, 26s e nad5 e da análise compartilhada. $\mathrm{Cl}=$ índice de consistência; $\mathrm{Rl}=$ índice de retenção.

\begin{tabular}{ccccc}
\hline & RPS4 & 26s & NAD5 & RPS4 +26s+NAD5 \\
\hline Taxas Incluídos & 47 & 42 & 46 & 47 \\
Tamanho da Matriz & 676 & 1093 & 1401 & 3170 \\
Caracteres Constantes & 521 & 969 & 1258 & 2748 \\
Sítios Variáveis & 78 & 64 & 98 & 240 \\
Informativos & 97 & 90 & 45 & 232 \\
N. de Árvores & 10000 & 10000 & 10000 & 10000 \\
Comp. da Árvore & 331 & 258 & 174 & 919 \\
Cl & 0.568 & 0.547 & 0.851 & 0.610 \\
RI & 0.695 & 0.723 & 0.855 & 0.659 \\
Modelo de Evolução & TVM+l+G & TIM1+l+G & TPM1uf+G & GTR+G \\
Log. likelihood & $-21,327.856$ & $-4,326.575$ & $-78,671.245$ & $-96,012.1731$ \\
\hline
\end{tabular}

A monofilia da família Thuidiaceae composta somente pelos gêneros Thuidium, Pelekium e Thuidiopsis foi fortemente suportada (Fig. 1) em todas as análises realizadas com valores consistentes (parcimônia 80, verossimilhança 79 e bayesiana 0,98 ). A monofilia do gênero Pelekium só pode ser confirmada com a inclusão de Thuidiopsis. Este clado é fortemente suportado com valores consistentes (parcimônia 98, verossimilhança 96 e bayesiana 1), o que sugere 
a grande proximidade entre estes dois gêneros e a necessidade de uma nova circunscrição.

Thuidium apresentou-se como polifilético, com a formação de dois clados (Fig. 1), sugerindo uma nova circunscrição para o grupo.

De acordo com a atual circunscrição adotada para Leskeaceae, a nãomonofilia da família também foi comprovada. A Figura 1, apesar dos baixos valores de suporte, oferece uma boa noção dos verdadeiros limites de Leskeaceae, onde somente o agrupamento formado Leskea polycarpa, Rauiella praelonga, Haplocladium angustifolium e Hylocomiopsis cylindricarpa é monofilético.

Os resultados obtidos neste estudo não corroboram o conceito mais amplo da família baseado somente em caracteres morfológicos estabelecidos por Touw (2001a), com a família contendo 16 gêneros e 72 espécies. Dos 16 gêneros estabelecidos por Touw (2001a), dez foram utilizados neste estudo (Abietinella, Actinothuidium, Boulaya, Haplocladium, Helodium, Hylocomiopsis, Pelekium, Rauiella, Thuidiopsis e Thuidium), os outros seis (Bryonoguchia, Echinophyllum, Aequatoriella, Bryochenea, Indothuidium e Orthothuidium) não foram utilizados devido à ausência de material fresco para retirada de DNA. Também foram utilizados gêneros que já foram tratados dentro de Thuidiaceae em sistemas de classificações ultrapassados (Claopodium, Fauriella, Heterocladium e Myurella).

Em relação ao conceito da família Thuidiaceae proposta por Buck \& Crum (1990), com a divisão em duas subfamílias (Cyrtohypnoideae e Thuidioideae), os resultados aqui apresentados também não corroboram a teoria de Buck \& Crum (1990), tendo em vista que os gêneros Boulaya, Rauiella e Abietinella não fazem parte do agrupamento monofilético que delimitou a família Thuidiaceae. Além disso, as duas subfamílias propostas são polifiléticas de acordo com os resultados aqui apresentados.

É possível evidenciar a formação de três clados monofiléticos bem definidos dentro de Thuidiaceae (Fig. 1), divididos da seguinte forma:

Clado 1 - Pelekium: formado por todos os representantes de Pelekium e Thuidiopsis, com a presença da espécie-tipo do gênero Pelekium ( $P$. velatum) e do gênero Thuidiopsis ( $T$. furfurosa). Este clado possui valores de suporte 
elevados, próximo aos valores máximos de confiança no agrupamento (98 parcimônia, 96 verossimilhança e 1 bayesiana). O gênero Pelekium apresentou-se como polifilético, com a formação de dois agrupamentos. $O$ primeiro constituído por todos os representantes de Pelekium, com exceção de P. minutulum que juntamente com Thuidiopsis sparsa e Thuidiopsis furfurosa formaram o segundo agrupamento, considerado grupo irmão do primeiro. Sendo assim, para que o gênero fosse considerado monofilético, optou-se por agrupar todos dentro do mesmo clado.

Clado 2 - Thuidium: composto por todos os representantes de Thuidium, com exceção de $T$. delicatulum e $T$. recognitum. Clado com elevado suporte, garantindo a robustez das análises (96 parcimônia, 91 verossimilhança e 1 bayesiana).

Clado 3 - (informalmente denomiado Pseudothuidium): composto somente por Thuidium delicatulum e Thuidium recognitum.

Muitos gêneros tradicionalmente alinhados dentro de Thuidiaceae, tais como: Abietinella, Actinothuidium, Boulaya, Claopodium, Haplocladium, Helodium, Heterocladium, Hylocomiopsis e Rauiella, não pertencem ao clado formando por Pelekium, Thuidiopsis e Thuidium, aqui tratadas como Thuidiaceae verdadeiras.

A polifilia de Rauiella, gênero que já foi tratado como Thuidiaceae e também como Leskeaceae é bastante evidente. A monofilia da família Rigodiaceae também pode ser observada, confirmando a mesma como uma família monoespecífica constituída somente pelo gênero Rigodium, com Myurella (Pterigynandraceae) como grupo basal (Fig. 1).

Actinothuidium hookeri, grupo irmão das Thuidiaceae, é morfologicamente distinto dos gêneros monofiléticos que compõem Thuidiaceae, não apresentando uma das principais características do grupo, a presença de células papilosas, é aqui tratado como um gênero fora de Thuidiaceae.

Analisando a topologia da árvore e seus clados, foi possível estabelecer uma correlação de agrupamentos (morfológico e genético) de táxons dentro do mesmo clado com base na morfologia da seta e das papilas (Fig. 2 e Fig. 3). Dentro do clado 1 (Pelekium), observa-se a formação de três agrupamentos. $O$ primeiro grupo formado por: $P$. scabrosulum, P. schistocalyx, P. gratum, $P$. 
velatum e $P$. involvens possui seta papilosa. $O$ segundo grupo formado por: $P$. versicolor, $P$. muricatulum, $P$. siphotheca e $P$. pygmaeum tem como característica a presença de seta lisa, que também é compartilhada com 0 grupo formado por $P$. minutulum, Thuidiopsis furfurosa e Thuidiopsis sparsa. Dentro do clado 2 (Thuidium) e clado 3 (Pseudo-thuidium) todas as espécies compartilham a característica de apresentarem seta lisa.

Em relação as papilas, dentro de um mesmo clado observam-se diferentes tipos morfológicos de papilas, distribuídas dentro do mesmo agrupamento (Fig. 3). Basicamente podemos dividi-las quanto ao número de papilas presente no lúmen celular da seguinte forma: unipapilosa - somente uma papila e com variações na morfologia (alta, baixa e estrelada) e pluripapilosa - duas a cinco papilas.

Dentro do clado 1 (Pelekium), o grupo formado pelas espécies $P$. siphotheca, $P$. sparsifolium e $P$. muricatulum são unipapilosas simples, com papilas características das espécies de Pelekium unipapilosas.

Em contrapartida, o agrupamento constituído de $P$. involvens, $P$. schistocalyx, $P$. scabrosulum, $P$ minutulum, $P$. velatum, $P$. gratum e Thuidiopsis sparsa são pluripapilosos, com as papilas localizadas na periferia do lúmen celular, característica típica das espécies de Pelekium pluripapilosas.

No clado 2 (Thuidium), o agrupamento formado por T. peruvianum, $T$. assimile, T. cymbifolium, T. glaucinoides e T. philibertii 2 são unipapilosos, com uma papila alta e curva. $O$ agrupamento formado por $T$. tomentosum e $T$. mattogrossense apresenta uma característica pouco comum dentro do gênero Thuidium, células pluripapilosas localizadas no centro do lúmen celular. Apesar de $T$. bifidum estar presente no mesmo agrupamento de $T$. tomentosum e $T$. mattogrossense, suas células são unipapilosas bífidas.

Ainda dentro do clado Thuidium, podemos observar um agrupamento formado por $T$. tamariscinum, $T$. pristocalyx e $T$. philibertii 1, que apresentam uma papila de tamanho mediano, curvada ou reta.

Por fim o agrupamento formado por $T$. delicatulum e $T$. recognitum tem como característica uma papila de tamanho variável, de pequena a mediana. 


\section{Discussão}

A circunscrição da família Thuidiaceae sempre foi bastante duvidosa, com a inclusão e exclusão de diversos gêneros ao longo de sua história (Touw 2001a). Seu parentesco com Leskeaceae e por vezes a monofilia de ambas as famílias sempre foi questionada. Geneticamente Thuidiaceae e Leskeaceae estão muito próximas e morfologicamente sua proximidade de se deve ao fato de ambas apresentarem algumas características pouco comuns dentre os musgos, tais como a presença de paráfilos e papilas. Todavia a classificação e os limites da família sempre foram estabelecidos com base somente em critérios morfológicos.

Os resultados aqui apresentados não suportam a atual divisão da família baseada em caracteres morfológicos (Touw 2001a). Podemos confirmar a monofilia da família Thuidiaceae constituída somente pelos gêneros Pelekium, Thuidium e Thuidiopsis e também a polifilia de Leskeaceae.

Baseado no agrupamento monofilético aqui apresentado, podemos definir morfologicamente Thuidiaceae como táxons que apresentam padrão de ramificação pinado; paráfilos com células papilosas; filídios unipapilosos a pluripapilosos, nunca lisos e caulídio em secção transversal sem hialoderme, com uma pequena camada de células de parede espessa, bordeadas por células largas de parede delgada.

A polifilia de Thuidium foi fortemente suportada em todas as análises realizadas, com a formação de dois clados (2 e 3), sendo o último basal aos demais representantes da família. Os resultados aqui encontrados sugerem a necessidade de um estudo morfológico aprofundado para definir a nova circunscrição para as espécies do clado 3 ( $T$. delicatulum e $T$. recognitum), provavelmente com a criação de um novo gênero. Morfologicamente a criação de um novo gênero não se sustenta, tendo em vista a ausência de caracteres morfológicos distintivos para a separação entre grupos extremamente parecidos do ponto de vista morfológico.

A monofilia do gênero Pelekium só pode ser confirmada com a inclusão de Thuidiopsis. Este agrupamento possui valores de suporte (parcimônia e probabilidades posteriores) elevados, demonstrando a robustez, a similaridade genética e morfológica deste agrupamento. A proximidade de Thuidiopsis e 
Pelekium observada aqui e nos trabalhos de García-Avila et al. (2009) e Cox et al. (2010), sugere um forte parentesco entre estes dois gêneros.

Morfologicamente Thuidiopsis se assemelha bastante a Pelekium, tanto na morfologia dos paráfilos, quanto na forma das papilas dos filídios. Thuidiopsis e Pelekium possuem paráfilos não ramificados, enquanto Thuidium possui paráfilos ramificados. Além disso, Thuidiopsis e Pelekium possuem papilas tanto na face abaxial quanto na face adaxial do filídio, enquanto Thuidium possui papilas apenas na face abaxial. Também podemos destacar a morfologia das papilas que são bastante semelhantes nas espécies pluriplapilosas de Thuidiopsis e Pelekium, com as papilas dispostas na periferia no lúmen celular. Desta forma, entende-se ser necessária a sinonimização destes dois gêneros, com a inclusão de todas as espécies de Thuidiopsis dentro de Pelekium. 


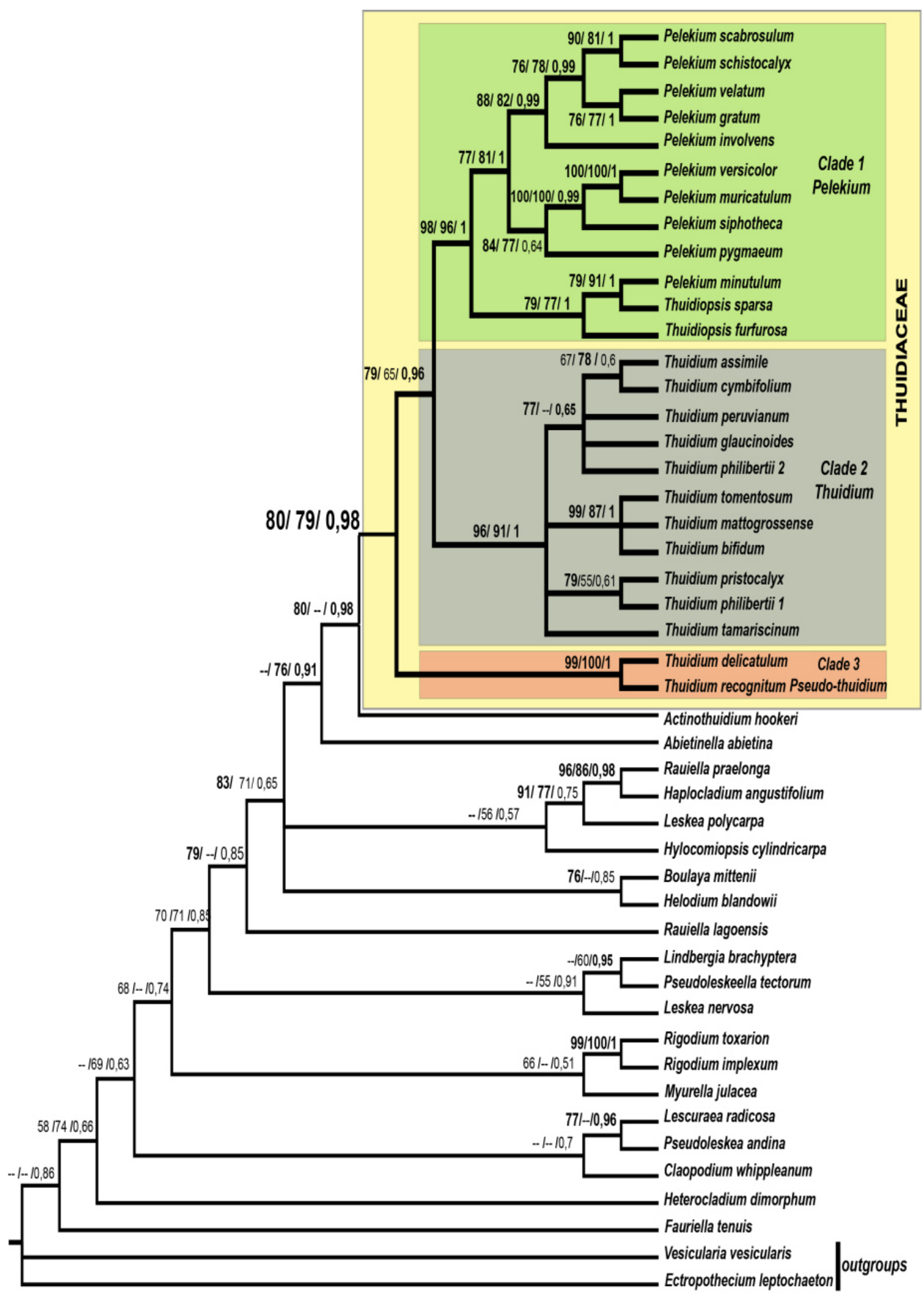

Figura 1: Cladograma de consenso obtido por análise bayesiana com a matriz combinada (rps4+26s+nad5). Os valores sobre os ramos correspondem aos valores de bootstrap de parcimônia, verossimilhança e probabilidades posteriores da análise Bayesiana respectivamente. Valores abaixo de 50\% para bootstrap e 0,5 para probabilidades posteriores foram descartados no cladograma. 
De acordo com García-Avila et al. (2009), a família Thuidiaceae só poderia ser considerada monofilética se considerarmos somente o grupo denominado "Thuidioid" (sensu Touw 2001a), formado pelos gêneros Pelekium, Thuidium, Thuidiopsis e Aequatoriella, o que, de fato, com exceção de Aequatoriella que não foi utilizada aqui devido a ausência de material fresco para extração de DNA, corrobora nossos resultados, onde somente 0 agrupamento foi considerado monofilético.

O gênero Actinothuidium, tradicionalmente agrupado dentro de Thuidiaceae, aparece como grupo irmão da família em nosso estudo e também nos resultados de García-Avila et al. (2009). Morfologicamente Actinothuidium possui medula central homogênea, filídios fortemente serreados, paráfilos com células alongadas e lisas, filídios com células alongadas, prorulosas ou lisas, características contrárias às utilizadas aqui para definir Thuidiaceae e consequentemente ausentes nas espécies do grupo "Thuidioid" (sensu Touw 2001a). Touw (2001a), em sua revisão de Thuidiaceae, conclui que Actinothuidium é um gênero basal e o coloca dentro do grupo "Heloidioid" (sensu Touw 2001a), que aqui apresenta-se como um grupo polifilético. 


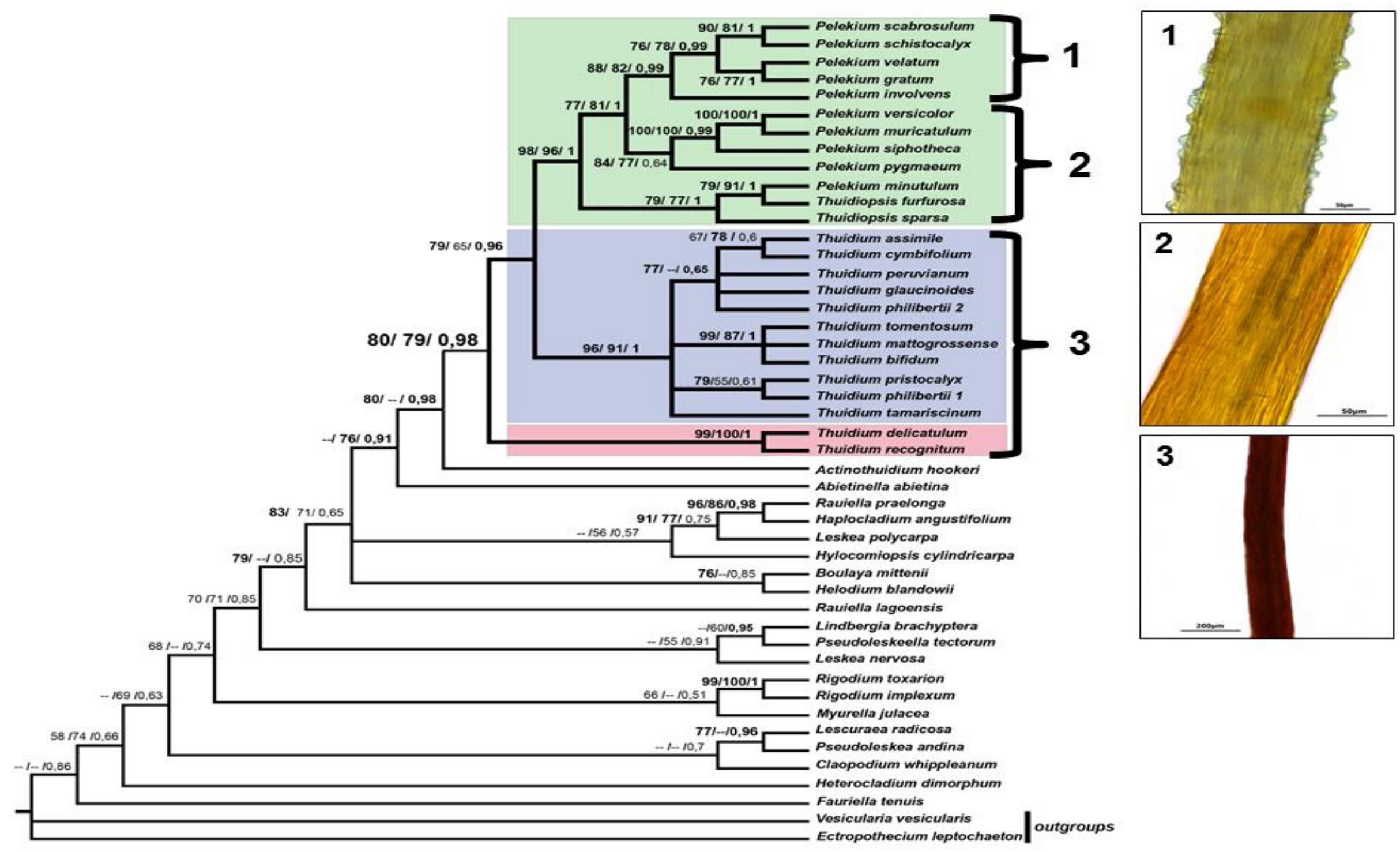

Figura 2: Cladograma (bayesiana) obtido com a matriz combinada (rps4+26s+nad5). Os valores sobre os ramos correspondem aos valores de bootstrap de parcimônia e verossimilhança, e probabilidades posteriores da análise Bayesiana. 1 = Seta papilosa/rugosa. 2 e $3=$ Seta lisa. 


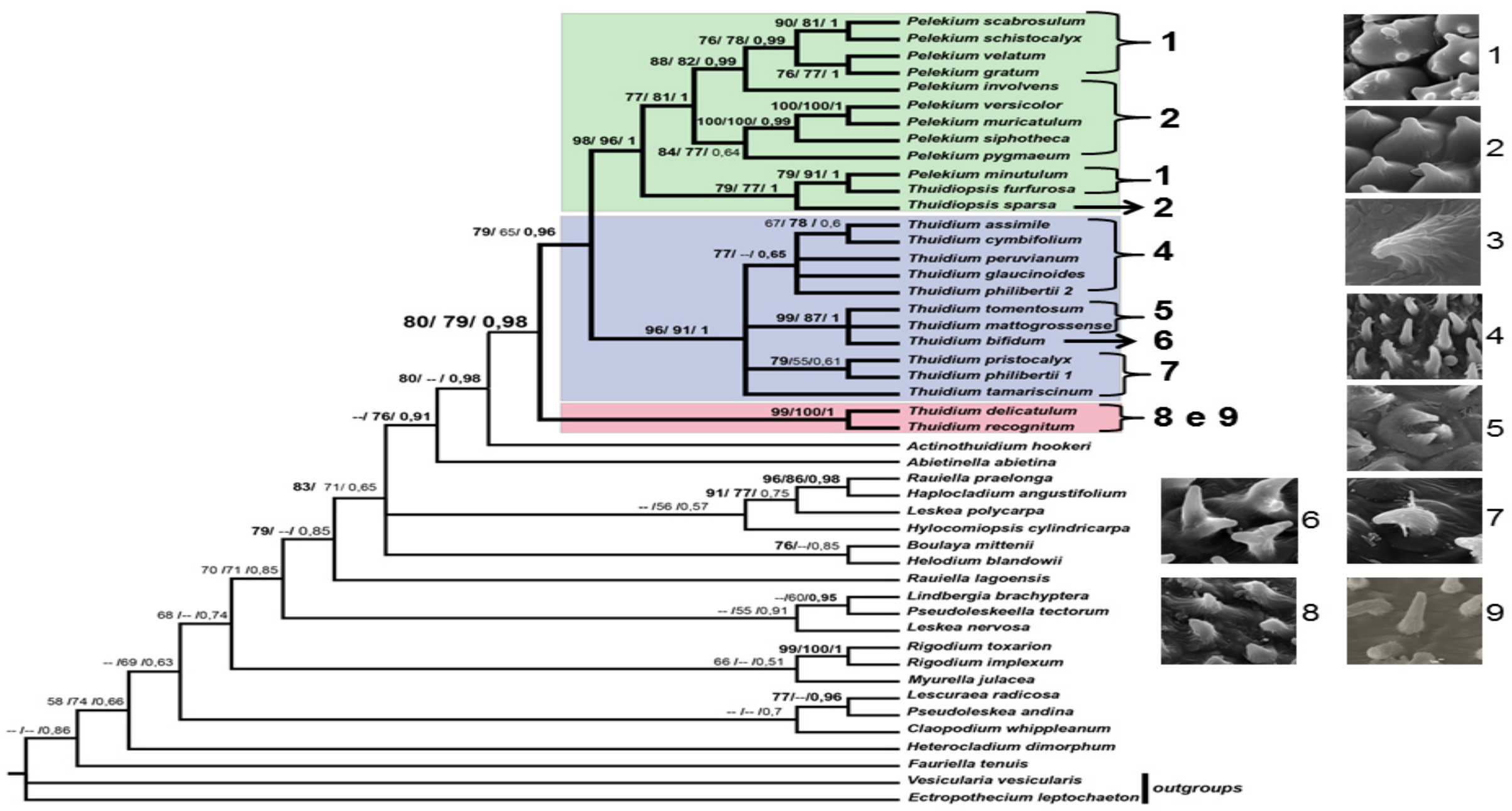

Figura 3: Cladograma (bayesiana) obtido com a matriz combinada (rps4+26s+nad5). Os valores sobre os ramos correspondem aos valores de bootstrap de parcimônia e verossimilhança, e probabilidades posteriores da análise Bayesiana. 1 = pluripapilosa com as papilas na periferia do lúmen, 2 = unipapilosa, 3 = unipapilosa com papila baixa, 4 = unipapilosa com papila alta, 5 = pluripapilosa com as papilas no centro do lúmen, 6 = unipapilosa bífida, 7 = unipapilosa com papila curvada e mediana, $8=$ unipapilosa com papila mediana e $9=$ unipapilosa com papila alta. 
O agrupamento morfológico baseado na morfologia da seta (fig.2), evidência a formação de grupos monofiléticos que se diferenciam com base na seta dentro do clado Pelekium, onde o padrão de seta papilosa apresenta-se como uma característica distal em relação a característica basal de seta lisa. Touw (2001a) já havia mencionado a formação de dois grupos informais com base na morfologia da seta. Ele chamou estes grupos de muricatulum (seta lisa) e velatum (seta papilosa).

O grupo muricatulum (sensu Touw 2001a) é representado em nossas análises pelo agrupamento formado por $P$. muricatulum, $P$. versicolor, $P$. siphotheca e $P$. pygmaeum, que juntos formam um grupo monofilético fortemente suportado, que tem como características a presença de seta lisa e paráfilos com células inconspicuamente papilosas. O grupo velatum (seta papilosa), aqui representado pelas espécies $P$. velatum, $P$. scabrosulum, $P$. schistocalyx, $P$. gratum e $P$. involvens, também formam um grupo monofilético (Fig. 2), que tem como característica a seta papilosa e paráfilos com células conspicuamente papilosas. Diante disto, a morfologia da seta apresenta-se como uma característica segura e distintiva para a separação dos agrupamentos monofiléticos formados dentro do clado 1 - Pelekium.

Baseados somente em características morfológicas Buck \& Crum (1990) e Touw (2001a) estabeleceram os limites da família Thuidiaceae. A divisão em duas subfamílias proposta por Buck \& Crum (1990) foi parcialmente comprovada em nossas análises, pois verifica-se a presença de um grupo denominado Clado 1 - Pelekium (Fig. 1) que engloba os representantes do gênero Pelekium e também outro agrupamento denominado Clado 2 - Thuidium. Estes dois clados podem ser entendidos como a divisão em duas subfamílias proposta por Buck \& Crum (1990). Os demais gêneros das subfamílias (Boulaya, Rauiella e Abietinella) não pertencem a Thuidiaceae de acordo com o conceito monofilético adotado aqui, sendo mais prováveis de serem classificados como Leskeaceae.

A divisão proposta por Touw (2001a) também pode ser parcialmente comprovada, tendo em vista a confirmação da monofilia do grupo “Thuidioid”, que já havia sido confirmada por García-Avila et al. (2009). Por outro lado a não monofilia do grupo “Combinado" também pode ser confirmada neste trabalho e por García-Avila (2009), devido à presença de Leskea polycarpa (espécie-tipo da família Leskeaceae) entre os representantes deste grupo, indicando que estas espécies provavelmente estão mais intimamente relacionadas com Leskeaceae do que com Thuidiaceae. 
A confirmação dos limites da família Thuidiaceae somente com os representantes do grupo "Thuidioid" (sensu Touw 2001), tal como observado também nos estudos de García-Avila et al. (2009), sugere um reordenamento de Thuidiaceae e de Leskeaceae, com a inclusão dos grupos "Helodioid" e "Combinado" (sensu Touw 2001) dentro de Leskeaceae.

A impossibilidade de inclusão neste estudo dos gêneros Aequatoriella, Bryochenea, Indothuidium, Orthothuidium agrupados dentro do grupo "Thuidioideo" (sensu Touw 2001), devido à ausência de material apto a fornecer DNA de qualidade, indica a necessidade de estudos futuros que visem a inclusão destes gêneros para delimitar com maior precisão sua verdadeira circunscrição. García-Avila et al. (2009), incluiu Aequatoriella em seu estudo, demonstrando que este gênero pertence ao clado das Thuidiaceae e deve ser levado em consideração nas futuras delimitações da família.

Em relação a Indothuidium, Orthothuidium e Bryochenea, os mesmos são gêneros monotípicos, relativamente novos, de ocorrência restrita ao Sudoeste da Ásia, Malásia e região Sino-Japonesa (Touw 2001a), o que dificulta a obtenção de material fresco para DNA.

Indothuidium tem como espécie-tipo Indothuidium kiasense R.S. Williams (Touw), cujo basiônimo é Thuidium kiasense R.S. Williams, que morfologicamente se assemelha as atuais espécies de Pelekium, diferindo somente no tamanho diminuto e arquitetura do gametófito que é frequentemente 1-pinado. Tem distribuição restrita a Malásia e Ásia Continental Tropical.

Orthothuidium tem como espécie-tipo Orthothuidium curtisetum D.H. Norris \& T.J. Kop., cujo basiônimo é Cyrto-hypnum curtisetum (D.H. Norris \& T.J. Kop.) W.R. Buck \& H.A. Crum, que morfologicamente possui diversas características que o levariam a ser classificado com um representante de Pelekium. Sua distribuição é extremamente restrita a Papua-Nova Guiné.

Bryochenea tem distribuição restrita a região Sino-Japonesa. Sua única espécie válida é Bryochenea vestitissima (Besch.) Touw, cujo basiônimo é Thuidium vestitissimum Besch. Aa espécie é pequena (assim como Pelekium), possui paráfilos não-ramificados e células unipapilosas (Touw 2001a), o que morfologicamente remete aos representantes de Pelekium. 
De acordo com Touw (2001a), Indothuidium, Orthothuidium e Bryochenea se assemelham as atuais espécies de Pelekium. Sendo assim, acredita-se que a inclusão destes gêneros dentro do clado Thuidiaceae em futuros estudos filogenéticos seja completamente plausível e necessária.

Historicamente a circunscrição de Thuidiaceae sempre foi bastante controversa devido ao seu parentesco conflitante com Leskeaceae. Este trabalho é o dos pesquisadores já citados (Gardiner et al. 2005; Ignatov et al. 2007; García-Avila et al. 2009 e Cox et al. 2010), comprovam que as famílias Thuidiaceae e Leskeaceae são geneticamente diferentes, não havendo argumentos filogenéticos e morfológicos para agrupar as duas dentro da mesma família. Além disso, Thuidiaceae é formada somente pelos representantes dos gêneros Thuidium, Pelekium e Thuidiopsis. Estudo futuros com representantes dos gêneros Aequatoriella, Bryochenea, Indothuidium e Orthothuidium, provavelmente devem confirmar estes gêneros como representantes de Thuidiaceae, corroborando a delimitação estabelecida por Touw (2001a) e denominada grupo "Thuidioideo" (sensu Touw 2001a).

Desta forma, é necessária a revisão dos sistemas de classificações atuais, com uma revisão a nível global de Thuidiaceae e Leskeaceae e a inclusão dos demais representantes do grupo "Thuidioideo" sensu Touw (2001a) em estudos futuros.

\section{Agradecimentos}

Os autores agradecem ao Conselho Nacional de Desenvolvimento Cientifico e Tecnológico - CNPq, pela concessão da bolsa de estudos ao primeiro autor, ao Laboratório de Biologia Molecular do Departamento de Botânica da Universidade de Brasília e a todos os pesquisadores envolvidos diretamente e indiretamente com a realização deste trabalho. 


\section{Referências Bibliográficas}

Beckert, S., S. Steinhauser, H. Muhle, \& V. Knoop. 1999. A molecular phylogeny of bryophytes based on nucleotide sequences of the mitochondrial nad5 gene. Plant Systematics and Evolution 218: 179-192.

Bell, N. E. \& A. E. Newton. 2005. The paraphyly of Hypnodendron and the phylogeny of related non-hypnalaean pleurocarpous mosses inferred from chloroplast and mitochondrial sequence data. Systematic Botany 30: 34-51.

Brotherus, V. F. 1908. Bryales. In A. Engler and K. Prantl (eds). Die naturlichen Pflanzenfamilien, Leipzig: Engelmann. Part. I(3): 1153-1246.

Brotherus, V. F. 1925. Musci (Laubmoose) 2. In A. Engler \& K. Prantl (eds.). Die natürlichen Pflanzenfamilien, Leipzig: Engelmann 11.

Buck, W. R. \& H. Crum. 1990. An evaluation of familial limits among the genera traditionally aligned with the Thuidiaceae and Leskeaceae. Contributions of the University of Michigan Herbarium 17: 55-69.

Buck, W. R. \& B. Goffinet. 2000. Morphology and classification of mosses. In A. J. Shaw \& B. Goffinet (eds), Pp. 71-123. Bryophyte Biology. Cambridge: Cambridge University Press.

Buck, W. R. \& D. H. Vitt. 1986. Suggestions for a new familial classification of pleurocarpous mosses. Taxon 35: 21-60.

Cox, C. J., B. Goffinet, N. J. Wickett, S. B. Boles \& A. J. Shaw. 2010. Moss diversity: a molecular phylogenetic analysis of genera. Phytotaxa 9: 175-95.

Crosby, M. R., R. E. Magill, B. Allen \& S. B. Boles. 2004. A Checklist of Mosses. St. Louis: Missouri Botanical Garden.

Darriba D, Taboada G. L, Doallo R, Posada D. 2012. jModelTest 2: more models, new heuristics and parallel computing. Nature Methods 9(8), 772.

De Luna, E., A. E. Newton, D. Whithey, D. González \& B. D. Mishler. 1999. The transition to pleurocarpy: a phylogenetic analysis of the main diplolepidous lineages based on rbcL sequences and morphology. The Bryologist 102: 634650.

De Luna, E., W. R. Buck, H. Akiyama, T. Arikawa, H. Tsubota, A. E. Newton \& A. J. Shaw,. 2000. Ordinal phylogeny within the hypnobryalean pleurocarpous mosses 
inferred from cladistic analyses of three chloroplast DNA sequence data sets: trnL-F, rps4 and rbcL. The Bryologist 103: 242-256.

Doyle, J. J. \& J. L. Doyle. 1987. A rapid DNA isolation procedure for small quantities of fresh leaf tissue. Phytochemical Bulletin 19: 11-15.

Felsenstein, J. 1985. Confidence limits on phylogenies: an approach using the bootstrap. Evolution 39: 779-783.

Fleischer, M. 1922. Thuidiaceae. Die Musci der Flora von Buitenzorg, 4: 1494-1533.

García-Avila, D., E. De Luna \& A. E. Newton. 2009. Phylogenetic relationships of the Thuidiaceae and the non-monophyly of the Thuidiaceae and the Leskeaceae based on rbcL, rps4 and the rps4-trnS intergenic spacer. The Bryologist 112(1): 80-93.

Gardiner, A., M. Ignatov, S., Huttunen \& A. Troitsky. 2005. On resurrection of the families Pseudoleskeaceae Schimp. and Pylaisiaceae Schimp. (Musci, Hypnales). Taxon 54(3): 651-663.

Goffinet, B. \& W. R. Buck. 2004. Systematics of Bryophyta (Mosses): from molecules to a revised classification. Monographs in Systematic Botany from the Missouri Botanical Garden 98: 205-239.

Goffinet, B., W. R. Buck \& A. J. Shaw. 2009. Morphology and classification of the Bryophyta. In J. Shaw \& B. Goffinet (eds.), Pp. 55-138. Bryophyte Biology. Cambridge: Cambridge University Press.

Goffinet, B., C. J. Cox, A. J. Shaw \& T. A. J. Hedderson. 2001. The Bryophyta (mosses): Systematic and evolutionary inferences from rps4 gene (cp DNA) phylogeny. Annals of Botany 87: 191-208.

Grout, A. J. 1932. Leskea and Pseudoleskea. pp. 185-196. In Moss Flora of North America v. 3. eds. A.J. Grout. Vermont: Newfane.

Higgins, D. G. \& P. M. Sharp. 1988. Clustal: A package for performing multiple sequence alignment on a micocomputer. Gene 73: 237-244.

Ignatov, M. S., A. A. Gardiner, V. K. Bobrova, I. A. Milyutina, S. Huttunen \& A. V. Troitsky. 2007. On the relationships of mosses of the order Hypnales, with special reference to taxa traditionally classified in the Leskeaceae. The Systematics Association Special Volume 71: 269-286. 
Kuzoff, R. K., J. A. Sweere, D. E. Soltis \& E. A. Zimmer. 1998. The phylogenetic potential entire 26s rDNA sequence in plants. Molecular Biology and Evolution 15: 251-263.

La-Farge-England, C. 1996. Grouth form, branching pattern, and perichaetial position in mosses: cladocarpy and pleurocarpy redifined. The Bryologist 99: 170-186.

Nadot, S., R. Bajon, \& B. Lejeune. 1994. The choloroplast gene rps4 as a tool for the study of Poaceae phylogeny. Plant Systematics and Evolution 191: 27-38.

Newton, A.E., C.J. Cox, J. G. Duckett, J. A. Wheeler, B. Goffinet, T. A. J. Hedderson, B. D. Mishler. 2000. Evolution of the Major Moss Lineages: Phylogenetic Analyses Based on Multiple Gene Sequence and Morphology. The Bryologist 103(2): 187211.

Newton, A.E., N. Wikstrom, N. Bell, L. L. Forrest, \& M. S. Ignatov. 2007. Dating the diversification of the pleurocarpous mosses. The Systematics Association Special Volume 71: 337-66.

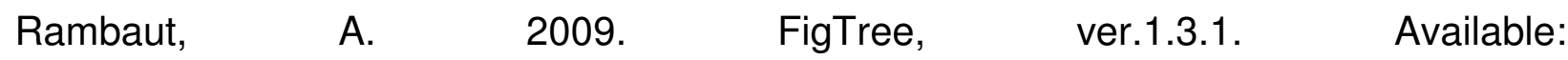
http://tree.bio.ed.ac.uk/software/figtree/.

Ronquist, F. \& J. P. Huelsenbeck. 2003. MRBAYES 3: Bayesian phylogenetic inference under mixed models. Bioinformatics 19: 1572-1574.

Schimper, W. P. 1876. Synopsis muscorum europaeorum praemissa introductione de elementis bryologicis tractante. Ed. 2. Stuttgart: E. Schweizerbart.

Shaw, A. J. 2000. Phylogeny of the Sphagnopsida based on chloroplast and nuclear DNA sequences. The Bryologist 103: 277-306.

Shaw, A.J. \& Renzaglia K. 2004. Phylogeny and diversification of bryophytes. American Journal of Botany 91(10):1557.

Stamatakis, A. 2014. "RAxML Version 8: A tool for Phylogenetic Analysis and PostAnalysis of Large Phylogenies". In Bioinformatics.

Swofford, D. L. 2002. PAUP*. Phylogenetic analysis using parsimony (*and other methods). Version 4. Sunderland: Sinauer Associates.

Touw, A. 2001a. A review of Thuidiaceae (Musci) and a realignment of taxa traditionally accommodated in Thuidium sensu amplo (Thuidium Schimp., Thuidiopsis (Broth.) M. Fleisch, and Pelekium Mitt.) including Aequatoriella gen. nov. and Indothuidium gen. nov. Journal of the Hattori Botanical Laboratory 90: 167-209. 
Touw, A. 2001b. A Taxonomic Revision of the Thuidiaceae (Musci) of Tropical Asia, the Western Pacific, and Hawaii. Journal of the Hattori Botanical Laboratory 91: 1136.

Tsubota, H., E. De Luna, D. González, M. S. Ignatov \& H. Deguchi. 2004. Molecular phylogenetics and ordinal relationships based on analyses of a large-scale data set of $600 \mathrm{rbcL}$ sequences of mosses. Hikobia 14: 149-170. 


\title{
3. CAPÍTULO 2
}

A ser submetido para a revista The Bryologist

\section{Novo arranjo taxonômico dos gêneros Pelekium e Thuidiopsis baseado em marcadores de mitocôndria, cloroplasto e núcleo e em evidências morfológicas.}

\author{
Abel Eustáquio R. Soares ${ }^{1}$ \& Paulo E.A.S. Câmara ${ }^{1}$ \\ 1 Universidade de Brasília, UnB, Depto. de Botânica. Campus Universitário Darcy Ribeiro, \\ Asa Norte, Brasília, DF. Brazil
}

\section{Resumo}

Os gêneros Pelekium, Thuidium e Thuidiopsis são típicos representantes da família Thuidiaceae e juntos formam um grupo monofilético fortemente suportado. Historicamente Pelekium e Thuidiopsis eram separados morfologicamente com base em sua sexualidade. Com o advento da biologia molecular diversos autores relataram a grande proximidade entre Pelekium e Thuidiopsis, com ambos se mostrando um grupo monofilético. Foram visitados os principais herbários do Brasil e do exterior com coleções significativas de Thuidiaceae. 26 espécies de Thuidiaceae e duas espécies de Hypnaceae foram selecioandas para as análises filogenéticas e morfológicas. O DNA genômico foi extraído do material fresco. Marcadores de três regiões diferentes do genoma foram utilizados (rps4, 26S e nad5). Análises de parcimônia, verossimilhança e bayesiana foram utilizadas para a reconstrução filogenética. Os gêneros Pelekium e Thuidiopsis formam um clado monofilético bem suportado. Os resultados aqui apresentados não suportam a atual divisão da família baseada em caracteres morfológicos. Pelekium e Thuidiopsis necessitam de uma nova circunscrição que está sendo apresentada neste estudo baseada em evidências filogenéticas e morfológicas.

Palavras Chaves: Thuidiaceae, monofilétilo, filogenia. 


\section{Introdução}

Thuidiaceae é uma família de musgos pleurocárpicos que apresenta características morfológicas pouco comuns entre os pleurocárpicos, tais como paráfilos papilosos e padrão de ramificação pinado. Durante sua história enfrentou diversos problemas de circunscrição, o que gerou diversas classificações e transferências de gêneros entre Thuidiaceae e Leskeaceae desde sua proposição (Schimper 1860). Para maiores detalhes da história taxonômica vide Soares \& Câmara (capítulo 4).

Do ponto de vista morfológico e/ou filogenético, os gêneros Pelekium Mitt., Thuidum Brunch \& Schimp. e Thuidiopsis (Broth.) M. Fleisch., são típicos representantes de Thuidiaceae e formam um grupo monofilético fortemente suportado (Touw 2001a, Buck \& Crum 1990, Gardiner et al. 2005, Cox et al. 2010, García-Avila et al. 2009 \& Soares \& Câmara Capítulo 1).

Basicamente Pelekium e Thuidiopsis eram separados morfologicamente com base em sua sexualidade (monóicas X dióicas) (Buck \& Crum 1990, Touw 2001a). Ambas compartilham características importantes tais como paráfilo simples e pêlos axilares com uma simples célula distal, que são diferentes das características encontradas nos representantes de Thuidium. Pelekium e Thuidiopsis inicialmente eram tratadas dentro de Thuidium e somente a partir dos trabalhos de Brotherus (1908) e Fleischer (1922) foram elevadas ao status de gênero.

Com o advento da biologia molecular alguns autores (Cox et al. 2010 e García-Avila et al. 2009) relataram a grande proximidade entre Pelekium e Thuidiopsis, onde ambos têm se mostrado um grupo monofilético altamente similar em termos genéticos. Cox et al. (2010) já tinha fornecido evidências da grande proximidade entre Pelekium e Thuidiopsis, cujo resultados demostraram que ambos os gêneros eram grupos irmãos e estavam muito mais próximos geneticamente entre si do que de Thuidium. Os autores utilizaram poucos representantes dos gêneros Pelekium, Thuidium e Thuidiopsis, e por isso seus resultados não favorecem um entendimento mais amplo da proximidade entre Pelekium e Thuidiopsis.

García-Avila et al. (2009) também demostraram a grande proximidade entre Pelekium e Thuidiopsis, pois foi observada a formação de um grupo 
monofilético bem suportado formado pelas espécies Pelekium velatum Mitt., Thuidiopsis sparsa (Hook. f. \& Wilson) Broth., Aequatoriella bifaria (Bosch \& Sande Lac.) Touw. e Thuidium plumulosum (Dozy \& Molk.) Dozy \& Molk., com as duas últimas formando o grupo irmão e basal de Pelekium e Thuidiopsis, portanto corroborando o forte parentesco genético entre Pelekium e Thuidiopsis. Neste mesmo estudo as outras três espécies de Thuidium utilizadas (T. delicatulum (Hedw.) Schimp., T. cymbifolium (Dozy \& Molk.) Dozy \& Molk. e T. tamariscinum (Hedw.) Schimp.) formaram um clado basal ao mencionado anteriormente.

Fortes evidências filogenéticas confirmando a grande proximidade entre Pelekium e Thuidiopsis também foram fornecidas nos estudos de Soares \& Câmara (Capítulo 1). Nas análises realizadas com diversos representantes de Thuidiaceae, Leskeaceae e algumas famílias cujos gêneros já foram classificados dentro de Thuidiaceae em sistemas de classificações antigos, demostraram mais uma vez a proximidade filogenética entre ambos. Neste estudo observa-se a formação de um clado fortemente suportado formado por Pelekium minutulum (Hedw.) Touw., Thuidiopsis sparsa e Thuidiopsis furfurosa (Hook. f. \& Wilson) M. Fleisch. Este clado é basal ao clado formado por todos os outros representantes de Pelekium utilizados no estudo e ambos foram considerados um grupo monofilético.

O gênero Pelekium possui distribuição predominante nos trópicos da África, Américas, Eurásia, Pacífico e Austrália, mas também está presente em regiões extratropicais da Europa, Leste da Ásia, Américas, Macaronésia e África do Sul (Touw 2001a). Possui aproximadamente 20 espécies bem conhecidas, formando dois grupos distintos (sem status taxonômico formal) que podem ser divididos com base no ápice do filídio do caulídio e da ornamentação da seta (Touw 2001a). Caracterizam-se por seu tamanho diminuto (quando comparadas a Thuidium); paráfilo simples, não ramificados; pêlos axilares com uma simples célula distal e filídios com células pluripapilosas ou unipapilosas em ambas as faces.

Thuidiopsis consiste em um pequeno gênero com duas espécies muito similares (Touw 2001a). São caracterizadas por serem espécies de tamanho mediano; paráfilo simples e não ramificado; filídio do caulídio cordado, ápice 
acuminado, frequentemente falcado; células unipapilosas e pluripapilosas em ambas as faces do filídio. Ocorrem na América do Sul, Austrália, Nova Zelândia, algumas ilhas no sul do Pacifico e no Sul da Malásia. Thuidiopsis cresce em ambientes úmidos e secos, florestais ou abertos, sobre troncos vivos ou em decomposição, solos e rochas.

Diante do exposto, o objetivo deste estudo é testar a monofilia dos gêneros Pelekium e Thuidium, apresentando uma filogenia centrada nos principais gêneros e típicos representantes de Thuidiaceae (Pelekium, Thuidium e Thuidiopsis), com o uso de marcadores moleculares provenientes de diferentes regiões do genoma (cloroplasto, mitocôndria e núcleo), resolvendo o parentesco entre estes gêneros.

\section{Material e Métodos}

Foram visitados os principais herbários do Brasil e do exterior com coleções significativas de Thuidiaceae: BM, INPA, NY, MO, R, RB, SP e UB, além da solicitação de empréstimo para instituições nacionais e internacionais: ALCB, BHCB, CEN, E, G, H, HEPH, IBGE, JE, L, M, MAK, MG, PACA, PC, PH, UFPE, S, UFG, US e W. Foram realizadas coletas em 11 Estados brasileiros: AM, BA, ES, GO, MA, MG, MT, RJ, RR, SC, SP e DF. As coletas se concentraram em áreas com vegetação florestal no Cerrado, Amazônia e Mata Atlântica. Ao final foram estudadas 2.650 exsicatas de Thuidiaceae e o material tipo de 60 táxons.

Foram selecionadas 26 espécies de Thuidiaceae e duas espécies de Hypnaceae (Ectropothecium Mitt. e Vesicularia (Müll. Hal.) Müll. Hal.) como grupo externo (Tab. 2). A escolha do grupo externo (outgroup) se baseou no trabalho de Cox et al. (2010). As espécies foram selecionadas para refletirem a variação morfológica e geográfica do grupo.

O DNA genômico foi extraído do material fresco e do material proveniente dos herbários quando disponível, viável e autorizado, utilizando as dependências do Laboratório de Biologia Molecular de Plantas do Departamento de Botânica da Universidade de Brasília. 
O DNA foi obtido utilizando o protocolo mini-CTAB (Doyle \& Doyle 1987). Foram utilizados marcadores de três regiões diferentes do genoma (Tabela 1). Para o cloroplasto foi utilizada a proteína ribossomal 4 (rps4); para o genoma mitocondrial foi utilizado a desidrogenase subunidade 5 (nad5) e para o genoma nuclear foi utilizado sequência parcial do DNA ribossomal 26s. Também foram utilizadas sequências disponíveis no GenBank - NCBI quando as sequências obtidas não eram de qualidade aceitável e para aumentar a matriz de dados.

$\mathrm{O}$ nad5 foi amplificado em dois fragmentos sobrepostos: nad5K - nad5Li e nad5Ki - nad5Le (Bell \& Newton 2005).

Tabela 1: Primers e temperaturas de anelamento utilizados no estudo.

\begin{tabular}{ccc}
\hline Marcador & Referência & $\begin{array}{c}\text { Temperatura de } \\
\text { anelamento C }\end{array}$ \\
\hline rps4 F & Nadot et al. 1994 & $51-54$ \\
rps4 R & Nadot et al. 1994 & $51-54$ \\
nad5K & Beckert et al. 1999 & $52-54$ \\
nad5Li & Beckert et al. 1999 & $52-54$ \\
nad5Ki & Beckert et al. 1999 & $58-60$ \\
nad5Le & Beckert et al. 1999 & $58-60$ \\
26s R- LSOF & Shaw 2000 & $50-52$ \\
26s F - LS12R & Shaw 2000 & $50-52$ \\
\hline
\end{tabular}

A tabela 2 lista todos os táxons utilizados neste estudo, com o respectivo voucher de todas as espécies, bem como o número de acesso no GenBank. 
Tabela 2: Táxons utilizados no estudo, localidade de coleta, coletor e número de coleta, herbário onde está depositado e número de acesso no GenBank. * Sequências do GenBank.

\begin{tabular}{|c|c|c|c|c|c|}
\hline \multirow[b]{2}{*}{ Espécie } & \multirow[b]{2}{*}{ Voucher } & \multirow[b]{2}{*}{ Origem } & \multicolumn{3}{|c|}{ GenBank } \\
\hline & & & RPS4 & $26 S$ & NAD5 \\
\hline Ectropothecium leptochaeton (Schwägr.) W.R. Buck * & Whittemore 5594 (MO) & Belize & AY908558.1 & HM751405.1 & AY908405.1 \\
\hline Pelekium involvens (Hedw.) Touw & Costa $3982(\mathrm{RB})$ & Brasil & & & \\
\hline Pelekium minutulum (Hedw.) Touw & Soares 1131 (UB) & Brasil & & & \\
\hline Pelekium scabrosulum (Mitt.) Touw & Soares 1196 (UB) & Brasil & & & \\
\hline Pelekium schistocalyx (Müll. Hal.) Touw & Rivera s.n. (UB) & Brasil & & & \\
\hline Pelekium siphotheca (Müll. Hal.) Touw & Câmara 2370 (UB) & Brasil & & & \\
\hline Pelekium velatum Mitt. & Kien-Thai 8190 (KLU) & Malásia & & & \\
\hline Thuidium assimile (Mitt.) A. Jaeger & Pisarenko 67 (MO) & Sibéria & & & \\
\hline Thuidium cymbifolium (Dozy \& Molk.) Dozy \& Molk. & Jia $9714(\mathrm{MO})$ & China & & & \\
\hline Thuidium delicatulum (Hedw.) Schimp. & Buck 51893 (NY) & USA & & & \\
\hline
\end{tabular}




\begin{tabular}{|c|c|c|c|c|c|}
\hline \multirow[b]{2}{*}{ Espécie } & \multirow[b]{2}{*}{ Voucher } & \multirow[b]{2}{*}{ Origem } & \multicolumn{3}{|c|}{ GenBank } \\
\hline & & & RPS4 & $26 S$ & NAD5 \\
\hline Thuidium glaucinoides Broth. & Shevock 32330 (MO) & China & & & \\
\hline Thuidium peruvianum Mitt. & Villaroel 1911 (MO) & Bolívia & & & \\
\hline Thuidium philibertii 1 Limpr. & Ignatov 171 (MO) & Rússia & & & \\
\hline Thuidium bifidum Soares A.E.R. \& Câmara, P.E.A.S & Oliveira 250 (UFP) & Brasil & & & \\
\hline Thuidium tamariscinum (Hedw.) Schimp. & Kurbatova 246 (MO) & Rússia & & & \\
\hline Thuidium tomentosum Schimp. & Soares 1482 (UB) & Brasil & & & \\
\hline Thuidium recognitumi (Hedw.) Lindb. & Allen 29238 (MO) & USA & & & \\
\hline
\end{tabular}


A amplificação foi feita utilizando-se a técnica de reação em cadeia da polimerase (PCR), utilizando um volume final de $20 \mu \mathrm{l}$, sendo $2 \mu \mathrm{l}$ de "thermophilic" tampão, $0,8 \mu \mathrm{l}$

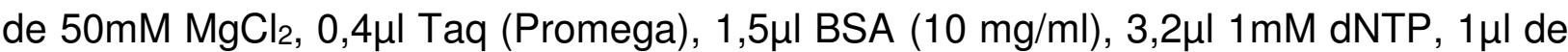
cada primer $(10 \mathrm{mM}), 3 \mu \mathrm{l}$ de DNA, completados com $7,1 \mu \mathrm{l}$ de água Milli-q. O DNA genômico utilizado foi diluído na proporção de 1:10 antes do uso. As condições de amplificação foram as seguintes para todos os primers, com diferenças apenas nas temperaturas de anelamento (Tab. 1) de acordo com a especificidade de cada primer e espécie: $94^{\circ} \mathrm{C}-1 \mathrm{~min}$ (desnaturação), $50-60^{\circ} \mathrm{C}-1 \mathrm{~min}$ (anelamento), $72^{\circ} \mathrm{C}-1 \mathrm{~min}$, repetidos durante 35 ciclos, sempre precedidos de um passo inicial de 2 minutos a $94^{\circ} \mathrm{C}$ e uma extensão final de 7 minutos a $72^{\circ} \mathrm{C}$.

A limpeza da reação de PCR e o sequenciamento (sem clonagem) foram terceirizados e realizados pela MACROGEN Inc. (Seoul, Korea). A montagem das sequências (Contigs) foi feita utilizando o software CodonCode Aligner (versão 4.2.7; CodonCode Corporation, MA, USA). Todas as sequências serão submetidas ao GenBank (Tab. 2).

Inicialmente o alinhamento foi realizado de forma automática utilizando o software ClustalX (Higgins \& Sharp 1988), e então ajustados e checados manualmente utilizando o software Phyde (versão 0.9971; Phylogenetic Data Editor).

A análise dos dados e a reconstrução filogenética foram feitas por meio dos critérios da parcimônia, verossimilhança e análise bayesiana.

Para a análise de máxima parcimônia foi utilizado o software PAUP versão 4.0b10 para Macintosh (Swofford 2002). Busca heurística foi realizada com 100 replicações randômicas e TBR (tree-bisection reconnection) com no máximo 10.000 árvores. Todos os caracteres foram desordenados e igualmente ponderados, gaps foram tratados como ausência de dados. O bootstrap foi calculado como parâmetro de suporte para os clados (Felsenstein 1985), com 1.000 replicações. Valores de bootstrap superiores a 75 são considerados confiáveis e aceitáveis.

As análises de Verossimilhança foram realizadas no software RaxML. (Stamatakis 2014). O modelo de evolução ideal para cada locus foi calculado utilizando o software jModeltest 2.1.3 (Darriba et al. 2012). O suporte para os clados foi calculado utilizando bootstrap (Felsenstein 1985), com 1.000 replicações.

As inferências Bayesianas foram feitas no software Mr. Bayes v.3.2.2 (Ronquist \& Huelsenbeck 2003). O modelo de evolução ideal para cada locus foi calculado 
utilizando o software jModeltest 2.1.3 (Darriba et al. 2012). Quatro corridas, cada uma com quatro cadeias MCMC (Markov Chain Monte Carlo Chain) foram executadas para 5.000.000 gerações, amostradas a cada 1.000 gerações, em corridas paralelas. $O$ suporte para os nós foi calculado por meio das probabilidades posteriores. Os valores das probabilidades posteriores variam entre 0 e 1 , sendo que valores abaixo de 0,95 foram considerados não confiáveis. O software Tracer 1.5 (Rambaut \& Drummond 2013) foi utilizado para determinar quando a amostragem das árvores estava estabilizada. Os primeiros $25 \%$ das árvores foram descartados (burn-in). Uma árvore de consenso foi construída a partir das demais árvores resultantes para estimar as probabilidades posteriores.

As árvores obtidas foram editadas utilizando o software FigTree 1.4.2 (Rambaut 2009).

Para cada método de reconstrução filogenética (parcimônia, verossimilhança e bayesiana) foram utilizadas uma matriz de dados individual para cada marcador. Como não houve incongruências uma matriz concatenada com os três marcadores (rps4 + $26 s+$ nad5) também foi utilizada.

Foram selecionados táxons para representar os gêneros Pelekium, Thuidium e Thuidiopsis em sua amplitude morfológica e geográfica nos estudos morfológicos realizados. As espécies foram estudadas utilizando-se de microscópio óptico e microscópio eletrônico de varredura. Microfotografias foram feitas utilizando o microscópio Leica DM-500 acoplado a câmera digital. O material utilizado nos estudos de microscopia eletrônica de verredura (MEV) foram os caulídios e paráfilos. Foram utilizados os laboratórios de microscopia eletrônica de varredura da Universidade de Brasília (UnB) e do Jardim Botânico de Nova lorque (NYBG). As amostras foram preparadas de acordo com os protocolos de Bozzola \& Russel (1998) e descritos em Câmara \& Kellogg (2010). O material foi desidratado em série alcoólica iniciada em $50 \%$ e finalizada a 100\%, com as trocas a cada 2 horas. Após a desidratação em série alcoólica, as ocorrendo amostras foram submetidas a secagem em ponto crítico utilizando os equipamentos Denton DCP-1 dryer (Denton Vacuum LLC, Moorestown, NJ USA) e Bal-Tec CPD 030 dryer (Bal-Tec AG, Balzers, Liechtenstein), com CO² liquído como fluído de transição. Após a secagem as amostras foram montadas em stubs e metalizadas com ouro-paládio utilizando os equipamentos Hummer 6.2 (Anatech, Union City, CA, USA) e Bal-Tec SCD 050 (Bal-Tec AG). A seguir as 
amostras foram visualizadas no microscópio eletrônico de varredura JSM-840 ASM e JSM-5410 LV (JEOL, Tokyo, Japan).

\section{Resultados}

O alinhamento das 27 sequências geradas resultou em uma matriz compartilhada (rps4 + 26s + nad5) com 3.147 caracteres, sendo 2.893 constantes, 163 variáveis e 141 informativos. Dentre todas as árvores obtidas individualmente para cada marcador e para a análise compartilhada (rps $4+26 s+$ nad5), os resultados provenientes da análise compartilhada obtiveram os valores mais elevados de índice de confiança (bootstrap e probabilidades posteriores) e a topologia da árvore foi a mais consistente.

Todas as árvores obtidas individualmente para cada marcador apresentaram a mesma topologia, diferindo somente no grau de resolução dos nós, demonstrando a consistência dos dados e das análises realizadas. Os poucos conflitos observados na topologia referem-se aos agrupamentos com baixo valor de suporte e as politomias. Como não houve incongruência nas análises individuais para cada marcador, as matrizes foram concatenadas para a obtenção de uma matriz única e mais robusta, que também apresentou a mesma topologia das matrizes individuais.

A tabela 3 apresenta as características individuais de cada marcador utilizado no estudo, bem como as características da matriz compartilhada.

Tabela 3: Estatísticas individuais para cada marcador utilizado e da análise compartilhada. $\mathrm{Cl}=$ índice de consistência; $\mathrm{Rl}=$ índice de retenção.

\begin{tabular}{ccccc}
\hline & RPS4 & 26s & NAD5 & RPS4 +26s+NAD5 \\
\hline Taxas Incluídos & 27 & 27 & 27 & 27 \\
Tamanho da Matriz & 676 & 1073 & 1398 & 3147 \\
Caracteres Constantes & 571 & 1007 & 1315 & 2893 \\
Sítios Variáveis & 78 & 64 & 98 & 163 \\
Parcimônia Informativos & 67 & 43 & 31 & 141 \\
N. de Árvores & 10000 & 10000 & 10000 & 10000 \\
Comp. da Árvore & 186 & 88 & 95 & 451 \\
Cl & 0.661 & 0.818 & 0.884 & 0.736
\end{tabular}




\begin{tabular}{ccccc}
\hline & RPS4 & 26s & NAD5 & RPS4 +26s+NAD5 \\
\hline RI & 0.773 & 0.872 & 0.864 & 0.754 \\
Modelo de Evolução & TVM+l+G & TIM1+l+G & TPM1uf+G & TPM1uf+l+G \\
Log. likelihood & $-17,089.346$ & $-6,455.876$ & $-52,870.008$ & $-86,655.541$ \\
\hline
\end{tabular}

Os gêneros Pelekium e Thuidiopsis formam um clado monofilético bem suportado (77 parcimônia, 85 verossimilhança e 1 bayesiana), o que sugere a grande proximidade entre estes dois gêneros e a necessidade de uma nova circunscrição.

Foi observada a formação de dois clados monofiléticos (Fig. 1) divididos da seguinte forma: Clado Thuidium - composto por todos os representantes de Thuidium, com $T$. delicatulum e $T$. recognitum com grupo basal e Clado Pelekium - formado por todos os representantes de Pelekium e Thuidiopsis.

Analisando a topologia da árvore e seus clados, foi possível estabelecer uma correlação de agrupamentos (morfológico e genético) de táxons dentro do clado com base na morfologia dos paráfilos (Fig. 2). Dentro do clado Pelekium todas as espécies possuem paráfilo simples, não ramificado, formado por 2-10 células, distribuído de forma abundante ou escassa nos caulídios. No clado Thuidium, todas as espécies possuem paráfilos ramificados, formados por 10-40 células, distribuídos de forma abundante no caulídio. 


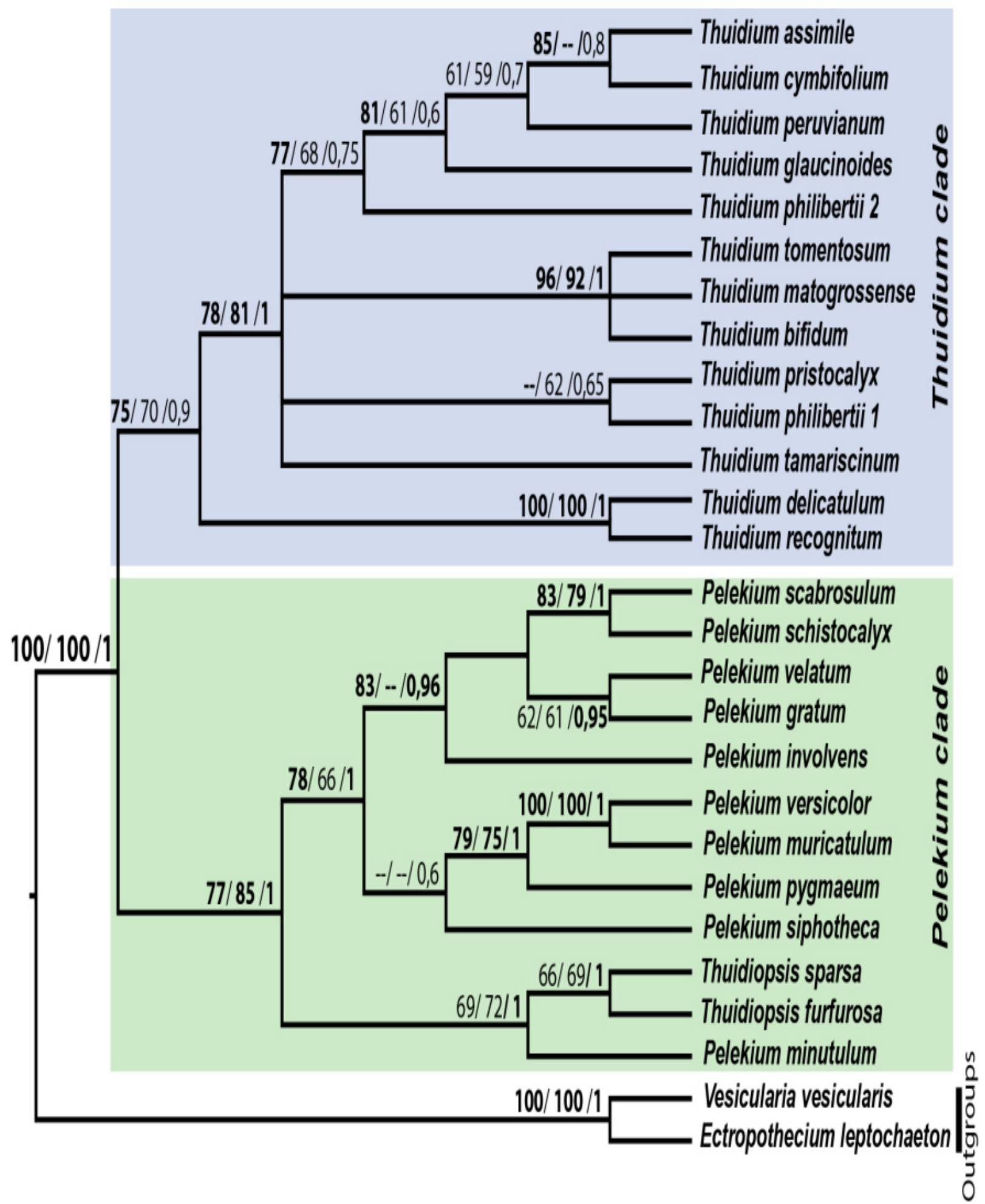

Figura 1: Cladograma de consenso obtido por análise bayesiana com a matriz combinada (rps4+26s+nad5). Os valores sobre os ramos correspondem aos valores de bootstrap de parcimônia, verossimilhança e probabilidades posteriores da análise Bayesiana respectivamente. Valores abaixo de $50 \%$ para bootstrap e 0,5 para probabilidades posteriores foram descartados no cladograma. 


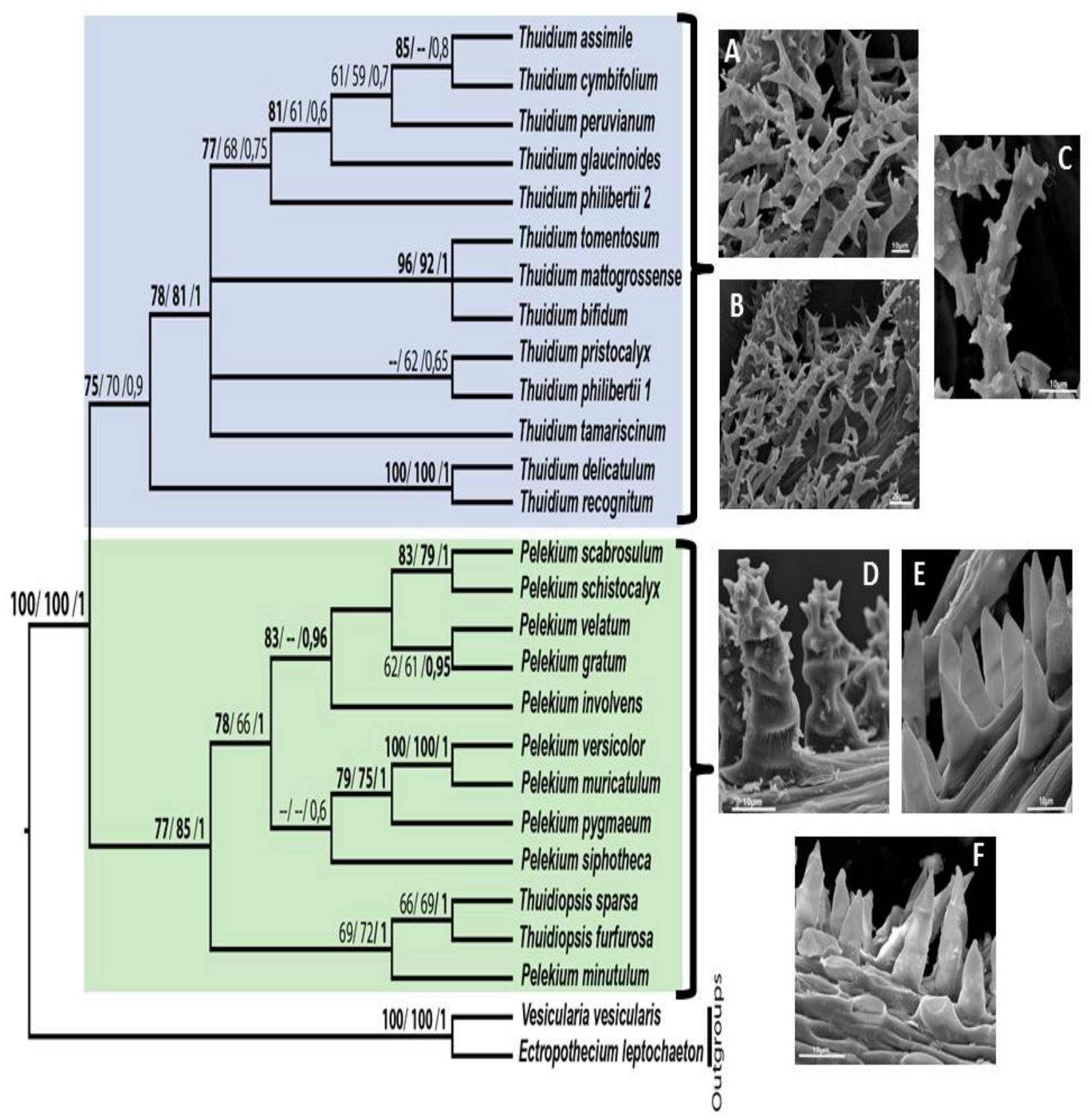

Figura 2: Cladograma (bayesiana) obtido com a matriz combinada (rps4+26s+nad5). Os valores sobre os ramos correspondem aos valores de bootstrap de parcimônia e verossimilhança, e probabilidades posteriores da análise Bayesiana. $A, B$ e $C=$ Paráfilo ramificado típico do gênero Thuidium. $\mathrm{D}, \mathrm{E}$ e $\mathrm{F}=$ Paráfilo simples típico de Thuidiopsis e Pelekium. 


\section{Discussão}

A monofilia do gênero Pelekium só pode ser confirmada com a inclusão de Thuidiopsis que está aninhado dentro do clado Pelekium. Este agrupamento possui valores de suporte (parcimônia e probabilidades posteriores) elevados, demonstrando a robustez, a similaridade genética e morfológica deste agrupamento. A proximidade de Thuidiopsis e Pelekium observada aqui e nos trabalhos de García-Avila et al. (2009) e Cox et al. (2010), sugere um forte parentesco entre estes dois gêneros.

Os resultados aqui apresentados não suportam a atual divisão da família (Touw 2001a). Pelekium e Thuidiopsis necessitam de uma nova combinação transferindo as espécies de Thuidiopsis ( $T$. furfurosa e T. sparsa) para dentro do Pelekium, conforme proposto neste estudo baseado em características filogenéticas e morfológicas. Pelekium tem a preferência por ser o nome mais antigo em relação a Thuidiopsis.

Thuidiopsis se assemelha bastante a Pelekium, tanto na morfologia dos paráfilos (Fig. 3 a 6), quanto na forma das papilas dos filídios (Fig. 9 a 12). Thuidiopsis e Pelekium possuem paráfilos não ramificados, pequenos, constituídos de 2 a 10 células (Fig. 3 a 6), enquanto Thuidium possui paráfilos ramificados, geralmente grandes e robustos, constituídos de 10 a 40 células (Fig. 7 e Fig. 8). Além disso, Thuidiopsis e Pelekium possuem papilas tanto na face abaxial quanto na face adaxial do filídio, enquanto Thuidium possui papilas apenas na face abaxial.

Também podemos destacar a morfologia das papilas que são bastante semelhantes nas espécies de Thuidiopsis e Pelekium. Nas espécies com células pluripapilosas as papilas estão dispostas na periferia no lúmen celular (Fig. 11 e Fig. 12), ao passo que em Thuidium as papilas estão localizadas no centro do lúmen celular (Fig. 15 e Fig. 16). Além disso, nas espécies unipapilosas de Pelekium e Thuidiopsis, as papilas são pequenas, baixas e geralmente inconspícuas (Fig. 9 e Fig. 10), enquanto em Thuidium nas espécies unipapilosas que representam a grande maioria dos táxons do gênero, as papilas geralmente são grandes, altas a medianas, frequentemente encurvadas, conspícuas e vistosas (Fig. 13 e Fig. 14). Do mesmo modo, representantes de Thuidiopsis e Pelekium apresentam gametófito pequeno e 12-pinado, enquanto Thuidium possui um gametófito grande, robusto e 2-3-pinado.

Desde Fleischer (1922) e Brotherus (1925) estes gêneros eram separados com base em características de sua sexualidade (monóicas $x$ dióicas). Estas características nem sempre estão presentes, o que dificulta e limita a delimitação destes grupos. As 
espécies de Thuidiopsis (dióicas) dificilmente exibem estruturas reprodutivas, tendo em vista sua preferência pela reprodução vegetativa, que é a principal forma de reprodução deste gênero (Touw 2001).

A utilização do tipo de paráfilo para a separação morfológica dos dois clados aqui apresentados, juntamente com o padrão de papila, disposição das papilas nas faces adaxial e abaxial dos filídios, bem como o padrão dos pêlos axilares, parece ser mais adequado para a delimitação e separação deste dois clados, tendo em vista os recentes resultados dos estudos filogenéticos realizados nos últimos anos por diversos pesquisadores (García-Avila et al. 2009, Cox et al. 2010, Soares \& Câmara Capítulo 1) e das evidências morfológicas apresentadas no presente estudo.

Desta forma, podemos definir como características morfológicas distintivas para a nova combinação e para o clado Pelekium: plantas com paráfilos simples, pequenos, constituídos de 2 a 10 células, papilosos; pêlos axilares com uma simples célula distal, papilas nas espécies pluripapilosas localizados na periferia do lúmen celular e filídios com papilas na face abaxial e adaxial.

\section{Novas Combinações}

Pelekium furfurosum (Hook. f. \& Wilson) Soares, A.E.R. \& Câmara, P.E.A.S, comb. nov. - Hypnum furfurosum Hook. f. \& Wilson, Fl. Nov.-Zel. 2: 10, 88 f. $7.1854-$ Thuidium furfurosum (Hook. f. \& Wilson) Reichardt, Reise Novara 1(3): 187. 1870. Tipo: New Zeland, Bay of Islands, near the sea, at dry roots of Metrosideros truncate, 8. 1841, J.D, Hooker 390 (Lectotipo: BM!). Lectotipificada por Touw \& Falter-Van den Haak (1989).

Pelekium sparsum (Hook. f. \& Wilson) Soares, A.E.R. \& Câmara, P.E.A.S. comb. nov. - Hypnum sparsum Hook. f. \& Wilson, Fl. Nov.-Zel. 2: 109, 89 f. 5. 1854. Thuidiopsis sparsa (Hook. f. \& Wilson) Broth., Nat. Pflanzenfam. (ed. 2) 11: 323. 1925. Tipo: New Zealand, North Island: Wangarei, J. Bolton s.n. (holotype: BM!, isotype: NY!). 

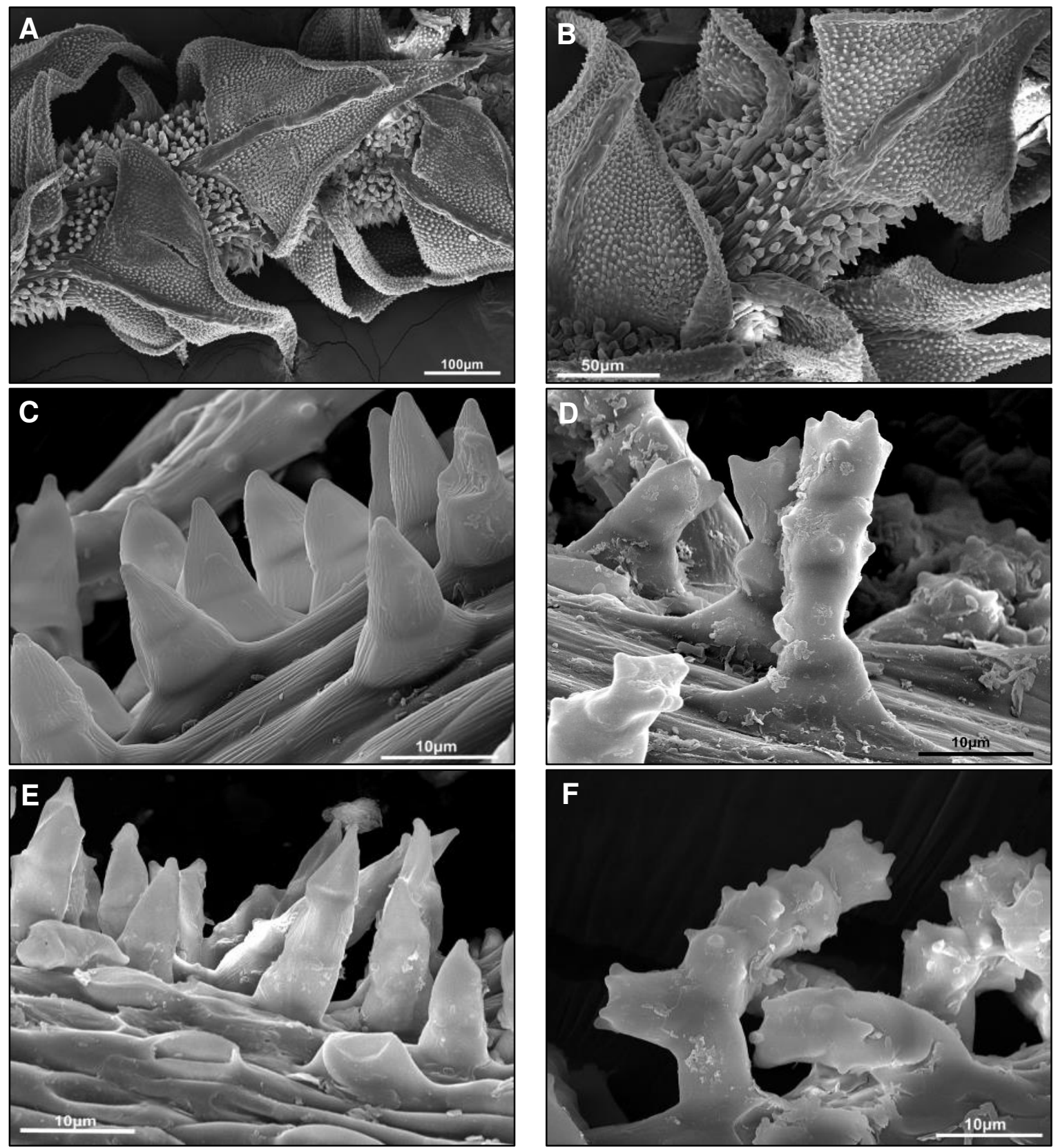

Figura 3: Paráfilo simples em Pelekium. A e $\mathrm{B}=$ visão geral do caulídio e paráfilos em Pelekium siphotheca. C e E = Paráfilo com ápice agudo em Pelekium siphotheca. $\mathrm{D}$ e $\mathrm{F}=$ Paráfilo com ápice truncado em Pelekium scabrosulum. 

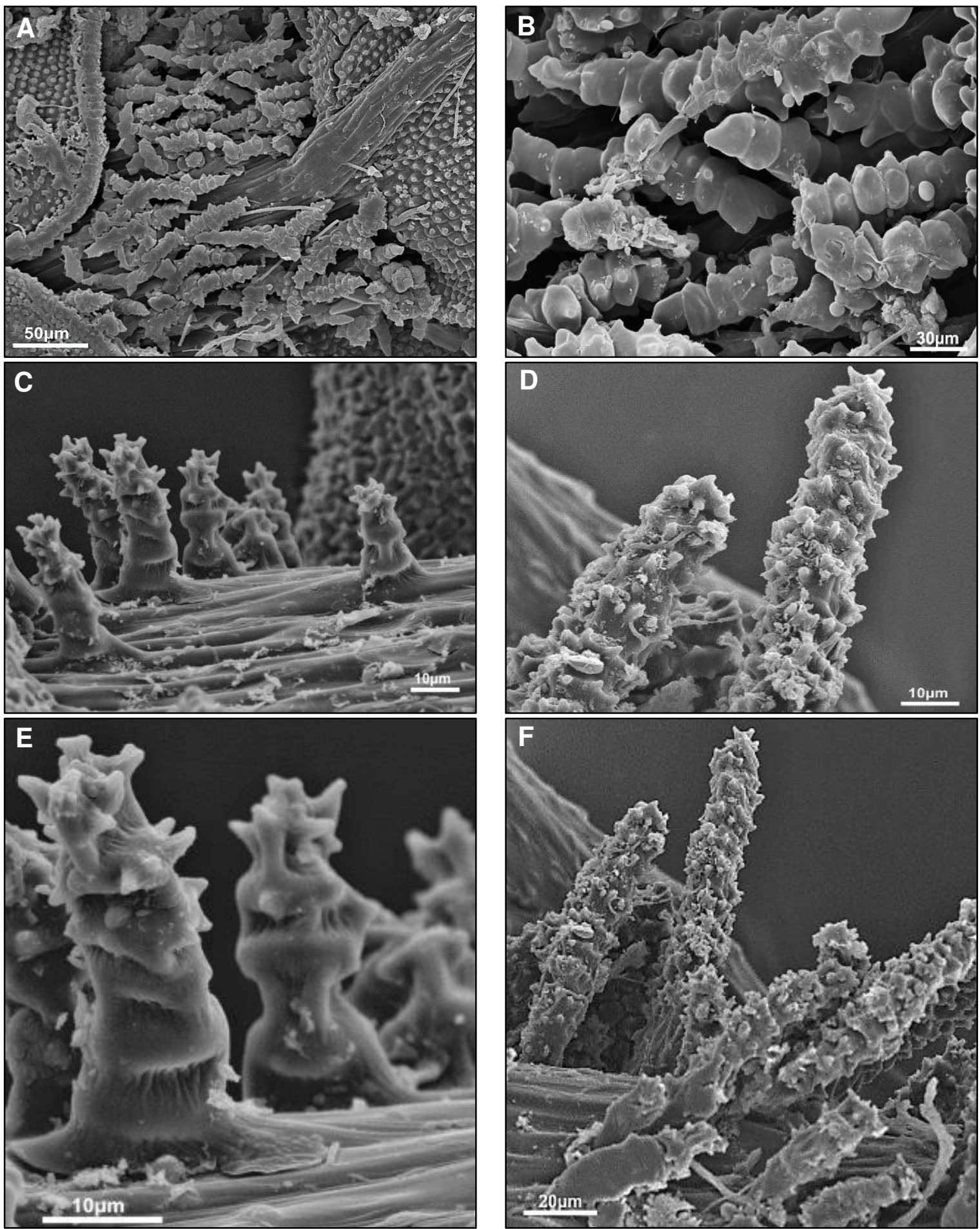

Figura 4: Paráfilo simples em Thuidiopsis. A = visão geral do caulídio e paráfilos em Thuidiopsis furfurosa. $\mathrm{B}=$ Paráfilos em Thuidiopsis furfurosa. $\mathrm{C}, \mathrm{D}, \mathrm{E}$ e $\mathrm{F}=$ Paráfilo simples em Thuidiopsis sparsa. 

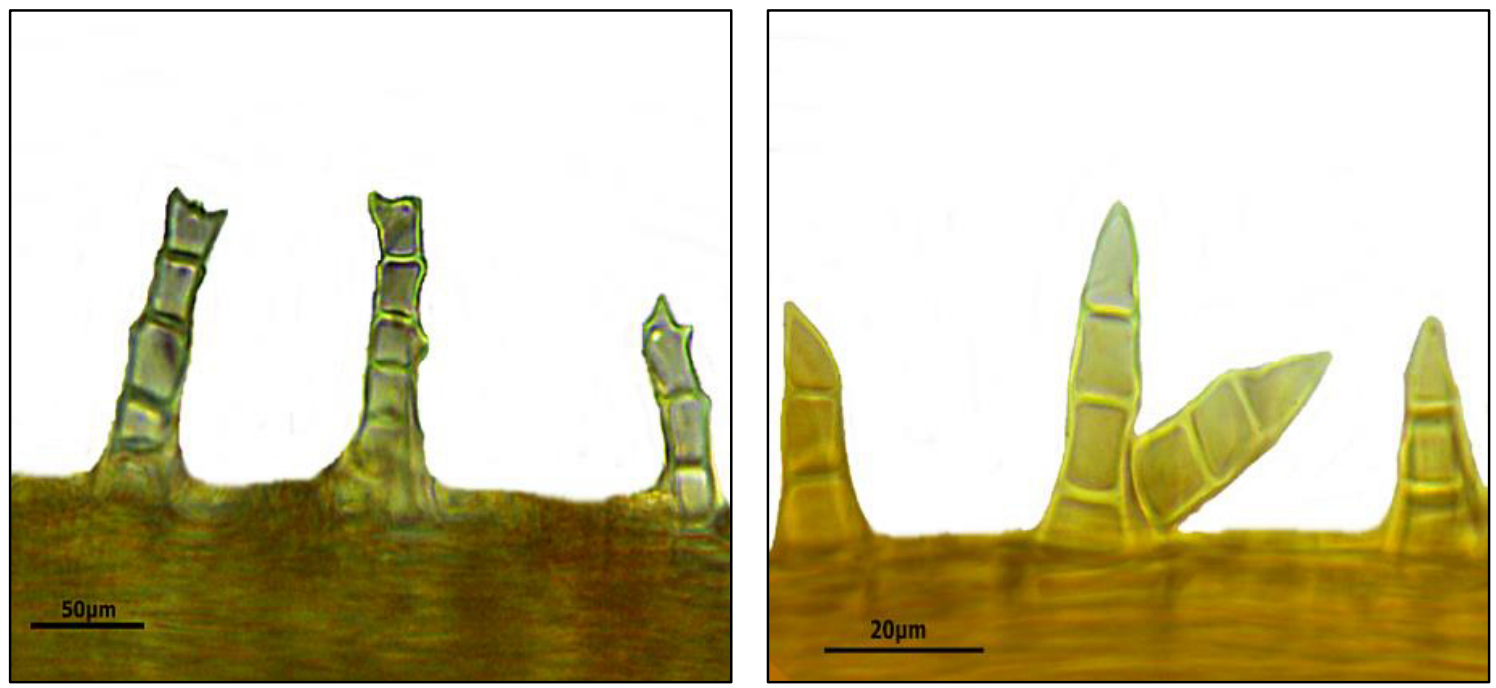

Figura 5: Paráfilo simples, não ramificado típico do gênero do Pelekium.
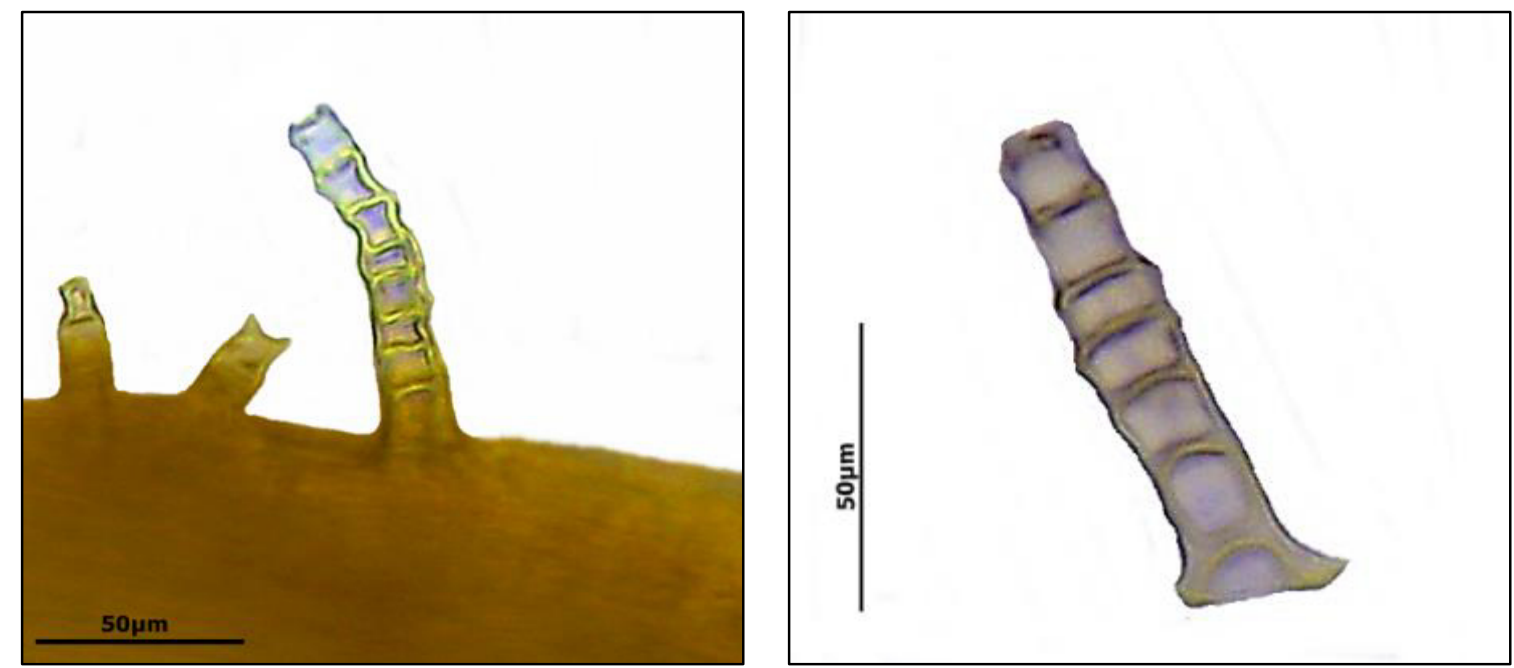

Figura 6: Paráfilo simples, não ramificado típico do gênero Thuidiopsis. 

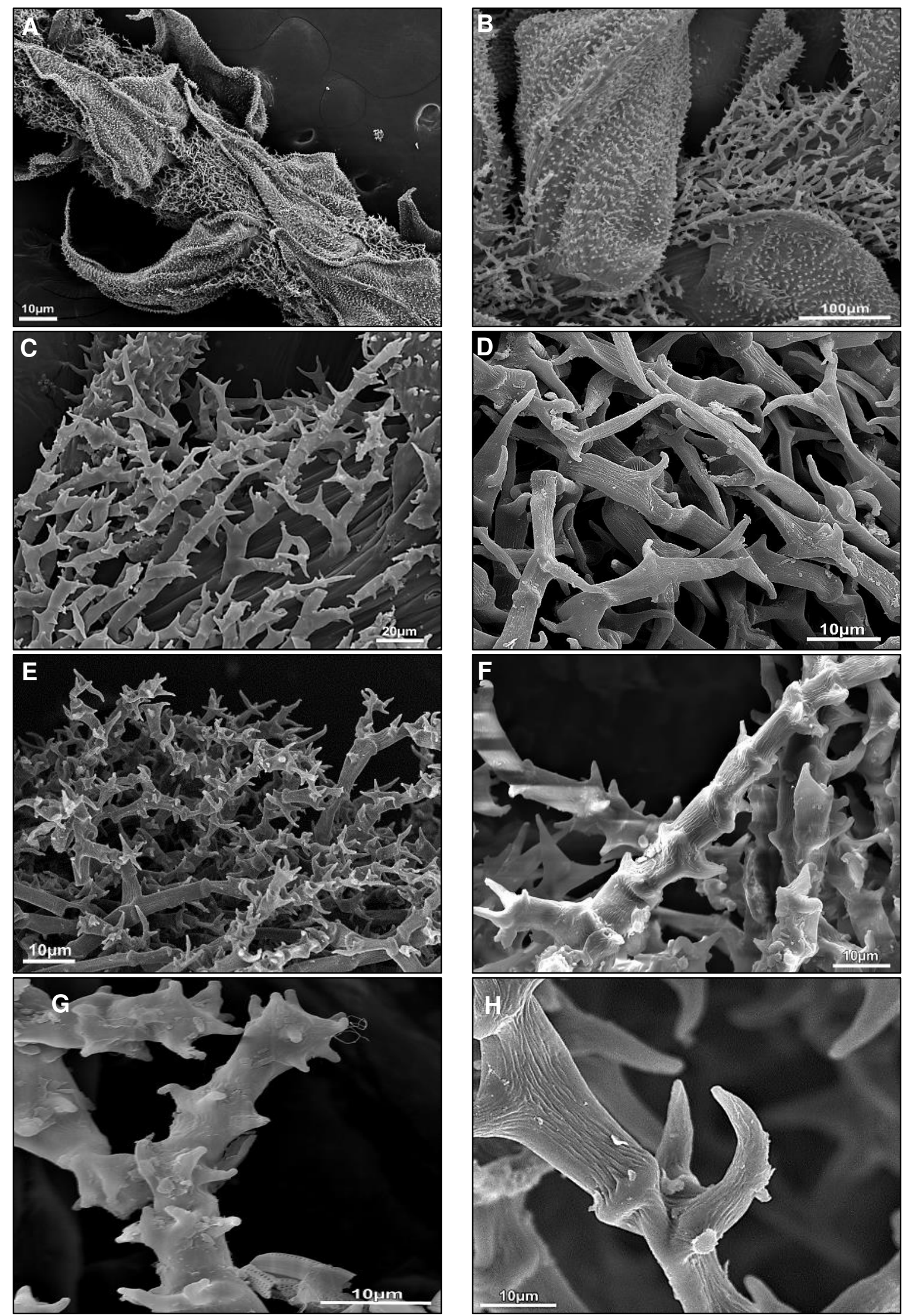

Figura 7: Paráfilo ramificado em Thuidium. $\mathrm{A}$ e $\mathrm{B}=$ Caulídio e paráfilos em Thuidium brasiliense. $\mathrm{C}$ e $\mathrm{D}=T$. delicatulum. $\mathrm{E}$ e $\mathrm{F}=T$. brasiliense. $\mathrm{G}=$ Paráfilos com papilas em $T$. pseudoprotensum. $\mathrm{H}=$ Paráfilo com papilas em $T$. brasiliense. 

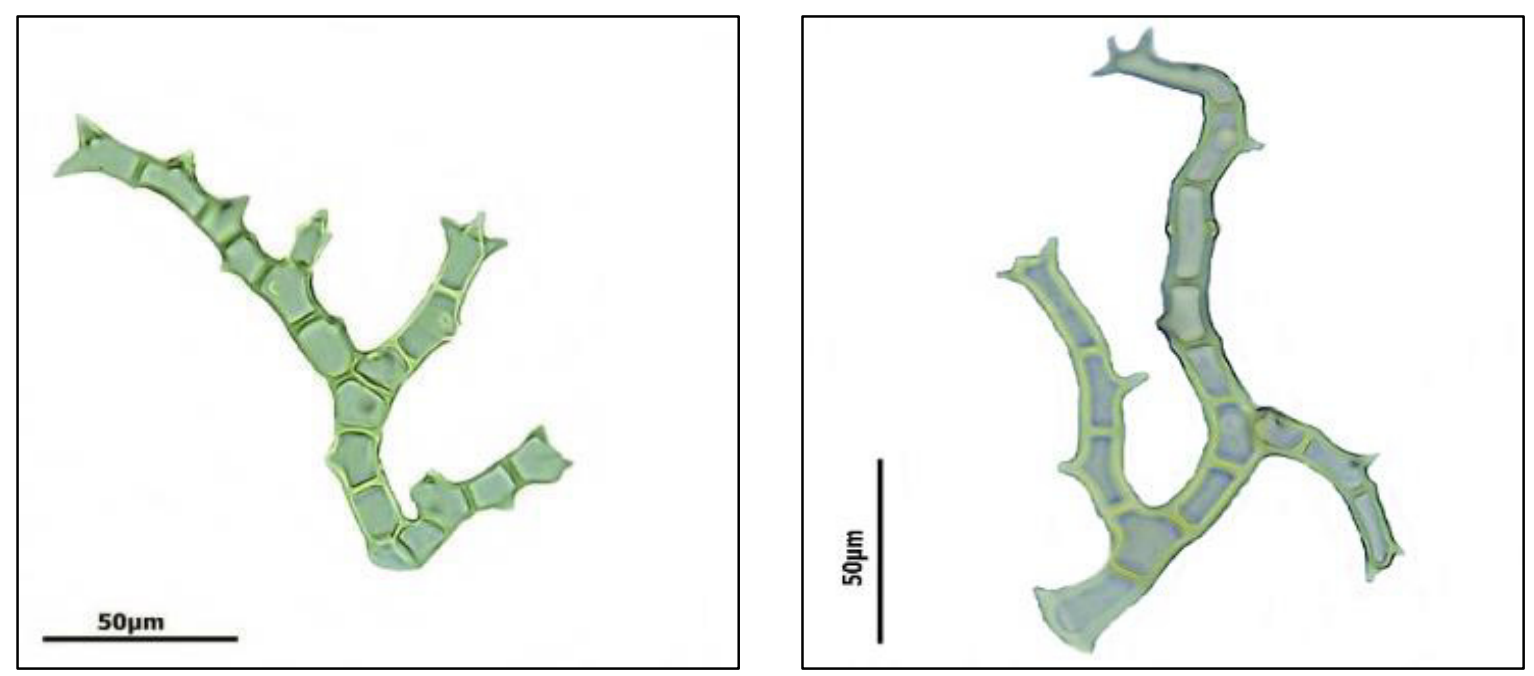

Figura 8: Paráfilo ramificado típico do gênero Thuidium.
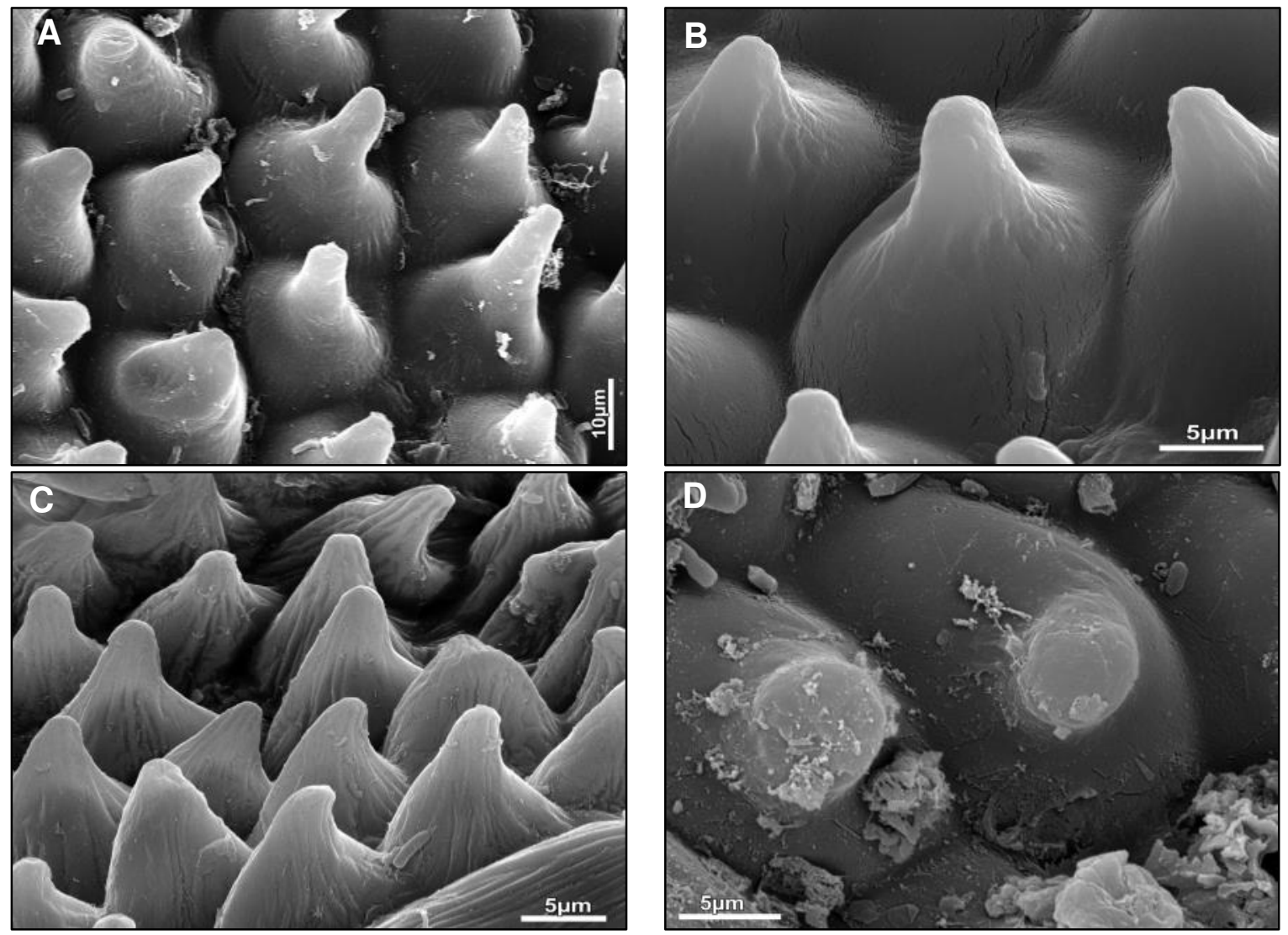

Figura 9: Células unipapilosas com papilas típicas de Pelekium e Thuidiopsis. A $=$ Pelekium muricatulum . B e C = Pelekium siphotheca. $\mathrm{D}=$ Thuidiopsis furfurosa. 

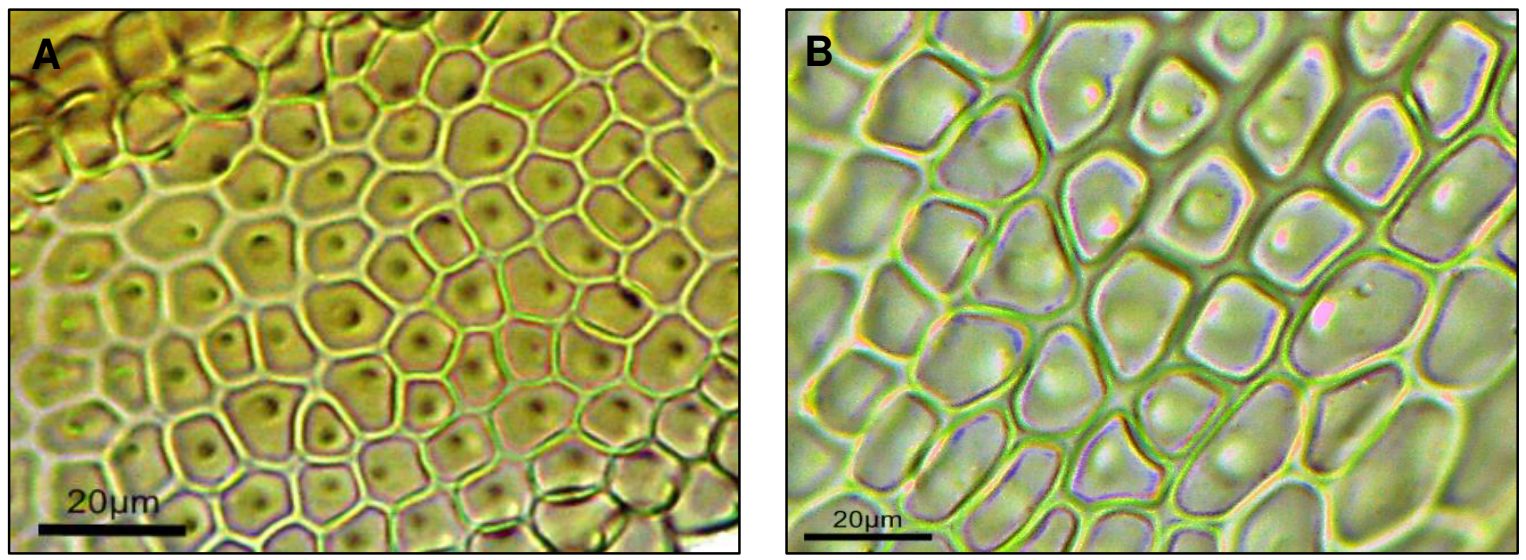

Figura 10: Células unipapilosas com papilas típicas de Pelekium e Thuidiopsis. A

= Pelekium muricatulum. $\mathrm{B}=$ Thuidiopsis furfurosa.
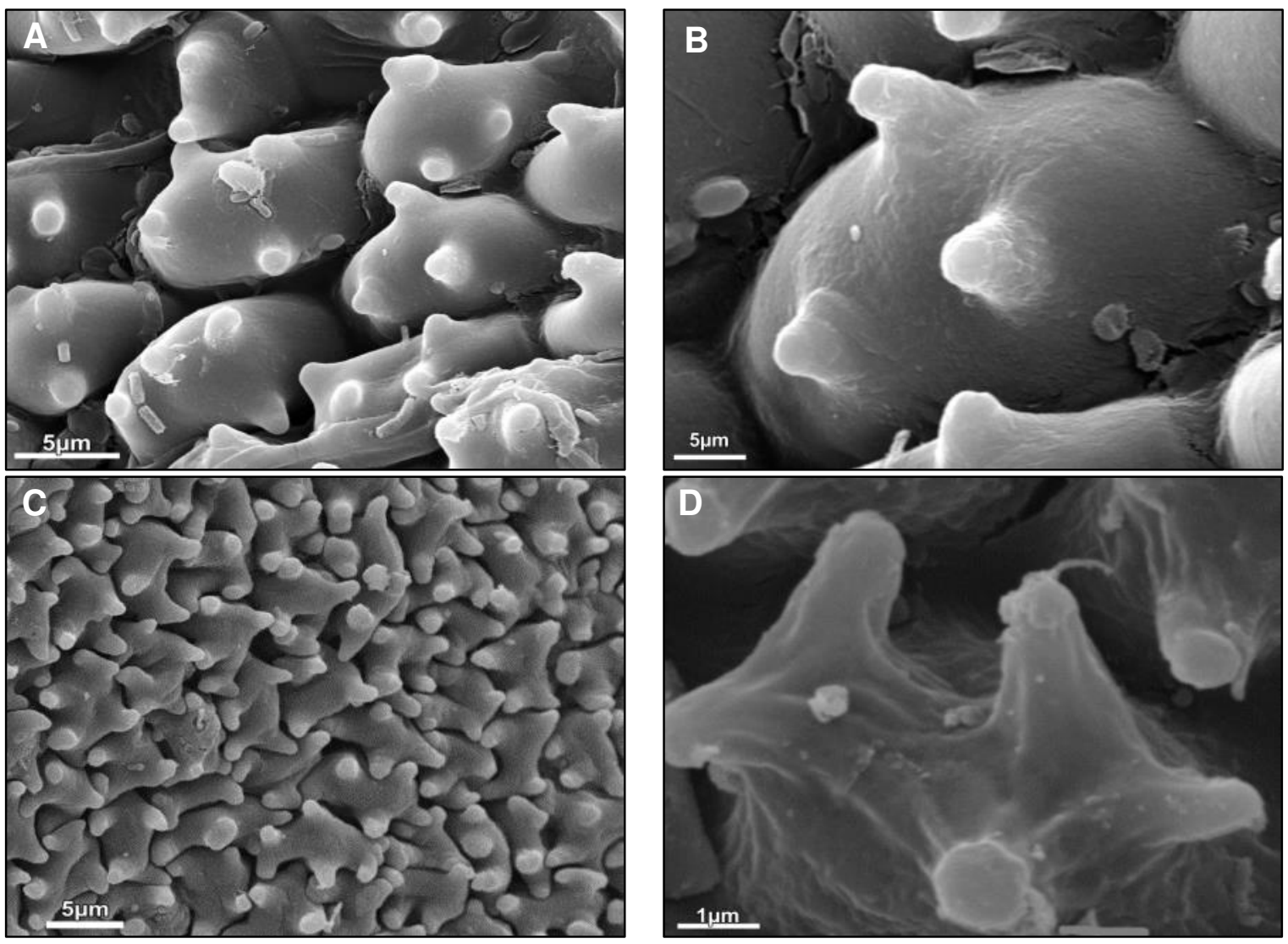

Figura 11: Células pluripapilosas com papilas típicas de Pelekium e Thuidiopsis. A e B = Pelekium scabrosulum. C e D = Thuidiopsis sparsa. 

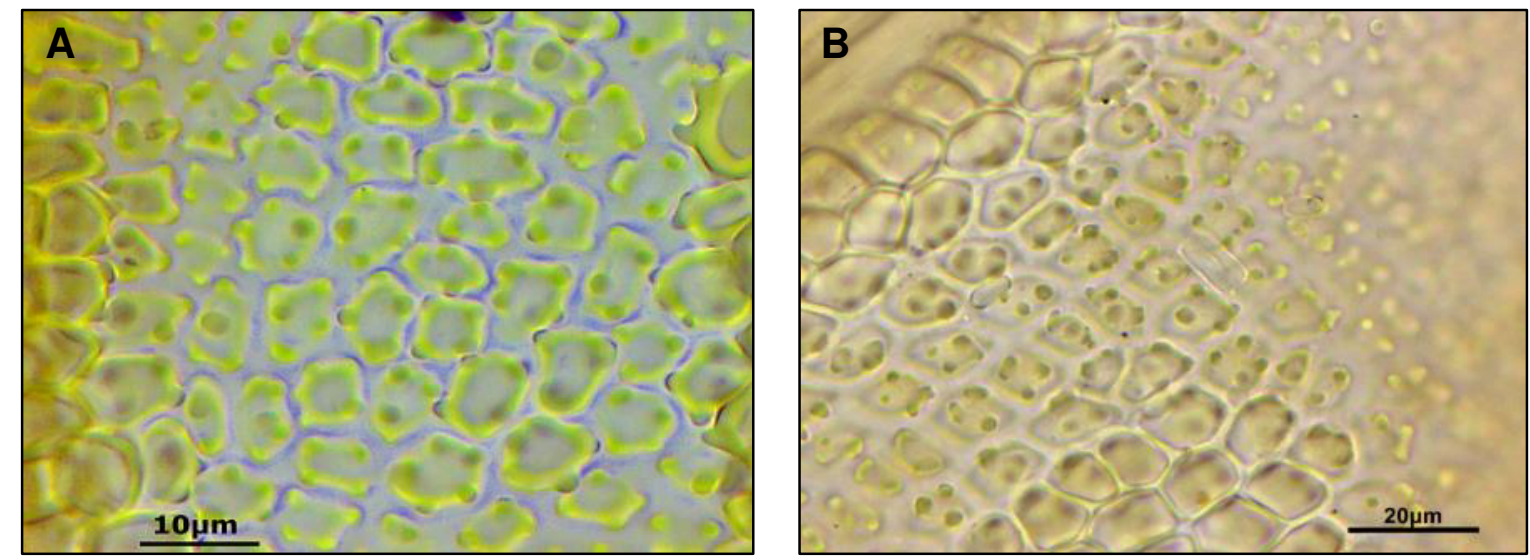

Figura 12: Células pluripapilosas com papilas típicas de Pelekium e Thuidiopsis.

A e $\mathrm{B}=$ Pelekium scabrosulum. $\mathrm{C}$ e $\mathrm{D}=$ Thuidiopsis sparsa.
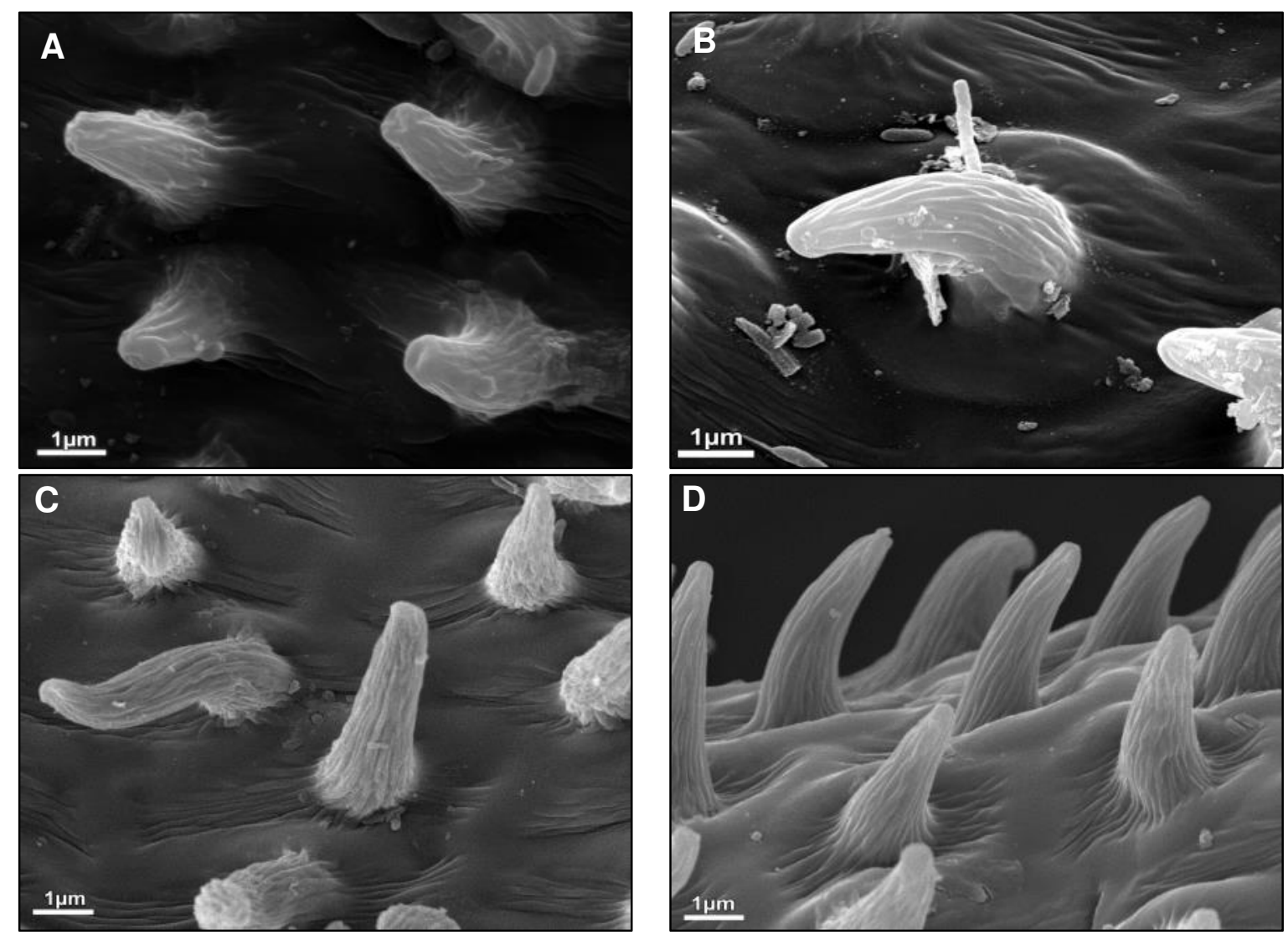

Figura 13: Células unipapilosas com papilas típicas de Thuidium. A e B = Thuidium delicatulum. C e D = Thuidium brasiliense. 

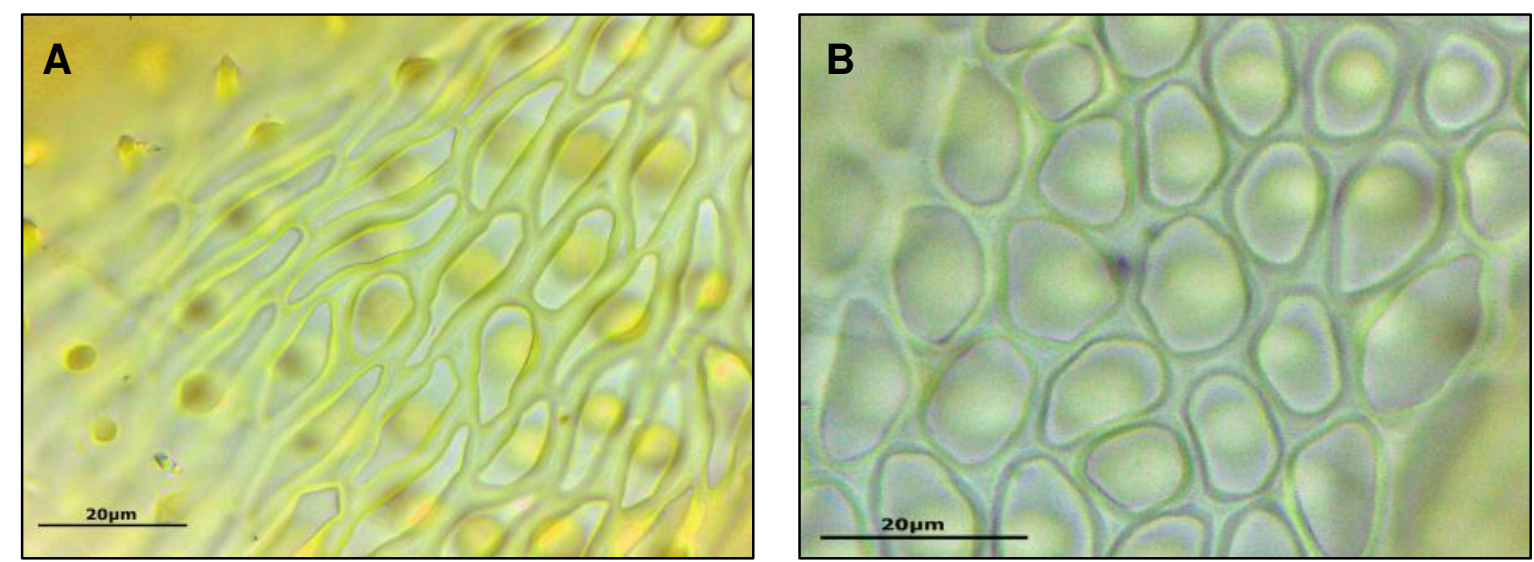

Figura 14: Células unipapilosas com papilas típicas de Thuidium. $\mathrm{A}=$ Thuidium brasiliense. $\mathrm{B}=$ Thuidium delicatulum.
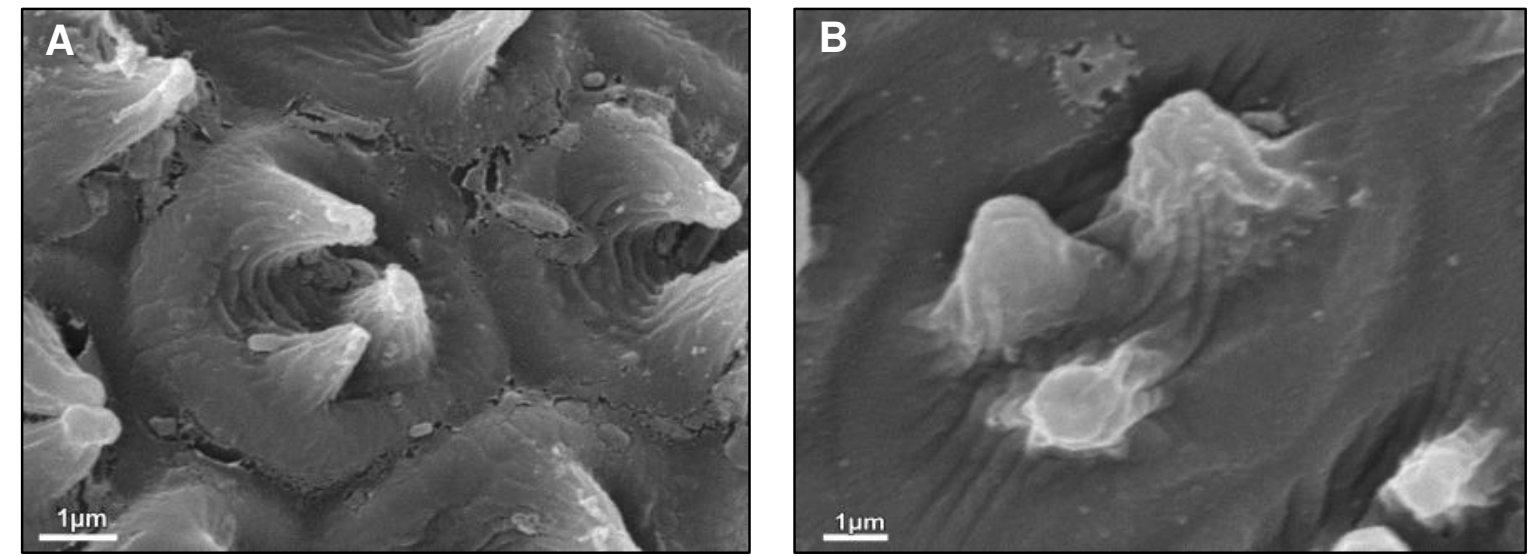

Figura 15: Células pluripapilosas com papilas típicas de Thuidium, localizadas no centro do lúmen celular. $\mathrm{A}$ e $\mathrm{B}=$ Thuidium tomentosum.

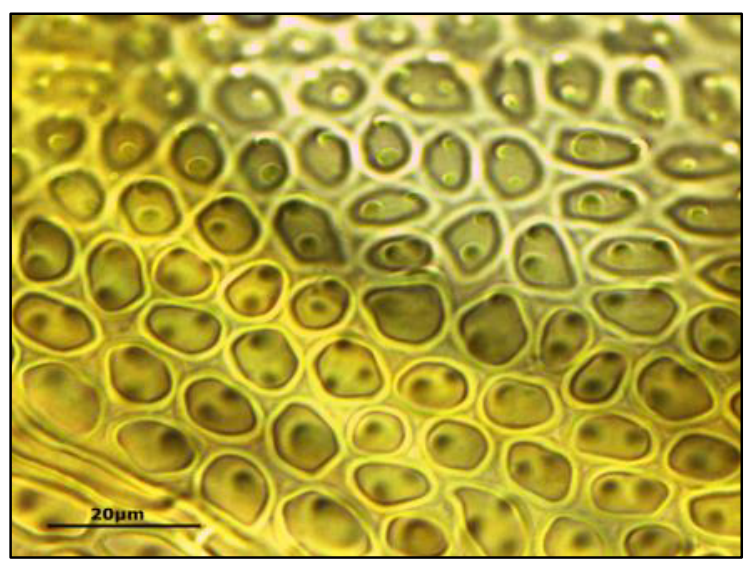

Figura 16: Células pluripapilosas com papilas típicas de Thuidium tomentosum, localizadas no centro do lúmen celular. 


\section{Agradecimentos}

Os autores agradecem ao Conselho Nacional de Desenvolvimento Cientifico e Tecnológico - CNPq, pela concessão da bolsa de estudos ao primeiro autor e ao Laboratório de Biologia Molecular do Departamento de Botânica da Universidade de Brasília e ao PNADB - CAPES. 


\section{Referências Bibliográficas}

Beckert, S., S. Steinhauser, H. Muhle, \& V. Knoop. 1999. A molecular phylogeny of bryophytes based on nucleotide sequences of the mitochondrial nad5 gene. Plant Systematics and Evolution 218: 179-192.

Bell, N. E. \& A. E. Newton. 2005. The paraphyly of Hypnodendron and the phylogeny of related non-hypnalaean pleurocarpous mosses inferred from chloroplast and mitochondrial sequence data. Systematic Botany 30: 34-51.

Brotherus, V. F. 1925. Musci (Laubmoose) 2. In A. Engler \& K. Prantl (eds.). Die natürlichen Pflanzenfamilien, Leipzig: Engelmann 11.

Bozzola, J. \& L. D. Russel. 1998. Electron microscopy: principles and techniques for biologists. Ed.2. Jones \& Bartlett Learning, Massachussets.

Buck, W. R. \& H. Crum. 1990. An evaluation of familial limits among the genera traditionally aligned with the Thuidiaceae and Leskeaceae. Contributions of the University of Michigan Herbarium 17: 55-69.

Câmara, P. E. A. S. \& E. A. Kellogg. 2010. Morphology and development of leaf papillae in Sematophyllaceae. The Bryologist 113(1): 22-33.

Cox, C. J., B. Goffinet, N. J. Wickett, S. B. Boles \& A. J. Shaw. 2010. Moss diversity: a molecular phylogenetic analysis of genera. Phytotaxa 9: 175-95.

Darriba D, Taboada G. L, Doallo R, Posada D. 2012. jModelTest 2: more models, new heuristics and parallel computing. Nature Methods 9(8), 772.

Doyle, J. J. \& J. L. Doyle. 1987. A rapid DNA isolation procedure for small quantities of fresh leaf tissue. Phytochemical Bulletin 19: 11-15.

Felsenstein, J. 1985. Confidence limits on phylogenies: an approach using the bootstrap. Evolution 39: 779-783.

Fleischer, M. 1922. Thuidiaceae. Die Musci der Flora von Buitenzorg 4: 1494-1533.

García-Avila, D., E. De Luna \& A. E. Newton. 2009. Phylogenetic relationships of the Thuidiaceae and the non-monophyly of the Thuidiaceae and the Leskeaceae based on rbcL, rps4 and the rps4-trnS intergenic spacer. The Bryologist 112(1): 80-93.

Gardiner, A., M. Ignatov, S., Huttunen \& A. Troitsky. 2005. On resurrection of the families Pseudoleskeaceae Schimp. and Pylaisiaceae Schimp. (Musci, Hypnales). Taxon 54(3): 651-663. 
Higgins, D. G. \& P. M. Sharp. 1988. Clustal: A package for performing multiple sequence alignment on a micocomputer. Gene 73: 237-244.

Nadot, S., R. Bajon, \& B. Lejeune. 1994. The choloroplast gene rps4 as a tool for the study of Poaceae phylogeny. Plant Systematics and Evolution 191: 27-38.

Rambaut, A. 2009. FigTree, ver.1.3.1. Available: www.tree.bio.ed.ac.uk/software

Rambaut A. \& A. J. Drummond. 2013. Tracer v1.5. Available: http://beast.bio.ed.ac.uk/Tracer.

Ronquist, F. \& J. P. Huelsenbeck. 2003. MRBAYES 3: Bayesian phylogenetic inference under mixed models. Bioinformatics 19: 1572-1574.

Schimper, W. P. 1860. Synopsis muscorum europaeorum. E. Schweizerbart, Stuttgart.

Shaw, A. J. 2000. Phylogeny of the Sphagnopsida based on chloroplast and nuclear DNA sequences. The Bryologist 103: 277-306.

Stamatakis, A. 2014. RAxML Version 8: A tool for Phylogenetic Analysis and PostAnalysis of Large Phylogenies. Bioinformatics 30(9):1312-3.

Swofford, D. L. 2002. PAUP*. Phylogenetic analysis using parsimony (*and other methods). Version 4.: Sinauer Associates, Sunderland.

Touw, A. 2001a. A review of Thuidiaceae (Musci) and a realignment of taxa traditionally accommodated in Thuidium sensu amplo (Thuidium Schimp., Thuidiopsis (Broth.) M. Fleisch, and Pelekium Mitt.) including Aequatoriella gen. nov. and Indothuidium gen. nov. Journal of the Hattori Botanical Laboratory 90: 167-209.

Touw, A. \& L. Falter-Van den Haak. 1989. A revision of the Australasian Thuidiaceae (Musci), with notes on species from adjacent regions. Journal of the Hattori Botanical Laboratory 67: 1-5 


\title{
4. CAPÍTULO 3
}

Aceito para publicação na revista The Bryologist

Registro: BRYOLOGIST-D-15-00016.

\section{A new species of Thuidium (Thuidiaceae) from Brazil and a Key to the Brazilian species of the genus.}

\author{
Abel Eustáquio Rocha Soares ${ }^{1}$ and Paulo Eduardo Aguiar Saraiva Câmara ${ }^{1}$ \\ 1 Universidade de Brasília, UnB, Depto. de Botânica. Campus Universitário Darcy Ribeiro, Asa \\ Norte, Brasília, DF. Brazil.
}

\begin{abstract}
During a revision of the Thuidiaceae for Brazil, we found a new species of Thuidium endemic to Brazil. It occurs in the south, southeast and midwest regions of the country, in the Atlantic Forest and Cerrado regions, and is considered near threatened. Thuidium bifidum is mainly characterized by bifid papillae and short-celled paraphyllia. Details of its morphological characters are illustrated and the geographical distribution mapped. A key to the species of Thuidium in Brazil is also provided.
\end{abstract}

Key Words: Mosses, Atlantic Forest, Cerrado, bifid papillae. 
Thuidium Bruch \& Schimp. is a widespread genus of Thuidiaceae occurring in boreal and temperate areas of the northern hemisphere, in tropical areas of Asia, Pacific and the Americas, and in Africa, Australia and New Zealand (Touw 2001a). According to Touw (2001b), in the tropics the genus occurs mainly in the mountains, although a few species have a wide vertical distribution and occur close to sea level.

Thuidium is characterized by robust stems with branches regularly bipinnate or partly tripinnate, abundant paraphyllia covering the stems, and papillose paraphyllia. The paraphyllia are forked, uniseriate, and intermediate cells are quadrate to rectangular. Leaves of the stem and branches are generally unipapillose.

The genus Thuidium was initially described by Bruch et al. (1852), with five species. The circumscription of New World Thuidium is difficult, because in the past many species that are now allocated in independent genera were grouped into Thuidium (e.g., Cyrto-hypnum (Hampe) Hampe \& Lorentz) and also because of the close morphological similarities between species.

According to Touw (2001b) there are about 20-25 Thuidium species worldwide; in Tropical Asia, the Western Pacific, and Hawaii, there are six species (Touw 2001b). In the same year, Touw (2001a) revised the Thuidiaceae and limited the family to 16 genera and 72 species.

In the Neotropics, available distributional data comes only from local floras and checklists such as Gradstein et al. (2001), who cite 16 species for Tropical America, of which probably only 5-10 are valid. Gier (1980) listed 17 species of Thuidium for Latin America, but his study did not take into account the existence of several synonyms. Sharp et al. (1994) mentioned two Thuidium species for Mexico. Buck (1998) cites five Thuidium species for the West Indies. Churchill \& Linares (1995) reported the occurrence of 10 Thuidium species for Colombia, and Schiavone \& Suárez (2007) cited three species for Argentina. For Brazil, according to Costa \& Soares (2015), there are nine Thuidium species distributed in almost all regions of the country, mainly in humid forest areas.

In South America many nomenclatural problems persist, particularly due to the use of floras from Europe, Asia and North America to identify the South American species. This created a chain reaction, as for many years these were the only existing bibliographies, which caused the use of names that do not correspond to the actual 
local taxa and do not correctly represent the morphology of the species. This scenario has been changing in recent years as several local researchers have revised families and visited international herbaria to study the types.

During the investigation of the family Thuidiaceae in Brazil, we came across a previously unknown species of Thuidium, which is described here. Details of its morphological characters are illustrated and its geographical distribution is mapped. A key to the species of Thuidium in Brazil is also provided.

\section{Materials and Methods}

Loans totaling 2650 specimens and the type material of 60 taxa were obtained from 31 herbaria (ALCB, BHCB, BM, CEN, E, F, G, H, HEPH, HUCS, IBGE, INPA, JE, L, M, MAK, MG, MO, NY, PACA, PC, PH, RB, S, SP, UFG, UFPE, UB, US e W). Specimens were rehydrated in boiling water and then mounted in Hoyer's solution (Anderson 1954). All observations and measurements were made from mounted material.

Species were recognized on the basis of morphological differences. All measurements were made from leaves taken from the middle of the stem or branch and viewed under a Nikon Labophot-2 light microscope. All illustrations were made from type material.

Leaf papilla morphology has been investigated under scanning electron microscopy (SEM). Samples were prepared according to Bozzola \& Russel (1998) and Câmara \& Kellogg (2010), although with a more gradual dehydration series, in 5\% increments, at the same time intervals, between $50 \%$ and $100 \%$ followed by two final steps at $100 \%$ and $100 \%$ in plants with thinner cell walls. Plants were submitted to critical point drying using a Denton DCP-1 dryer (Denton Vacuum LLC, Moorestown, NJ USA) and a Bal-Tec CPD 030 dryer (Bal-Tec AG, Balzers, Liechtenstein), with liquid $\mathrm{CO} 2$ as the transition fluid. After drying, leaves were mounted on stubs and sputtercoated with gold and gold-palladium layers using two sputter coaters: a Hummer 6.2 (Anatech, Union City, CA, USA) and a Bal-Tec SCD 050 (Bal-Tec AG). The sputtercoated specimens were kept in a dessicator containing silica gel before SEM visualization. The samples were observed and photomicrographs were taken with JSM840 A SM and JSM-5410 LV scanning electron microscopes (JEOL, Tokyo, Japan) at $15 \mathrm{kV}$ and at a working distance of $10 \mathrm{~mm}$. 


\section{Taxonomy}

Thuidium bifidum Soares, A.E.R. \& Câmara, P.E.A.S., sp. nov.

A Thuidium tomentosum unipapillose apud papillae bifida differt.

TYPE: BRAZIL. SÃO PAULO: Itapeva, Estação Experimental de Itapeva, margem

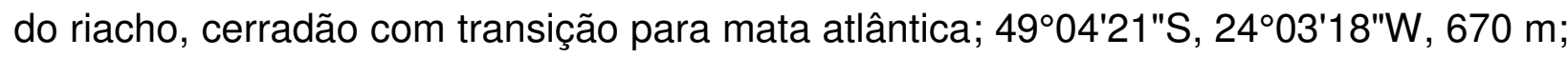
6 May 2010, D.F. Peralta 11461 (holotype: SP!, isotype: UB!).

\section{Description.}

Plants median, 7-10 cm long, green, dark-green, yellow-green. Stems prostate, mostly arched, ramification frequently bipinnate, sometimes tripinnate, branches to 0.5 $0.9 \mathrm{~cm}$ long. In cross section with 3-5 rows of small thick-walled cells and yellow-golden, dark-red, surrounding yellow to hyaline cells with thinner walls, central strand small. Paraphyllia abundant, in special on the stems, mostly crowded, to ca. 120-280 $\mu \mathrm{m}$ long, abundant on primary branches, few or sometimes absent on the secondary branches, branched, mostly uniseriate, intermediate cells quadrate, short, ca. 1-2:1, 6$15 \mu \mathrm{m}$ long, 6-8 $\mu \mathrm{m}$ wide, papillose, 2-3 papillae, margins papillose-serrulate, apical cell usually truncate and papillose. Pseudoparaphyllia foliose. Axillary hairs consisting of 1-2 basal cells, brown and 1-3 elongate distal cells. Stem and branch leaves differentiated. Stem leaves appressed-erect when dry, barely spreading when moist, deltoid, ovate-deltoid, 0.7-1 mm long, 0.3-0.5 mm wide, acuminate, short-cordate, concave, scarcely plicate; margins crenulate-papillose or serrulate-papillose, recurved upward, sometimes narrowly recurved below; costa strong, ca. 4/5 the leaf length, ending in but not filling the acumem, abaxial face prominent, roughened by spinose papillae and projecting short, often appendiculate near insertion; median leaf cells isodiametric to quadrate, 1-2:1, 8-12 $\mu \mathrm{m}$ long, 5-7 $\mu \mathrm{m}$ wide, bifid papillae, tall, both sides, sometimes in adaxial face papillae inconspicuous or smooth; cells of the acumen less strongly ornamented; apical cell mostly acute and smooth, occasionally bearing small papillae; alar cells not differentiated but cells in 2-4 rows across the insertion rectangular and smooth. Branch leaves erect when dry, spreading when moist, ovatedeltoid, 0.3-0.6 mm long, 0.15-0.3 mm wide, acute, short-cordate, concave; margin crenulate-papillose or serrulate-papillose, plane; costa usually ca. $2 / 3$ to $3 / 4$ the leaf length, sometimes forked above, mostly weakly prominent abaxially, smooth or seldom 
spinose papillae; median leaf cells oval to irregularly isodiametric, 1:1, 4-6 $\mu \mathrm{m}$ long, 3-5 $\mu \mathrm{m}$ wide, bifid papillae, tall, both sides, sometimes in adaxial face papillae inconspicuous or smooth; apical cell truncate, usually crowned with 1-2 papillae or smooth. Perichaetial leaves erect, lanceolate to triangular-lanceolate, $3-5 \mathrm{~mm}$ long, loriform, often piliferous acumen; margins serrulate in the acumem, ciliate at base of the acumem, entire, plane; costa narrow; median cells oblong to rectangular, smooth or nearly so. Setae elongate, smooth, brow to reddish, $2-4 \mathrm{~cm}$ long; capsules horizontal to inclined, ca. to $3 \mathrm{~mm}$ long, smooth, asymmetric, cylindric; exothecial cells thin walled, subquadrate; annulus and operculum not seen; exostome orange-yellow, lanceolate, shouldered, bordered, cross-striolate below, finely papillose above, trabeculate at back; endostome lanceolate, papillose, smooth basal membrane, tall, keeled, perforate; spore 8-15 $\mu \mathrm{m}$ diam., finely papillose; calyptrae not seen.

\section{Discussion}

This species is characterized by bifid or trifid papillae (Fig. 2a), paraphyllia with short and quadrate cells (Fig. 1C), bipinnate (Fig. 1a), stem leaves small and deltoid, acuminate, costa with abaxial face prominent, roughened by spinose papillae, and branch leaves ovate, acute.

In Asia, there are a few species that sometimes have bifid or trifid papillae near the leaf base, but this is not a constant feature and occurs only in some cells of some leaves. In T. bifidum the bifid/trifid papillae are constant. Moreover, the Asiatic species with bifid or trifid papillae are generally more robust and the stem leaves are larger than $1 \mathrm{~mm}$.

Thuidium bifidum has been overlooked in Brazil and probably in Tropical America; all specimens studied here were initially identified as $T$. tomentosum, a name commonly applied to plants with bifid papillae.

Thuidium bifidum can be misidentified as $T$. tomentosum (the morphologically closest species), as it shares many similar features such as habit and paraphyllia; however, the two species can be differentiated by their papillae (Fig. 2). Thuidium tomentosum is pluripapillose, whereas T. bifidum is unipapillose (bifid or trifid), a unique feature of $T$. bifidum. The main difficulty in separating $T$. bifidum from $T$. tomentosum lies in distinguishing between pluripapillose cells and bifid/trifid papillae. However, careful inspection will show that the bifid/trifid papillae originate at a single point in the 
cell lumen, and divide only at the apex of the papillae (Fig. 2a), whereas pluripapillose cells have 2-4 papillae developing separately, located in the center of the cell lumen (Fig. 2b).

Unfortunately it is not always easy to see the difference under the light microscope, so another useful feature that helps to differentiate the two species is the paraphyllia and the stem leaves. Thuidium bifidum has 2-4 papillae per cell on its paraphyllia (Fig. 1C) and the stem leaves are acuminate with a narrow base (Fig. 1e); $T$. tomentosum has 1-2 papillae per cell on its paraphyllia (Fig. 1d), and the stem leaves are short-acuminate with a wide base (Fig. 1f).

\section{Etymology.}

The specific epithet refers to the main characteristic of the plant, the leaves with bifid papillae.

\section{Ecology and distribution.}

Endemic to Brazil, Thuidium bifidum occurs in the southern, southeastern and midwestern regions (Fig. 3), in the Atlantic Forest and in gallery forest in the Cerrado biome, in moist shady places. It grows on trunks of live and dead trees and less frequently in rocky streams, at elevations of 400 to $1300 \mathrm{~m}$.

The Atlantic Forest, one of 34 hotspots for biodiversity conservation (Mittermeier et al. 2004), is a region with extremely rich biodiversity, high species diversity and high levels of endemism (Fonseca 1985). The Atlantic Forest has one of the richest floras of bryophytes in South America, with approximately 1230 species, including $71 \%$ of the species recognized for Brazil, 30\% for the Neotropics and 6\% for the world (Costa 2009).

The Cerrado is also one of the world's biodiversity hotspots. In the last 35 years, more than $50 \%$ of its approximately 2 million $\mathrm{km} 2$ has been transformed into pasture and agricultural land planted in cash crops (Klink \& Machado 2005). The Cerrado has the richest flora among the world's savannas, and high levels of endemism with approximately 478 bryophyte species recognized, comprising $30 \%$ of all species recognized for Brazil (Costa \& Peralta 2015), 10\% for the Neotropics (Gradstein et al. 2001) and 3\% for the world. 
Most likely the species has a wider distribution than currently known, but the difficulty in recognizing it as a distinct species (probably due to its similarity with $T$. tomentosum) has obscured recognition of its actual distribution, which is probably much broader than that presented here.

At the beginning of our study with Thuidiaceae we sometimes came across species with similar characteristics to T. bifidum collected in the Atlantic Forest, but due to lack of knowledge at the time they were classified as T. tomentosum.

\section{Conservation Considerations.}

The species is known only from six locations; three are in unprotected areas near urban centers, and the other three are in protected areas, such as Itatiaia National Park and the Caraça RPPN (Private Natural Reserve). The distribution patterns and the first author's experience with Thuidiaceae in Brazil suggest that $T$. bifidum may occur in other forest areas, particularly in areas of Atlantic Forest and gallery forests.

Therefore, $T$. bifidum was assigned a lower-risk rating because it does not fit any of the IUCN (2001) criteria for definition as "endangered" (CR, EN, VU). The species was classified as near threatened (NT) according to IUCN criteria (IUCN 2001).

\section{Additional specimens examined.}

BRAZIL. GOIÁS: Formoso, D.M. Vital 12790 (SP). MINAS GERAIS: Nova Lima, D.F. Peralta 11646 (SP). RIO DE JANEIRO: Itatiaia, A.E.R. Soares 1813 (UB). RIO GRANDE DO SUL: Nova Roma do Sul, J.R.P.M. Oliveira 250 (UFP). SANTA CATARINA: A. Sehnem 14384 (PACA). 


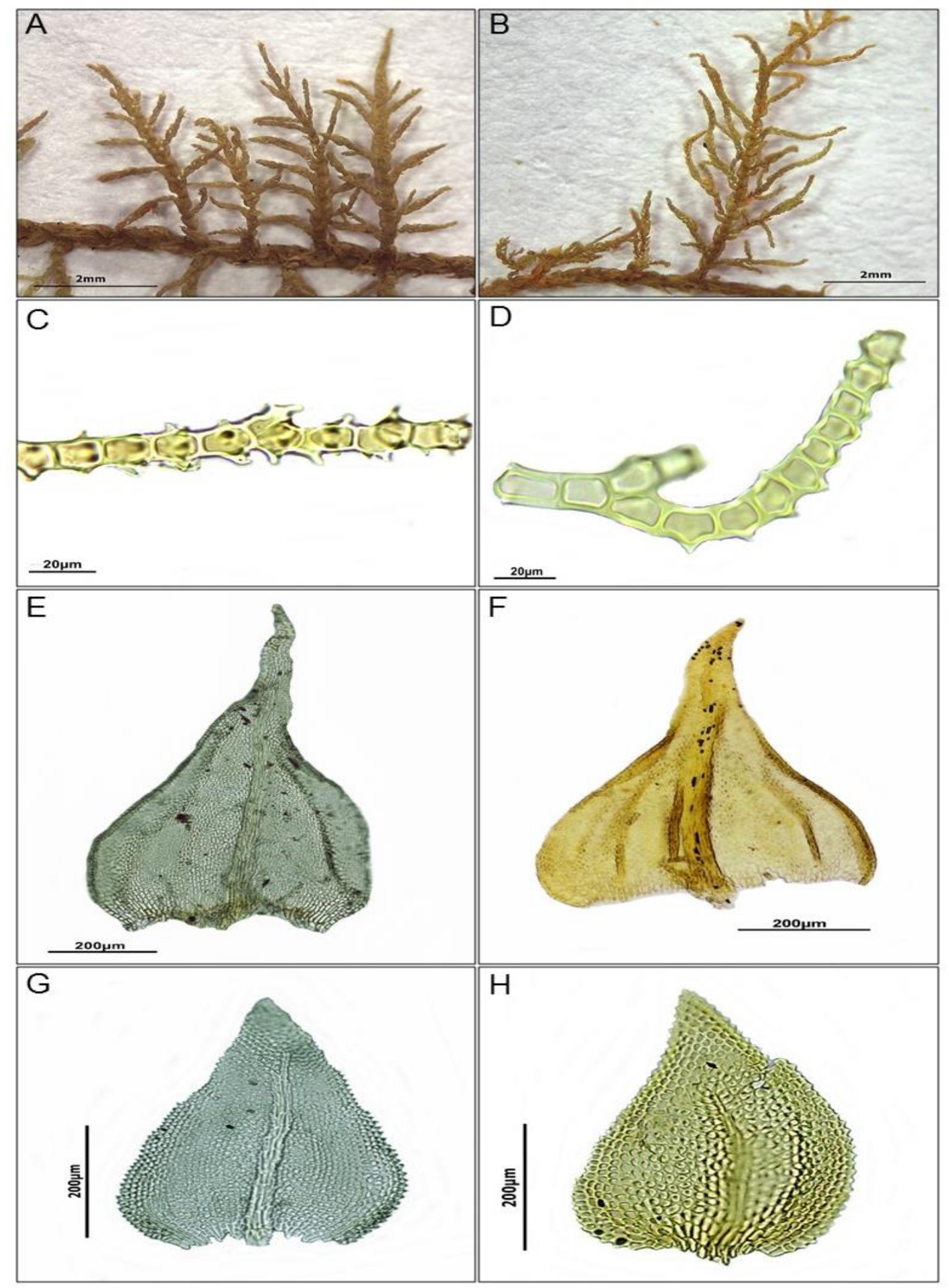

Figure 1: Comparison of the morphological differences between Thuidium bifidum and T. tomentosum. A. Gametophyte of T. bifidum. B. Gametophyte of T. tomentosum. C. T. bifidum paraphyllia with 2-4 papillae per cell. D. T. tomentosum paraphyllia with 1-2 papillae per cell. E. T. bifidum stem leaf with narrow base. F. T. tomentosum stem leaf with wide base. G. T. bifidum branch leaf. H. T. tomentosum branch leaf. 

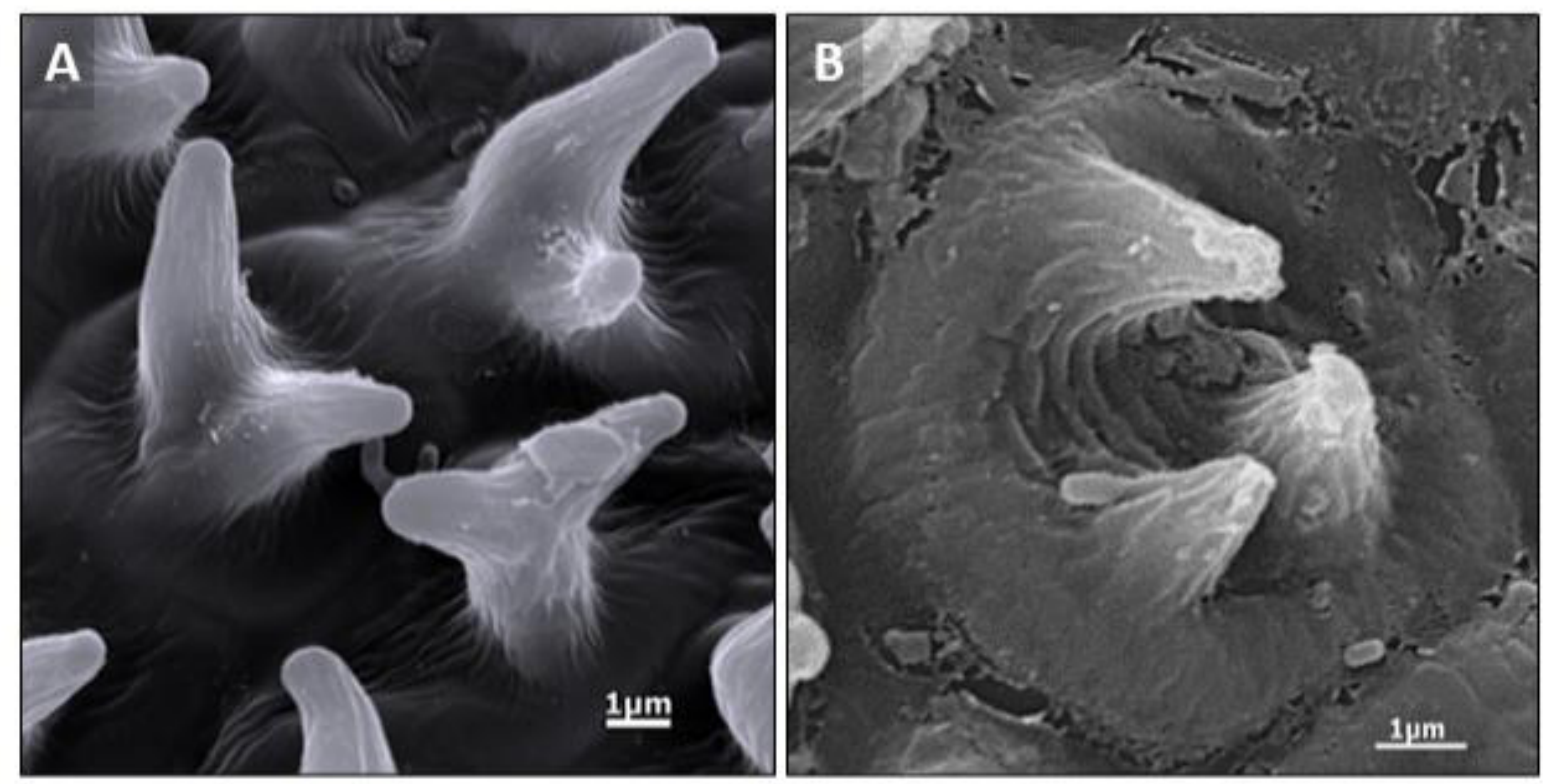

Figure 2: Comparison of the morphological differences between Thuidium bifidum and T. tomentosum. A. Bifid papillae on T. bifidum (observed with scanning electron microscopy). B. Pluripapillose cells on T. tomentosum (observed with scanning electron microscopy).
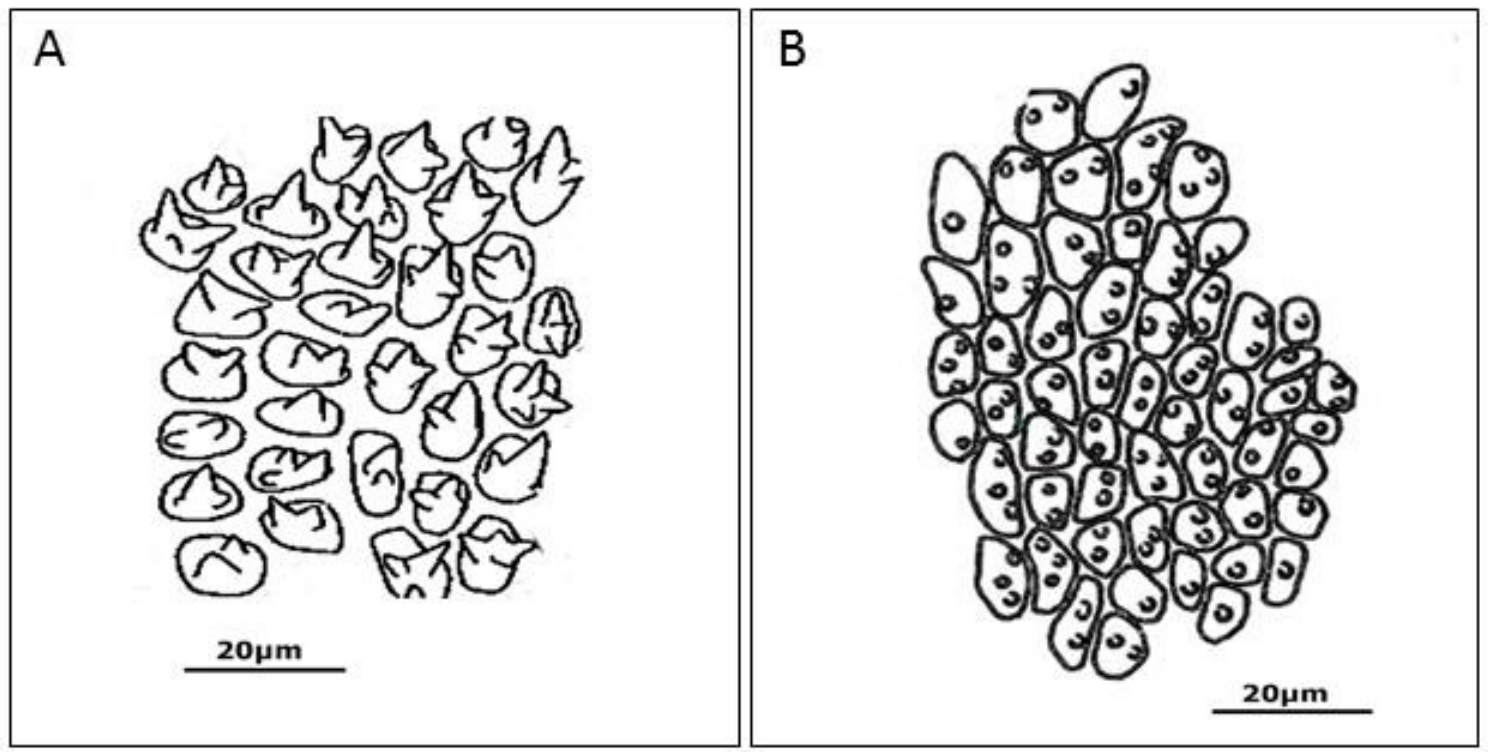

Figure 3: Comparison of the morphological differences between T. bifidum and $T$. tomentosum. A: Bifid papillae on T. bifidum. B: Pluripapillose cells on T. tomentosum. 
A key to the species of Thuidium in Brazil

1. Leaves with pluripapillose cells.

T. tomentosum

1. Leaves with unipapillose cells 2

2. Apical cell of branch leaves pointed

T. tamariscinum

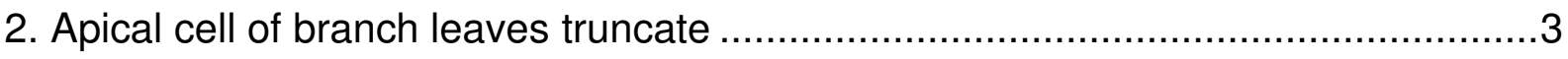

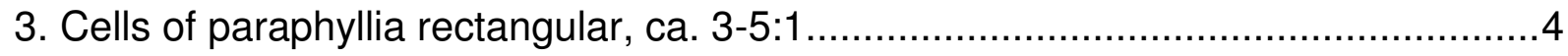

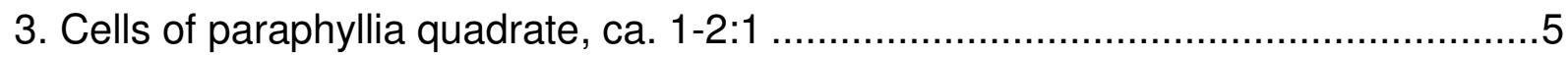

4. Branch leaf cells elongated, elliptical to rectangular-linear; costa ending $1 / 2$ the leaf length. T. brasiliense

4. Branch leaf cells oval to isodiametric; costa ending 2/3-3/4 the leaf length

T. delicatulum

5. Costa filling the acumen T. urceolatum

5. Costa ending in but not filling the acumen. .6

6. Stem leaves ending in a uniseriate hair tip, ca. 2-5 cells, usually hyaline.

T. philibertii

6. Stem leaves having no pointed process or awn (muticous). .7

7. Branch leaf cells with tall papillae, papillae bifid, stem leaves with $0.7-1 \mathrm{~mm}$ long....

T. bifidum

7. Branch leaf cells with lower papillae, papillae simple, stem leaves with $1.2-1.5 \mathrm{~mm}$ long. T. pseudoprotensum 


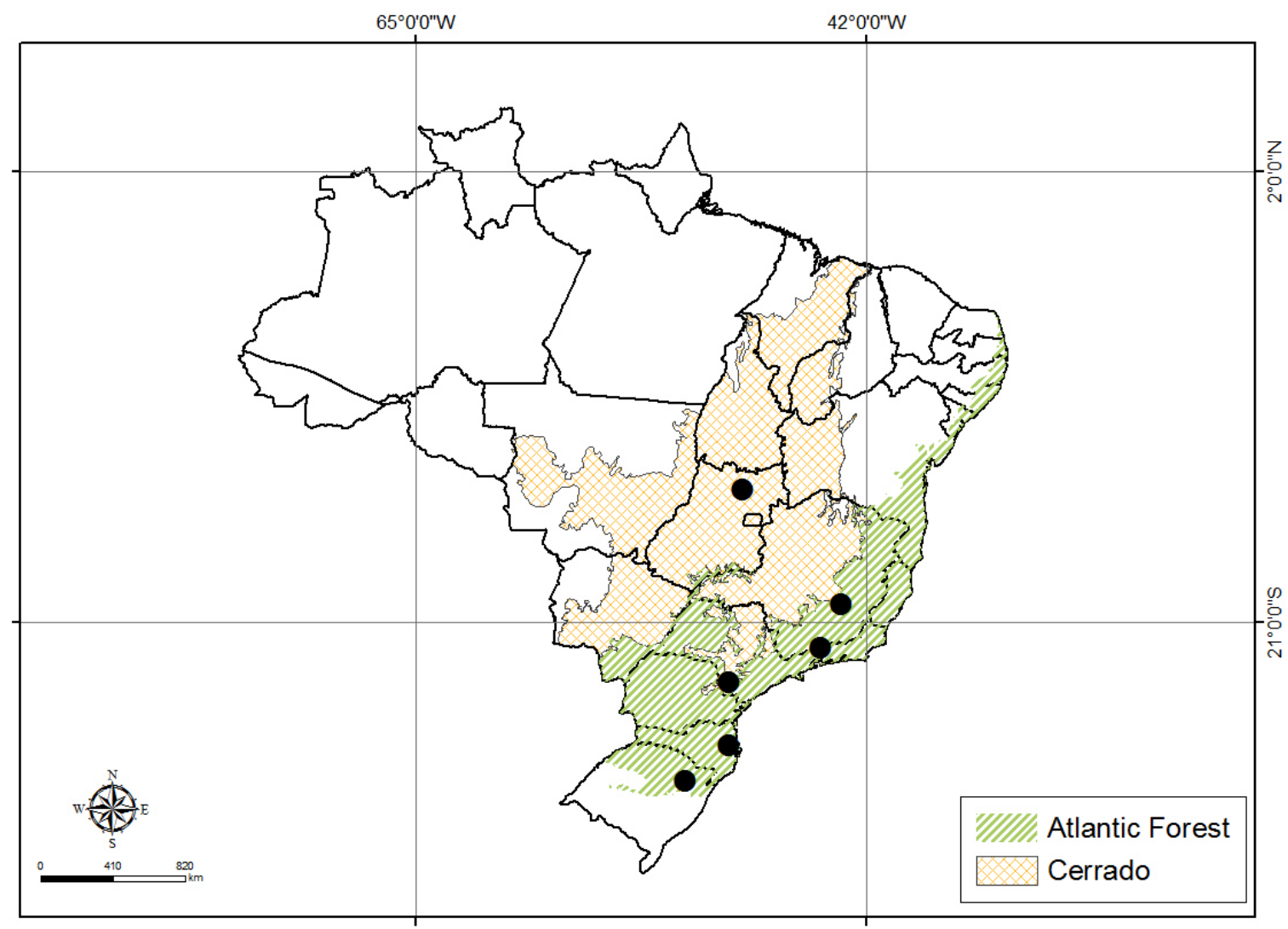

Figure 4. Known geographical distribution of Thuidium bifidum in Brazil, highlighting its occurrence area within the Atlantic Forest and Cerrado.

\section{ACKNOWLEDGMENTS}

Funds were provided by CNPq (Brazilian Government) and University of Brasília (Brazil). We are grateful to Micheline Carvalho-Silva for his assistance and Janet Reid for text revision. We also thank the PNADB program from CAPES and PROTAX program from CNPq. 


\section{Llterature cited}

Anderson, L. E . 1954. Hoyer's solution as a rapid permanent mounting medium for bryophytes. The Bryologist 57: $242-244$.

Bozzola, J.J. \& L. D. Russel. 1998. Electron Microscopy. Principles and Techniques for Biologists. 2nd ed. Jones \& Bartlett, Sudbury.

Buck, W. R. 1998. Pleurocarpous mosses of the West Indies. Memoirs of the New York Botanical Garden 82: 1-400.

Câmara, P. E. A. S. \& E. A. Kellogg. 2010. Morphology and development of leaf papillae in Sematophyllaceae. The Bryologist 113: 22-33.

Churchill, S. P. \& E. L. Linares. 1995. Prodromus bryologiae Novo-Granatensis: introducción a la flora de musgos de Colombia. Parte 2: Grimmiaceae a Trachypodaceae. Biblioteca José Jerónimo Triana 12(2): 831-843.

Costa, D. P. 2009. Briófitas. Pages 13-17. In: J. R. Stehmann, R. C. Forzza, A. Salino, M. Cabral, D. P. Costa \& L. H. Y. Kamino (eds.), Plantas da Floresta Atlântica. Instituto de Pesquisas Jardim Botânico do Rio de Janeiro, Rio de Janeiro.

Costa, D. P. \& A. E. R. Soares. Thuidiaceae. In: Lista de Espécies da Flora do Brasil. Jardim Botânico do Rio de Janeiro. Available: <http://www.floradobrasil.jbrj.gov.br/jabot/floradobrasil>. Access: 10 January 2015.

Costa, D. P. \& D. F. Peralta. Briófitas. In: Lista de Espécies da Flora do Brasil. Jardim Botânico do Rio de Janeiro. Available: <http://floradobrasil.jbrj.gov.br/jabot/floradobrasil/FB128472>. Access: 10 January 2015.

Fonseca, G. A. B. 1985. The vanishing Brazilian Atlantic Forest. Biological conservation 34: 17-34.

Gier, L. J. 1980. A preliminary study of the Thuidiaceae (Musci) of Latin America. Journal of Bryology 11:253-309.

Gradstein, S. R., S. P. Churchill \& N. Salazar-Allen. 2001. Guide to the Bryophytes of Tropical America. Memoirs of The New York Botanical Garden 86: 1-577. 
IUCN. 2001. IUCN Red List Categories and Criteria: Version 3.1. IUCN Species Survival Commission. IUCN, Gland, Switzerland and Cambridge, UK.

Klink, C. A. \& R. B. Machado. 2005. A conservação do Cerrado brasileiro. Megadiversidade 1(1): 147-155

Mittermeier, R. A., P. R. Gil, M. Hoffmann, J. Pilgrim, T. Brooks, C. G. Mittermeier. J. Lamourex \& G. A. B. Fonseca. 2004. Hotspots revisited. CEMEX, Mexico City.

Ribeiro, M. C., J. P. Metzger, A. C. Martensen, F. J. Ponzoni \& M. M. Hirota. 2009. The Brazilian Atlantic Forest: How much is left, and how is the remaining forest distributed? Implications for conservation. Biological Conservation 142: 11441156.

Schiavone, M. M. \& G. M. Suárez. 2007. Las Thuidiaceae en el noroeste de Argentina. Boletín de la Sociedad Argentina de Botánica 42: 211-230.

Sharp, A. J., H. Crum \& P. M. Eckel. 1994. The moss flora of Mexico. Memoirs of the New York Botanical Garden 69(in 2 parts): [i]-vii + 1-580 + I-XVII; [i]-viii + 581$1113+$ I-XVII.

Stheman, J. R., R. C. Forzza, A. Salino, M. Sobral, D. P. Costa \& L. H. Y. Kamino. 2009. Diversidade Taxonômica na Floresta Amazônica. Pages 27- 37. In: J. R. Stheman, R. C. Forzza, A. Salino, M. Sobral, D. P. Costa \& L. H. Y. Kamino (eds.), Plantas da Floreta Atlântica. Instituto de Pesquisas Jardim Botânico do Rio de Janeiro, Rio de Janeiro.

Touw, A. 2001a. A review of Thuidiaceae (Musci) and a realignment of taxa traditionally accommodated in Thuidium sensu amplo (ThuidiumSchimp., Thuidiopsis(Broth.) M. Fleisch, and Pelekium Mitt.) including Aequatoriella gen. nov. and Indothuidium gen. nov. Journal of the Hattori Botanical Laboratory 90: 167-209.

Touw, A. 2001b. A Taxonomic Revisionof the Thuidiaceae (Musci) of Tropical Asia, the Western Pacific and Hawaii. Journal of the Hattori Botanical Laboratory 91: 1-136. 


\title{
5. CAPÍTULO 4
}

A ser submetido para a revista The Bryologist

\section{A Família Thuidiaceae Schimp. (Bryophyta) no Brasil}

\author{
Abel E. R. Soares ${ }^{1}$ \& Paulo E. A. S. Câmara ${ }^{1}$ \\ ${ }^{1}$ Universidade de Brasília, UnB, Depto. de Botânica. Campus Universitário Darcy Ribeiro, Asa \\ Norte, Brasília, DF. Brazil
}

\section{Resumo}

A família Thuidiaceae pode ser caracterizada por uma ampla combinação de caracteres compartilhados por todos os seus gêneros. É representada mundialmente por 72 espécies e 16 gêneros distribuídos em regiões tropicais e temperadas no mundo. Sua circunscrição sempre foi controversa devido ao seu parentesco conflitante com Leskeaceae. Foram estudadas exsicatas provenientes de diversos herbários nacionais e internacionais e o material-tipo de todas as espécies com registro de ocorrência no Brasil. Expedições de coleta foram realizadas em 11 estados brasileiros e no Distrito Federal. O tratamento taxonômico apresenta chaves para identificação dos gêneros e espécies, descrições, fotos, distribuição geográfica e comentários para todas as espécies. Sinônimos e lectotipificações são apresentados, bem como a localização do material-tipo. Estão sendo tratadas 16 espécies e dois gêneros de Thuidiaceae para o Brasil. Duas novas ocorrências para o Brasil e uma nova espécie são apresentadas.

Palavras Chaves: Papilas, Paráfilos, Thuidium, Pelekium. 


\section{Introdução}

Thuidiaceae é uma família cosmopolita que coloniza substratos diversos. É caracterizada por uma ampla combinação de caracteres compartilhados por todos os seus gêneros, tais como: crescimento prostrado, ramificação pinada, dimorfismo entre os filídios do caulídio e das ramificações nas espécies 2-3 pinadas, filídios com células uni- a pluripapilosas, paráfilos simples ou ramificados, papilosos, esporófito do tipo hipnóide (com exostômio e endostômio alterno e bem definidos) e seta frequentemente papilosa (Buck \& Crum 1990; Touw 2001a).

A família é representada por 16 gêneros e ca. de 72 espécies distribuídas em regiões tropicais e temperadas no mundo (Touw 2001a); no neotrópico cerca de 30 espécies (Gradstein et al. 2001). Ocorrem principalmente na Ásia, América do Sul e Central e Oceania, sendo a Ásia seu centro de diversidade.

A circunscrição de Thuidiaceae é controversa. Um dos principais problemas taxonômicos da família envolvia o seu parentesco conflitante com Leskeaceae, o que gerou diversas classificações diferentes ao longo de sua história, pois durante anos foi extremamente comum a transferência de gêneros entre estas duas famílias, resultando em uma enorme confusão taxonômica.

Schimper (1852) foi o primeiro a reconhecer as diferenças taxonômicas do grupo, propondo o estabelecimento do gênero Thuidium, inicialmente com cinco espécies combinadas de Hypnum (Hypnaceae). Schimper também foi o primeiro a descrever Thuidiaceae (Schimper 1860, 1876), porém o autor preferiu reconhecê-la como uma subfamília de Leskeaceae que ficou subdividida em três subfamílias: Leskeeae (Myurella Bruch \& Schimp., Leskea Hedw. e Anomodon Hook. \& Taylor), Pseudoleskeeae (Pseudoleskea Bruch \& Schimp.) e Thuidieae (Heterocladium Bruch \& Schimp. e Thuidium Bruch \& Schimp.).

Schimper (1860) também foi o primeiro a reconhecer que futuramente as pequenas espécies monóicas agrupadas dentro de Thuidium (Pelekium) deveriam ser agrupadas em um gênero próprio. Ele acomodando Thuidium minutulum (Hedw) Schimp. em uma sessão sem nome próprio, ja reconhecendo as diferenças taxonômicas que futuramente levariam estas pequenas plantas monóicas a serem agrupadas dentro do seu próprio gênero (hoje Pelekium Mitt. e anteriormente Cyrtohypnum (Hampe) Hampe \& Lorentz), mas que na época eram agrupadas dentro de Thuidium. 
Kindberg (1897) foi o primeiro a reconhecer Thuidiaceae como família, elevando a subfamília Thuidieae proposta por Schimper (1876) ao status de família (Thuidiaceae) e transferindo alguns gêneros de Leskeaceae para Thuidiaceae. O autor considerou seis gêneros em Leskeaceae (Helicodontium (Mitt.) A. Jaeger, Lescuraea Bruch \& Schimp., Leskea Hedw., Myrinia Schimp., Pterygynandrum Hedw. ex Lindb. e Thelia Sull.) e cinco em Thuidiaceae (Heterocladium, Myurella, Pseudoleskeella Kindb, Pseudoleskea e Thuidium). Porém, sua proposta não encontrou respaldo na comunidade científica, sendo que os pesquisadores da época preferiram manter a classificação proposta por Schimper $(1860,1876)$, com todos os gêneros agrupados apenas na família Leskeaceae e divididos em subfamílias.

A importância dos comentários de Schimper (1860) a respeito das diferenças taxonômicas que futuramente levariam as pequenas espécies monóicas relacionadas a Thuidium minutulum a serem agrupadas dentro do seu próprio gênero (hoje Pelekium), só foi reconhecida anos mais tarde por Warnstorf (1905), que elevou as pequenas espécies monóicas de Thuidium a um gênero próprio chamado de Microthuidium (Limpr.) Warnst.

Baseando-se na proposta de Schimper (1876), Brotherus (1908) reconheceu apenas a família Leskeaceae que foi dividida em cinco subfamílias e 23 gêneros: Anomodonteae (Anomodon, Haplohymenium Dozy \& Molk., Herpetineuron (Müll. Hal.) Cardot e Miyabea Broth.), Heterocladieae (Fauriella Besch. e Heterocladium), Leskeeae (Lescuraea, Leskea, Leskeella (Limpr.) Loeske, Lindbergia Kindb., Pseudoleskea, Pseudoleskeella e Pseudoleskeopsis Broth.), Thelieae (Myurella e Thelieae) e Thuidieae (Actinothuidium Broth., Claopodium (Lesq. \& James) Renauld \& Cardot, Duthiella Müll. Hal. ex Broth., Haplocladium (Müll. Hal.) Müll. Hal., Helodium Warnst., Pelekium, Rauia Austin e Thuidium). Brotherus também incluiu 158 espécies em Thuidium e o subdividiu em cinco subgêneros: Thuidiella Schimp., Thuidiopsis Broth., Tetrastichium Mitt., Euthuidium Lindb., e Abietinella (Mull. Hal.) Broth. Assim como Warnstorf (1905), Brotherus também reconheceu as diferenças taxonômicas das pequenas espécies monóicas agrupadas dentro de Thuidium, mas preferiu ignorar o trabalho de Warnstorf (1905), mantendo as mesmas dentro de Thuidium, porém agrupadas dentro do subgênero Thuidiella.

Posteriormente, Fleischer (1922) manteve Leskeaceae apenas com a subfamília Leskeeae, grupo que ele denominou de Leskeaceae "reais" e acrescentou mais uma subfamília denominada Rhegmatodonteae (Rhegmatodon Brid. ex Rchb.). As quatro 
subfamílias restantes, apesar de serem bem distintas, foram combinadas e transferidas a Thuidiaceae (elevando novamente Thuidiaceae a categoria de família), que ficou organizada em quatro subfamílias e 18 gêneros: Anomodontoideae (Anomodon, Claopodium, Haplocladium, Haplohymenium, Herpetineuron e Miyabea), Euthuidiodeae (Abietinella, Boulaya Cardot, Pelekium, Rauia, Thuidiopsis e Thuidium), Helodioideae (Actinothuidium, Helodium, Hylocomiopsis Cardot e Tetrastichum) e Heterocladiodeae (Heterocladium e Leptopterygynandrum Müll. Hal. ex Broth.).

Brotherus (1925) reconheceu o trabalho de Fleischer (1922), respeitando as estruturas da família e das subfamílias de Thuidiaceae, fazendo algumas pequenas modificações a nível genérico, mas mantendo a essência da classificação de Fleischer (1922) com Thuidiaceae dividida em quatro subfamílias e 17 gêneros. Os gêneros foram classificados principalmente de acordo com o tamanho do gametófito, sexualidade, padrão de ramificação, formato dos filídios periqueciais, peristômio e ornamentação da seta.

Trabalhando apenas com as espécies da América do Norte, Grout (1932) resgatou os conceitos de Leskeaceae propostos por Brotherus (1908), mas reconheceu apenas 12 gêneros divididos em quatro subfamílias: Anomodonteae (Anomodon e Herpetineuron), Leskeae (Leskea, Lindbergia, Pseudoleskea e Pterigynandrum Hedw.), Thelieae (Myurella e Thelia) e Thuidioideae (Claopodium, Helodium, Heterocladium e Thuidium), rebaixando novamente Thuidiaceae ao status de subfamília.

Em sua revisão da família Thuidiaceae para o Japão, Watanabe (1972) adotou o conceito de Thuidiaceae proposto por Brotherus (1925), com pequenas modificações na composição das subfamílias. Ele dividiu Thuidiaceae em três subfamílias da seguinte forma: Anomodontoideae (Anomodon, Haplohymenium, Herpetineuron e Miyabea), Heterocladioideae (Heterocladium e Leptopterygynandrum) e Thuidioideae (Abietinella, Actinothuidium, Boulaya, Bryonoguchia Z. Iwats. \& Inoue, Claopodium, Haplocladium, Helodium, Hylocomiopsis, Pelekium, Rauiella e Thuidium).

Baseando-se em características do esporófito, Crum \& Anderson (1981) fizeram um rearranjo nas famílias Leskeaceae e Thuidiaceae, abolindo os conceitos de subfamílias, ficando Leskeaceae com oito gêneros (Anomodon, Haplohymenium, Lescuraea, Leskea, Leskeella, Lindbergia, Pterigynandrum e Theliae) e Thuidiaceae com sete gêneros (Haplocladium, Helodium, Heterocladium, Myurella, Pseudoleskea, Pseudoleskeella e Thuidium). 
A partir da década de 90 duas propostas (Buck \& Crum 1990; Touw 2001) surgem para explicar as relações de parentesco entre Leskeaceae e Thuidiaceae e dentro desta última família. A primeira proposta, publicada por Buck \& Crum (1990), embora não apresente um estudo cladístico, especula sobre as relações filogenéticas entre Thuidiaceae e Leskeaceae. Para esses autores Thuidiaceae é composta apenas pelos representantes de Thuidioideae e diferencia os gêneros com base, principalmente, no tamanho e sexualiadade das plantas (pequenas monóicas $\mathrm{x}$ grandes dióicas), papilosidade dos filídios e das paráfilas e morfologia da seta e creditam a maior parte das demais variações morfológicas observadas a efeitos ecológicos.

Buck \& Crum (1990), transferiram gêneros para outras famílias e criaram novas famílias para abrigar alguns gêneros. Eles incluíram 18 gêneros em Leskeaceae (Bryobartlettia W. R. Buck, Bryohaplocladium R. Watan. \& Z. Iwats., Claopodium, Fabronidium Müll. Hal., Lescuraea, Leskea, Leskeadelphus Herzog, Leskeella, Leptopterigynandrum, Lindbergia, Mamillariella Lazarenko, Okamuraea Broth., Orthoamblystegium Dixon \& Sakurai, Pseudoleskea, Pseudoleskeella, Pseudoleskeopsis, Rigodiadelphus Dixon e Schwetschkea Müll. Hal.) e retomaram o conceito de subfamília que havia sido extinto por Crum \& Anderson (1981) para Thuidiaceae. Os autores dividiram Thuidiaceae em duas subfamílias: Cyrtohypnoideae (Boulaya, Cyrto-hypnum, Lorentzia Hampe e Rauiella) e Thuidioideae (Abietinella, Thuidiopsis e Thuidium) e transferiram os gêneros Hylocomiopsis e Actinothuidium antes em Thuidiaceae para Hylocomiaceae. Eles transferiram as antigas espécies agrupadas dentro do subgênero Microthuidium / Thuidiella Reimers, pertencentes a Thuidium subfamília Thuidioideae para o gênero Cyrto-Hypnum subfamília Cyrtohypnoideae. Os referidos autores também criaram duas novas famílias: Pterigynandraceae e Helodiaceae. Em Pterigynandraceae acomodaram os seguintes gêneros: Habrodon Schimp., Heterocladium, Iwatsukiella W.R. Buck \& H.A. Crum, Myurella e Pterigynandrum e em Helodiaceae somente o gênero Helodium.

Touw (2001) especula sobre as relações filogenéticas em Thuidiaceae sem também apresentar um estudo cladístico. O referido autor adota uma classificação baseada em múltiplos caracteres, tais como a papilosidade dos filídios, dos paráfilos, o padrão de pinação, o formato dos filídios, o peristômio e a caliptra. $O$ autor limitou Thuidiaceaea a 16 gêneros e 72 espécies e dividiu a família em três grupos informais: "Combinado" (Abietinella, Boulaya, Haplocladium e Rauiella), "Helodioideo" (Actinothuidium, Bryonoguchia, Echinophyllum T.J. O'Brien, Helodium e Hylocomiopsis) 
e "Thuidioideo" (Aequatoriella A. Touw, Bryochenea C. Gao \& G.C. Zhang, Indothuidium A. Touw, Orthothuidium D.H. Norris \& T.J. Kop., Pelekium, Thuidium e Thuidiopsis). Também propôs dois novos gêneros (Aequatoriella e Indothuidium), novas combinações transferindo Cyrto-hypnum para Pelekium e considerou que as características morfológicas entre Thuidiaceae e Leskeaceae são bastantes distintivas para mantê-las separadas.

Por fim, García-Avila et al. (2009) realizou um estudo filogenético com Thuidiaceae e Leskeaceae utilizando somente marcadores de cloroplasto e métodos cladísticos. Os autores concluíram que Thuidiaceae e Leskeaceae não são grupos monofiléticos e que seria necessária uma análise mais ampla, incluindo mais representantes de ambas as famílias, além da inclusão de mais marcadores para tornar seus resultados mais conclusivos. Além disso, pode-se verificar a grande proximidade entre Leskeaceae e Thuidiaceae, bem como a existência de um grupo monofilético "thuidioide" (sensu Touw 2001), formado por Aequatoriella, Bryochenea C. Gao \& G.C. Zhang, Indothuidium, Orthothuidium D.H. Norris \& T.J. Kop., Pelekium, Thuidium e Thuidiopsis).

Os primeiros relatos sobre a ocorrência de espécies de Thuidiaceae na América Latina datam de 1867 e foram publicados em uma lista de musgos coletados em uma viagem transcontinental pelo vale do Amazonas e Montanhas Andinas da América do Sul (Spruce 1867). Mitten (1869), relatou a ocorrência de 24 espécies de Thuidium e outras 30 espécies agrupadas dentro de Thuidiaceae em seu trabalho sobre Musci Austro-Americani. Gier (1980) foi o primeiro e único a propor um estudo sobre as Thuidiaceae na América Latina, listando a ocorrência de 10 gêneros e 96 espécies.

No Brasil, os primeiros relatos de Thuidiaceae ocorreram a partir da publicação de Brotherus (1891), onde foram realizadas coletas nos estados de Minas Gerais e Rio de Janeiro, sendo amostradas 97 espécies de Briófitas, dentre as quais apenas três eram Thuidiaceae.

A partir de Brotherus (1891), alguns trabalhos tais como floras regionais fazem referência a ocorrência de Thuidiaceae para o Brasil. Dentre os mais importantes podemos citar o Catálogo de Musgos Brasileiros (Yano 2011), onde são citadas a ocorrência de quatro gêneros, 27 espécies e uma variedade de Thuidiaceae e a Lista de Espécies da Flora do Brasil (Costa \& Soares 2015), com três gêneros e 16 espécies. 
Sendo assim, o objetivo deste trabalho é realizar uma revisão taxonômica da família Thuidiaceae para o Brasil, apresentando chaves, descrições, comentários, ilustrações, mapas e distribuição geográfica de todas as espécies ocorrente no Brasil.

\section{Material e Métodos}

Foram estudadas 2.650 exsicatas de Thuidiaceae e o material tipo de 60 táxons. Foram visitados os principais herbários do Brasil e do exterior com coleções significativas de Thuidiaceae: BM, INPA, NY, MO, R, RB, SP e UB, além da solicitação de empréstimo para 23 instituições nacionais e internacionais: $A L C B, B H C B, C E N, E$, F, G, H, HEPH, HUCS, IBGE, JE, L, M, MAK, MG, PACA, PC, PH, UFPE, S, UFG, US eW.

Foram selecionadas algumas áreas consideradas prioritárias para coleta de amostras visando abranger os diferentes biomas ocorrentes no Brasil e também a coleta de material fresco para extração de DNA. Foram realizadas coletas em 11 Estados brasileiros: AM, BA, ES, GO, MA, MG, MT, RJ, RR, SC, SP e DF. As coletas se concentraram em áreas com vegetação florestal no Cerrado, Amazônia e Mata Atlântica, pois sabe-se que as espécies de Thuidiaceae são encontradas preferencialmente no interior de ambientes florestais, onde há maior disponibilidades de substrato e umidade. O material coletado foi depositado no herbário UB e duplicatas foram enviadas para instituições parceiras.

A coleta e preparação do material foi realizada de acordo com Yano (1984) e Gradstein et al. (2001). A metodologia de coleta foi aleatória, sendo coletada uma pequena amostra de todo material visível utilizando técnica habitual para o grupo. As amostras foram coletadas com o auxílio de espátula, canivete ou manualmente em todos os substratos disponíveis, colocadas em sacos de papel pardo e secas ao ar livre. Apos a identificação, as amostras foram depositadas no Herbario UB, com duplicatas para instituições parceiras.

As amostras foram analisadas no Laboratório de Criptógamas do Departamento de Botânica da Universidade de Brasília e no Jardim Botânico de Nova Iorque. Foram utilizados microscópio óptico (Nikon E200) e microscópio estereoscópico (Zeiss). Lâminas semi-permanentes foram feitas, quando necessário, com solução de Hoyer (Anderson 1954). Foram observados os gametófitos e quando possível os esporófitos. Pequenas porções dos materiais foram separadas, sendo rehidratadas sobre lâmina de 
vidro com água, dissecados com estiletes e pinças e então as estruturas a serem observadas foram montadas em lâmina e lamínula para uma análise detalhada em microscópio óptico. A identificação das espécies foi feita através do estudo do materialtipo e consulta a bibliografia especializada.

O tratamento taxonômico apresenta chaves para identificação dos gêneros e espécies, descrições, fotos, distribuição geográfica e comentários para todas as espécies. Sinônimos são apresentados, bem como a localização do material-tipo estudado.

A distribuição geográfica foi baseada no material analisado e nas coletas de campo realizadas. Somente uma amostra por localidade foi citada no material analisado.

As abreviações dos estados seguiram as siglas do Instituto Brasileiro de Geografia e Estatística - IBGE.

A terminologia briológica está padronizada de acordo com a versão brasileira do Glossarium Polyglottum Bryologiae (Luizi-Ponzo et al. 2006).

Os mapas de distribuição das espécies foram confeccionados utilizando o software ArcGIS 9.3 (ESRI).

\section{Resultados e Discussão}

Após a revisão nomenclatural da lista, análise dos tipos, estudo das coleções de diferentes herbários do Brasil e do mundo e das amostras coletadass durante os trabalhos de campo, foi possível confirmar a ocorrência de 16 espécies e dois gêneros de Thuidiaceae para o Brasil, ocorrendo em 22 estados e no Distrito Federal. Também podemos confirmar a ocorrência de três espécies endêmicas, sendo duas de ocorrência restrita a Mata Atlântica. Duas espécies são novas ocorrências para o país: Pelekium siphotheca (Müll. Hal.) Touw e Thuidium assimile (Mitt.) A. Jaeger. e uma nova espécie está sendo apresentada Thuidium bifidum Soares, A.E.R. \& Câmara, P.E.A.S. Novas sinonimizações, combinações e lectotipificações também estão sendo propostas.

Inicialmente duas listagens divergiam quanto ao número de espécies e gêneros de Thuidiaceae ocorrentes no Brasil. Yano (2011) cita 27 espécies e cinco genêros, 
enquanto a Lista de Espécies do Brasil (Costa \& Soares 2015) cita a ocorrência de 16 espécies e três gêneros.

Em relação a listagem de Yano (2011), houve uma redução de $42 \%$ no número total de táxons registrados para o país. O gênero Rauiella e suas espécies (Rauiella lagoensis e Rauiella praelonga) foram excluídas da listagem, pois de acordo com os últimos trabalhos de filogenia que envolveram representates de Thuidiaceae (Cox et al. 2010, García-Avila et al. 2009, Soares \& Câmara capítulo 1), o gênero está mais intimamente relacionado com Leskeaceae e não pertence ao agrupamento monofilético que delimitou a família Thuidiaceae. Seis espécies foram sinonimizadas ( $T$. mattogrossense, $T$. patrum, $T$. pinnatulum, $T$. purpureum, $T$. pusillum e $T$. subgranulatum) e seis foram excluídas por se tratarem de registros duvidosos, identificações errôneas ou pela ausência de material testemunho nos herbários visitados.

Em relação a Lista de Espécies do Brasil (Costa \& Soares 2015), houve a exclusão de duas espécies de Thuidium por se tratarem de registros duvidosos ou pela ausência de material testemunho.

Dentro do gênero Pelekium, houve a inclusão de uma nova citação para o Brasil (Pelekium siphotheca), a confirmação da ocorrência de Pelekium muricatulum e Pelekium subpinnatum até então conhecidas somente pelo material tipo coletado no Brasil no século 19 e a exclusão de Cyrto-hypnum frontinoae (Mull. Hal.) Churchill \& Linares, citada por Yano (2011), por se tratar de uma amostra de Pelekium muricatulum. Thuidiopsis furfurosa (Hook. f. \& Wilson in Wilson \& Hooker) M. Fleisch, também foi excluída pois todas as amostras analisadas tratavam-se de Pelekium sparsum.

Quanto ao gênero Thuidium, houve a exclusão de três espécies devido à ausência de material testemunho e por serem conhecidas somente pela espécie-tipo, sendo elas: Thuidium serricola (Müll.Hal.) Paris, Thuidium granulatum (Hampe) A. Jaeger e Thuidium subtamariscinum (Hampe) Broth.

Outras três espécies de Thuidium tratavam-se de táxons com a identificação duvidosa. T. recognitum var. philibertii e $T$. peruvianum eram identificações duvidosas. Após análises das amostras e das espécies-tipo, verificou-se que tratavam-se de representantes de $T$. assimile. Não foram localizadas amostras de $T$. recognitum nos herbários estudados e nas coletas de campo realizadas. 
A revisão da família para o Brasil também resultou na sinonimização de seis táxons. T. mattogrossense foi considerado sinônimo de T. tomentosum; T. patrum foi considerado um representante de Haplocladium (Leskeaceae); T. pinnatulum, T. purpureum e $T$. subgranulatum foram sinonimizadas com $T$. minutulum e $T$. pusillum foi sinonimizada com T. muricatulum.

Também foi realizada lectotipificação para as espécies: Pelekium scabrosulum, Thuidium antillarum e Thuidium acuminatum.

No Brasil são reconhecidos dois gêneros e 16 espécies de Thuidiaceae, o que representa aproximadamente $52 \%$ do total de espécies desta família registradas para a América tropical e $22 \%$ para o mundo.

Quanto ao padrão de distribuição das espécies brasileiras, três (18\%) são endêmicas do Brasil, cinco (32\%) são Neotropicais, três (18\%) são de ocorrência nas Américas e cinco (32\%) apresentam outros tipos de distribuição. As regiões Sul (27\%) e Sudeste (39\%) foram as mais ricas e representativas em termos de riqueza, seguidas pelo Norte (17\%), Centro-Oeste (12) e Nordeste (5\%). Este padrão de distribuição concentrada nas regiões sul/sudeste, com $66 \%$ de toda a riqueza de Thuidiaceae já era esperado, tendo em vista que a Mata Atlântica, bioma predominante na região, de acordo com Costa (2009) é a mais rica região em termos de diversidade de Briófitas no Brasil.

Analisando o padrão de distribuição por Bioma, também podemos concluir que a Mata Atlântica é o bioma que apresenta a maior riqueza de Thuidiaceae, concentrando $66 \%$ das espécies registradas, seguida pela Amazônia (18\%), Cerrado (13\%), Caatinga e Pantanal (1\%), não foram registradas ocorrências para os Pampas (Figura 1 e Figura 2). A Lista de Briófitas das Espécies da Flora do Brasil (Costa \& Peralta 2015) também coloca a Mata Atlântica como o centro de diversidade e endemismo de Briófitas no Brasil, concentrando aproximadamente $49 \%$ de toda a riqueza, isso se deve provavelmente a diversidade ecológica do Domínio Atlântico, cuja a região nuclear do Domínio corresponde a uma série de ecossistemas quase contínuos ao longo da costa brasileira, ocorrendo desde o Rio Grande do Norte ao Rio Grande do Sul (Stehmann et al. 2009).

De acordo com Stehmann et al. (2009), diferentemente da maioria das florestas tropicais, a Floresta Atlântica possui um conjunto de variáveis geográficas e climáticas que a tornam singular, tais como: amplitude latitudinal, variação longitudinal, variação 
altitudinal desde o nível do mar até $2.890 \mathrm{~m}$ nas serras do Complexo da Mantiqueira e diferenças na pluviosidade, que varia de locais sub-úmidos, com estações secas no nordeste brasileiro (baixa riqueza de Thuidiaceae), até áreas hiper-úmidas, acima dos $3.600 \mathrm{~mm}$ anuais, na Serra do Mar (alta riqueza). Todos estes fatores, em especial as altas altitudes e as áreas úmidas e hiper-úmidas, são ambientes altamente propícios para a elevada riqueza de Thuidiaceae na Mata Atlântica, tendo em vista que boa parte dos táxons ocorrentes nesta área ocorrem em regiões altas, úmidas e com temperaturas moderadas a baixas.

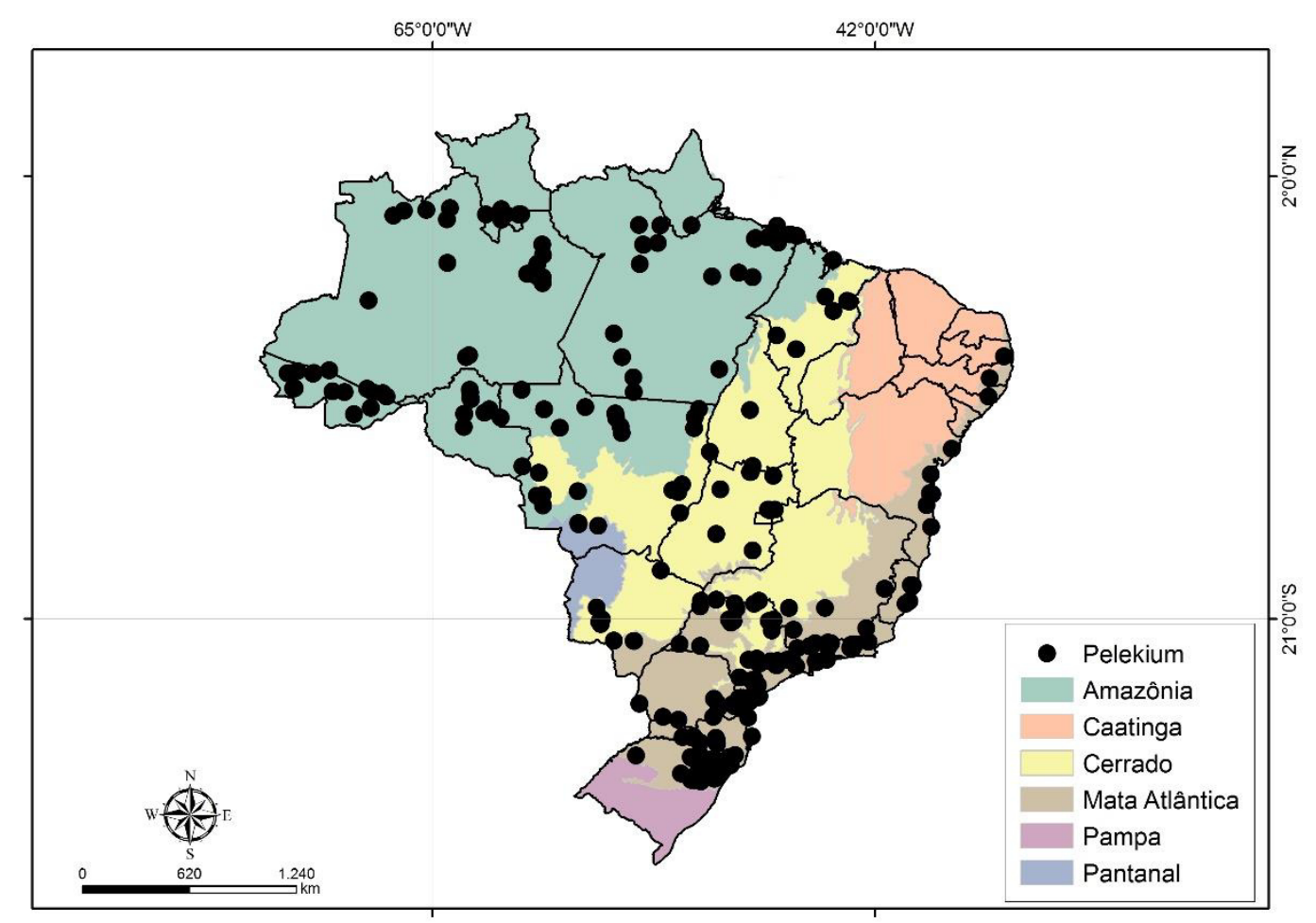

Figura 1: Locais, Estados e Biomas de ocorrência do gênero Pelekium no Brasil. 


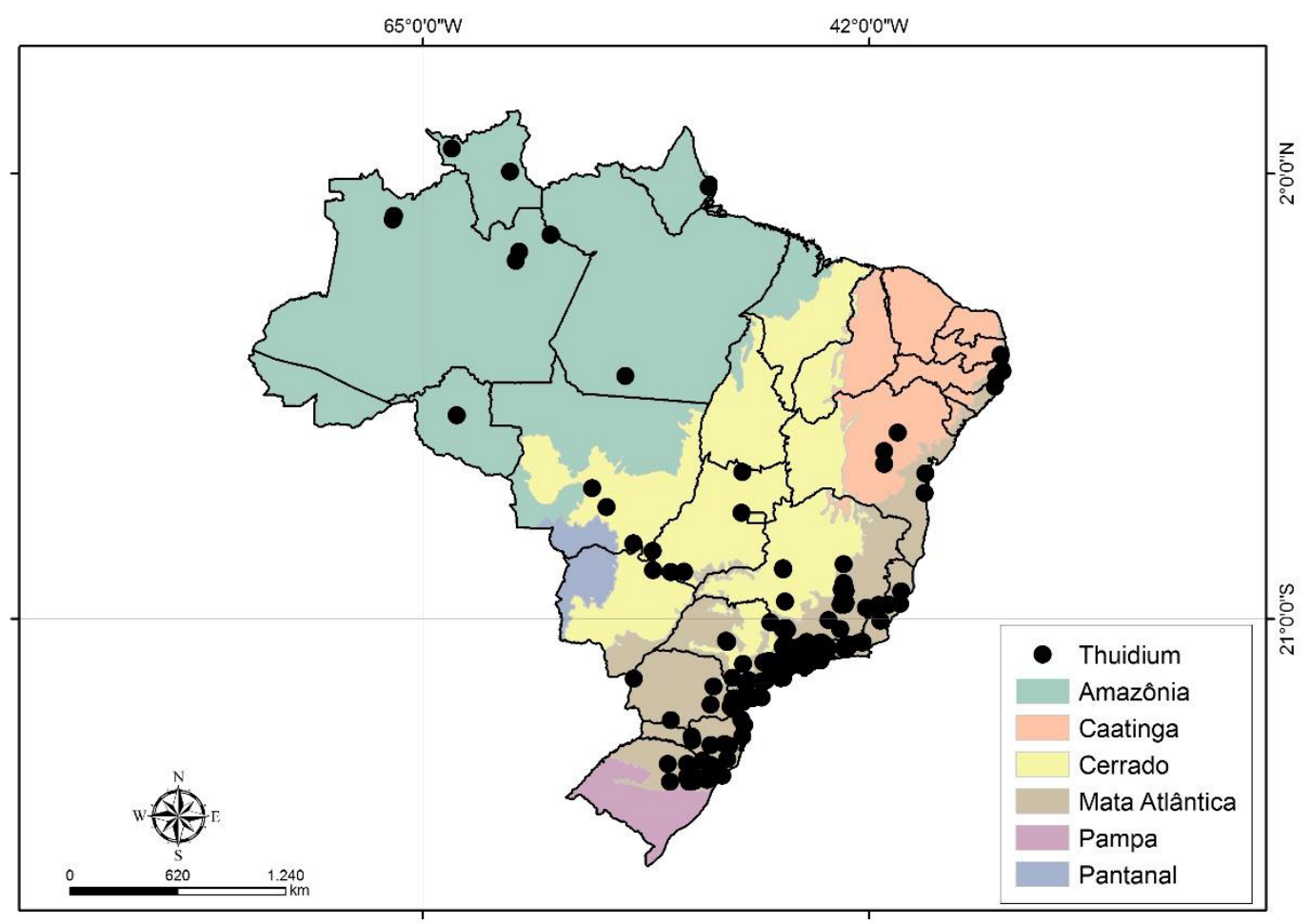

Figura 2: Locais, Estados e Biomas de ocorrência do gênero Thuidium no Brasil.

Analisando separadamente o padrão de distribuição dos dois gêneros ocorrente no Brasil, Pelekium apresenta uma distribuição mais homogênea entre os três principais biomas, com 55\% na Mata Atlântica, 29\% na Amazônia e 19\% no Cerrado (Figura 1) e também uma maior amplitude altitudinal (Figura 3), ocorrendo de forma mais homogênea entre diferentes altitudes, demonstrando a maior amplitude ecológica deste gênero e sua capacidade de ocupar diferentes gradientes altitudinais. Thuidium apresenta uma distribuição predominante na Mata Atlântica com 83\% das ocorrências, enquanto Cerrado (11\%) e Amazônia (5\%) apresentam baixas taxas de ocorrência (Figura 2), evidenciando a preferência deste gênero por áreas com temperaturas mais baixas e altitudes mais elevadas (Figura 4), como por exemplo as encontradas na Serra da Mantiqueira, Serra Geral e Serra do Mar, locais com elevada riqueza do gênero Thuidium. De um modo geral, as espécies de Thuidium não possuem ampla distribuição altitudinal, dificilmente ocorrendo próximo ao nível do mar ou em regiões de terra baixas como as encontradas na Amazônia. 


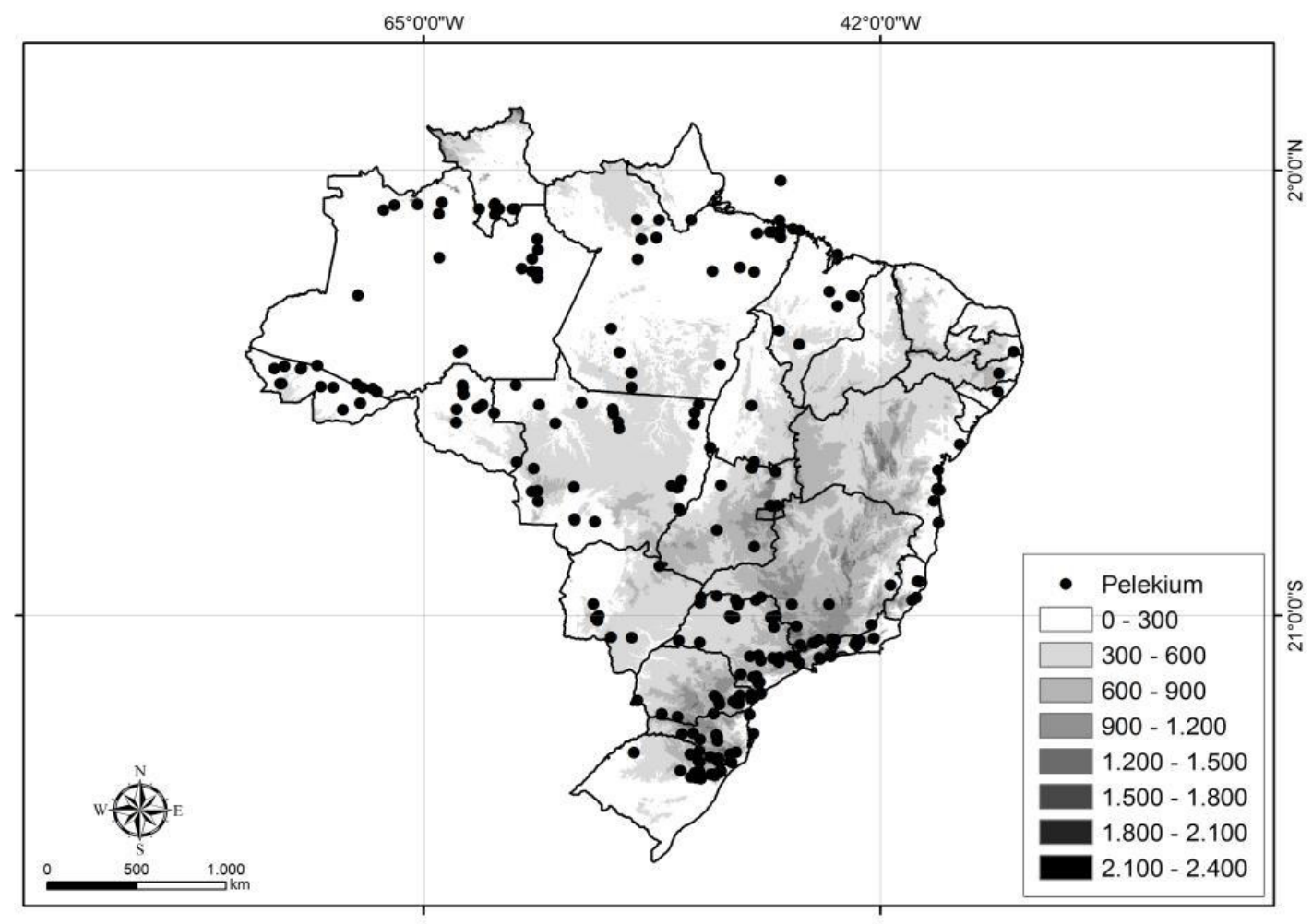

Figura 3: Variação altitudinal do gênero Pelekium no Brasil.

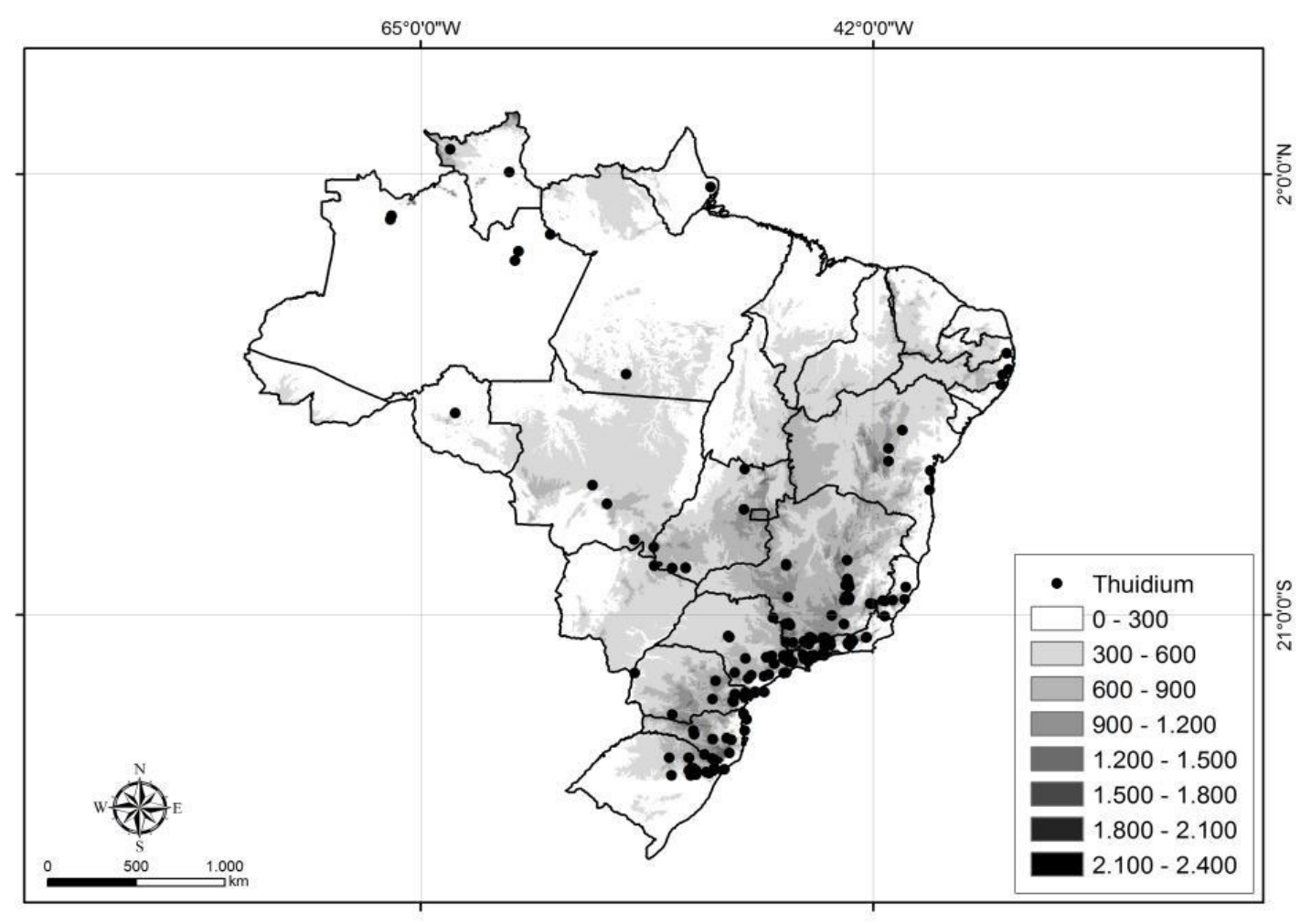

Figura 4: Variação altitudinal do gênero Thuidium no Brasil. 


\section{Tratamento Taxonômico}

\section{THUIDIACEAE Schimp.}

Thuidiaceae Schimp. Syn. Musc. Eur. 493. 1860. - Tipo-gênero: Thuidium Bruch \& Schimper in B.S.G.

Plantas pequenas a robustas, $3-20 \mathrm{~cm}$ de compr., formando tapetes, às vezes extensos e vistosos, verde, amarelada ou dourada. Caulídios rastejantes ou ascendentes, às vezes arqueados, regularmente ou irregularmente 1-3 pinados; medula central presente, caulídios em secções transversais sem hialoderme, com uma pequena camada de células de paredes espessas, bordeadas por células largas de paredes delgadas; paráfilos presentes, freqüentemente abundantes, em especial nos caulídios, filamentosos ou folhosos, polimórficos, uniseriados ou pluriseriados, simples ou ramificados, 15-300 $\mu \mathrm{m}$ de compr., 2-40 células, células medianas quadradas, subquadradas, oblatas, retangulares a longo-retangulares, unipapilosas ou pluripapilosas, células apicais truncadas, arredondadas ou agudas, papilosas; pseudoparáfilos folhosos, raro filamentosos; pêlos axilares usualmente com 1 (-2) célula basal, verdeclara ou marrom e (-1) 2-3 (-5) células distais amareladas ou hialinas e alongadas. Filídios dos caulídios e das ramificações frequentemente diferenciados. Filídios dos caulídios adpressos, imbricados, eretos ou ereto-patentes quando secos, eretos a patentes quando úmidos, ovados, obovados, deltóides a deltóide-lanceolados, 0,3-3mm de compr., acuminados, longo-acuminados ou pilíferos, às vezes cordados ou decurrentes, às vezes côncavos e plicados; margens crenulada-papilosas ou serruladapapilosas, planas ou recurvadas; costa forte, simples, percurrentes a sub-percurrentes, faces abaxiais constantemente proeminentes, às vezes ornamentadas na base; células medianas quadradas, hexagonais, oblongas, isodiamétricas ou retangulares, paredes celulares delgadas ou incrassadas, unipapilosas ou pluripapilosas em ambas as faces ou somente na abaxial; células apicais truncadas, arredondadas ou agudas, comumente mais alongadas, papilosas ou lisas; células alares não diferenciadas ou raro fracamente diferenciadas. Filídios da primeira ramificação similares aos filídios do caulídio. Filídios das ramificações secundárias e terciárias menores, encurvados, adpressos, imbricados, eretos ou ereto-patentes quando secos, eretos a patentes quando úmidos, ovados, obovados ou deltóides, acuminados, obtusos ou agudos; 
margens crenuladas a serrulada-papilosas, freqüentemente planas; costa simples, subpercurrentes; células medianas isodiamétricas, sub-quadradas, retangulares, romboidais ou ovais, paredes celulares delgadas ou incrassadas, unipapilosas ou pluripapilosas em ambas as faces ou somente na abaxial; células apicais truncadas e com papilas ou às vezes aguda a obtusa e lisa; células alares não diferenciadas. Monóicas ou Dióicas. Periquécios conspícuos, eretos, lanceolado-oblongos, acuminados, longo-acuminados a filiformes, côncavos, às vezes plicados; margens serruladas, crenuladas ou sub-inteiras, ciliadas ou não, planas ou recurvadas; costa simples, às vezes inconspícuas e ausentes; células retangulares, oblongas, geralmente alongadas e lisas. Setas alongadas, avermelhadas ou alaranjadas, lisas ou rugosas; cápsulas inclinadas, horizontais ou sub-eretas, lisas, assimétricas, cilíndricas ou oblonga-cilindrícas; células do exotécio não colenquimatosas; ânulos diferenciados; opérculos cônicos ou rostrados. Peristômios duplos; exostômios amarelados ou alaranjados, lanceolados, bordeados, com ombros, estriados abaixo, papilosos acima, trabeculados; endostômios lanceolados, papilosos, quilhados, com as membranas basais altas; cílios presentes em grupos de 1-3. Esporos esféricos, papilosos ou lisos. Caliptras cuculadas, lisas, raro com pêlos.

Thuidiaceae é uma família que possue características morfológicas incomuns à maioria das famílias de musgos pleurocárpicos, como a presença de paráfilos com papilas e padrão de pinação vistoso, facilmente identificável em campo. É representada mundialmente por 16 gêneros e 72 espécies distribuídas pelas regiões temperadas e tropicais (Buck \& Crum 1990; Churchill \& Linares 1995, Touw 2001a).

A família pode ser caracterizada por uma larga combinação de caracteres: ramificação regularmente pinada (1-3 pinada); paráfilos nos caulídios, na maioria das espécies abundantes; filídio do caulídio freqüentemente deltóide ou deltóide-ovado, ápice acuminado ou longo-acuminado, filídio geralmente plicado; costa simples; células dos filídios ornamentadas por papilas; dimorfismo dos filídios da ramificação nas espécies 2-3 pinadas, em relação aos filídios dos caulídios; cápsula ovóide ou cilíndrica e peristômio tipicamente hypnóide (Touw 2001b).

Durante muitos anos Thuidiaceae foi considerada uma subfamília de Leskeaceae. Hoje evidências filogenéticas e morfológicas sustentam a separação de ambas as famílias em grupos distintos. Leskeaceae possui algumas características ausentes em 
Thuidiaceae tais como: paráfilos lisos, ramificações irregulares, cápsula ereta e filídios do caulídio e da ramificação sem diferenciação.

De acordo com Buck \& Vitt (1986), Thuidiaceae é uma família do hemisfério sul, mas muitos dos seus taxas basais são da Laurasia, com o centro de diversidade florística na região Sino-Japonesa. É amplamente distribuída em todos os continentes com exceção da Antártida, ocorrendo das florestas tropicais às florestas temperadas, do nível do mar a altas altitudes, como por exemplo Himalaia e Cordilheira dos Andes. Muitos gêneros e espécies são endêmicos da Ásia e da América do Sul, sendo estes os locais de maior diversidade (Touw 2001a). Todavia, Oceania e partes da América Central e do Norte também apresentam diversidade significativa. Espécies de Thuidiaceae crescem geralmente na camada inferior de ambientes mésicos ou florestas úmidas (Touw 2001a), poucas espécies são encontradas em ambientes secos. Colonizam diferentes substratos, ocorrendo sobre rochas, solos e troncos, em especial no interior de florestas.

\section{Chave para os gêneros}

1. Paráfilos não ramificados, 2-10 células compr.; 1-2-pinada 1. Pelekium

1. Paráfilos ramificados, $10-40$ células compr.; 2-3-pinada

2. Thuidium

\section{PELEKIUM Mitt.}

Pelekium Mitt., J. Linn. Soc., Bot. 10: 176. 1868, emend. Touw, J. Hattori Bot. Lab. 90: 203. 2001, nom. cons. - Tipo: Pelekium velatum Mitt., J. Linn. Soc., Bot. 10: 176. pl. 6: f. c. 1868. SAMOA. Tutuila, T Powell 14 (lectotype: NY!, isotypes: BM!, H!, L!, MO!).

Thuidium Schimp. sect. Minutula Bruch \& Schimp, Bryol. Eur. 5: 161 (fasc. 49-51 Mon. 5). 1852. Thuidium Schimp. Subg. Microthuidium Limpr. Laubm. Deutschl. 2: 822. 1895. Thuidium Hedw. sect. Microthuidium (Limpr.) Kindb., Eur. N. Amer. Bryin. 1: 54. 1897, nom. ileg. Microthuidium (Limpr.) Warnst., Krypt.-FI. Brandenburg, Laubm. 677. 1905. Thuidium Schimp. subg. Thuidiella Schimp. ex Broth., Nat. Pflanzenfam. I(3): 1012. 1908, nom. illeg. - Tipo: Thuidium minutulum 
(Hedw.) Schimp., Bryol. Eur. 5: 161. 481 (fasc. 49-51 Monogr. 5. 1). 1852. Tipo: USA. Pensilvania, legit? (holotype: G!).

Hypnum Hedw. subg. Cyrto-hypnum Hampe, Flora 50(5): 78. 1867. Hypnum Hedw. sect. Cyrto-hypnum Hampe, Ann. Sci. Nat., Bot. Sér. 5, 5: 300-342. 1866, nom. nud. Cyrto-hypnum (Hampe) Hampe \& Lorentz, Bot. Zeitung (Berlin) 27(28): 455. 1869. - Tipo: Cyrto-hypnum brachythecium Hampe \& Lorentz, Bot. Zeitung (Berlin) 27: 455. 1869. EQUADOR. Loja, H. Krause s.n. (holotype: BM).

Lorentzia Hampe, Flora 50: 75. 1867. - Tipo: Lorentzia longirostris Hampe. Nuovo Giorn. Bot. Ital. 4: 288. 1872. MALÁSIA. Sarawak, O. Beccari 24 (holotype: BM!).

Plantas pequenas, ca. de $3-10 \mathrm{~cm}$ compr., formando diminutos tapetes laxos, verdes a verde-amareladas. Caulídios rastejantes, regularmente 1-2 pinado; medula central presente, caulídios em secções transversais sem hialoderme, com uma pequena camada de células de paredes espessas, bordeadas por células largas de paredes delgadas; paráfilos abundantes ou escassos nos caulídios, escassos ou

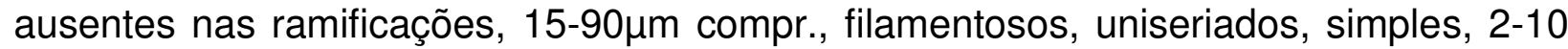
células, células medianas quadradas ou retangulares, papilosas, células apicais truncadas ou agudas, papilosas; pseudoparáfilos folhosos, ovado-lanceolados a deltóides; pêlos axilares com 1 (-2) célula basal pequena, verde-clara ou marrom e 1-2 célula distal hialina. Filídios dos caulídios frequentemente encurvados, imbricados ou eretos quando secos, eretos a ereto-patentes quando úmidos, ovados, deltóides ou ovado-deltóides, 0,3-1 mm compr., acuminados, sub-decurrentes, plicados ou lisos; margens comumente crenulada-papilosas ou serrulada-papilosas, recurvadas abaixo, planas acima ou inteiramente planas; costa sub-percurrente, frequentemente $2 / 3$ do tamanho do filídio, às vezes projetando um espinho no ápice, face abaxial fracamente ou fortemente proeminente, às vezes ornamentada na base; células medianas quadradas, retangulares ou isodiamétricas, $3-12 \mu \mathrm{m}$ compr., paredes delgadas ou moderadamente espessas e incrassadas, pluripapilosas ou unipapilosas, papilas dispostas (quando pluripapilosas) na periferia do lúmen celular, papilas em ambas as faces, abaxial com ornamentação mais acentuada; células apicais truncadas ou arredondadas, às vezes agudas, papilosas ou lisas; células alares não diferenciadas. Filídios da primeira ramificação similares aos filídios dos caulídios. Filídios das ramificações secundárias diferenciados no tamanho e forma, menores, ovados, 
oblongos ou ovado-oblongos, 0,2-0,5mm compr., comumente obtusos, às vezes curtoacuminados, côncavos, não plicados; margens crenulada-papilosas ou serruladas, planas ou recurvadas na base; costa sub-percurrente, 1/2 a 2/3 do tamanho do filídio, às vezes projetando um pequeno espinho no ápice; células medianas isodiamétricas, ovais a romboidais, $3-8 \mu \mathrm{m}$ compr., delgadas ou moderadamente incrassadas, frequentemente pluripapilosas, raro unipapilosas, papilas dispostas (quando pluripapilosas) na periferia do lúmen celular, papilas em ambas as faces; células apicais truncadas, raro agudas ou obtusas; células alares não diferenciadas. Monóicas ou Dióicas. Periquécios eretos, lanceolados ou ovado-lanceolados, acuminados ou longo-acuminados a filiformes, plicados; margens serruladas, ciliadas ou não, planas ou recurvadas na base; costa ampla, às vezes bem definida; células oblongas, alongadas, lisas ou levemente papilosas. Setas alongadas, delgadas, avermelhadas, 1,0-2,8cm compr., lisas ou rugosas; cápsulas sub-eretas a horizontais, 0,8-2,6mm compr., lisas, assimétricas, cilíndricas a obovóide-ovóide; células do exotécio curtoretangulares, quadradas ou isodiamétricas, paredes delgadas ou incrassadas; ânulos pouco diferenciados; opérculo cônico, às vezes obliquo-rostrado. Peristômios com exostômios lanceolados, bordeados, estriados abaixo, às vezes levemente papilosos acima, trabeculados; endostômios lanceolados, quilhados, com a membrana basal alta; cílios em grupos de 1-2, bem desenvolvidos ou vestigiais. Esporos esféricos, 7-20 $\mu \mathrm{m}$, levemente papilosos. Caliptra cuculada, lisa.

O gênero Pelekium possui cerca de 30 espécies na região Neotropical das quais oito ocorrem no Brasil. Crescem sobre solos, troncos caídos, bases de árvores e rochas. Possui distribuição predominantemente tropical, ocorrendo na América do Sul, África, Ásia, Pacifico, Austrália, mas também podem ser encontrados em partes extratropicais e temperadas da Europa, Ásia, Américas, Macaronésia e África do Sul (Touw 2001a).

Caracterizam-se por seu tamanho diminuto (quando comparadas a Thuidium); paráfilo simples, não ramificados e filídios com células pluripapilosas ou unipapilosas em ambas as faces. Nas espécies pluripapilosas (maioria), as papilas encontram-se dispostas na periferia do lúmen celular, o que por vezes (em material antigo e mal conservado) torna difícil sua visualização. Nas espécies unipapilosas a papila encontrase no centro do lúmen celular. De acordo com Buck (1998), a maneira mais fácil de 
reconhecer Pelekium (em relação aos outros gêneros) é pelo seu tamanho diminuto e característico, tornando possível o reconhecimento do gênero a olho nu.

Desde os primeiros estudos sobre Thuidiaceae (Schimper 1860), as pequenas espécies monóicas, hoje conhecidas como Pelekium e anteriormente como Cyrtohypnum, eram comumente tratadas dentro do gênero Thuidium ou como um subgênero. Os sistemas de classificação de Fleischer (1922) e Brotherus (1925) foram os mais aceitos pela grande maioria dos pesquisadores na classificação de Thuidiaceae durante o século XX. Eles dividiram Thuidiaceae em quatro sub-famílias, com as pequenas espécies monóicas (hoje Pelekium) agrupadas dentro da sub-família Euthuidioideae, gênero Thuidium subg. Thuidiella.

Fleischer (1922) e Brotherus (1925) já reconheciam o gênero Pelekium (ex.: $P$. bifarium (Bosch \& Sande Lac.) M. Fleisch. e $P$. velatum Mitt) de uma maneira distinta da atual, constituído de poucos indivíduos, com a grande maioria das espécies que hoje são reconhecidas como Pelekium agrupadas dentro de Thuidium. Pelekium (sensu Brotherus) era composto por espécies monóicas e dióicas, não particularmente similares, que compartilhavam seta rugosa e caliptra campanulada (Touw 2001a).

Durante muitos anos diversos autores mantiveram as pequenas espécies monóicas dentro de Thuidium (ex.: Bartram 1939, 1949; Breen 1963; Crum 1973; Crum \& Anderson 1981; Crum \& Steere 1957; Grout 1932), com destaque para Thuidium minutulum (Hedw.) Schimp., T. involvens (Hedw.) Mitt. e T. schistocalyx (Müll. Hal.) Mitt, hoje típicos representantes de Pelekium.

Em uma tentativa de resolver os problemas de parentescos entre as Thuidiaceae, Buck \& Crum (1990) retiraram as pequenas espécies monóicas de Thuidium e realocaram no gênero Cyrto-hypum proposto por Hampe em 1869, mas que nunca tinha sido amplamente aceito e utilizado. Buck \& Crum (1990) ainda estabelecaram as caracteristicas que definiriam o grupo quando comparadas a Thuidium: pequena estatura, monóicas, pêlos axilares com duas células, paráfilos esparsos nos caulídios e não ramificados, células dos filídios papilosas em ambas as faces e seta comumente rugosa.

Com a proposta de Buck \& Crum (1990), dois gêneros intimamente relacionados do ponto de vista morfológico (Cyrto-hypnum e Pelekium) passaram a existir, ambos compartilhavam as seguintes caracteristicas: filídios com papilas em ambas as faces, pêlos axilares com duas células, presença frequente de seta rugosa e pequena 
estatura. Pelekium diferia de Cyrto-hypnum apenas por apresentar indivíduos monóicos e dióicos (enquanto Cyrto-hypnum apenas monóicos) e caliptra mitrada (Buck \& Crum 1990). Todavia, alguns indivíduos de Cyrto-hypnum apresentam caliptra levemente mitrata quando imaturos (Buck \& Crum 1990).

Hedenäs (1997), já adotando a classificação proposta por Buck \& Crum (1990), não investigou a monofilia de Cyrto-hypnum, mas concluiu que Pelekium e Cyrtohypnum estavam intimamente relacionados e alinhados dentro de Thuidium.

Por fim, Touw (2001a) redefiniu os limites da família e acomodou todas as espécies monóicas de Thuidium subg. Thuidiella, posteriormente reconhecidas por Buck \& Crum (1990) como Cyrto-hypnum no gênero Pelekium. O referido autor reconheceu que não existiam diferenças morfológicas suficientes que mantivessem a separação de Cyrto-hypnum e Pelekium e propôs uma nova combinação, utilizando como nome válido Pelekium. Foi proposta ainda as seguintes caracteristicas para separar Pelekium de Thuidium: tamanho diminuto, pêlos axilares com uma simples célula distal, paráfilos simples, filídios periqueciais lisos ou levemente plicados e seta curta. Outras diferenças são menos constantes como: paráfilos com ápice agudo, costa do filídio do caulídio pouco ou não ornamentada, filídios adaxiais com as células medianas fortemente ornamentadas e seta ornamentada (Touw 2001a).

\section{Chave para as espécies}

1. Plantas dióicas; filídio do caulídio cordado, 0,7-1mm compr., ápice falcado; seta lisa 7. P. sparsum

1. Plantas monóicas; filídio do caulídio deltóide, 0,3-0,5mm compr., ápice acuminado ou curto acuminado; seta rugosa ou lisa

2. Filídios da região mediana unipapilosos

3. Paráfilo com a célula apical truncada. 3. P. muricatulum

3. Paráfilo com a célula apical aguda

4. Paráfilo com células quadradas, ca. de 1:1, plantas 2-pinada. 6.P. siphoteca

4. Paráfilo com células retangulares a longo-retangulares, ca. de 2-4:1, plantas 1-pinada, 
2. Filídios da região mediana pluripapilosos

5. Plantas 1-pinada

6. Paráfilos escassos no caulídio; seta rugosa 1. P. involvens

6. Paráfilos abundantes no caulídio; seta lisa 2.P. minutulum p.p

5. Plantas 2-pinada

7. Paráfilo com 2-3 células, incospicuamente papilosas; irregularmente 2pinado; seta lisa.

2. P. minutulum p.p

7. Paráfilo com 3-10 células, conspicuamente papilosas; regularmente 2pinado; seta rugosa

8. Filídios da ramificação patente e encurvado quando seco, laxamente disposto; paráfilos com 3-5 células; filídios periqueciais não ciliados

4 .P. scabrosulum

8. Filídios da ramificação imbricado ou adpresso quando seco; paráfilos com 5-10 células; filídios periqueciais ciliados

5. P. schistocalyx

1. Pelekium involvens (Hedw.) A. Touw, J., Hattori Bot. Lab. 90: 203. 2001. Leskea involvens Hedw. Sp. Musc. Frond. 218. 1801. Hypnum involvens (Hedw.) P. Beauv., Prodr. Aethéogam. 65. 1805. Thuidium involvens (Hedw.) Mitt., J. Linn. 12: 575. 1869. Cyrto-hypnum involvens (Hedw.) W.R. Buck \& H.A. Crum, Contr. Univ. Michigan Herb.17: 66. 1990. - Tipo: JAMAICA. sine leg. (isotype: NY!).

Thuidium exilissimum Müll. Hal., Hedwigia 37: 264. 1898. - Tipo: JAMAICA. Kingston, O. Hansen s.n. (isotype: NY!).

Fig. 5 e Fig. 6.

Plantas pequenas, ca. de $2-4 \mathrm{~cm}$ compr., delgadas, verdes a verde-amareladas. Caulídios 1-pinado, ramificações com 2-4mm compr.; paráfilos escassos nos caulídios, ausentes nas ramificações, 25-40 $\mu$ m compr., 2-6 células, células medianas quadradas, ca. de 1:1, 5-8um compr., fracamente papilosas, células apicais truncadas. Filídios dos caulídios e das ramificações similares; filídios dos caulídios encurvados quando secos, patentes quando úmidos, ovados a ovado-deltóides, 0,3-0,5x0,1-0,15mm, curtoacuminados, côncavos; margens crenulada-papilosas, planas ou recurvadas nas 
metades inferiores; costas simples, ca. de 2/3 do tamanho dos filídios ou terminando muito próxima aos ápices, faces abaxiais fracamente proeminentes; células medianas quadradas ou isodiamétricas, 1:1, ca. de 7-9um compr., pluripapilosas (2-4), papilas dispostas na periferia do lúmen celular; células apicais alongadas, truncadas, papilosas. Filídios das ramificações encurvados quando secos, patentes quando úmidos, laxamente dispostos, oblongo-deltóides, 0,2-0,4×0,1-0,15mm, obtusos ou agudos, côncavos; margens crenulada-papilosas, planas ou recurvadas nas metades inferiores; costas ca. de 2/3 do tamanho dos filídios ou terminando muito próximo aos ápices; células medianas quadradas a isodiamétricas, 1:1, ca. de 5-7 $\mu \mathrm{m}$ compr., delgadas, pluripapilosas (2-4); células apicais truncadas. Monóicas. Periquécios lanceolados, ca. de 1,2mm compr., longo-acuminados; margens serruladas acima, inteiras abaixo, planas; costas preenchendo os ápices; células oblongas, lisas. Setas 11,2cm compr., rugosas; cápsulas sub-eretas ou horizontais, $1 \mathrm{~mm}$ compr., curtocilíndricas; células dos exotécios curto-retangulares, incrassadas; opérculos rostrados. Peristômios com exostômios estriatos abaixo, levemente papilosos acima; endostômios com os segmentos levemente papilosos. Esporos 10-12 $\mu \mathrm{m}$.

Pelekium involvens caracteriza-se pelo gametófito 1-pinado com os filídios fortemente encurvados quando secos e dispostos laxamente no caulídio. Os filídios do caulídio e da ramificação são monomórficos, sem diferenciação. Os paráfilos são escassos sobre o caulídio e ausentes na ramificação. A sete é rugosa e os filídios periqueciais não possuem cílios.

Possui ampla distribuição, amplitude latitudinal e altitudinal, ocorrendo em diversas localidades, muitas destas inseridas dentro de unidades de conservação. Sendo assim, seu status de conservação foi considerado Pouco Preocupante (LC) de acordo com os critérios da IUCN (2001).

Crescem sobre o solo, rochas e troncos em decomposição, principalmente em ambientes secos ou mésicos, menos frequente em ambientes úmidos, 100-1200m alt.

Ocorrem na América do Sul, do Norte e Central.

Distribuição geográfica: AC, AM, BA, DF, GO, MA, MG, MT, MS, PA, PR, RO, RR e SP.

Domínios Fitogeográficos: Amazônia, Cerrado, Mata Atlântica e Pantanal. 


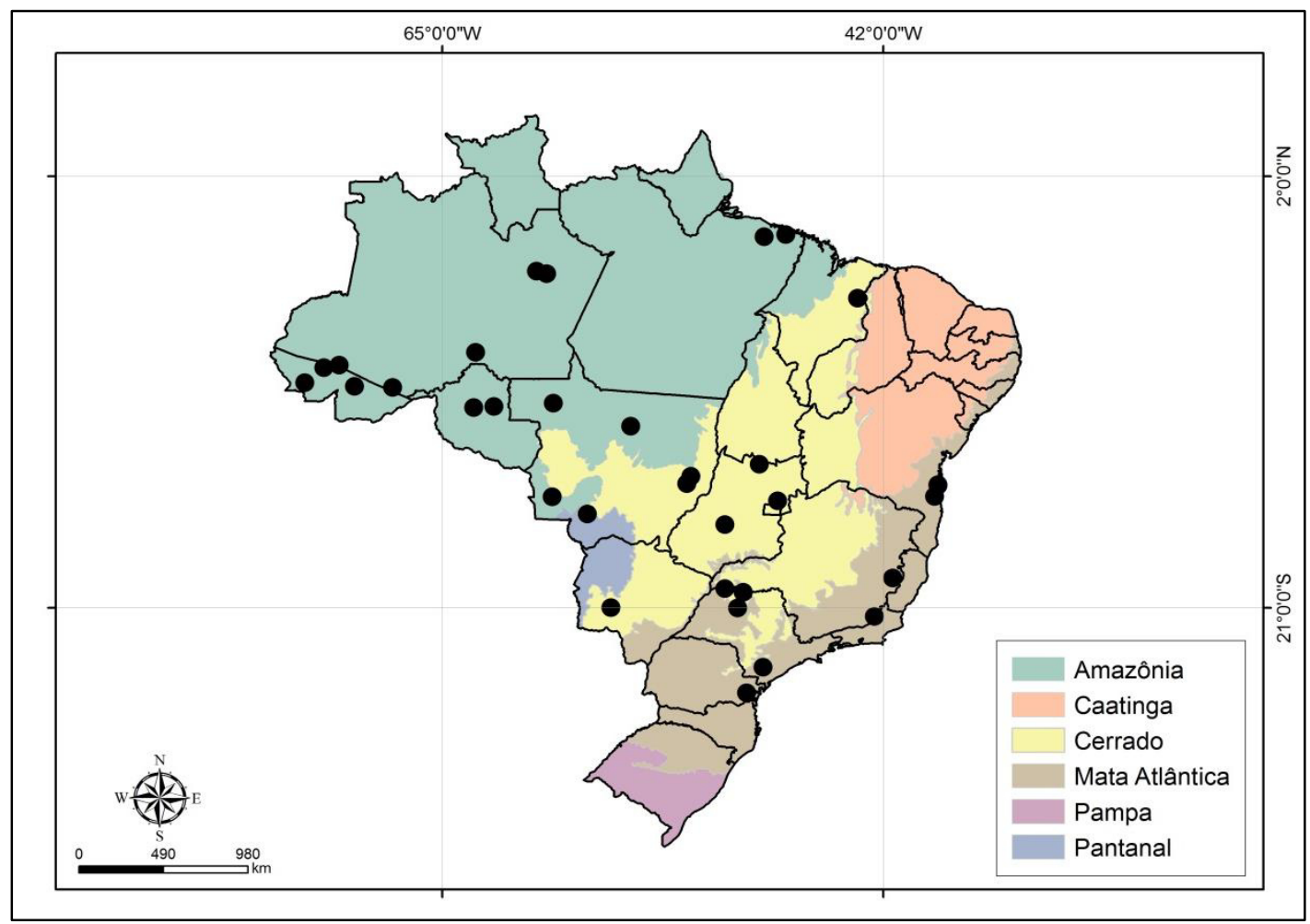

Figura 5: Mapa de distribuição de Pelekium involvens no Brasil.

Material analisado: Acre: Reserva Extrativa do Alto Jurúa, Costa et al. 3982 (RB); Rio Branco, Reese 13202 (NY); Santa Rosa, Daly et al. 10161 (NY); Tarauacá, Costa et al. 2820 (RB). Amazonas: Namorado Novo, Prance et al. 14680 (NY); Iranduba, Peralta \& Bordin 12012 (SP). Bahia: Ilhéus, Buck 20180 (NY); Itabuna, Vital 8677 (NY, SP); Jussari, Carvalho et al. 6871 (NY). Distrito Federal: Côrrego Landím, Irwin et al. 31702 (NY). Goiás: Paraúna, Vital 6320 (SP); Formoso, Vital 8507 (SP). Maranhão: Caxias, Nascimento s.n. (SP). Mato Grosso: Aripuanã, Lleras et al. P18323 (NY); Pontes e Lacerda, Thomas 4746 (NY); Cáceres, Saddi \& Vital 6147 (UB, SP); Cláudia, Peralta \& Borges 12366 (SP); Nova Xavantina, Athayde-Filho \& Fernandes 2646 (SP); Água Boa, Silva 10 (SP). Mato Grosso do Sul: Bonito, Peralta \& Branco 1885 (SP). Minas Gerais: Além Paraíba, Yano \& Santos 5027 (SP); Caratinga, Barros 147 (SP). Pará: Ananindeua, Brito 275 (SP); Capanema, Cardoso \& Reis 12 (SP). Paraná: Tijucas do Sul, Yano 27422 (SP). Rondônia: Alto Condeias, Fife 4095 (NY); Rio Pacaas Novos, Reese 13519 (NY). Roraima: Bonfim, Santiago s.n. (UFP 14332). São Paulo: Barretos, Peralta 6308 (SP); Iporanga, Vital 20596 (SP); Turmalina, Peralta 7661 (SP); Zacarias, Peralta 498 (SP). 

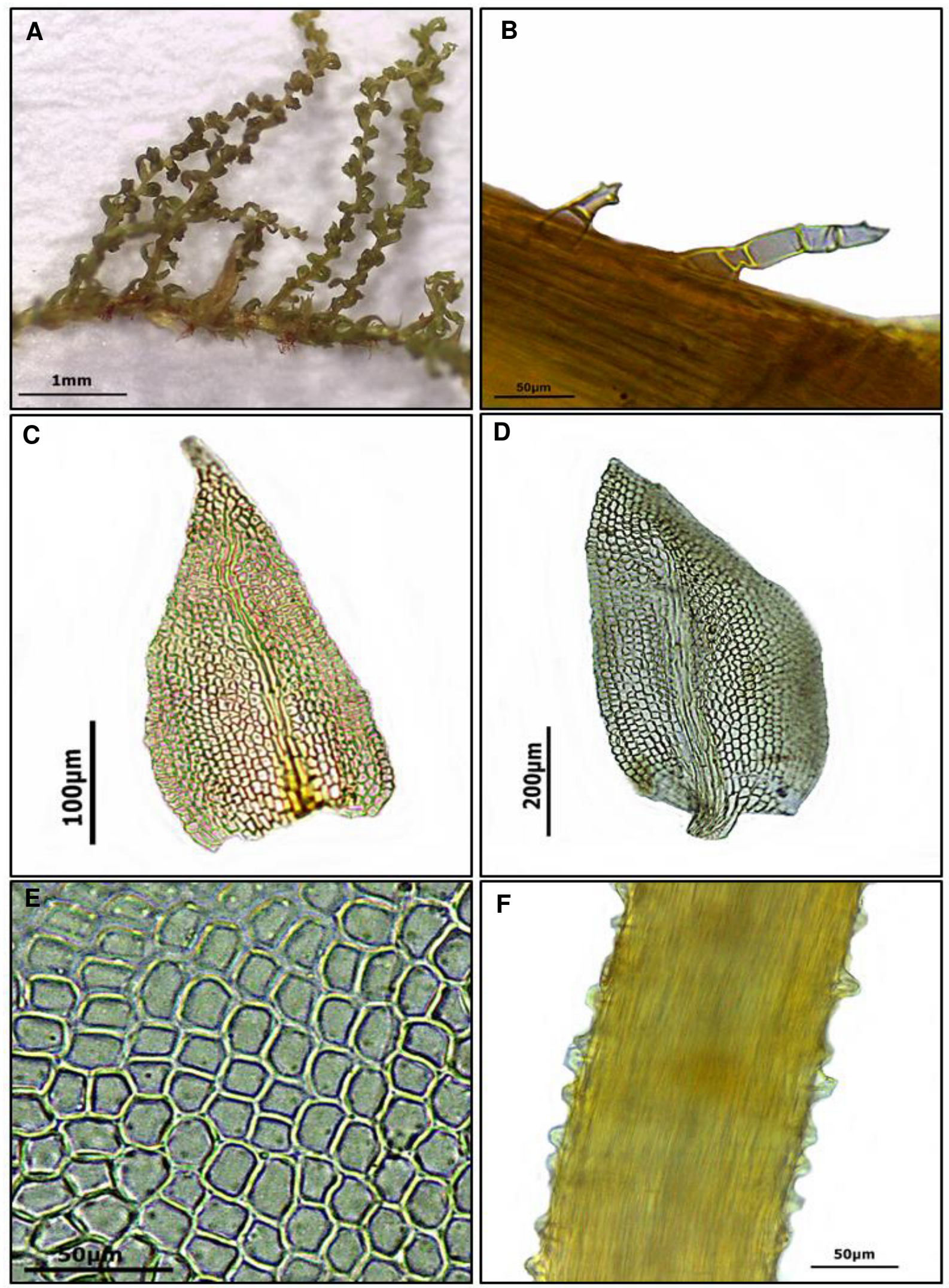

Figura 6: Pelekium involvens. A: Gametófito. B: Paráfilo. C: Filídio do caulídio. D: Filídio da ramificação. E: Células pluripapilosas da região mediana. F: Seta rugosa. 
2. Pelekium minutulum (Hedw.) Touw, J. Hattori Bot. Lab. 90: 204. 2001. Hypnum minutulum Hedw. Sp. Mus. Frond. 260. 1801. Thuidium minutulum (Hedw.) Schimp. Bryol. Eur. 5: 161.481 (fasc. 49--51 Monogr. 5. 1). 1852. Microthuidium minutulum (Hedw.) Warnst. Krypt.-Fl. Brandenburg, Laubm. 677. 683 f. 5. 1905. Cyrto-hypnum minutulum (Hedw.) W.R. Buck \& H.A. Crum. Contr. Univ. Michigan Herb.17: 66. 1990. - Tipo: USA. Pensilvania, sine leg. (Holotype: G!).

Thuidium exasperatum Mitt., J. Linn. Soc., Bot.12: 576. 1869. - Tipo: BRASIL. Weir 34 (Holotype: NY!, Isotype: BM!).

Thuidium pinnatulum (Hampe) Lindb., Öfvers. Förh. Kongl. Svenska Vetensk. -Akad. 33(4): 46. 1876. Hypnum pinnatulum Hampe, Vidensk. Meddel. Dansk Naturhist. Foren. Kjøbenhavn 1: 159. 1879 - Tipo: BRASIL, São Paulo, Apiaí, Puiggari s.n. (isotype: JE!), syn. nov.

Thuidium purpureum (Geh. \& Hampe) Paris, Index Bryolo. 1289. 1898. Hypnum purpureum Geh. \& Hampe, Flora 64: 437. 1881. - Tipo: BRASIL, São Paulo, Apiaí, Puiggari 626 (isotypes: E!, JE!), syn. nov.

Thuidium subgranulatum (Geh. \& Hampe) Kindb., Enum. Bryin. Exot., suppl. 2, 104. 1891. Hypnum subgranulatum Geh. \& Hampe, Vidensk. Meddel. Dansk Naturhist. Foren. Kjøbenhavn 1: 159. 1879. - Tipo: BRASIL, São Paulo, Apiaí, Puiggari 429 (holotype: E!, isotype: JE!). syn nov.

\section{Fig. 7 e Fig. 8.}

Plantas pequenas, ca. de $3-5 \mathrm{~cm}$ compr., delgadas, verdes a verde-amareladas. Caulídios irregularmente 2-pinados, raramente 1-pinado, ramificações com 3-6mm compr., delgadas; paráfilos abundantes ou raramente escassos nos caulídios, escassos ou ausentes nas ramificações, 15-38 $\mu \mathrm{m}$ de compr., 2-3 células, células

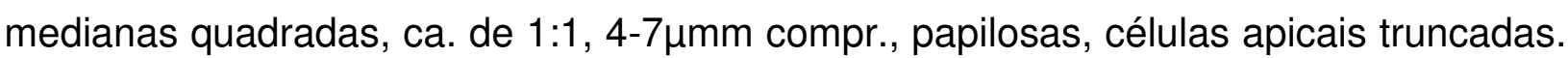
Filídios dos caulídios e das ramificaões diferenciados; filídios dos caulídios encurvados e eretos quando secos, patentes quando úmidos, ovado-deltóides, 0,4-0,6×0,1-0,3mm, acuminados, côncavos; margens crenulada-papilosas, planas ou recurvadas nas metades inferiores; costas simples, ca. de $4 / 5$ do tamanho dos filídios, faces abaxiais fracamente proeminentes; células medianas quadradas ou isodiamétricas, 1-2:1, ca. de 8-11 $\mu \mathrm{m}$ compr., pluripapilosas (2-4), papilas dispostas na periferia do lúmen celular; células apicais alongadas, truncadas, papilosas. Filídios das ramificações secundárias 
encurvados quando secos, patentes quando úmidos, ovados a ovado-deltóides, 0,20,5x0,15-0,2mm, agudos, menos frequentemente obtusos, côncavos; margens crenulada-papilosas, planas; costas ca. de 3/4 do tamanho dos filídios ou terminando muito próximo aos ápices; células medianas quadradas a isodiamétricas, 1:1, ca. de 5$8 \mu \mathrm{m}$ compr., delgadas, pluripapilosas (2-5), papilas dispostas na periferia do lúmen celular; células apicais truncadas. Monóicas. Periquécios lanceolados, ca. de 1,4mm compr., longo-acuminados, subulados; margens serruladas acima, inteiras abaixo, planas; costas preenchendo os ápices; células oblongas, lisas. Setas 0,9-1,5cm compr., lisas; cápsulas sub-eretas a horizontais, ca. de 1,2mm compr., curto-cilíndricas; células dos exotécios curto-retangulares, incrassadas; opérculos rostrados. Peristômios com exostômios estriados abaixo, levemente papilosos acima; endostômios com os segmentos levemente papilosos. Esporos 9-11 $\mathrm{mm}$.

Pelekium minutulum caracteriza-se principalmente pela seta lisa, gametófito delgado, irregularmente bipinado (às vezes 1-pinado) e paráfilo pequeno constituído de 2-3 células. Os filídios também são encurvados quando secos e dispostos laxamente no caulídio. Às vezes pode ser confundida com outras espécies pluripapilosas de Pelekium, porém difere por apresentar seta lisa e gametófito fracamente bipinado, características únicas no grupo dos pluripapilosos.

Sua amplitude latitudinal e altitudinal, aliada a ampla área de ocorrência, muitas destas inseridas dentro de unidades de conservação, faz com que o status de conservação de $P$. minutulum de acordo com os critérios da IUCN (2001), seja considerada Pouco Preocupante (LC).

Crescem sobre solos, rochas, troncos vivos e em decomposição, principalmente em ambientes mésicos, úmidos e sombreados, 100-1800m alt.

Ocorrem na América do Sul, do Norte, Central e Europa.

Distribuição geográfica: AP, AM, DF, ES, MA, MG, MS, MT, PA, PR, RJ, RO, RR, RS e SP.

Domínios Fitogeográficos: Amazônia, Cerrado e Mata Atlântica. 


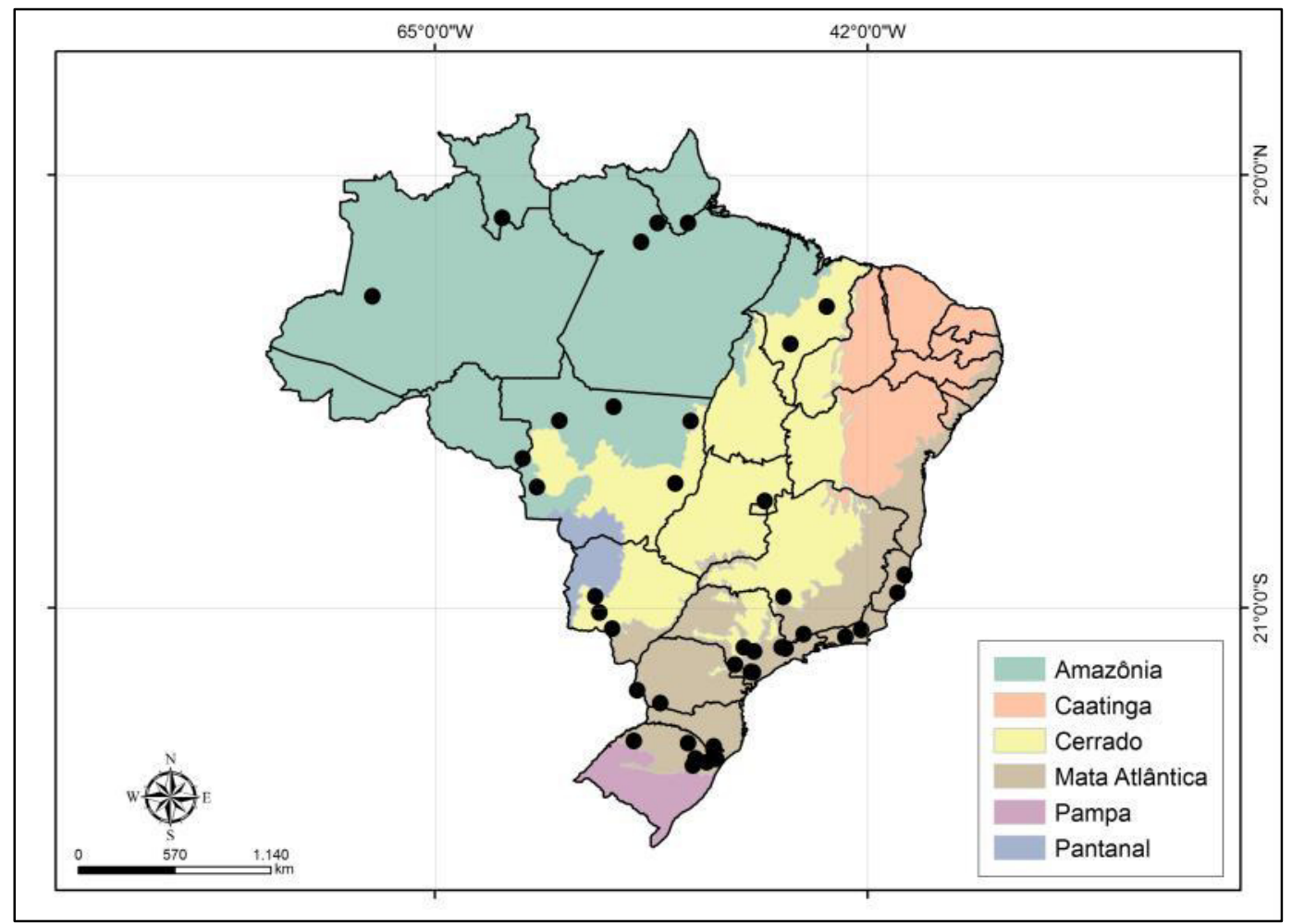

Figura 7: Mapa de distribuição de Pelekium minutulum no Brasil.

Material analisado: Amapá: Reserva Biológica do Lago Piratuba, Pietrobom 6136 (SP). Amazonas: Rio Jutaí, Zartman 7625 (INPA). Distrito Federal: Sobradinho, Irwin 33253 (SP); Espírito Santo: Domingos Martins, Schafer-Verwimp 12862 (NY); Linhares, Yano 26530 (SP). Maranhão: Fortaleza dos Nogueiras, Brito 408 (SP); Governador Archer, Brito 344 (SP). Mato Grosso: Juína, Windisch 8531 (SP); Luciara, Pirani 1282 (MO); Nova Canaã do Norte, Ristow 1647 (SP); Nova Xavantina, Genevro 41 (SP). Vila Bela da Santíssima Trindade, Soares et al. 1615 (UB). Mato Grosso do Sul: Antônio João, Vital 6453 (SP); Jardim, Peralta \& Branco 1940 (SP); Bonito, Peralta \& Branco 1743 (SP). Minas Gerais: Passos, Vital 7649 (SP). Pará: Almerim, Pietrobom 8249 (SP); Monte Alegre, Pietrobom 8342 (SP). Paraná: Foz do Iguaçu, Buck 12092 (SP); Marmeleiro, Hatschbach 26418 (NY). Rio de Janeiro: Nova Friburgo, Costa \& Gomes 461 (RB); Parque Nacional da Tijuca, Costa 54 (RB). Rio Grande do Sul: Cambará do Sul, Peralta 10756, 10757 (SP); Caxias do Sul, Bordin 188 (MO, SP); Cerro Largo, Sehnem 3667 (SP, RB); Ciríaco, Vital \& Buck 12136 (NY); Flores da Cunha, Wasum s.n. (ALCB 18165); Gramado, Sehnem 4696 (PACA); Jaquirana, Dal Pont s.n. (NY); Montenegro, Sehnem 3715 (PACA); São Salvador, Sehnem 3789 (RB, PACA); Touros, Sehnem 5979 (PACA). Rondônia: Colorado do Oeste, Neiva 13 (SP). Roraima: Rorainopólis, Soares 1131 (UB). São Paulo: Avaré, Yano 356 (MO, SP); 
Cajati, Vital 5579 (MO, SP); Campos do Jordão, Yano 26140 (SP); Eldorado Paulista, Vital \& Buck 12479 (NY); Ipiranga, Joly 1231; Itapetininga, Vital 2137 (SP); Itapeva, Peralta \& Yano 11228, 11494 (SP); Itupeba, Puiggari 703 (SP); Jundiaí, Puiggari 33040 (MO); Mairiporã, Yano 31479 (SP); Pirajussana, Gehn 442 (JE, SP); Sete Barras, Ratter 4991 (MO). 

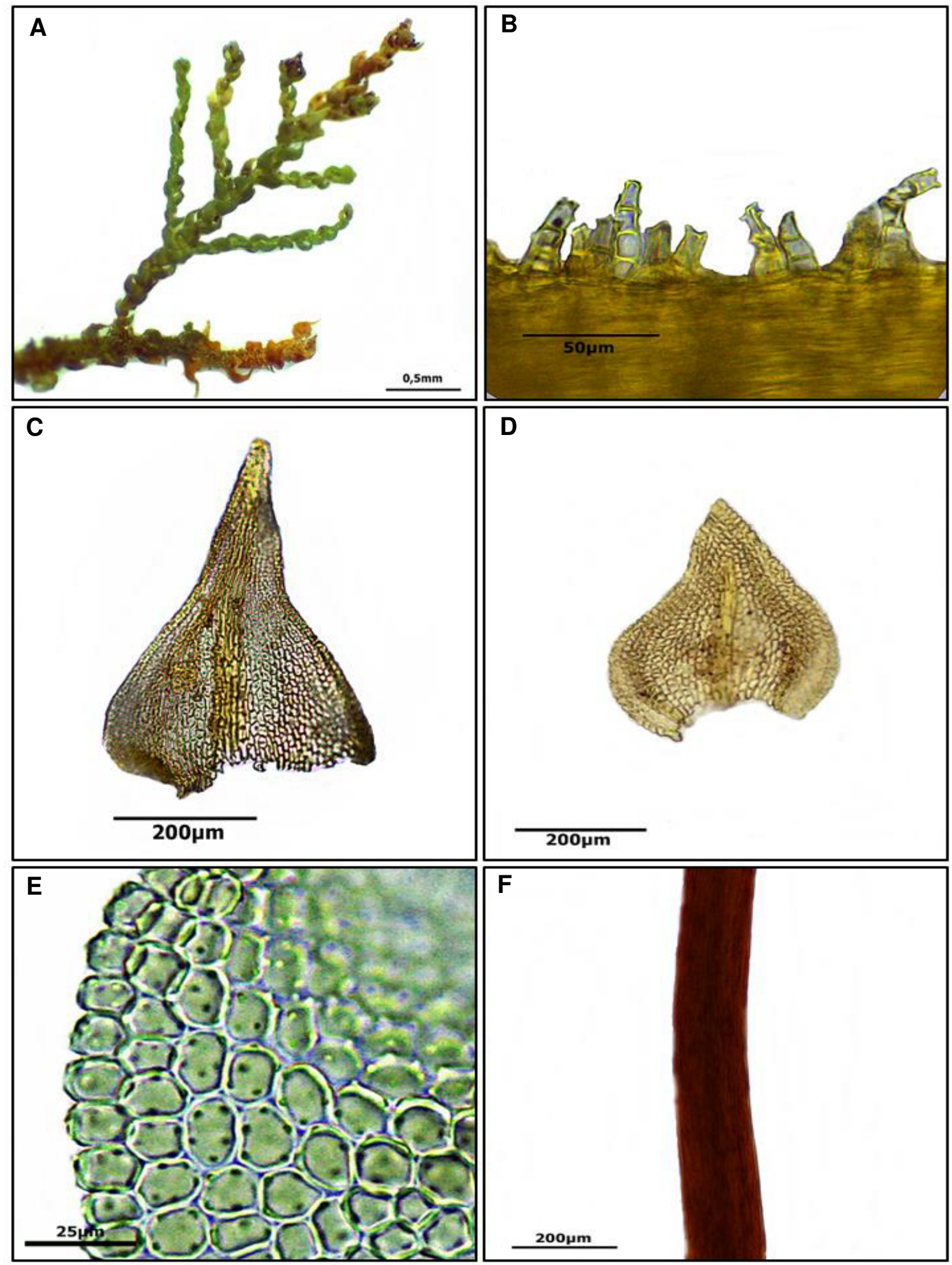

Figura 8: Pelekium minutulum. A: Gametófito. B: Paráfilo. C: Filídio do caulídio. D: Filídio da segunda ramificação. E: Células pluripapilosas da região mediana. F: Seta lisa. 
3. Pelekium muricatulum (Hampe) Touw, J. Hattori Bot. Lab. 90: 204. 2001. Hypnum muricatulum Hampe, Linnaea 20: 88. 1847. Thuidium muricatulum (Hampe) A. Jaeger, Ber. Thätigk. St. Gallischen Naturwiss. Ges 1876--77: 253 (Gen. Sp. Musc. 2: 319). 1878. - Tipo: COLÔMBIA. sine loco, Moritz 46 (holotype: BM!). Hypnum brachythecium Hampe \& Lorentz, Bot. Zeitung (Berlin) 26: 819. 1868. Thuidium brachythecium (Hampe \& Lorentz) A. Jaeger, Ber. Thätigk. St. Gallischen Naturwiss 1876--77: 254 (Gen. Sp. Musc. 2: 320). 1878. Cyrto-hypnum brachythecium (Hampe \& Lorentz) Hampe \& Lorentz, Bot. Zeitung (Berlin) 27: 455. 1869. - Tipo: EQUADOR. Loja, H. Krause s.n. (holotype: BM!).

Hypnum raphidostegum Müll. Hal., Syn. Musc. Frond. 2: 494. 1851. Thuidium raphidostegum (Müll. Hal.) Mitt. J. Linn. Soc., Bot. 12: 577. 1869. Tipo: CHILE. sine loco, Poeppig 235 (isotype BM!).

Thuidium pusillum Mitt., J. Linn. Soc., Bot12: 577. 1869. Tipo: VENEZUELA. Caracas, Funck et Schlim 351 (holotype: NY!). syn nov.

Fig. 9 e Fig.10.

Plantas pequenas, ca. de $4-7 \mathrm{~cm}$ compr., delgadas, verdes a verde-amareladas. Caulídios 2-pinados, ramificações com 4-7mm compr., paráfilos abundantes nos caulídios, escassos ou ausentes nas ramificações, 18-32 $\mu \mathrm{m}$ compr., 2-3 células, células medianas quadradas, ca. de 1:1, 4-6 $\mathrm{mm}$ compr., papilosas, células apicais truncadas. Filídios dos caulídios e das ramificações diferenciados; filídios dos caulídos encurvados quando secos, patentes quando úmidos, deltóides, 0,5-0,7×0,15-0,3mm, acuminados, côncavos; margens crenulada-papilosas, planas ou recurvadas nas metades inferiores; costas simples, ca. de $3 / 4$ do tamanho dos filídios, faces abaxiais fracamente proeminentes; células medianas quadradas ou isodiamétricas, 1-2:1, ca. de 7-12 $\mu \mathrm{m}$ compr., unipapilosas, papilas disposta no centro do lúmen celular; células apicais alongadas, truncadas, lisas ou inconspicuamente papilosas. Filídios das ramificações secundárias encurvados quando secos, patentes quando úmidos, ovadodeltóides, 0,3-0,6×0,2-0,3mm, agudos ou obtusos, côncavos; margens crenuladapapilosas, planas; costas ca. de $1 / 2$ a $3 / 4$ do tamanho dos filídios; células medianas quadradas a isodiamétricas, $1: 1, \mathrm{ca}$. de $6-8 \mu \mathrm{m}$ compr., delgadas, unipapilosas, papilas disposta no centro do lúmen celular; células apicais truncadas. Monóicas. Periquécios lanceolados, ca. de 1,2mm compr., longo-acuminados, subulados; margens serruladas 
acima, inteiras abaixo, planas; costas preenchendo os ápices; células oblongas, lisas. Setas ca. de $1 \mathrm{~cm}$ compr., lisas; cápsulas sub-eretas ou horizontais, ca. de $1 \mathrm{~mm}$ compr., cilíndricas; células dos exotécios curto-retangulares, incrassadas; opérculos rostrados. Peristômios com exostômios estriados abaixos, levemente papilosos acima; endostômios com os segmentos levemente papilosos. Esporos não observados.

Pelekium muricatulum é endêmica da América do Sul. Pode ser reconhecida por apresentar células unipapilosas, com a papila localizada no centro do lúmen celular; paráfilos com a célula apical truncada, compostos por 2-4 células de comprimento e seta lisa. Pode ser confundida com Pelekium siphoteca, porém difere por apresentar a célula apical da papila truncada enquanto $P$. siphotheca possui a célula apical da papila aguda.

Apresenta distribuição restrita a poucas localidades no Brasil, ocorrendo no Cerrado (em regiões de mata de galeria) e na Mata Atlântica. Desta forma, de acordo com os critérios da IUCN (2001), Pelekium muricatulum foi classificada como Vulnerável - VU (B1a,b(i, ii)).

Crescem sobre rochas e troncos vivos e em decomposição, principalmente próximo ao curso d’água em locais sombreados, 600-1200m alt.

Ocorre na América do Sul (endêmica).

Distribuição geográfica: DF, MG, PR, RS e SP.

Domínios Fitogeográficos: Cerrado e Mata Atlântica. 


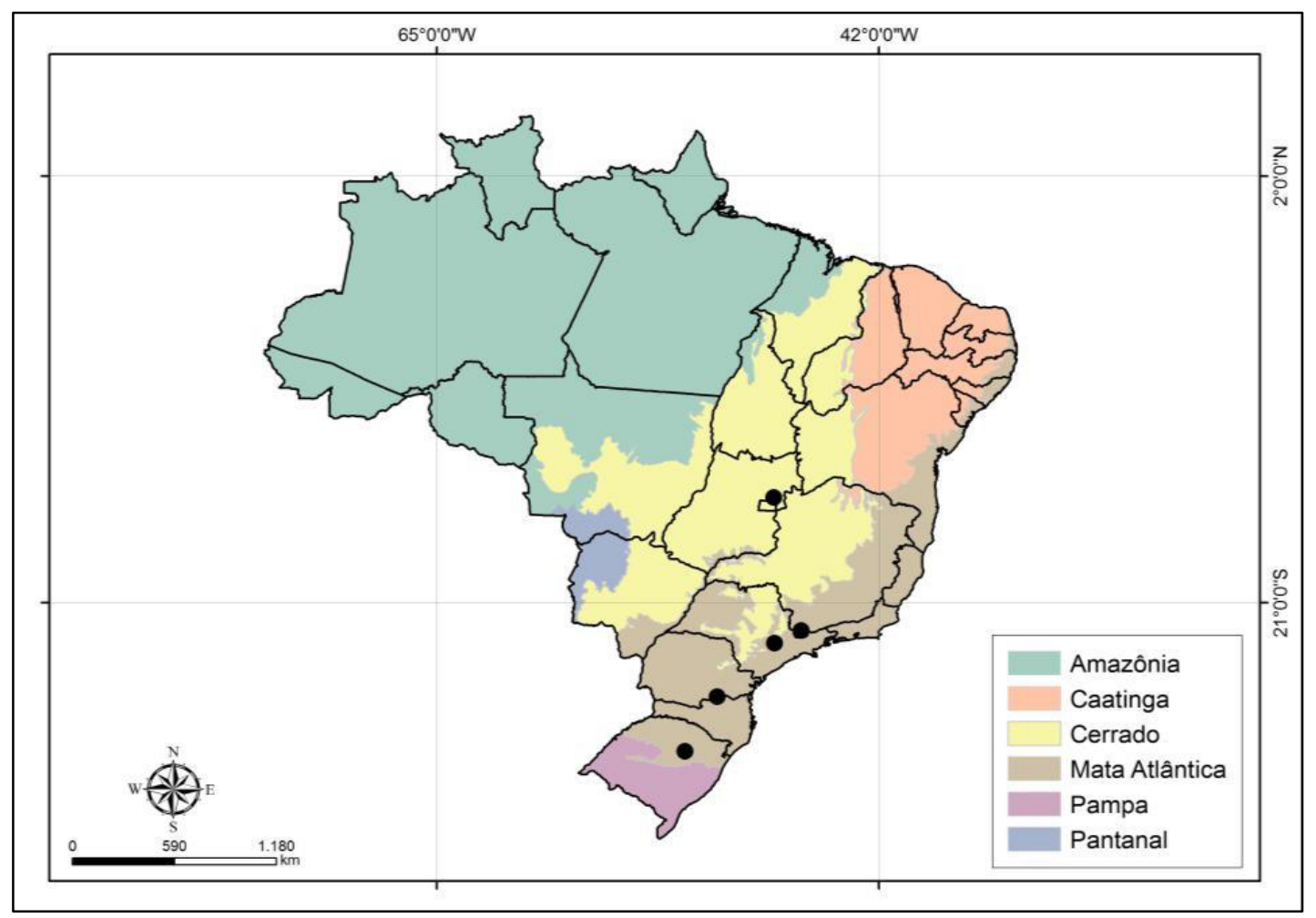

Figura 9: Mapa de distribuição de Pelekium muricatulum no Brasil.

Material analisado: Distrito Federal: Sobradinho, Irwin 33253 (UB). MINAS GERAIS: Monte Verde, Peralta 3476 (SP). Paraná: Iguaçu, Hosseus 16 (JE). Rio Grande do Sul: Ponte Velha, Wasum 10496 (SP). São Paulo: Iperó, Yano 32078 (SP). 


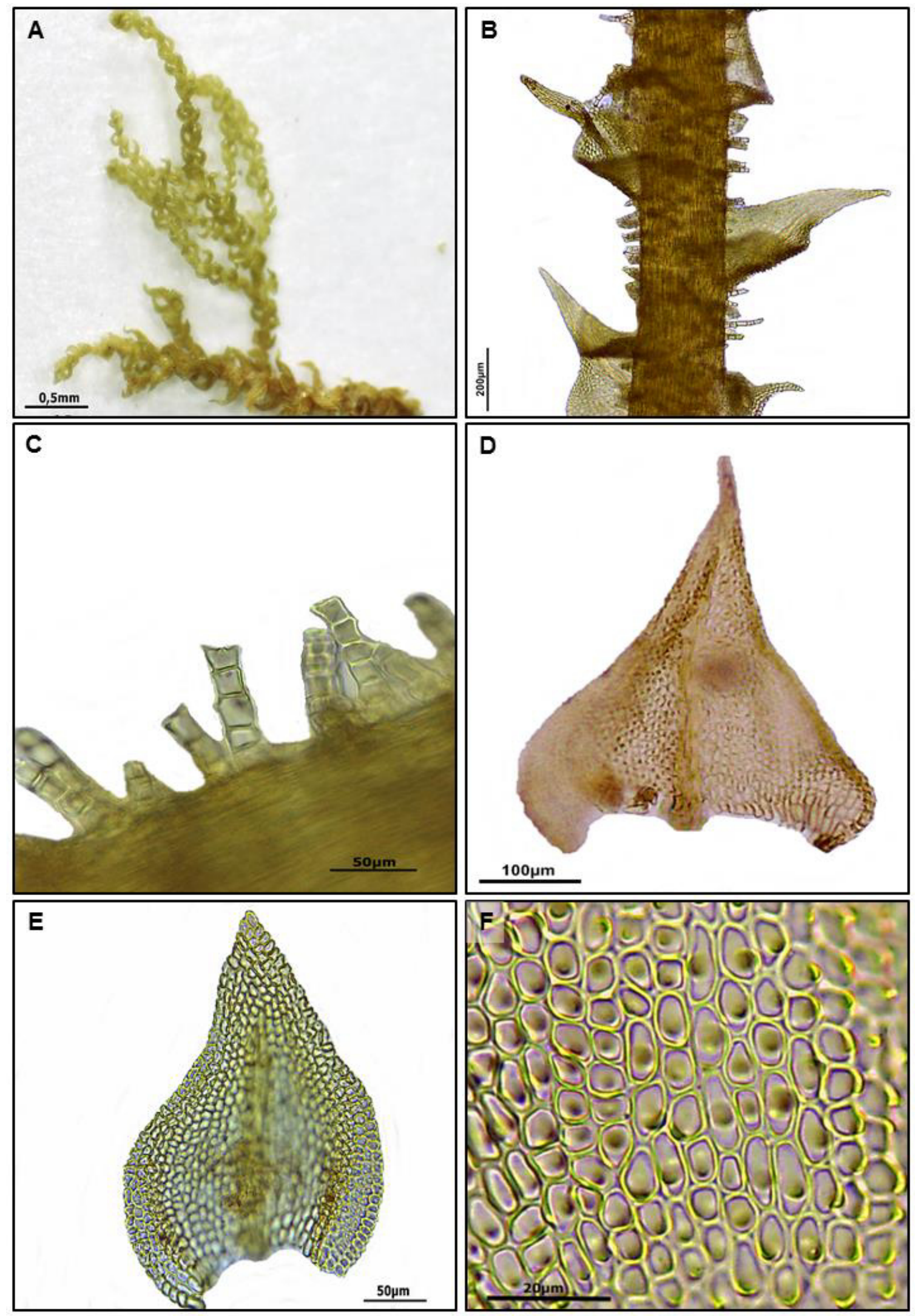

Figura 10: Pelekium muricatulum. A e B: Gametófito. C: Paráfilo. D: Filídio do caulídio. E: Filídio da segunda ramificação. F: Células unipapilosas do filídio da ramificação. 
4. Pelekium scabrosulum (Mitt.) Touw, J. Hattori Bot. Lab. 90: 204. Thuidium scabrosulum Mitt. J. Linn. Soc., Bot. 12: 574. 1869. Cyrto-hypnum scabrosulum (Mitt.) W.R. Buck \& H.A. Crum, Contr. Univ. Michigan Herb. 17: 67. 1990. - Tipo: BRASIL. Amazonas, próximo São Gabriel, Spruce 1456 (lectotype designated here: NY!, isolectotype: W!). Pará, Spruce 1463 (isosyntype: NY!). America Australi, Humboldt 40 et 29b (isosyntype: NY!). Sine loco, Spruce 1459 (isosyntype: NY?). Pará, Caipurú, Spruce 1460 (isosyntype: W!). Amazonas, Cauapuna, Spruce 1457 (isosyntype: NY!). Próximo S. Carlos, Spruce 1461 (isosyntype: NY?).

Thuidium complanum Mitt., J. Linn. Soc., Bot. 12: 575. 1869. - Tipo: TRINIDAD E TOBAGO, Black s.n. (holotype: NY!).

Fig. 11 e Fig. 12.

Plantas pequenas, ca. de $5-8 \mathrm{~cm}$ compr., delgadas, verdes a verde-amareladas. Caulídios regularmente 2-pinados, ramificações com 4-8mm compr., paráfilos abundantes nos caulídios, escassos ou ausentes nas ramificações, 30-78 $\mu \mathrm{m}$ compr., 3-

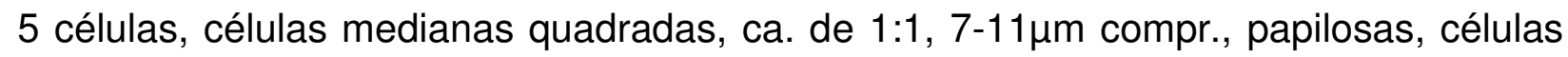
apicais truncadas. Filídios dos caulídios e das ramificações diferenciados. Filídios dos caulídios encurvados quando secos, patentes quando úmidos, laxamente dispostos, ovado-deltóides, 0,35-0,5×0,1-0,2mm, acuminados, côncavos; margens crenuladapapilosas, planas ou recurvadas na metade inferior; costas simples, ca. de $4 / 5$ do tamanho dos filídios, faces abaxiais fracamente proeminentes; células medianas

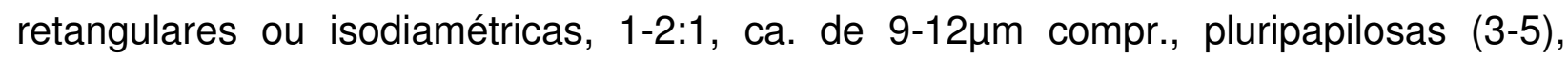
papilas dispostas na periferia do lúmen celular; células apicais alongadas, truncadas, papilosas. Filídios das ramificações secundárias fortemente encurvados quando secos, patentes quando úmidos, laxamente dispostos, ovado-deltóides, 0,15-0,2×0,1mm, agudos, as vezes obtusos, côncavos; margens crenulada-papilosas, planas; costas com ca. de 2/3 do tamanho dos filídios; células medianas quadradas a isodiamétricas, 1:1, ca. de 5-7um compr., delgadas, pluripapilosas (3-5), papilas dispostas na periferia do lúmen celular; células apicais truncadas. Monóicas. Periquécios lanceolados, ca. de $1,0 \mathrm{~mm}$ compr., subulado-acuminados; margens serruladas, planas; costas preenchendo os ápices; células retangulares, lisas. Setas 1-1,7cm compr., rugosas; cápsulas sub-eretas ou horizontais, ca. de 0,9mm compr., curto-cilíndricas; células dos 
exotécios curto-retangulares, incrassadas; opérculos rostrados. Peristômios com exostômio estriados abaixo, levemente papilosos acima; endostômio com os segmentos levemente papilosos. Esporos 12-15 $\mu \mathrm{m}$.

Pelekium scabrosulum é uma das espécies mais comuns no Brasil, que caracteriza-se pelos filídios das ramificações fortemente encurvados e laxos quando secos, deixando a superfície do caulídio visível e também pela margem dos filídios periqueciais sem a presença de cílios. Estas caracteristicas são muito importantes para separá-la de $P$. schistocalyx, pois na última os filídios da ramificação são imbricados quando secos, não deixando a superfície do caulídio visível e a margem do filídio periquecial é ciliada. Também apresenta como caracteristica a seta rugosa e 3-5 papilas por célula.

A espécie possui ampla distribuição, ocorrendo em diversas localidades, geralmente em grandes populações e dentro de unidades de conservação. Deve-se, portanto, ser considerada Pouco Preocupante (LC) em relação ao seu status de conservação (IUCN 2001).

Crescem em locais secos e úmidos, na sombra ou parcialemnte exposta ao sol, no solo, rochas e troncos vivos ou em decomposição em ambientes mésicos e florestas, principalmente na região amazônica, 200-900m alt.

Ocorre na América do Sul e Central.

Distribuição geográfica: AC, AL, AM, BA, DF, ES, GO, MA, MG, MS, MT, PA, PE, PR, RJ, RO, RR, RS e SP.

Domínios Fitogeográficos: Amazônia, Cerrado e Mata Atlântica. 


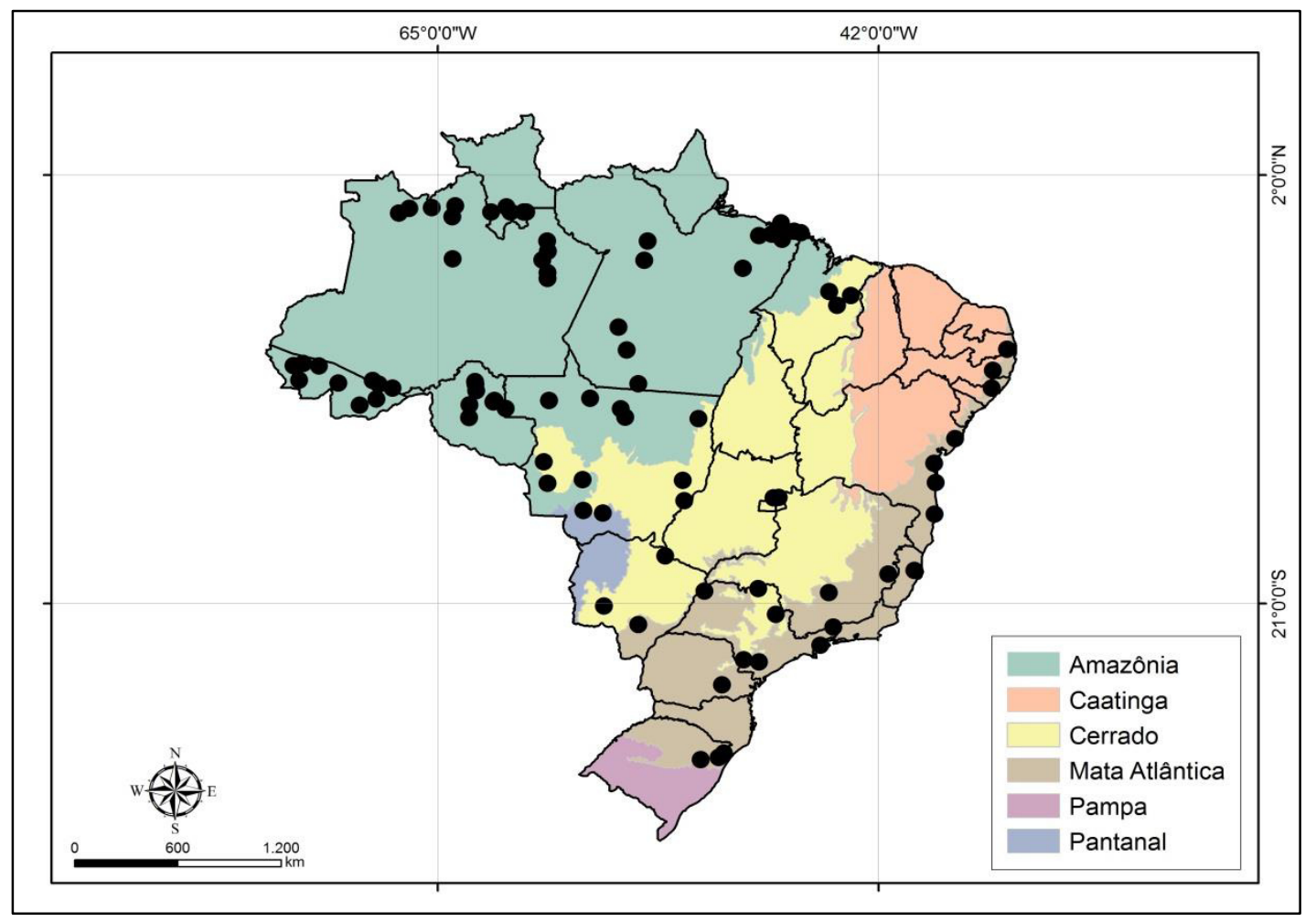

Figura 11: Mapa de distribuição de Pelekium scabrosulum no Brasil.

Material analisado: Acre: Alto Jurúa, Costa 3917 (RB, SP); Brasiléia, Reese 13272 (NY); Bujari, Daly 9467 (NY); Cruzeiro do Sul, Daly et al. 7321 (NY); Plácido Castro, Lowy 530 (NY); Porto Acre, Daly et al. 8020 (NY); Rio Branco, Reese 13175 (NY); Rio Juruá, Steward P13172 (NY); Santa Rosa, Daly 9954; Sena Madureira, Nelson 575 (NY); Serra da Moa, Prance et al. 12340 (NY); Tarauacá, Costa 2755 (RB). Alagoas: São Miguel dos Campos, Lima 80-6652 (SP). Amazonas: Balbina, Buck 2737 (NY); Juma, Traill s.n. (NY); Manaus, Griffin III et al. 643 (SP); Rio Mariê, Yano 1787 (SP); Rio Negro, Basset Maguire 60285 (NY); Namorado Novo, Prance 14712; Rio Uatumã, Buck 2740 (MO, NY); São Gabriel, Buck 2518 (NY); São Tomé, Buck 2203 (NY); Serra Curicuriari, Yano 1916 (SP); Serra de Jacamim, Yano 1594; Tapereira, Yano 1513 (SP); Temenduí, Yano (SP). Bahia: Eunápolis, Bôas-Bastos 715 (ALCB); Igrapiúna, Bastos 4065 (ALCB); Ilhéus, De Jesus et al. 864 (NY), Itanagra, Boom 960 (NY). Distrito Federal: Brasilia, Irwin et al. 31686 (NY), FERCAL, Moura 11 (SP). Espírito Santo: Linhares, Yano \& Santos 4885 (SP). Goiás: Formosa, Vital 8273 (SP). Maranhão: Caxias, Brito s.n. (SP38939); Governador Archer, Brito 316 (SP); Lago do Junco, Daly 503 (NY). Mato Grosso: Alta Floresta, Thomas et al. 4126 (NY); Aripuanã, Lleras p18275 (NY); Barra do Garça, Vital 1376 (MO, SP); Cáceres, Hoehne 482 (JE); Colíder, Dias et al. 483 (SP); Comodoro, Boelter 13 (INPA, UB); Itaúba, Dias et al. 599 
(SP); Luciara, Pirani 1282 (NY); Nova Xavantina, Felter \& Fernandes 515 (SP); Poconé, Yano 27496 (SP); Rio Aripuanã, Prance et al. 18344; Serra de Ricardo Franco, Windisch 2069 (NY); Tangará da Serra, Câmara et al. 2761 (UB), Vila Bela da Santíssima Trindade, Soares et al. 1617 (UB). Mato Grosso do Sul: Bonito, Peralta \& Branco 1642 (SP); Costa Rica, Pietrobom 2988; Dourados, Clemente s.n. (SP). Minas Gerais: Caratinga, Barros 106 (SP); São Francisco de Paula, Brandão s.n. (SP). Pará: Belém, Occhioni 53 (RB); BR 163, km 885, Prance et al. p25175 (NY); Bragança, Pietrobom et al. 8357 (SP); Capanema, Ferreira \& Brito 8 (SP); Capitão Poço, Tavares et al. 867 (RB); Monte Alegre, Swallen 3403 (UB); Olvídos, Occhioni 22 (RB); Primavera, Pietrobom et al. 8449 (SP); Rio Curuá, Reese 16545 (NY); Rio Jamanxím, Reese 16702 (NY); Santa Maria do Pará, Pietrobom et al. 8390 (SP); Serra do Cachimbo, Reese 16109 (MO, NY); Tailândia, Souza 617 (SP). Paraná: São João do Triunfo, Vital 3311 (SP). Pernambuco: Quipapá, Yano 2846 (SP); São Vicente Ferrer, Silva 221 (SP). Rio de Janeiro: Parque Nacional do Itatiaia, Vital 3525 (SP). Rio Grande do Sul: Montenegro, Sehnem 4041 (PACA); São Francisco de Paula, Jágmin 786 (SP); Serra de Pedra, Reitz 2919 (PACA). Rondônia: Alto Condeias, Fife 4124 (MO, NY); Ariquemes, Fife 4079 (NY); Jarú, Vital 14346 (SP); Ji-Paraná, Vital 14398 (SP); Ouro Preto D' Oeste, Vital 14113 (SP); Porto Velho, McFarland et al. 255 (MO, NY); Rio Jamari, Pires 9995 (SP); Rio Pacaas Novos, Reese 13513 (NY). Roraima: BR-174 km 328, Buck 1858 (NY); llha de Maracá, Hopkins 769 (NY); Posto Mucajaí, Prance et al. 11088 (NY); Rio Branco, Pires 14527 (NY); Rorainópolis, Soares 1196 (UB); Uaicá, Prance et al. 19961 (NY). São Paulo: Descalvado, Vital 752 (SP); Guapiara, Buck 20437 (NY, SP); Itapeva, Peralta \& Yano 11391 (SP); Pereira Barreto, Yano 9693 (SP); Ribeirão Preto, Nonato 175 (SP) e Ubatuba, Peralta 2217 (SP). 

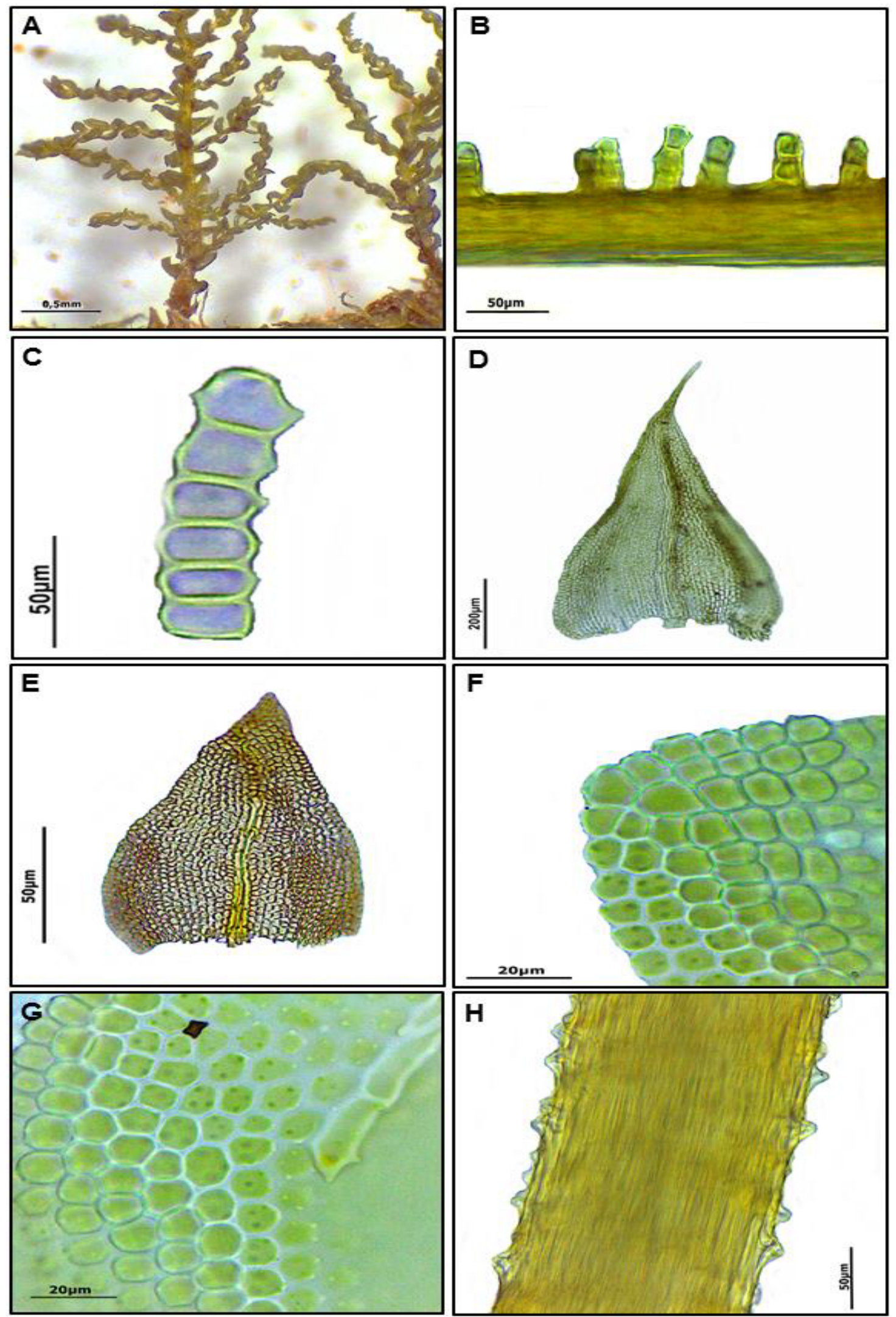

Figura 12: Pelekium scabrosulum. A: Gametófito. B e C: Paráfilo. D: Filídio do caulídio. E: Filídios da última ramificação. F: Ápice do filídio da ramificação. G: Células pluripapilosas do filídio da ramificação. H: Seta rugosa. 
5. Pelekium schistocalyx (Müll.Hal.) Touw, J. Hattori Bot. Lab. 90: 204. 2001. Hypnum schistocalyx Müll. Hal. Syn. Musc. Frond. 2: 691. 1851. Thuidium schistocalyx (Müll. Hal.) Mitt. J. Linn. Soc., Bot. 12: 575. 1869. Cyrto-hypnum schistocalyx (Müll. Hal.) W.R. Buck \& H.A. Crum, Contr. Univ. Michigan Herb. 17: 67. 1990. - Tipo: NICARAGUA. Matagalpa, A.S. Oersted s.n. (isotypes: JE! NY!). Thuidium subinvolvens Müll. Hal., Hedwigia 37: 263. 1898. - Tipo: CUBA. Charles Wright s.n. (isotype: NY!).

Fig. 13 e Fig. 14.

Plantas pequenas, ca. de $6-8 \mathrm{~cm}$ compr., delgadas, verdes a verde-amareladas. Caulídios regularmente 2-pinados, ramificações com $5-7 \mathrm{~mm}$ compr., paráfilos abundantes nos caulídios, escassos ou ausentes nas ramificações, 40-82 $\mu \mathrm{m}$ compr., 5-

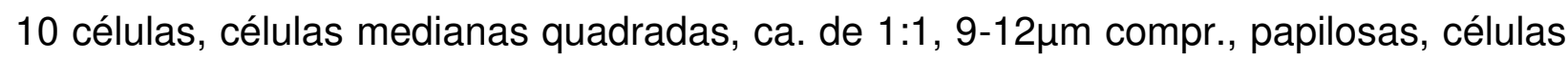
apicais truncadas. Filídios dos caulídios e das ramificações diferenciados; filídios dos caulídios adpressos ou imbricados quando secos, patentes quando úmidos, deltóides, 0,3-0,6 $\times 0,1-0,2 \mathrm{~mm}$, acuminados, côncavos; margens crenulada-papilosas, planas, recurvadas na metade inferior; costas simples, ca. de $4 / 5$ do tamanho dos filídios, faces abaxiais proeminentes; células medianas isodiamétricas, 1-2:1, ca. de 8-11 $\mu \mathrm{m}$ compr., pluripapilosas (3-5), papilas dispostas na periferia do lúmen celular; células apicais alongadas, truncadas, papilosas. Filídios das ramificações secundárias imbricados quando secos, ereto-patentes quandos úmidos, ovado-deltóides, 0,2-0,3×0,1 mm, agudos ou obtusos, côncavos; margens crenulada-papilosas, planas; costas com ca. de 2/3 a 3/4 do tamanho dos filídios; células medianas quadradas a isodiamétricas, 1:1, ca. de 4-8 $\mu \mathrm{m}$ compr., delgadas, pluripapilosas (3-5), papilas dispostas na periferia do lúmen celular; células apicais truncadas. Monóicas. Periquécios lanceolados, ca. de $1,3 \mathrm{~mm}$ compr., subulados; margens serruladas, fortemente ciliadas, planas; costas preenchendo os ápices; células retangulares, lisas. Setas 1-1,4cm compr., rugosas; cápsulas sub-eretas ou horizontais, ca. de $1 \mathrm{~mm}$ compr., curto-cilíndricas; células do exotécio curto-retangulares, incrassadas; opérculos rostrados. Peristômios com exostômios estriados abaixo, levemente papilosos acima; endostômios com os

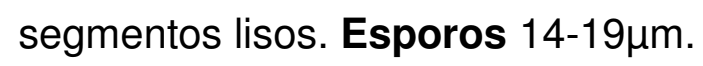

P. schistocalyx caracteriza-se pelas células pluripapilosas, seta rugosa, filídios periqueciais com a margem ciliada e principalmente por apresentar os filídios da 
ramificação imbricados quando secos, não deixando a superfície da ramificação visível, sendo está última característica, juntamente com a margem do filídio periquecial ciliada, as principais caracteristicas utilizadas para separá-la de $P$. scabrosulum.

Devido a sua ampla distribuição, amplitude latitudinal e altitudinal, ocorrendo em diversas localidades, muitas destas inseridas dentro de unidades de conservação, seu status de conservação foi considerado Pouco Preocupante (LC) de acordo com os critérios da IUCN (2001).

Crescem em locais úmidos, geralmente protegidos do sol, sobre rochas e troncos vivos ou em decomposição, em ambientes mésicos e florestais, 200-1000m alt.

Ocorrem na América do Sul, do Norte e Central.

Distribuição geográfica: AC, AM, DF, GO, MA, MG, MS, MT, PA, PR, RJ, RO, RR, RS, SC, SP e TO.

Domínios Fitogeográficos: Amazônia, Cerrado e Mata Atlântica.

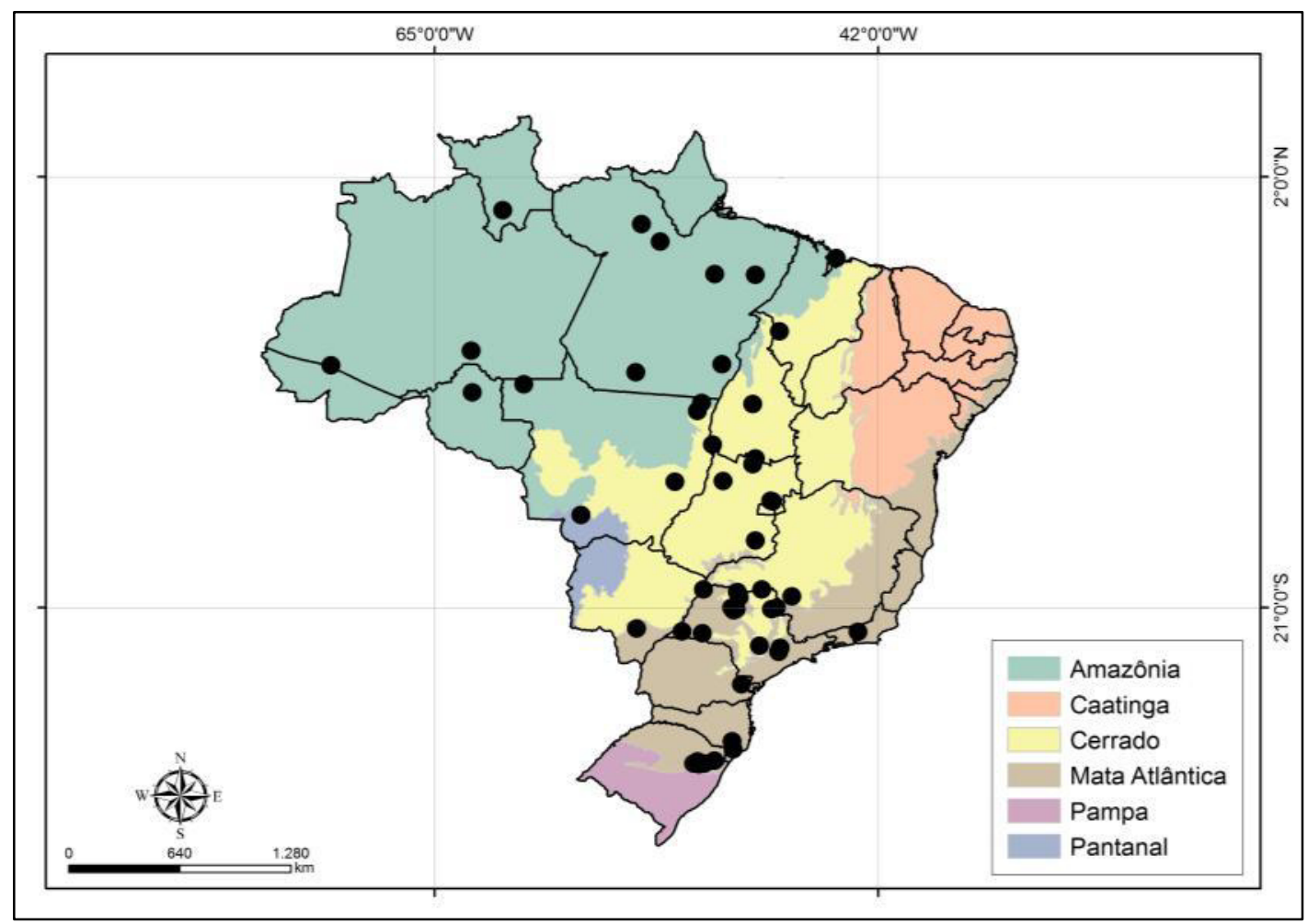

Figura 13: Mapa de distribuição de Pelekium schistocalyx no Brasil.

Material analisado: Acre: Tarauacá, Costa et al. 2576 (RB). Amazonas: Humaitá, McFarland et al. 298 (NY). Distrito Federal: Sobradinho, Soares \& Salmito 1370 (UB).

Goiás: Caldas Novas, Pietrobom 2643 (SP); Crixás, Rivera et al. s.n. (UB); Formoso, Vital 8517 (NY, SP). Maranhão: Porto Franco, Hatschbach 38699 (NY); São Luís, 
Correira s.n. (SP). Mato Grosso: Aripuanã, Windisch 8549 (SP); Cáceres, Soares et al. 1595 (UB); Campinápolis, Freitas 39 (SP); Nova Xavantina, Athayde-Filho et al. 3900 (SP); Porto Alegre do Norte, Teixeira 40 (SP); Santa Teresinha, Thomas 4390 (MO, NY). Mato Grosso do Sul: Aparecida do Taboado, Pietrobom 2836 (SP); Dourados, Clemente s.n. (SP). Minas Gerais: Passos, Vital (MO). Pará: Anapu, Prance et al. P26483 (MO); Capitão Poço, Tavares et al. 860 (RB); Conceição do Araguaia, Plowman 409 (NY); Coqueiro, Kuhlmann 2120 (RB); Prainha, Pietrobom et al. 8337 (SP); Presidente Kennedy, Plowman 8155 (NY); Rio Xingú, Prance 26483 (NY); Serra do Cachimbo, Reese et al. 16690 (MO, NY). Paraná: Bocaiúva do Sul, Ristow et al. 2763 (SP). Rio de Janeiro: Magé, Santos \& Costa 129 (RB). Rio Grande do Sul: Boa Vista do Sul, Sehnem 5626 (PACA); Bom Retiro do Sul, Sehnem 6993 (PACA); Canela, Gomes s.n. (PACA); Loreto, Guerra et al. s.n. (MO); Montenegro, Sehnem 1975 (PACA); Sapiranga, Wasum et al. s.n. (NY). Rondônia: Ariquemes, McFarland et al. 166 (NY). Roraima: Boiaçu, Griffin III et al. 639 (SP); Caracarai, Griffin IIl et al. 656 (SP). Santa Catarina: São Joaquim, Reitz 15994 (SP); Serra da Pedra, Reitz 364 (SP). São Paulo: Altinopólis, Bordin 969 (SP); Bofete, Peralta 6864 (SP); Cabreuva, Yano 971 (SP); Ibiúna, Visnadi 9527 (SP); Matão, Peralta et al. 6249 (SP); Mendonça, Pietrobom 3884 (SP); Palestina, Peralta 7646 (SP); Pereira Barreto, Peralta 310 (SP); Ribeirão Preto, Silva 270 (SP); São José do Rio Preto Silva 115 (SP); Teodoro Sampaio, Vital 2103 (SP); Ubarana, Peralta et al. 6108 (SP); Zacarias, Yano 26725 (SP). Tocantins: Paraíso do Norte (Paraíso de Tocantins), Vital 3012 (MO, SP). 

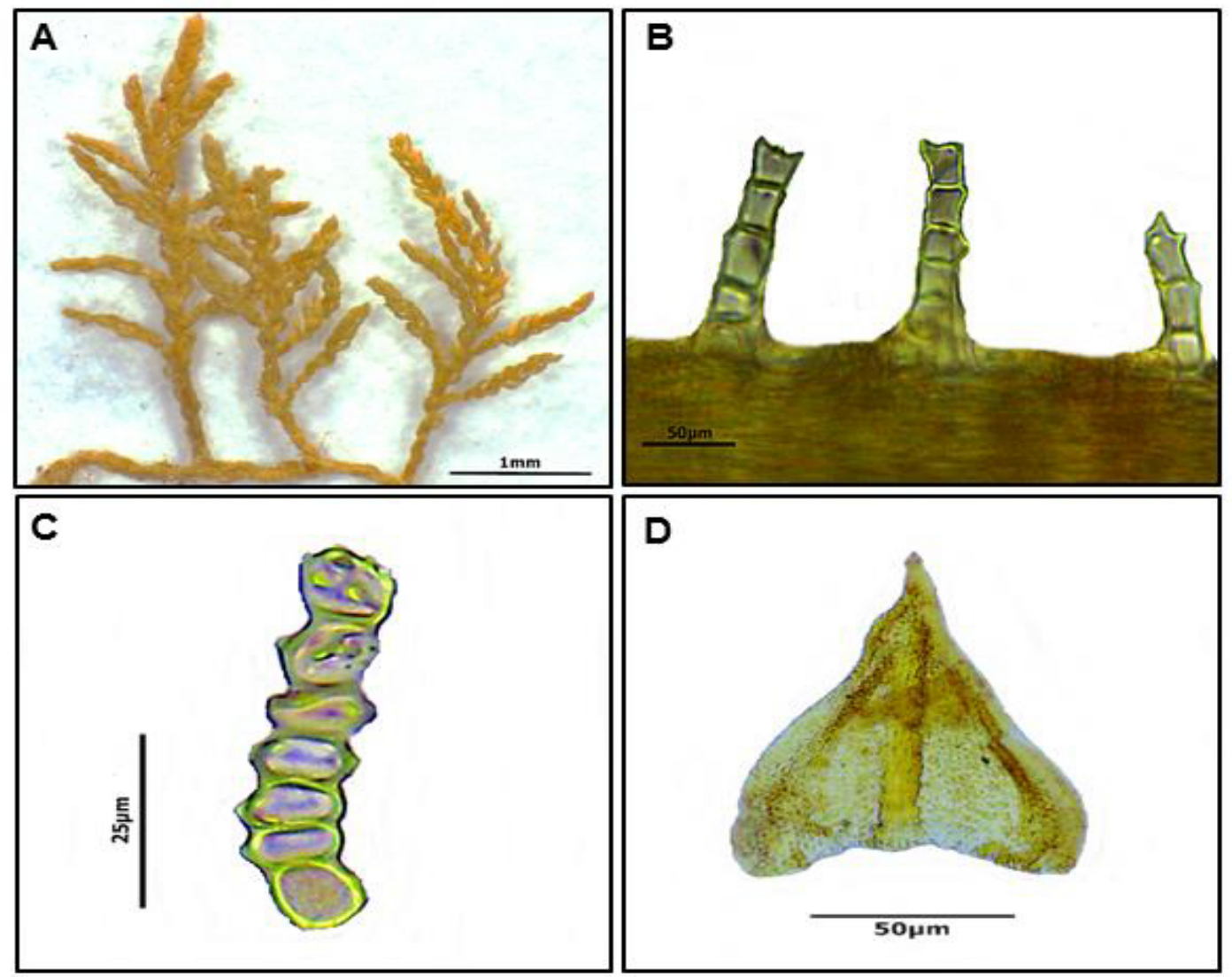

D
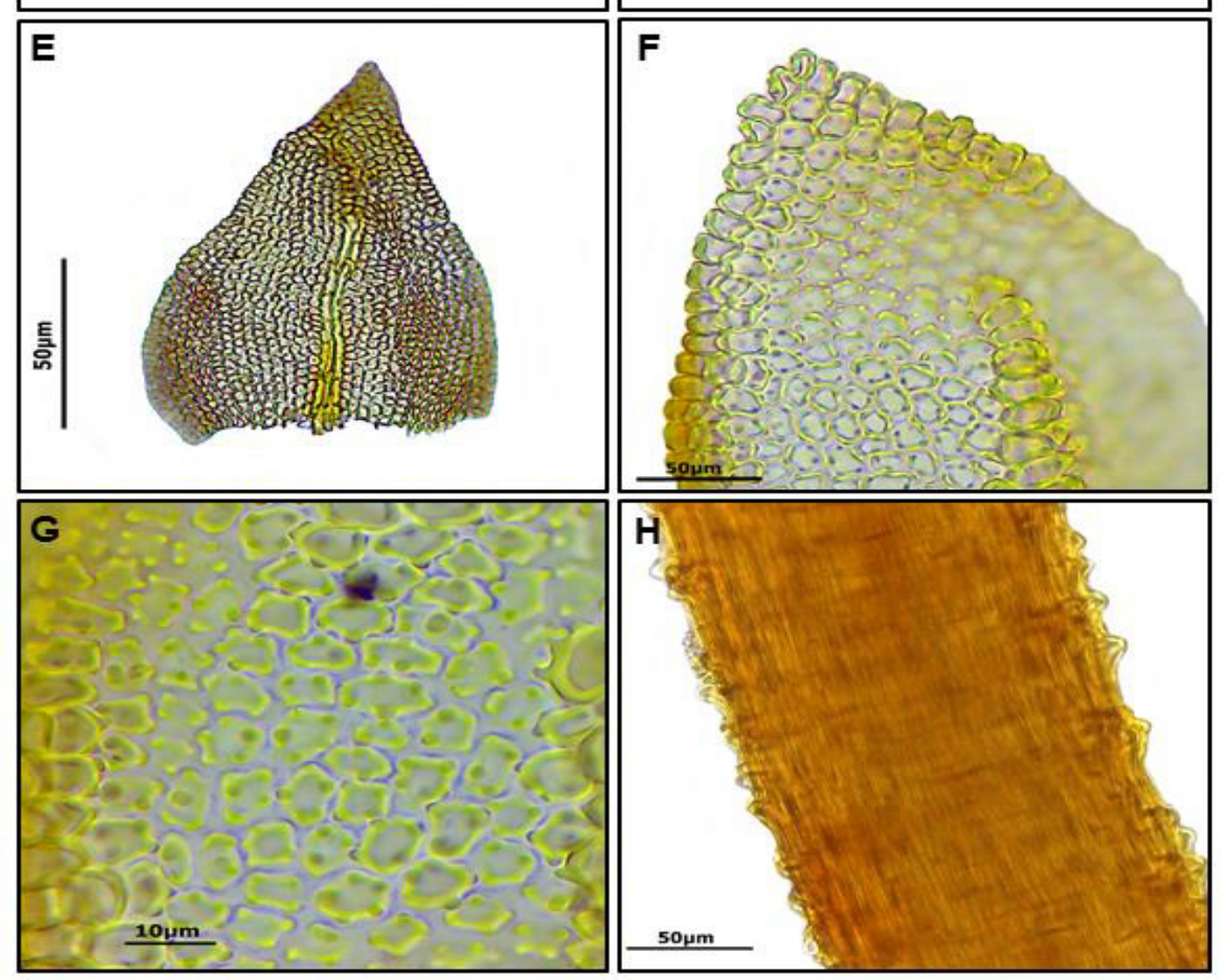

Figura 14: Pelekium schistocalyx. A: Gametófito. B e C: Paráfilo. D: Filídio do caulídio. E: Filídio ramificação secundária. F: Ápice do filídio da ramificação. G: Células pluripapilosas do filídio da ramificação. H: Seta rugosa. 
6. Pelekium siphotheca (Müll. Hal.) A. Touw, J. Hattori Bot. Lab. 90: 205. 2001. Hypnum siphotheca Müll. Hal., Bot. Zeitung (Berlin) 16: 171. 1858. Thuidium siphotheca (Müll. Hal.) A. Jaeger, Ber. Thätigk. St. Gallischen Naturwiss. Ges. 1876-77: 255. - Tipo: GUATEMALA. sine leg. (isotype: NY!).

Thuidium mexicanum Mitt., J. Linn. Soc., Bot. 12: 577. 1869. - Tipo: MÉXICO. Ruiz et Pavon s.n. (holotype: NY!).

Thuidium costaricense Broth. \& Thér., Recueil Publ. Soc. Havraise Études Diverses 88: 314. 8. 1921. - Tipo: Costa Rica, La Palma near San Jose, C. Werkle s.n. (holotype: H). Sinonimizada por Touw (2001a).

Thuidium orthocarpum Besch., Mémoires de la Société des Sciences Naturelles de Cherbourg 16: 235. 1872. - Tipo: MEXICO. Morelos, C.G. Pringle s.n. (isotype: NY!).

Fig. 15 e Fig. 16.

Plantas pequenas, ca. de $5-8 \mathrm{~cm}$ compr., delgadas, verdes a verde-amareladas. Caulídios regularmente 2-pinados, ramificações com 5-8mm compr., paráfilos abundantes nos caulídios, escassos ou ausentes nas ramificações, 20-38um compr., 2-

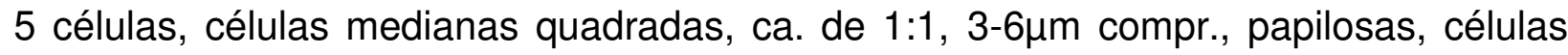
apicais agudas. Filídios dos caulídios e das ramificações diferenciados; filídios dos caulídos encurvados quando secos, patentes quando úmidos, deltóides, 0,6-0,7×0,2$0,3 \mathrm{~mm}$, acuminados, côncavos; margens crenulada-papilosas, recurvadas na metade inferior; costas simples, terminando muito próxima ao ápice, faces abaxiais fracamente

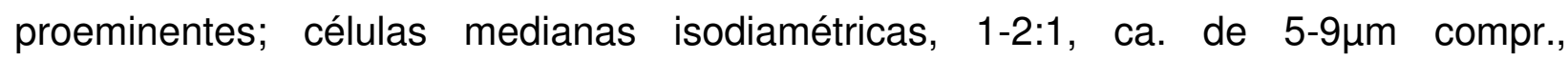
unipapilosas, papilas dispostas no centro do lúmen celular; células apicais alongadas, truncadas, lisas ou inconspicuamente papilosas. Filídios das ramificações secundárias encurvados quando secos, patentes quando úmidos, ovados, 0,2-0,3×0,1-0,2mm, agudos ou obtusos, côncavos; margens crenulada-papilosas, planas; costas com ca.

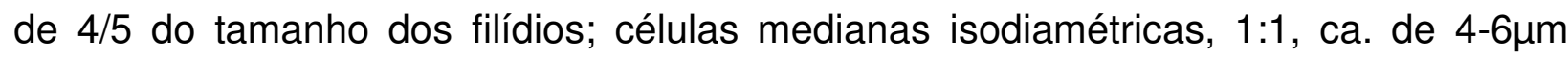
compr., delgadas, unipapilosas, papilas dispostas no centro do lúmen celular; células apicais truncadas. Monóicas. Periquécios lanceolados, ca. de 1,4mm compr., longoacuminados, subulados; margens levemente serruladas, planas; costas preenchendo os ápices; células oblongas, lisas. Setas ca. de $1,5 \mathrm{~cm}$ compr., lisas; cápsulas suberetas, ca. de 1,4mm compr., cilíndricas; células dos exotécios curto-retangulares, 
incrassadas; opérculos rostrados. Peristômios com exostômios estriados abaixo, levemente papilosos acima; endostômios com os segmentos levemente papilosos.

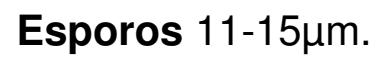

Pelekium siphotheca é uma espécie de distribuição restrita ao Cerrado, em locais altos e montanhosos, acima de $1000 \mathrm{~m}$ de altitude, facilmente distinguível por apresentar células unipapilosas, cápsula sub-ereta e principalmente por apresentar as células apicais dos paráfilos agudas, principal característica utilizada para separá-la de $P$. muricatulum que apresenta as células apicais do paráfilo truncadas.

Sua distribuição geográfica restrita, aliada a pequena extensão de ocorrência e a baixa área de ocupação, ocorrendo somente no Cerrado, Bioma que vem sofrendo diversas ameaças à sua biodiversidade, principalmente por conta da profusão das atividades econômicas do agronegócio, desperta atenção especial para seu status de conservação. Desta forma, de acordo com os critérios da IUCN (2001), P. siphotheca encontrasse Em Perigo (EN) de extinção (B1a,b(i, ii)).

Ocorrem no Cerrado, nas fitofisionomias de Mata de Galeria, sobre rochas e troncos vivos e em decomposição, em locais sombreados e úmidos, 1000-1200m alt.

Ocorrem na América do Sul e Central.

Distribuição geográfica: DF e GO.

Domínios Fitogeográficos: Cerrado. 


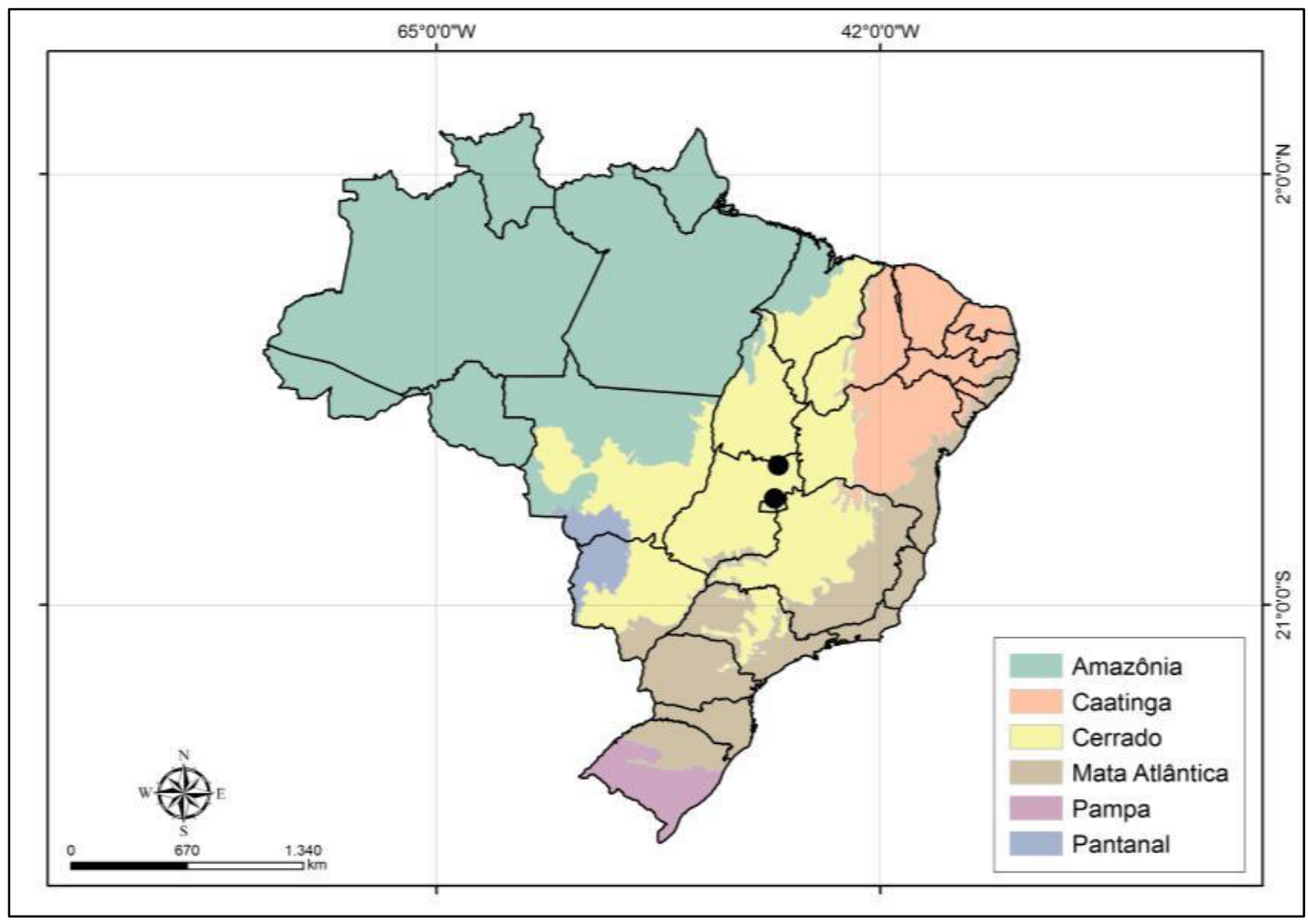

Figura 15: Mapa de distribuição de Pelekium siphotheca no Brasil.

Material analisado: Distrito Federal: Sobradinho, Irwin et al. 33253 (NY). Goiás: Alto Paraíso, Pinheiro et al. 135 (NY, UB); Cavalcante, Soares 1343 (UB). 


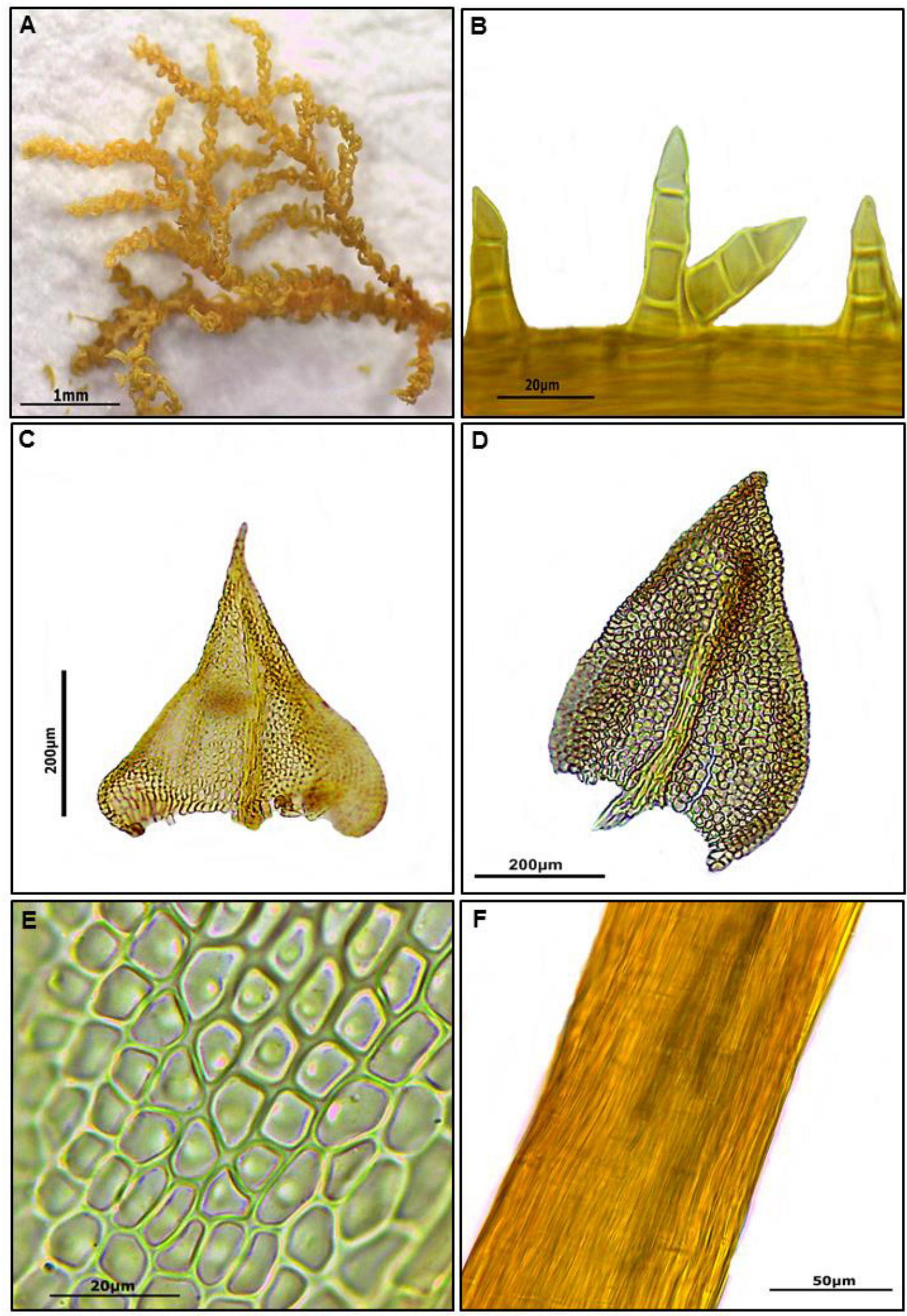

Figura 16: Pelekium siphotheca. A: Gametófito. B: Paráfilo. C: Filídio do caulídio. D: Filídio da ramificação. E: Células unipapilosas do filídio da ramificação. F: Seta lisa. 
7. Pelekium sparsum (Hook. f. \& Wilson) Soares, A.E.R. \& Câmara, P.E.A.S., comb. nov. Hypnum sparsum Hook. f. \& Wilson, Fl. Nov.-Zel. 2: 109, 89 f. 5. 1854. Thuidiopsis sparsa (Hook. f. \& Wilson) Broth., Nat. Pflanzenfam. (ed. 2) 11: 323. 1925. - Tipo: NOVA ZELÂNDIA. Wangarei, J. Bolton s.n. (holotype: BM!, isotype: NY!).

Cyrto-hypnum montei Hedenäs, Bryophyt. Biblioth. 44: 71. f. 19. 1992. - Tipo: ILHA DA MADEIRA. Barreto S.n. (syntype: MADS?). Sinonimizada por Touw (2001a).

Thuidium crispatulum Cardot, Rev. Bryol. 28: 115. 1901. - Tipo: CELEBES. sine loco, $H$. Fruhstorfer s.n. (holotype: PC!).

Thuidium filarium Mitt., J. Linn. Soc., Bot. 12: 579. 1869. - Tipo: BRASIL. sine loco, Burchell 1105-73 (holotype: NY!, isotype: L!).

Thuidium hyalopilum Dixon ex E.B. Bartram, Occas. Pap. Bernice Pauahi Bishop Mus. 19(11): 229. 1948. - Tipo: FIJl. Lautoka, G. Greenwood 889 (holotype: FH?, isotypes: BM?, L?). Sinonimizada por Touw (2001a).

Thuidium latopulvinatum Herzog, Biblioth. Bot. 87: 144. 8 f. 25-32. 1916. - Tipo: BOLIVIA. Herzog 4124 (holotype: JE!).

Thuidium liliputanum Broth., Oefvers. Förh. Finska Vetensk.-Soc. 42: 121. 1900. - Tipo: AUSTRÁLIA, New South Wales, Watts s.n. (isotype: NY!).

Fig. 17 e Fig. 18.

Plantas medianas, ca. de 7-9cm compr., verdes a verde-amareladas. Caulídios irregularmente 2-pinados, as vezes 1-pinado, ramificações com $4-9 \mathrm{~mm}$ compr., paráfilos abundantes nos caulídios, escassos nas ramificações, 45-95 $\mu \mathrm{m}$ compr., 4-10

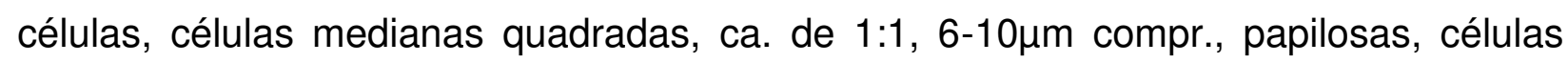
apicais truncadas. Filídios dos caulídios e das ramificações diferenciados; filídios dos caulídios encurvados quando secos, patentes quando úmidos, cordados ou deltóidecordados, $0,7-1 \times 0,5-0,7 \mathrm{~mm}$, acuminados a longo-acuminados, falcados, côncavos; margens crenulada-papilosas, recurvadas na metade inferior, planas na metade superior; costas simples, ca. de $4 / 5$ do tamanho dos filídios, faces abaxiais proeminentes; células medianas isodiamétricas, 1-2:1, ca. de 7-11 $\mu \mathrm{m}$ compr., delgadas, pluripapilosas (2-4), às vezes lisa na base e próxima a margem, ornamentações das faces abaxiais mais acentuadas; células apicais trucandas ou agudas. Filídios das ramificações secundárias encurvados quando secos, patentes 
quando úmidos, ovado-deltóides, 0,3-0,5×0,2-0,3mm, agudos, às vezes obtusos, côncavos; margens crenulada-papilosas, planas; costas com ca. de 4/5 do tamanho dos filídios; células medianas isodiamétricas, 1:1, ca. de 5-7 $\mu \mathrm{m}$ compr., delgadas, pluripapilosas (2-4); células apicais truncadas ou agudas. Dióicas. Periquécios lanceolado-ovados, ca. de 1,6mm compr., longo-acuminados, lisos; margens ciliadas, planas; costa preenchendo o ápice; células oblongas, lisas. Setas ca. de $2,5 \mathrm{~cm}$ de compr., lisas; cápsulas inclinadas, ca. de $2 \mathrm{~mm}$ compr., cilíndricas; células dos exotécios curto-retangulares, incrassadas; opérculos rostrados. Peristômios com exostômios estriados abaixo, levemente papilosos acima; endostômios com os segmentos levemente papilosos. Esporos 10-14 $\mu \mathrm{m}$.

Espécie de ampla distribuição na Mata Atlântica das regiões sul e sudeste do Brasil, em locais úmidos, sombreados e com temperaturas mais amenas. Caracterizase pelos filídios dos caulídios cordados e falcados, de fácil visualização quando os filídios estão secos, células pluripapilosas, dióicas e seta lisa.

Pelekium sparsum possui ampla distribuição na região sul do Brasil, sendo que muitas destas localidades de ocorrência estão dentro de unidades de conservação. Seu status de conservação foi considerado Pouco Preocupante (LC), pois não se enquadra em nenhuma das categorias de ameaça da IUCN (2001).

Crescem sobre rochas, solos e troncos vivos ou em decomposição, em ambientes sombreados e úmidos ou mésicos, geralmente em locais frios e com altitude mediana, 400-1600m alt.

Ocorrem na América do Sul, Ásia e Oceania.

Distribuição geográfica: ES, MG, PR, RJ, RS, SC e SP.

Domínios Fitogeográficos: Mata Atlântica. 


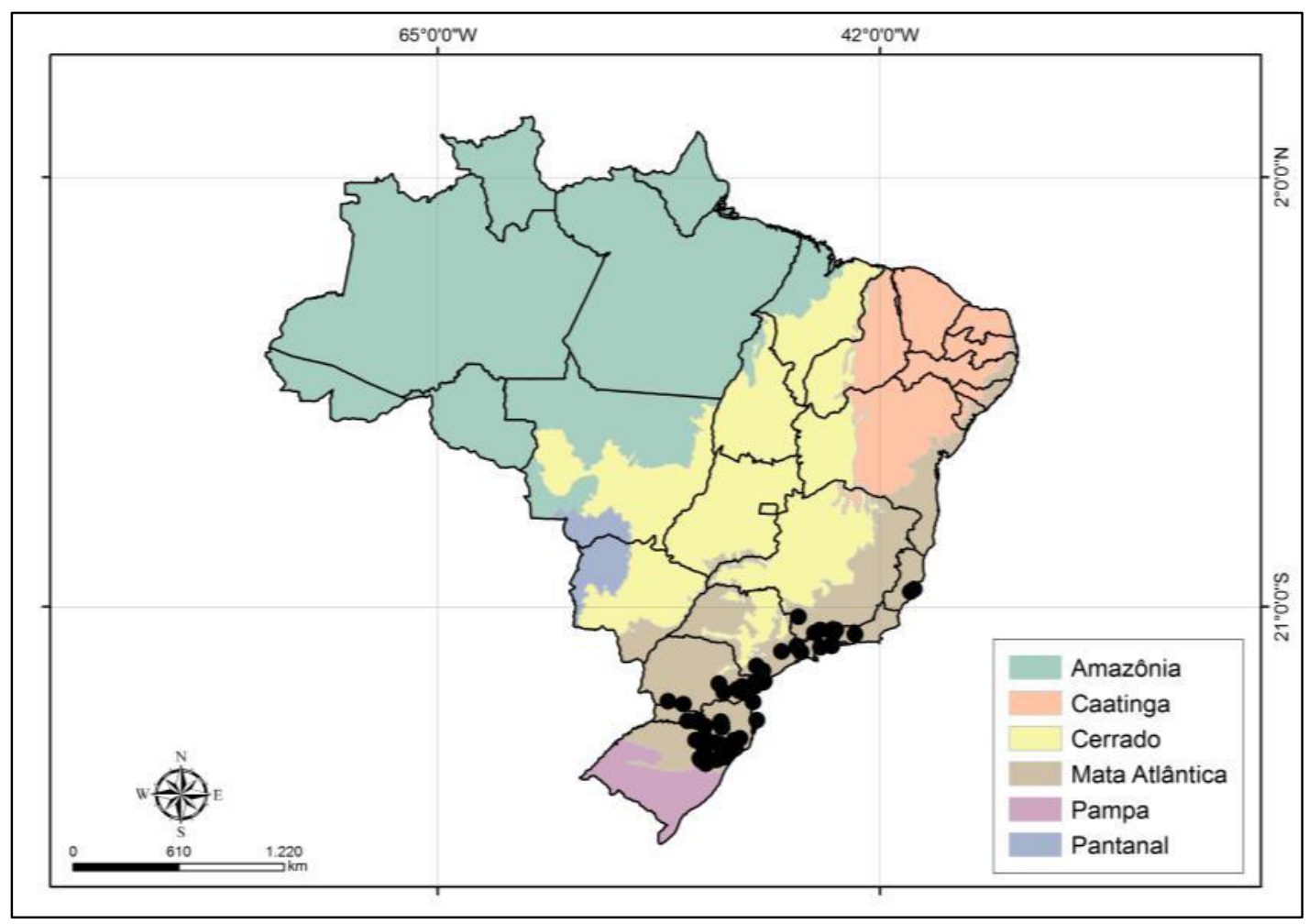

Figura 17: Mapa de distribuição de Pelekium sparsum no Brasil.

Material analisado: Espírito Santo: Domingos Martins, Schafer-Verwimp 12857 (SP); Serra, Yano et al. 4814 (SP). Minas Gerais: Caldas, Regnell s.n. (NY); Marmelópolis, Peralta 3573 (SP). Paraná: Antonina, Peralta 13127 (SP); Antônio Olinto, Wasum 3778 (SP); Clevelândia, Yano 5447 (SP); Curitiba, Yano 11363 (SP); Imbituva, Yano 6372 (SP); Lapa, Ristow 1788 (SP); Marmeleiro, Sehnem 13042 (PACA); Morretes, Yano 23158 (SP); Quatro Barras, Peralta 12720 (SP); Quintandinha, Vital 9490 (SP); São José dos Pinhais, Landrum 2428 (NY); Tijucas do Sul, Yano 27860 (SP). Rio de Janeiro: Nova Friburgo, Sehnem 7186 (PACA); Paraty, Vital 7750 (SP); Resende, Yano 7459 (SP); Rio de Janeiro, Glaziou 7926 (NY). Rio Grande do Sul: Antônio Prado, Tonini 49 (MO); Bom Jesus, Wasum 2288 (SP); Cambará do Sul, Pirani 6973 (SP); Canela, Vital 9300 (NY, SP); Caxias do Sul, Peralta \& Wasum 10617 (SP); Ciríaco, Vital 12136 (SP); Esmeralda, Wasum et al. s.n. (MO); Flores da Cunha, Wasum s.n. (MO, LE); Garibaldi, Rossato 3471 (SP); Gramado, Wasum 2147 (MO); Jaquirana, Wasum 5964 (PACA); Montenegro, Sehnem 4925 (PACA); Nova Petrópolis, Oliveira 178 (UFP); Nova Roma, Peralta 10468 (SP); Novo Hamburgo, Wasum 3696 (SP); São Francisco de Paula, Wasum et al. 2246 (MO); São Pedro, Sehnem 3714 (SP); São Salvador, Sehnem 2267 (SP); Vacaria, Vital 9358 (NY, SP). Santa Catarina: Anita Garibaldi, Reitz 15495 (SP); Bom Retiro, Sehnem 7064 (PACA); Concórdia, 
Jágmin 989 (SP); Curitibanos, Vital 9423 (NY, SP); Jaborá, Yano 6707 (SP); Lajes, Vital 9396 (NY, SP); Ponte Alta, Vital 9407 (NY, SP); Porto Belo, Yano 2434 (NY); São Joaquim, Reitz 15944 (SP); Serra da Pedra, Reitz 361 (MO); Urubici, Peralta 7960 (SP). São Paulo: Atibaia, Peralta 5626 (SP); Barra do Turvo, Peralta 8475 (SP); Cajati, Vital 5579; Campos do Jordão, Schafer-Verwimp (NY); Cananéia, Yano 8949 (SP); Cunha, Giancotti 33 (SP); Ibiúna, Yano 22433 (SP); Ilha do Cardoso, Yano 3128 (SP); Itapeva, Yano 32501 (SP); Mairiporã, Yano 4537 (SP); Mogi das Cruzes, Ristow 2636 (SP); São Bento do Sapucaí, Peralta 10109 (SP); São Luíz do Paraitinga, Yano 4294 (SP); São Roque, Vital 2151 (SP); Silveiras, Yano 1192 (SP). 

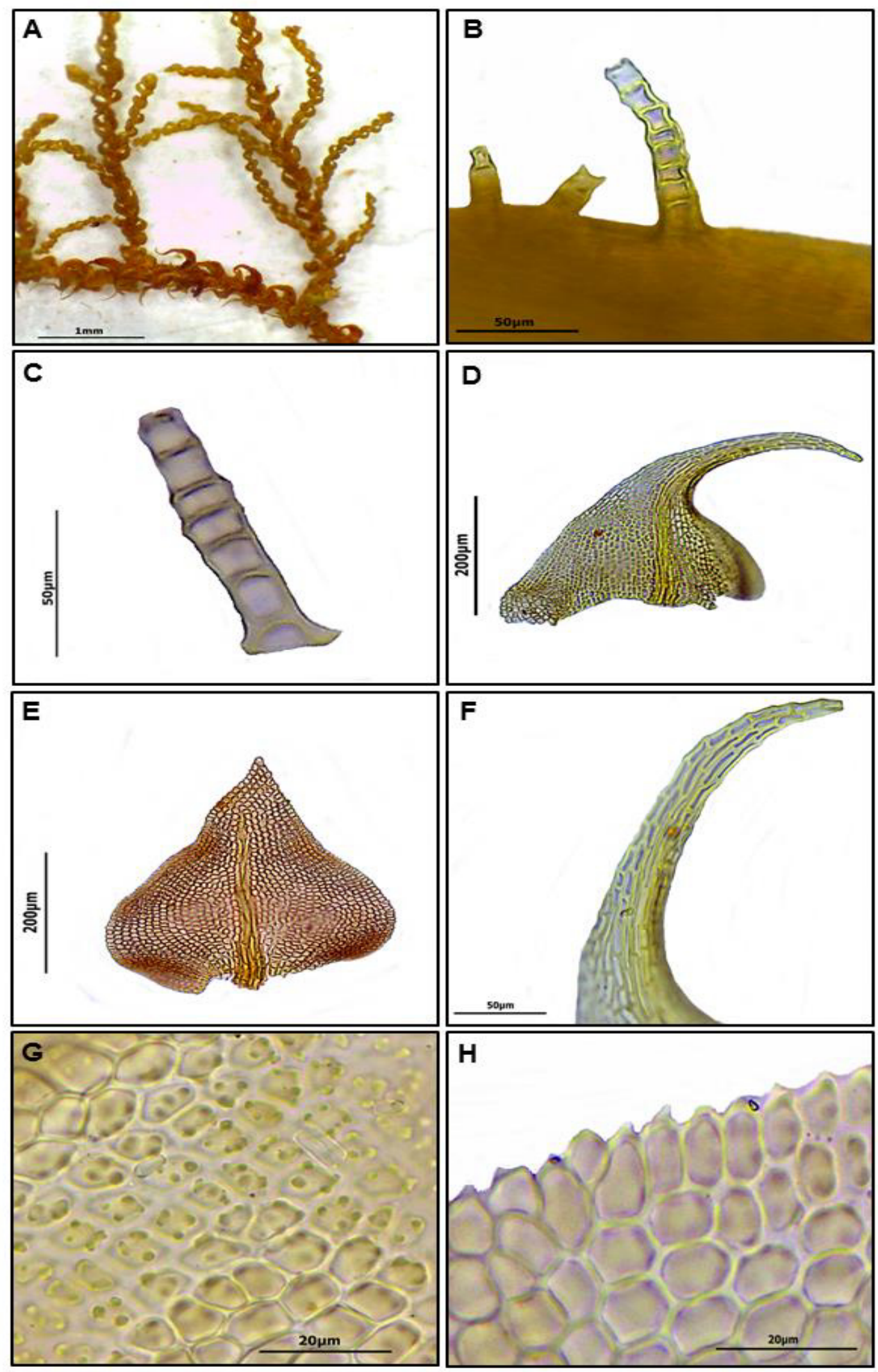

Figura 18: Pelekium sparsum. A: Gametófito. B e C: Paráfilo. D: Filídio falcado do caulídio. E: Filídio da ramificação. F: Ápice do filídio do caulídio. G: Células pluripapilosas. H: Margem do filídio. 
8. Pelekium subpinnatum (Broth.) Touw, J. Hattori Bot. Lab. 90: 205. 2001. Thuidium subpinnatum Broth. Bih. Kongl. Svenska Vetensk.-Akad. Handl. 21 Afd. 3(3): 66. 1895. - Tipo: BRASIL. Rio de Janeiro, Glaziou 11743 (holotype: H!, isotype: BM!). Fig. 19 e Fig. 20.

Plantas pequenas, ca. de 6-9cm compr., delgadas, verde-amareladas. Caulídios 1-pinado, ramificações com 4-10mm compr., paráfilos abudantes nos caulídios, escassos ou ausentes nas ramificações, $45-75 \mu \mathrm{m}$ compr., 3-8 células, células medianas retangulares a longo-retangulares, ca. de 2-4:1, 10-22 $\mu \mathrm{m}$ compr., papilas inconspícuas, às vezes lisas, células apicais agudas. Filídios dos caulídios e das ramificações similares; filídios dos caulídios encurvados quando secos, patentes quando úmidos, lanceolado-deltóides, 0,7-0,8×0,3-0,4mm, acuminados, côncavos; margens crenulada-papilosas, planas na metade inferior, recurvadas acima; costas simples, ca. de 5/4 do tamanho dos filídios ou terminando muito próximo aos ápices, faces abaxiais fracamente proeminentes; células medianas isodiamétricas a oblongas, 1-2:1, ca. de 7-11um compr., unipapilosas, papilas dispostas no centro do lúmen celular; células apicais alongadas, truncadas, lisas. Filídios das ramificações similares aos dos caulídios; menores, 0,6-0,7×0,2-0,3mm; células medianas isodiamétricas, 12:1, ca. de 6-9um compr. Monóicas. Periquécios lanceolados, ca. de 1,8mm compr., longo-acuminados, subulados; margens levemente lisas, planas; costas preenchendo os ápices; células oblongas, lisas. Setas ca. de $1,9 \mathrm{~cm}$ compr., lisas; cápsulas suberetas, ca. de 1,6mm compr., cilíndricas; células dos exotécios curto-retangulares, incrassadas; opérculos rostrados. Peristômios com exostômio estriados abaixo, levemente papilosos acima; endostômios com os segmentos levemente papilosos. Esporos $12-14 \mu \mathrm{m}$.

Espécie de distribuição bastante restrita, conhecida por apenas três coleções (MG, RJ e RS), endêmica do Brasil e de ocorrência apenas para a Mata Atlântica na região Sul e Sudeste. Caracteriza-se pelo seu gametófito 1-pinado; paráfilos com papilas incospícuas ou lisas e células do longo-retangulares, alongadas, ca. de 2-4:1, com as células apicais agudas e células dos filídios unipapilosas.

Seu status de conservação desperta atenção especial, tendo em vista sua distribuição geográfica e área de ocupação bastante restrita, próxima a grandes centros urbanos em áreas fragmentadas, fora de unidades de conservação e com duas das 
três coleções coletadas a mais de 100 anos. Diante disto, de acordo com os critérios da IUCN (2001), P. subpinnatum encontrasse Em Perigo (EN) de extinção (B1a,b(i, ii)).

Crescem sobre rochas em locais úmidos e sombreados, 200-700m alt.

Ocorrem no Brasil (endêmica).

Distribuição geográfica: MG, RJ e RS.

Domínios Fitogeográficos: Mata Atlântica.

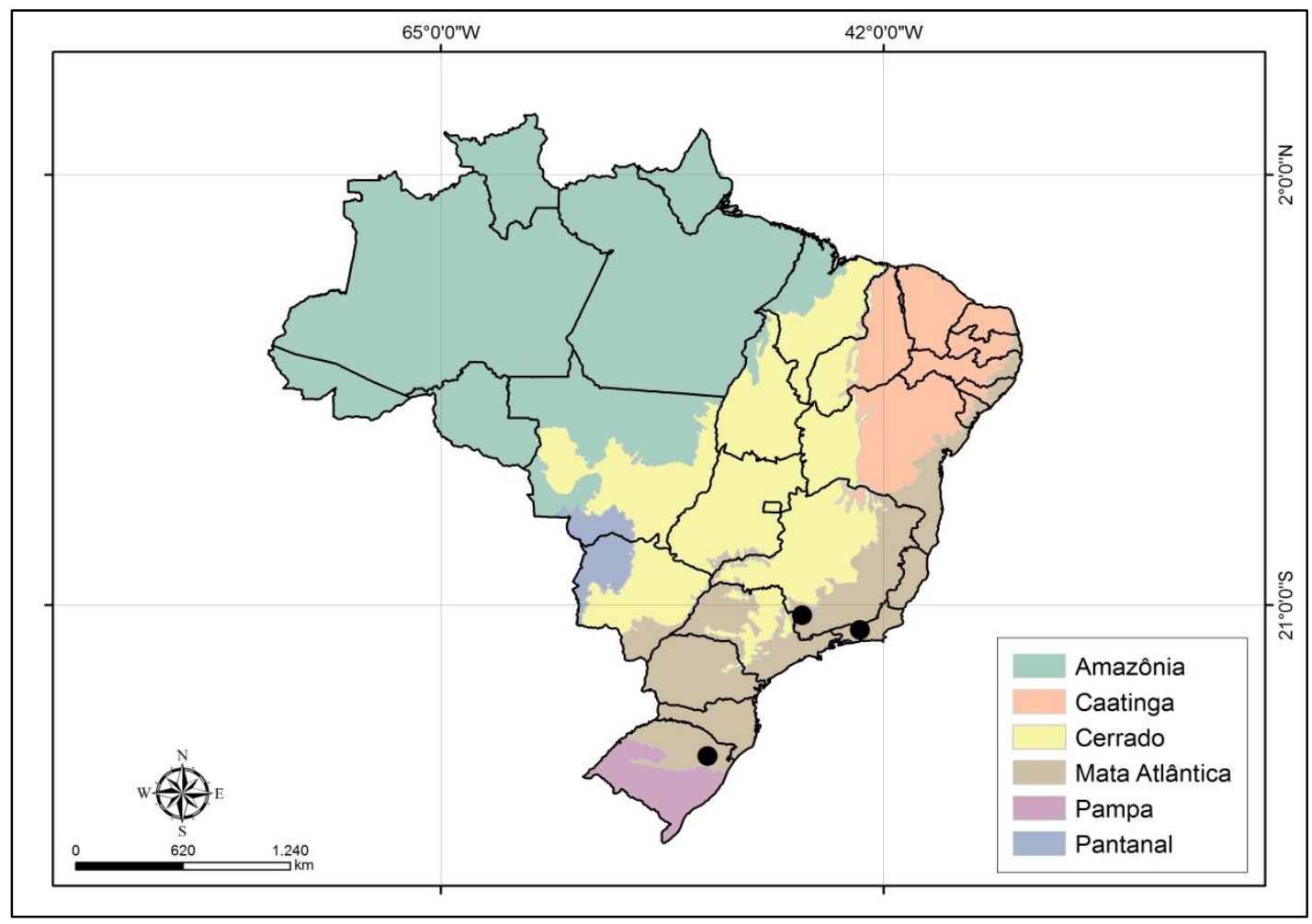

Figura 19: Mapa de distribuição de Pelekium subpinnatum no Brasil.

Material analisado: Minas Gerais: Mosén 418 (NY). Rio de Janeiro: Glaziou 11743 (BM). Rio Grande do Sul: Caxias do Sul, Peralta et al. 10617 (SP). 

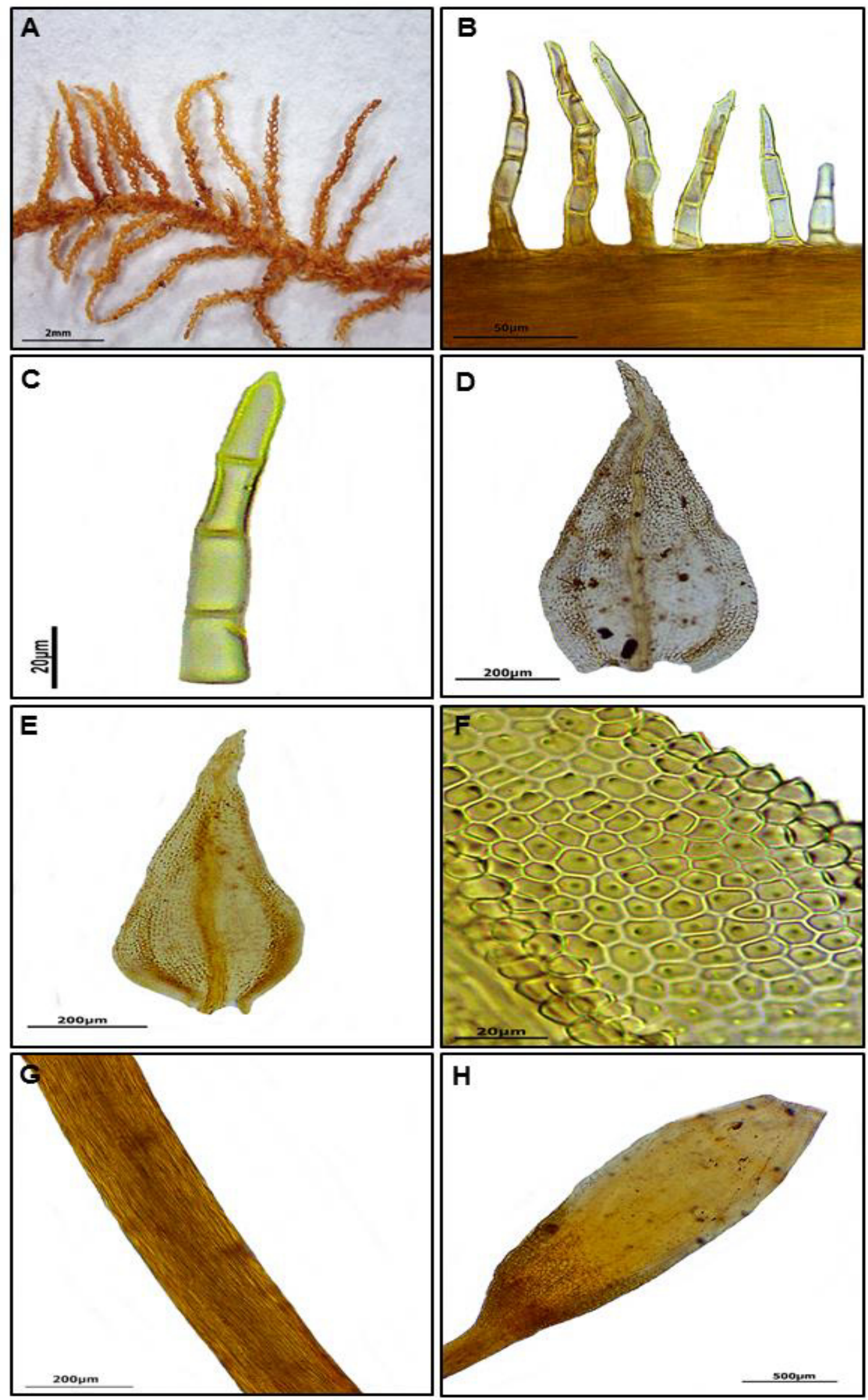

Figura 20: Pelekium subpinnatum. A: Gametófito. B e C: Paráfilo. D: Filídio do caulídio. E: Filídios da ramificação. F: Células unipapilosas. G: Seta lisa. H: Cápsula. 


\section{THUIDIUM Bruch \& Schimp.}

Thuidium Bruch \& Schimp., Bryol. Eur. 5: 157 (fasc. 49-51. Mon. 1.). 1852. Hypnum sect. Thuidium (Bruch \& Schimp.) Sull. in A. Gray, Manual, ed. 2, 667. 1864. Hypnum subg. Thuidium (Bruch \& Schimp.) Hobk., Syn. Brit. Mosses 145. 1873. Hypnum subsect. Thuidium (Bruch. \& Schimp.) Hampe, Ann. Sci. Nat., Bot., sér. 5, 5: 310. 1866. Leskea sect. Thuidium (Bruch \& Schimp.) Mitt., J. Proc. Linn. Soc., Bot. 8: 44. 1864. Thuidium subg. Thuidium (Bruch. \& Schimp.) Besch., Mém. Soc. Sci. Nat. Cherbourg. 16: 236. - Tipo: Thuidium tamariscinum (Hedw.) Bruch \& Schimp. Tipo: sine loco, in truncis humique passim, sine leg (isotype: BM!). (lectotipo designado por Buck \& Crum 1990).

Hypnum sect. Tamariscina Brid., Muscol. Recent. Suppl. 2: 135. 1812. - Thuidium sect. Tamariscina (Brid.) Bruch \& Schimp. in Bruch, Schimp. \& W. Gümbel, Bryol. Eur. 5 (fasc. 49/51, Monogr. 1): 163. 1852.

Plantas medianas a robustas, $10-30 \mathrm{~cm}$ compr, frequentemente formando tapetes entrelaçados, verdes, amareladas ou marrons. Caulídios rastejantes, arqueados ou ascendentes, regularmente 2-3 pinados; caulídios em secções transversais sem hialodermes, com uma pequena camada de células de paredes espessas, bordeadas por células largas de paredes delgadas; paráfilos abundantes nos caulídios, em menor quantidade ou ausentes nas ramificações, $110-300 \mu \mathrm{m}$, filamentosos, uniseriados, ramificados, 10-40 células, células medianas quadradas a retangulares ou longoretangulares, papilosas, células apicais truncadas, agudas ou arredondadas, pluripapilosas; pseudoparáfilos folhosos, ovado-lanceolados a deltóides; pêlos axilares com 1 (-2) células basais pequenas, marrons, 3-5 células distais, alongadas, hialinas ou amareladas. Filídios dos caulídios e das ramificações diferenciados. Filídios dos caulídios imbricados, eretos ou ereto-patentes quando secos, eretos a patentes quando úmidos, deltóides ou ovado-deltóides, acuminados, longo-acuminados ou pilíferos, curto-decurrentes, côncavos, comumente plicados; margens crenulada-papilosas ou serrulada-papilosas, recurvadas ou planas; costas percurrentes a sub-percurrentes, frequentemente $2 / 3$ ou mais do tamanho dos filídios, às vezes projetando um espinho nos ápices, faces abaxiais planas ou proeminentes; células medianas quadradas, isodiamétricas, ovais ou oblongas, $15-40 \mu \mathrm{m}$ compr., paredes delgadas ou incrassadas, frequentemente unipapilosas, raramente pluripapilosas ( $T$. tomentosum), papilas 
dispostas no centro do lúmen celular, geralmente somente nas faces abaxiais; células apicais truncadas, agudas ou arredondadas, alongadas, papilosas; células alares não diferenciadas. Filídios da primeira ramificação similares aos filídios dos caulídios. Filídios das ramificações secundárias e terciárias diferenciados no tamanho e na forma, menores, imbricados, eretos ou ereto-patentes quando secos, eretos a patentes quando úmidos, ovados a deltóide-ovados, acuminados, agudos ou obtusos, às vezes curto-decurrentes, côncavos; margens crenulada-papilosas, planas ou recurvadas; costas sub-percurrentes, ca. de $1 / 2$ a 3/4 do tamanho dos filídios, às vezes projetando um pequeno espinho nos ápices, faces abaxiais levemente proeminentes; células medianas isodiamétricas, arredondas ou retangulares, 10-25 $\mu \mathrm{m}$ compr., delgadas ou incrassadas, unipapilosas, raro pluripapilosas (T. tomentosum), papilas dispostas no centro do lúmen celular, geralmente somente nas faces abaxiais; células apicais frequentemente truncadas, agudas ou arredondadas, papilosas; células alares não diferenciadas. Dióicas. Periquécios lanceolados, acuminados, longo-acuminados a filiformes, plicados; margens serruladas, ciliadas ou não, planas; costas fortes, percurrentes a sub-percurrentes; células oblongas a lineares, lisas ou papilosas. Setas alongadas, delgadas, $2-5 \mathrm{~cm}$ compr., avermelhadas, lisas; cápsulas horizontais ou inclinadas, 3-4mm compr., lisas, assimétricas, cilíndricas ou ovóides; células dos exotécios isodiamétricas ou retangulares, paredes delgadas ou incrassadas; ânulos diferenciados; opérculos cônicos ou rostrados. Peristômios com exostômios amarelados ou avermelhados, lanceolados, bordeados, estriados abaixo, papilosos acima, trabeculados; endostômios lanceolados, quilhados, estritamente perfurados, nodosos, com a membrana basal alta; cílios em grupos de 2-3. Esporos esféricos, 8$19 \mu \mathrm{m}$, lisos ou levemente papilosos. Caliptras cuculadas, lisas.

Thuidium é um gênero extremamente cosmopolita de Thuidiaceae, ocorrendo das áreas boreais do hemisfério norte a áreas tropicais da Ásia, Pacífico e Américas e também na África, Austrália e Nova Zelândia (Touw 2001a). Acredita-se que atualmente existam ca. de 20-25 espécies a nível mundial (Touw 2001a). Gier (1980) listou a ocorrência de 17 espécies de Thuidium para a América Latina, porém seu trabalho não levou em consideração a presença de vários sinônimos. Para o Brasil são reconhecidas neste trabalho oito espécies, distribuídas principalmente em áreas florestais na Mata Atlântica. 
Espécies de Thuidium são freqüentes encontradas sobre o solo de florestas, base de árvores, troncos vivos ou em decomposição e rochas, principalmente quando associadas a ambientes úmidos. De acordo com Touw (2001a), nos trópicos o gênero é representado principalmente por espécies de montanhas e altas altitudes, poucas espécies tem ampla distribuição vertical e próximo ao nível do mar.

O gênero apresenta alguns problemas na delimitação das espécies causada pela ausência de caracteres morfológicos distintivos, combinada com características que muitas vezes se sobrepõem (Touw 2001a), o que por vezes torna difícil a delimitação destas espécies.

Thuidium caracteriza-se pelos caulídios robustos, com ramificações regularmente 2-3 pinada, abundantes paráfilos ramificados e papilosos, dióicas, células geralmente unipapilosas (exceção T. tomentosum), filídios periqueciais grandes e seta lisa. $O$ gênero recebeu esse nome porque seu padrão de ramificação assemelha-se ao padrão de ramificação frondoso de uma conífera chamada Thuja (Crum \& Anderson 1981).

\section{Chave para as espécies}

1. Filídio com célula pluripapilosa

7. T. tomentosum

1. Filídio com céula unipapilosa

2. Filídio do ramo com célula apical pontuda, lisa

6. T. tamariscinum

2. Filídio do ramo com célula apical truncada, papilosa

3. Ápice do filídio do caulídio filiforme, afilado, alongado, constituído de 2-4 células alongadas e pelúcidas 1. T. assimile

3. Ápice do filídio do caulídio acuminado ou longo-acuminado, não afilado, constituído de no máximo 1 célula, colorida

4. Paráfilo com células retangulares, alongadas, ca. de 3-5:1

5. Filídios da ramificação com células ovais a isodiamétricas; costa com ca. de 2/3-3/4 do tamanho do filídio

4. T. delicatulum

5. Filídios da ramificação com células alongadas, elípticas a retangularlinear; costa com ca. de 1/2 do tamanho do filídio 3. T. brasiliense

4. Paráfilo com células quadráticas, ca. de 1-2:1

6. Costa do filídio do caulídio preenchendo o ápice 8.T. urceolatum 
6. Costa do filídio do caulídio não preenchendo o ápice

7. Células do filídio da ramificação com papilas bífidas ou trifídas; filídios do caulídios com 0,7-1 mm compr., ápice ereto 2. T. bifidum 7. Células do filídio da ramificação com papilas simples, não ramificadas; filídios do caulídio com 1,4-2mm compr., ápice frequentemente falcado ...

5. T. pseudoprotensum

1. Thuidium assimile (Mitt.) A. Jaeg., Ber. Thätigk. St. Gallischen Naturwiss. Ges. 1876-77: 260. 1878. Leskea assimilis Mitt., J. Proc. Linn. Soc., Bot., Suppl. 2: 133. 1859. - Tipo: ÍNDIA. Kumaon, R. Strachey \& J.E. Winterbottom 92=74b (holotype: $N Y$ !, isotype: BM! H!).

Thuidium philibertii Limpr., Laubm. Deutschl. 2: 835. 1895. - Tipo: SUIÇA. Canton de Vaud, Philibert s.n. (lectotype: BP?). FRANÇA. Louhans, Philibert s.n. (isosyntypes: AUT?). Vosges, Philibert s.n. (isosyntypes: AUT?). Champagnat, Philibert s.n. (isosyntypes: AUT?). Sinonimizada por Touw (2001a).

Thuidium matarumense Besch., Ann. Sci. Nat., Bot., sér. 6, 10: 290. 1880. - Tipo: ILHA REUNIÃO. Cilaos, Valentin s.n. (holotype: BM!).

Thuidium subserratum Renauld \& Cardot., Bull. Soc. Roy. Bot. Belgique 32(1): 110. 1894. - Tipo: GRANDE COMORE. sine loco, Humblot s.n. (holotype: PC!, isotype: NY!, S!).

Fig. 21 e Fig. 22.

Plantas robustas, $15-20 \mathrm{~cm}$ compr., verde-amareladas. Caulídios arqueados, frequentemente 2-pinado, raro 3-pinado, ramificações com 15-20mm compr.; paráfilos abundantes, em menor quantidade nas ramificações, $130-240 \mu \mathrm{m}$ compr., $15-30$

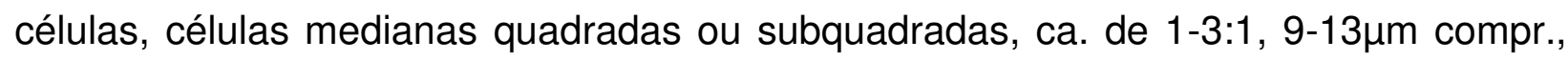
papilosas, 1 papila por célula, células apicais truncadas. Filídios dos caulídios adpressos ou eretos quando secos, patentes quando úmidos, deltóides, ovadodeltóides ou deltóide-lanceolados, 1,2-1,8x-0,8-1,1 mm, filiformes, ápices constituídos de 2-4 células alongadas ou retangulares, pelúcidas, às vezes falcados, côncavos, plicados; margens crenulada-papilosas, recurvadas abaixo, planas acima; costas subpercurrentes, terminando muito próxima aos ápices, ca. de 9/10 do tamanho dos 
filídios, faces abaxiais fortemente proeminentes, rugosas na metada inferior; células

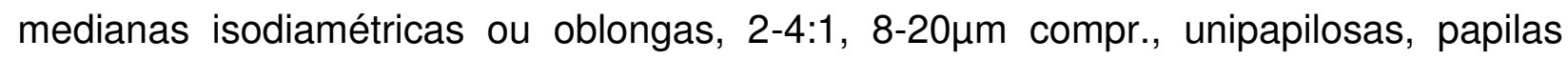
altas, retas, às vezes recurvadas, paredes celulares incrassadas; células apicais alongadas, lisas, pelúcidas. Filídios das ramificações secundárias eretos quando secos, patentes quando úmidos, 0,4-0,6×0,2-0,3mm, agudos, côncavos; margens crenuladapapilosas, planas; costas ca. de a $2 / 3$ do tamanho dos filídios, frequentemente bifurcadas no ápice; células medianas isodiamétricas, 1-2:1, ca. de 6-10 $\mu \mathrm{m}$ compr., unipapilosas, papilas altas ou baixas, retas, paredes celulares incrassadas; células apicais truncadas. Periquécios lanceolados, ca. de $5 \mathrm{~mm}$ compr., subulados, filiformes, fortemente plicados; margens serruladas, planas; costas sub-percurrentes; células oblongas, lisas. Setas ca. de $3 \mathrm{~cm}$ compr.; cápsulas inclinadas, ca. de 2,5mm compr., cilíndricas; células dos exotécios retangulares, incrassadas; opérculos rostrados. Peristômios avermelhados, exostômios bordeados, estriados abaixo, papilosos acima, trabeculados; endostômios lanceolados, quilhados, estritamente perfurados. Esporos 12-17um, levemente papilosos.

São espécies típicas de altas altitudes, sendo que no Brasil ocorrem somente acima de $1.000 \mathrm{~m}$ de altitude em regiões de Mata Atlântica. De acordo com Touw (2001b), T. assimile pertence a um complexo de espécies pobremente definidas que inclui os taxas $T$. delicatulum var. radicans (Kind.) Crum, Steere \& Anders., $T$. cymbifolium (Dozy \& Molk.) Dozy \& Molk., T. kanedae Sakurai e T. laeviusculum (Mitt.) Jaeg, sendo que as características para diferenciar estas espécies são bastante variáveis e se sobrepõem. Caracteriza-se pelo ápice dos filídios dos caulídios subulados ou filiformes, constituído de 2-4 células alongadas e pelúcidas que facilmente se quebram, dificultando a visualização do ápice, o que requer cuidado na montagem das lâminas.

Possui distribuição geográfica restrita, baixa amplitude altitudinal e longitudinal, ocorrendo somente acima dos $1.000 \mathrm{~m}$ de altitude em apenas em seis localidades, faz com que seu status de conservação, de acordo com os critérios da IUCN (2001), seja classificado como Vulnerável - VU (B1a,b(i, ii)).

Crescem sobre solos e rochas, em locais úmidos, montanhosos, em altas altitudes, geralmente entre 1000-2000m alt.

Ocorrem na América do Sul, do Norte, África e Ásia, sempre em regiões altas e montanhosas. 
Distribuição geográfica: RJ e SP.

Domínios Fitogeográficos: Mata Atlântica.

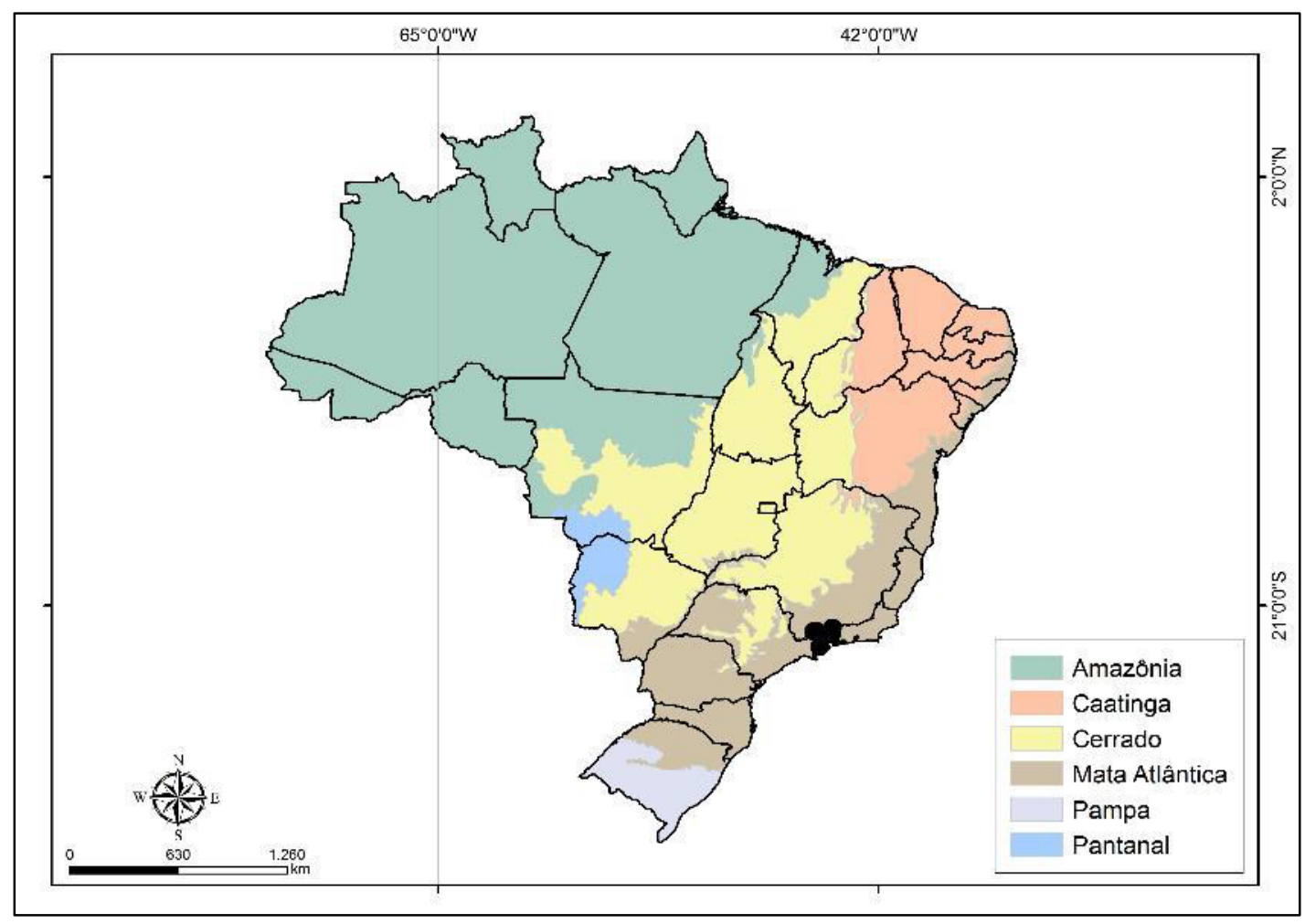

Figura 21: Mapa de distribuição de Thuidium assimile no Brasil.

Material Analisado: Rio de Janeiro: Parque Nacional do Itatiaia, Soares et al. 1772 (UB). São Paulo: Campos do Jordão, Soares 2025 (UB); Parque Nacional da Bocaína, Sucre 2859 (MO); Pindamonhangaba, Peralta 12428 (SP); São Bento do Sapucaí, Peralta 10097 (SP) e Serra do Mar, Vital 15186 (SP). 

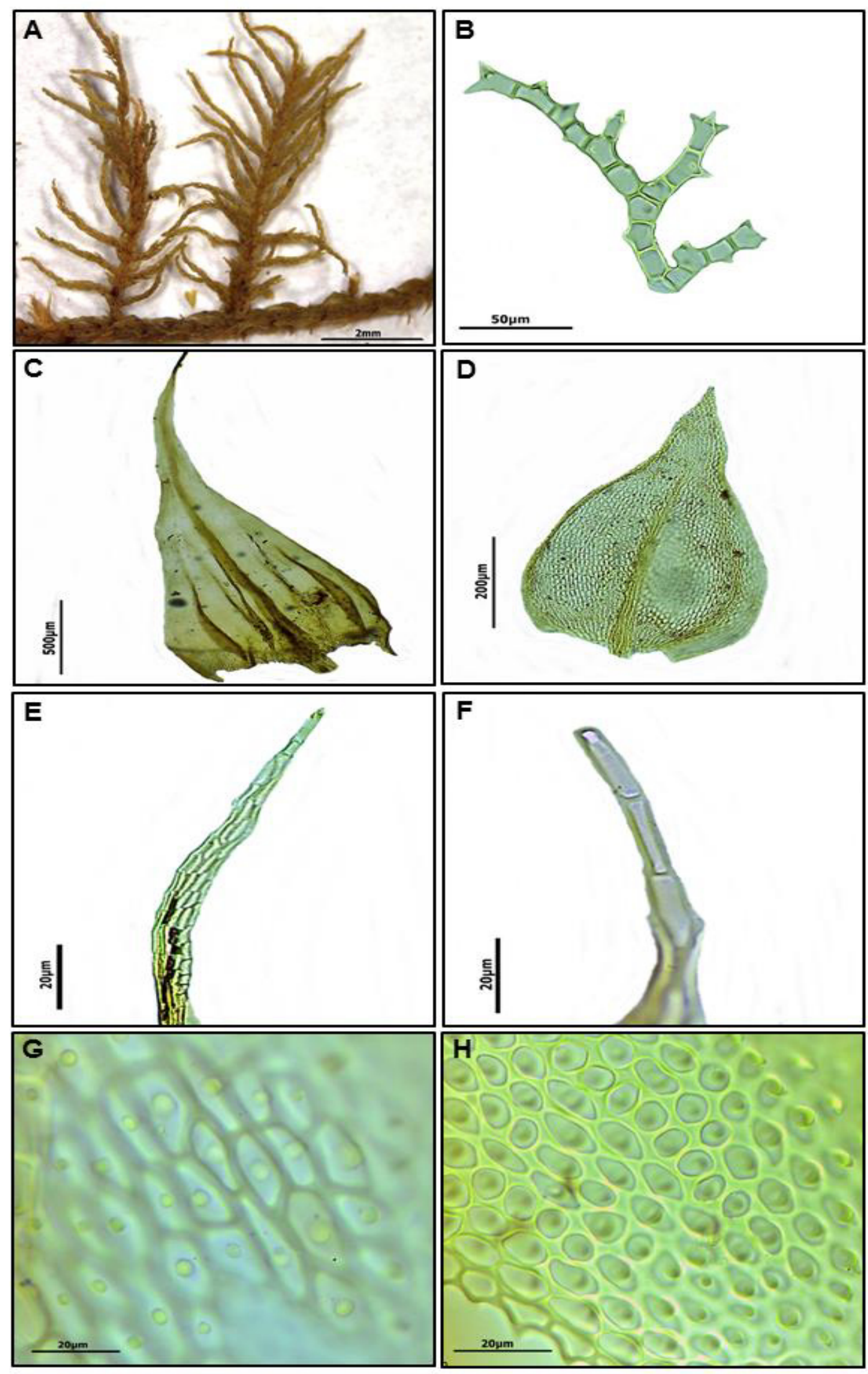

Figura 22: Thuidium assimile. A: Gametófito. B: Paráfilo. C: Filídio do caulídio. D: Filídio da ramificação. E: Ápice do filídio. F: Células do ápice do filídio. G: Células unipapilosas do filídio do caulídio. H: Células unipapilosas do filídio do ramo. 
2. Thuidium bifidum Soares, A.E.R. \& Câmara, P.E.A.S., Bryologist in press - Tipo: BRASIL, São Paulo, Itapeva, D.F. Peralta 11461 (holotype: SP!, isotype: UB!).

Fig. 23 e Fig. 24.

Plantas medianas, $7-10 \mathrm{~cm}$ compr., verdes a verde-amareladas. Caulídios arqueados, 2-pinado (raramente 3-pinado), ramificações com 5-10 mm compr.; paráfilos abundantes, em menor quantidade nas ramificações, 120-280 $\mu \mathrm{m}$ compr., 8-20 células, células medianas quadradas, pequenas, ca. de 1-2:1, 6-15um compr., papilosas, 2-3 papilas por células, células apicais truncadas. Filídios dos caulídios adpresso-eretos quando secos, patentes quando úmidos, deltóides ou ovado-deltóides, 0,7-1×0,30,5mm, acuminados, côncavos, levemente plicados; margens crenulada-papilosas ou serrulada-papilosas, recurvadas abaixo, levemente recurvadas acima ou planas; costas sub-percurrentes, ca. de 4/5 do tamanho dos filídios, faces abaxiais proeminentes, rugosas na metade inferior; células medianas isodiamétricas ou quadradas, 1-2:1, ca. de 8-12 $\mu \mathrm{m}$ compr., unipapilosas, papilas bífidas ou trífidas, altas, ambos os lados, inconspícuas nas faces adaxiais, paredes celulares delgadas; células apicais agudas, às vezes lisas. Filídios das ramificações secundárias, eretos quando secos, patentes quando úmidos, ovado-deltóides, 0,3-0,6X0,15-0,3mm, agudos, côncavos; margens crenulada-papilosas, planas; costa ca. de $2 / 3$ a $3 / 4$ do tamanho dos filídios, às vezes bifurcadas no ápice, levemente proeminentes nas faces abaxiais; células medianas

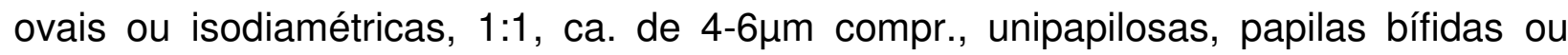
trífidas, altas, ambos os lados, inconspícuas nas faces adaxiais, paredes celulares delgadas; células apicais truncadas, com 1-2 papilas ou lisas. Periquécios lanceolados ou deltóide-lanceolados, ca. de 3mm compr., filiformes; margens serruladas acima, lisas abaixo, ciliadas na metade superior, planas; costas sub-percurrentes; células oblongas ou retangulares, lisas. Setas ca. de $2-4 \mathrm{~cm}$ compr., cápsulas horizontais, ca. de $3 \mathrm{~mm}$ compr., cilíndricas; células dos exotécios sub-quadradas; opérculos não observados. Peristômios vermelho-amarelados, exostômios bordeados, estriados abaixo, levemente papilosos acima, trabeculados; endostômios lanceolados, quilhados, estritamente perfurados. Esporos 8-15um, levemente papilosos.

Thuidium bifidum é uma espécie nova, descrita recentemente, endêmica do Brasil, sendo ainda pouco conhecida, apesar dos registros e da experiência dos autores com o grupo indicarem que sua distribuição tende a ser mais ampla do que a 
atualmente conhecida. Caracteriza-se por apresentar células unipapilosas com papilas bífidas ou trífidas, ou seja, que apresentam sua origem em um ponto central da célula, bifurcando-se em duas ou três extremidades somente no ápice, o que por vezes confere um aspecto estrelado ao ápice da papila. Também podem ser reconhecidas pelas células dos paráfilos quadradas, com 2-3 papilas por células e pelo gametófito bipinado. Pode ser confundida com T. tomensotum, que difere por possuir células tipicamente pluripapilosas, 1-2 papilas por paráfilo e filídio do caulídio com a base mais larga.

Sua ocorrência é conhecida apenas em seis localidades, destas três estão em áreas desprotegidas perto de centros urbanos e as demais estão em áreas protegidas, como o Parque Nacional de Itatiaia e RPPN Caraça. Os padrões de distribuição e a experiência do autor com a família Thuidiaceae no Brasil, sugerem que Thuidium bifidum pode ocorrer em outras áreas florestais, particularmente em áreas de Mata Atlântica e Mata de Galeria. Desta forma, pelo fato de não se encaixar em nenhuma dos critérios para ser definido como "em perigo" (CR, EN, VU), a espécie foi classificada como Quase Ameaçada (NT) de acordo com os critérios da IUCN (2001).

Ocorrem sobre rochas e troncos vivos ou em decomposição, no interior de áreas florestais, em locais sombreados e úmidos, geralmente próximos ao curso d’água, 400$1.300 \mathrm{~m}$ alt.

Distribuição Geográfica: GO, MG, RJ, RS, SC e SP.

Domínios Fitogeográficos: Cerrado e Mata Atlântica. 


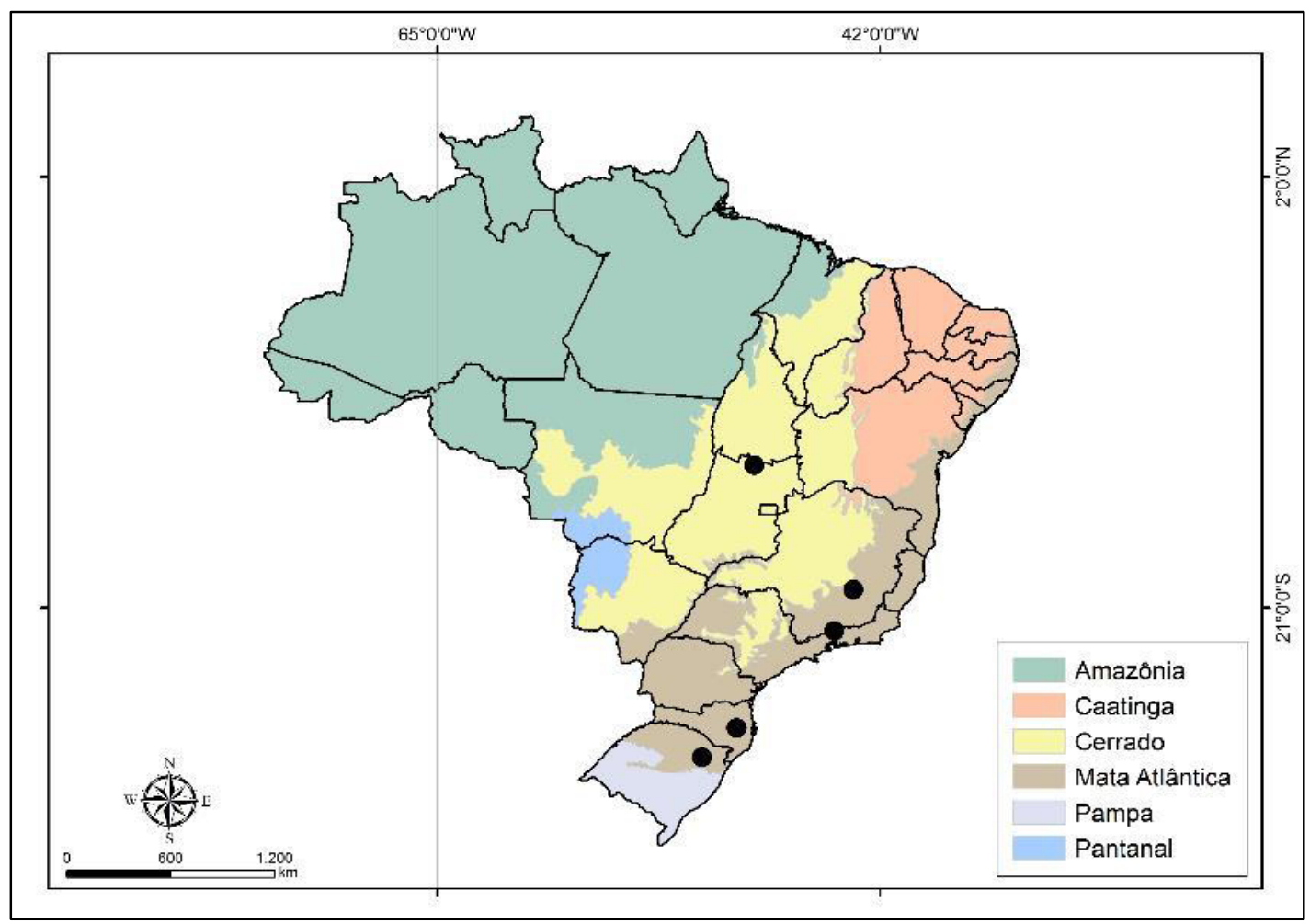

Figura 23: Mapa de distribuição de Thuidium bifidum no Brasil.

Material analisado: Goiás: Formoso, Vital 12790 (SP). Minas Gerais: Nova Lima, Peralta 11646 (SP). Rio de Janeiro: Itatiaia, Soares 1813 (UB). Rio Grande do Sul: Nova Roma do Sul, Oliveira 250 (UFP). Santa Catarina: Sehnem 14384 (PACA). 

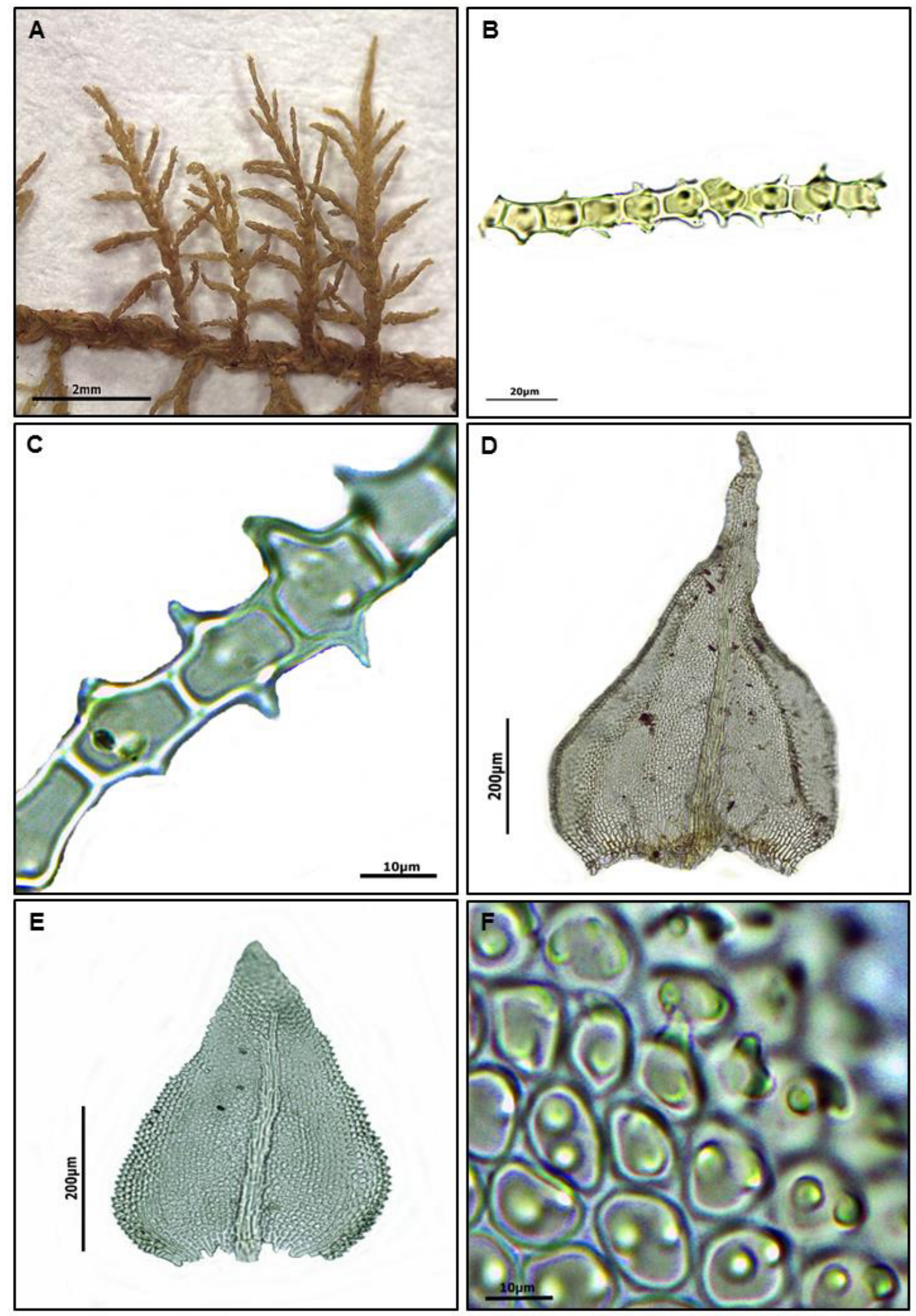

Figura 24: Thuidium bifidum. A: Gametófito. B: Paráfilo. C: Paráfilo, em detalhe células quadradas e papilas. D: Filídio do caulídio. E: Filídio da ramificação. F: Células unipapilosas bifídas. 
3. Thuidium brasiliense Mitt., J. Linn. Soc., Bot. 12: 579. 1869. - Tipo: BRASIL. sine loco, Burchell 3788 (holotype: NY!).

Fig. 25 e Fig. 26.

Plantas medianas, $12-20 \mathrm{~cm}$ compr., verde-amareladas. Caulídios ascendentes, 2 a 3-pinados, ramificações com 12-15mm compr.; paráfilos abundantes, em menor quantidade nas ramificações, 150-205 $\mu \mathrm{m}$ compr., 10-25 células, células medianas retangulares a longo-retangulares, ca. de 3-5:1, 18-27 $\mu \mathrm{m}$ compr., papilosas, com 1-2 papilas por células, células apicais truncadas ou agudas. Filídios dos caulídios eretos ou ereto-patentes quando secos, patentes quando úmidos, deltóides, 1,2-1,8×0,91,2mm, acuminados, côncavos, plicados; margens crenulada-papilosas, recurvadas abaixo, planas acima; costas sub-percurrentes, ca. de 3/4 do tamanho dos filídios, faces abaxiais proeminentes, rugosas na metade inferior; células medianas retangulares a longo-retangulares, sinuosas, 3-6:1, ca. de $28-36 \mu \mathrm{m}$ compr., unipapilosas, papilas pequenas, eretas, paredes celulares delgadas; células apicais truncadas. Filídios das ramificações secundárias e terciárias, eretos ou ereto-patentes quando secos, patentes quando úmidos, ovados a ovado-deltóides, 0,6-0,8×0,3-0,4mm, agudos, côncavos; margens crenulada-papilosas, planas; costa ca. de 2/3 a 1/2 do tamanho dos filídios; células medianas alongadas, longo-retangulares, retangular-linear

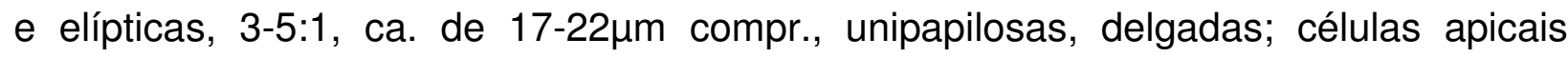
truncadas. Periquécio, Seta, Peristômio e Esporos não foram observados.

Caracteriza-se pelos filídios com células medianas longo-retangulares, alongadas, sinuosas, unipapilosas e paráfilos com células retangulares ou longo-retangulares. Pode ser confundida com $T$. delicatulum, diferindo pela morfologia das células que são retangulares em $T$. delicatulum.

Espécie endêmica do Brasil, de distribuição restrita as regiões Sul e Sudeste. Ocorrem em diversas áreas inseridas dentro de unidades de conservação. Foi considerada Quase Ameaçada (NT), pois ao ser avaliada pelos critérios da IUCN (2001), não se qualifica em nenhuma das categorias de ameaça, mas está perto da qualificação.

Ocorrem sobre rochas e solos, em locais úmidos ou parcialmente secos, sombreados ou pouco expostos ao sol, em altitudes medianas a altas, $800-1600 \mathrm{~m}$ alt.

Distribuição geográfica: MG, PR, RJ, RS, SC e SP. 
Domínios Fitogeográficos: Mata Atlântica.

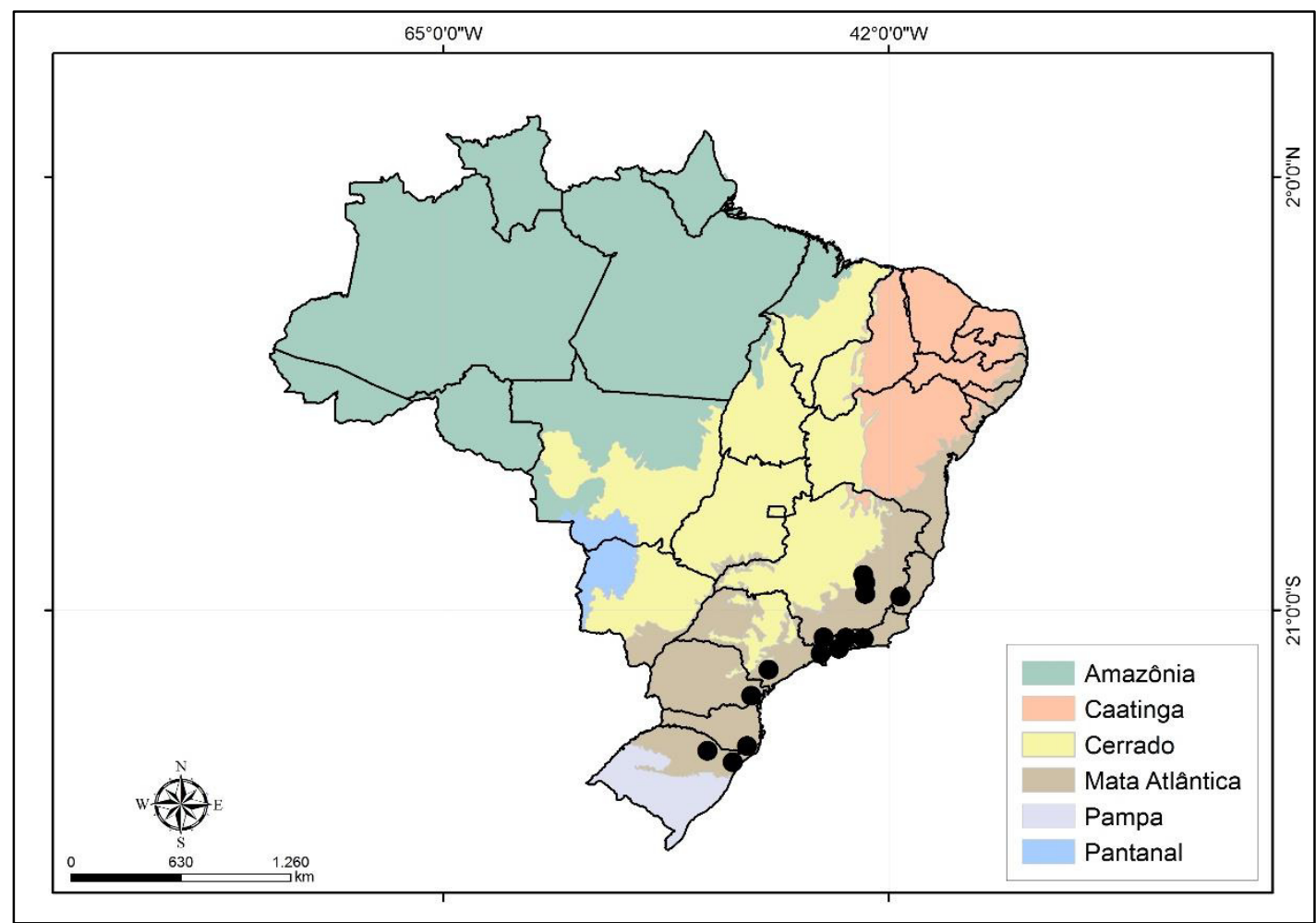

Figura 25: Mapa de distribuição de Thuidium brasiliense no Brasil.

Material analisado: Minas Gerais: Caraça, Windisch 468 (SP); Parque Nacional do Caparaó, Buck 26895 (NY); Santa Barbara, Buck 26624 (SP); Santana do Riacho, Câmara 1949 (SP). Paraná: Tijuca do Sul, Silva 795 (SP). Rio de Janeiro: Rio de Janeiro, Mills s.n. (NY). Rio Grande do Sul: Cambará do Sul, Vital \& Buck 12234 (NY); Nova Prata, Wasum s.n. (NY). Santa Catarina: Serra Geral, Vital \& Buck 12411 (SP). São Paulo: Alto da Serra, Wacket \& Decker 720 (JE); Campos da Cunha, Peralta 3709 (SP); Campos do Jordão, 26294 (SP); Guapiara, Vital 20512 (SP) e Salesópolis, Vital s.n. (SP). 


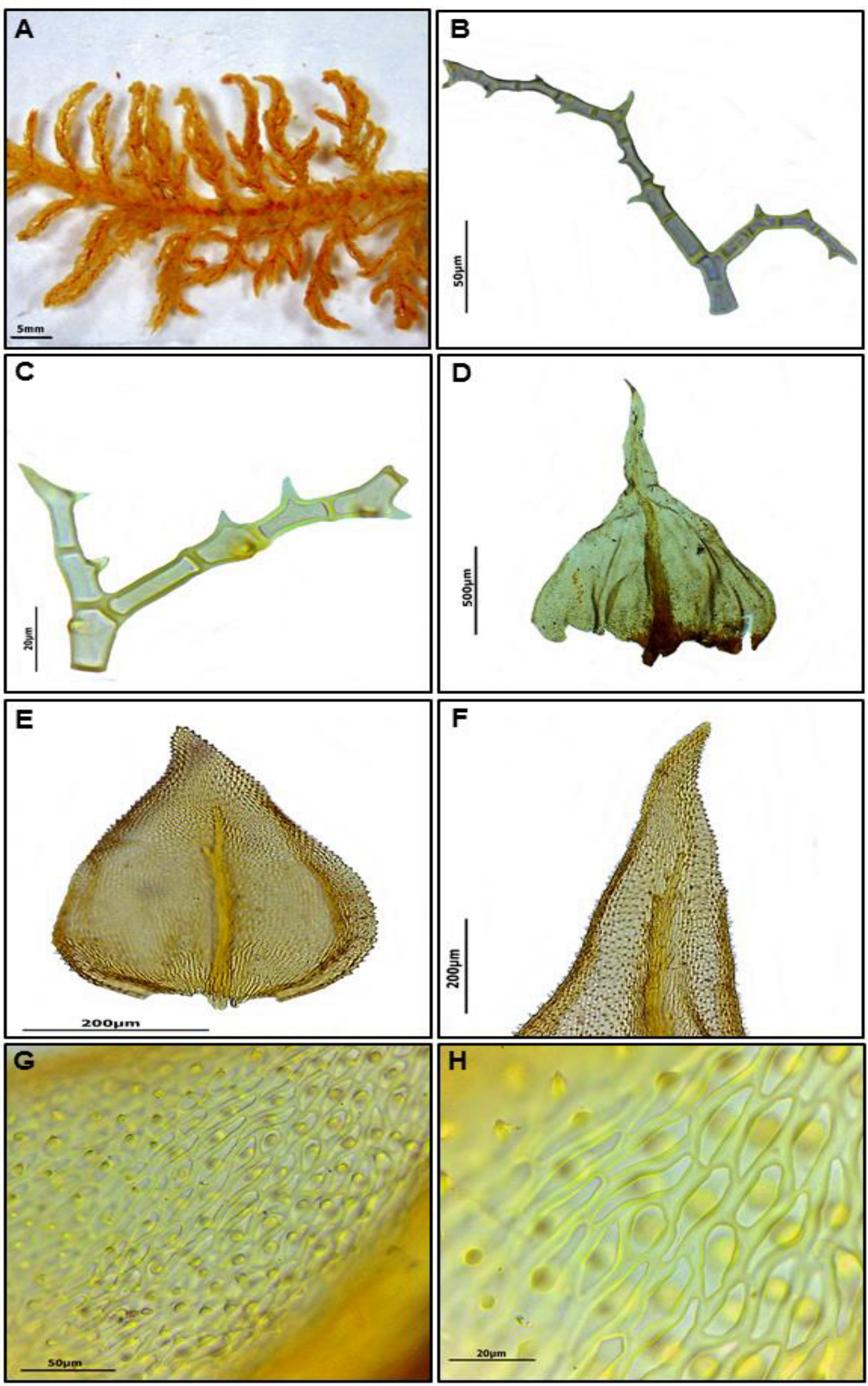

Figura 26: Thuidium brasiliense. A: Gametófito. B e C: Paráfilo. D: Filídio do caulídio. E: Filídio da ramificação. F: Ápice do filídio do caulídio. G: Células unipapilosas do filídio do caulídio e H: Células unipapilosas do filídio da ramificação. 
4. Thuidium delicatulum (Hedw.) Bruch \& Schimp., Bryol. Euro. 5: 164 (fasc. 49--51. Monogr. 8). 1852. Hypnum delicatulum Hedw., Sp. Musc. Frond. 260. 1801. Hypnum tamariscinum var. delicatulum (Hedw.) Brid., Muscol. Recent. Suppl. 2: 140. 1812. Leskea delicatula (Hedw.) Mitt., J. Proc. Linn. Soc., Bot. 8: 45. 1864. Leskea delicatula (Hedw.) Sw., Adnot. Bot. 175. 1829. Thuidium recognitum var. delicatulum (Hedw.) Warnst., Bot. Centralbl. 5: 185. 1881. - Tipo: USA. Pensilvânia, Dillenius s.n. (holotype G!).

Thuidium erectum Duby, Mém. Soc. Phys. Genève 24: 370. 1875. - Tipo: USA. Flórida, Chapmann s.n. (isotype: NY!).

Thuidium schlumbergeri Schimp. ex Besch., Mém. Soc. Sci. Nat. Math. Cherbourg 16: 236. 1872. - Tipo: MÉXICO. Schimper s.n. (isotype: BM!).

Thuidium subrobustum Cardot, Rev. Bryol. 37: 53. 1910. - Tipo: MÉXICO. Morelia, Solorzano s.n. (holotype: PC!).

Tamariscella ventrifolia Müll. Hal. Bull. Herb. Boissier 5: 220. 1897. Thuidium ventrifolium (Müll. Hal.) Paris, Index Bryol. 1294. 1898. - Tipo: GUATEMALA. Coban, Türckheim s.n. (isotype: BM!, NY!, PC!).

Thuidium uliginosum Cardot, Bull. Soc. Bot. Genève, Sér. 2 3: 283. 1911. - Tipo: COREIA. sine loco, Cardot s.n. (isotype: NY!).

Thuidium viride Mitt., Trans. Linn. Soc. London, Bot. 3: 188. 1891. - Tipo: JAPÃO. Kintoki, Maries and Bisset s.n. (holotype: NY!).

Thuidium xanthobasis Sakurai, Bot. Mag. (Tokyo) 64: 199. 1 m--o. 1951. Thuidium tetracladioides var. xanthobasis (Sakurai) Inouye. Misc. Bryol. Lichenol. 12: 4. 1957. - Tipo: JAPÃO. Naigu, T. Magofuku 1647, (isotype: NY!).

Fig. 27 e Fig. 28.

Plantas medianas, $12-17 \mathrm{~cm}$ compr., verdes a verde-amareladas. Caulídios ascendentes, 2 a 3-pinados, ramificações com 10-14mm compr.; paráfilos abundantes, em menor quantidade nas ramificações, 160-190 $\mu$ m compr., 8-20 células, células medianas retangulares, ca. de 3:1, 12-16 $\mu \mathrm{m}$ compr., papilosas, com 1-2 papilas por células, células apicais truncadas. Filídios dos caulídios eretos quando secos, eretopatentes ou patentes quando úmidos, deltóides ou ovado-deltóides, 0,8-1,2×0,6-0,8mm, acuminados, côncavos, plicados; margens crenulada-papilosas, recurvadas abaixo, planas acima; costas sub-percurrentes, ca. de 6/5 do tamanho dos filídios, faces 
abaxiais proeminentes, rugosas na metade inferior; células medianas retangulares ou isodiamétricas, 2-3:1, ca. de 12-22 $\mu \mathrm{m}$ compr., unipapilosas, papilas robustas, retas, às vezes recurvadas, paredes celulares delgadas; células apicais truncadas. Filídios das ramificações secundárias e terciárias eretos quando secos, patentes quando úmidos, ovados, 0,3-0,5x0,15-0,3mm, agudos, côncavos; margens crenulada-papilosas, planas; costas ca. de 2/3 a 3/4 do tamanho dos filídios, às vezes bifurcadas nos ápices; células medianas ovais ou isodiamétricas, 1-2:1, ca. de 9-12 $\mu$ m compr., unipapilosas, papilas recurvadas, paredes celulares incrassadas; células apicais truncadas, com 2-4 papilas. Periquécios lanceolados, ca. de 3,5mm compr., filiformes, plicados; margens serruladas, ciliadas, planas; costas sub-percurrentes; células longo-retangulares, lisas. Setas ca. de 3,5cm compr.; cápsulas horizontais, ca. de 2,5mm compr., cilíndricas; células dos exotécios retangulares, incrassadas; opérculos rostrados. Peristômios amarelados, exostômios bordeados, estriados abaixo, papilosos acima, trabeculados; endostômios lanceolados, quilhados, estritamente perfurado. Esporos 10-12 $\mu \mathrm{m}$, levemente papilosos.

O nome Thuidium delicatulum é comumente utilizado para descrever diversas espécies do gênero. Este nome tem sido equivocadamente utilizado no Brasil para descrever um conjunto de espécies com características morfológicas semelhantes. Caracteriza-se principalmente por apresentar as células dos paráfilos alongadas, filídios dos caulídios plicados, filídios dos ramos com as papilas robustas, encurvadas e com as paredes celulares incrassadas. No Brasil somente $T$. brasiliense e $T$. tamariscinum possuem paráfilos com células alongadas. Em relação a $T$. brasiliense difere por apresentar os filídios da ramificação com as células medianas ovais, enquanto em $T$. brasiliense as células são longo-retangulares. Em T. tamariscinum as células apicais dos filídios das ramificações são agudas e lisas, enquanto em $T$. delicatulum as células apicais dos filídios dos ramos são truncadas e papilosas.

Thuidium delicatulum possui ampla distribuição, principalmente no domínio Mata Atlântica, ocorrendo em diversas localidades, muitas destas inseridas dentro de unidades de conservação. Deve-se, portanto, considerar seu status de conservação como Pouco Preocupante (LC) de acordo com os critérios da IUCN (2001).

Crescem sobre solos, rochas e troncos em decomposição em locais sombreados ou parcialmente expostos ao sol e úmidos, 200-1600m alt.

Ocorrem na América do Sul, do Norte, Europa e Ásia. 
Distribuição geográfica: AM, BA, GO, MG, MT, PA, PR, RJ, RS, SC e SP.

Domínios Fitogeográficos: Amazônia, Caatinga, Cerrado e Mata Atlântica.

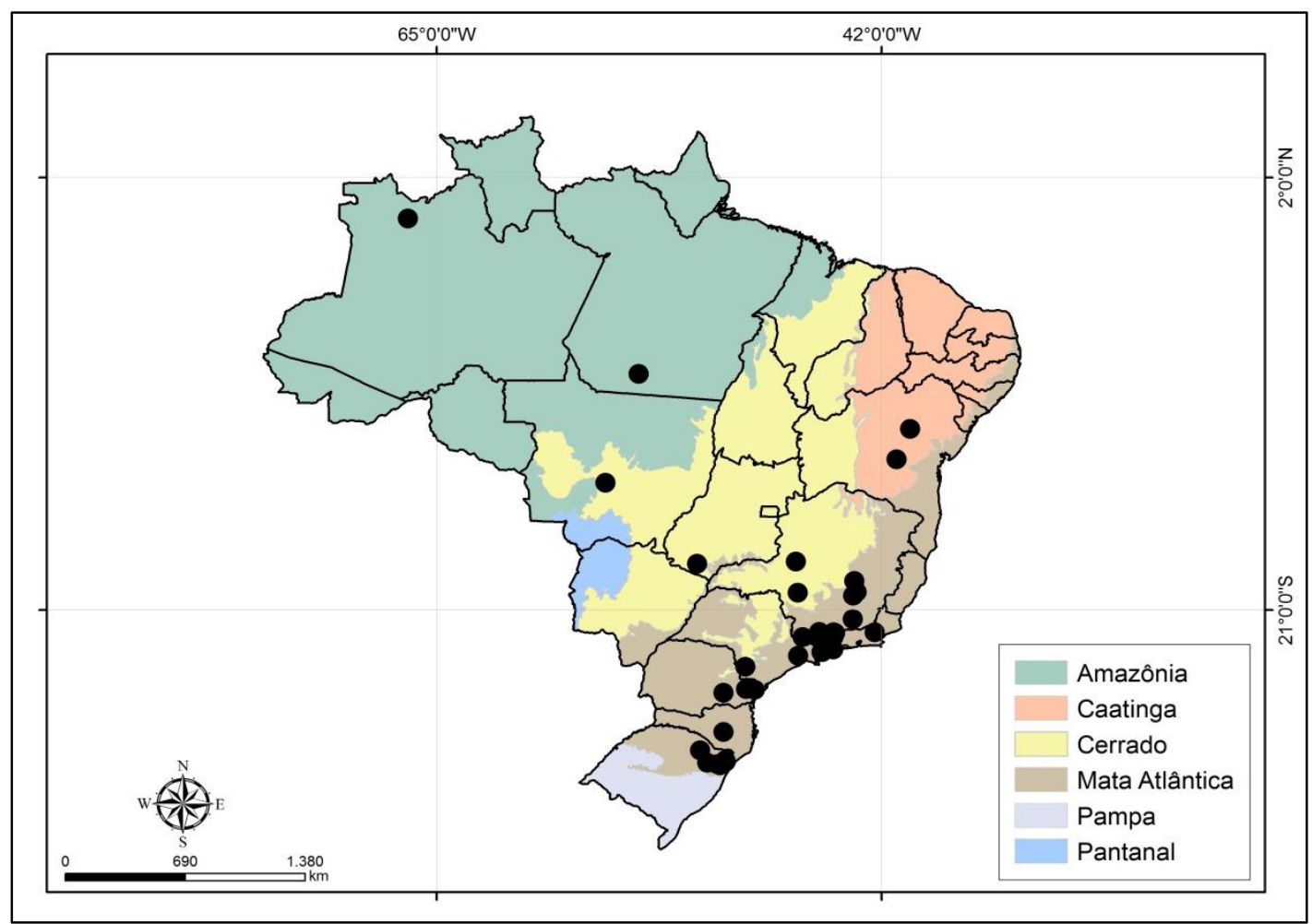

Figura 27: Mapa de distribuição de Thuidium delicatulum no Brasil.

Material Analisado: Amazonas: São Gabriel, Buck 2432 (MO). Bahia: Miguel Calmon, Santos 1934 (ALCB); Mucugê, Guedes s.n. (ALCB 37742). Goiás: Aporé, Silva 63 (MO). Mato Grosso: Diamantino, Silva 610 (MO). Minas Gerais: Camanducaia, Windisch 5896 (MO); Catas Altas, Peralta 6658; Itamonte, Vital 15947 (SP); Lima Duarte, Marquete 3196 (RB); Maria da Fé, Yano 31912 (SP); Marmelópolis, Soares et al. (NY, UB); Miguel Burnier, Hoehne 194 (SP); Nova Lima, Peralta 11646 (SP); Patos de Minas, Soares et al. 1554 (UB); Parque Nacional da Serra da Canastra, Peralta 15018 (SP); Parque Nacional do Itatiaia, Soares et al. 1745 (MUB, NY); Santa Bárbara, Vital 7675 (MO); Serra da Piedade, Hoehne 6577 (JE). Pará: Serra do Cachimbo, Reese 16108 (MO). Paraná: Morretes, Ristow 2831 (SP); Quatro Barras, Ristow et al. 2411 (SP); São João do Triunfo, Vital 3308 (SP). Rio de Janeiro: Paraty, Vital 7757 (MO, SP); Parque Nacional do Itatiaia, Soares 1454 (NY, UB); Serra de Friburgo, Bandeira s.n. (MO); Visconde de Mauá, Tomita s.n. (SP 125816). Rio Grande do Sul: Cambará do Sul, Wasum et al. s.n. (HUCS 2139, MO); Canela, Filho 1064 (SP); Caxias do Sul, Wasum et al. s.n. (HUCS 5873, MO); Jaquirana, Guerra s.n. (HUCS 784, MO); Nova Prata, Wasum s.n. (HUCS 2883, MO); São Franscisco de 
Paula, Cararo 10598 (MO). Santa Catarina: Lages, Vital 5667 (SP). São Paulo: Campos do Jordão, Peralta 12586 (SP); Itapeva, Peralta 11461 (SP); Natividade da Serra, Peralta 9210 (SP); Pindamonhangaba, Soares et al. 1853 (NY, UB); Santo André, Yano 939 (SP); São Bento do Sapucaí, Peralta 10123 (SP); São José do Barreiro, Vital 7370 (MO, SP); Silveira, Vital 7289 (SP) e Ubatuba, Costa 5075 (SP). 


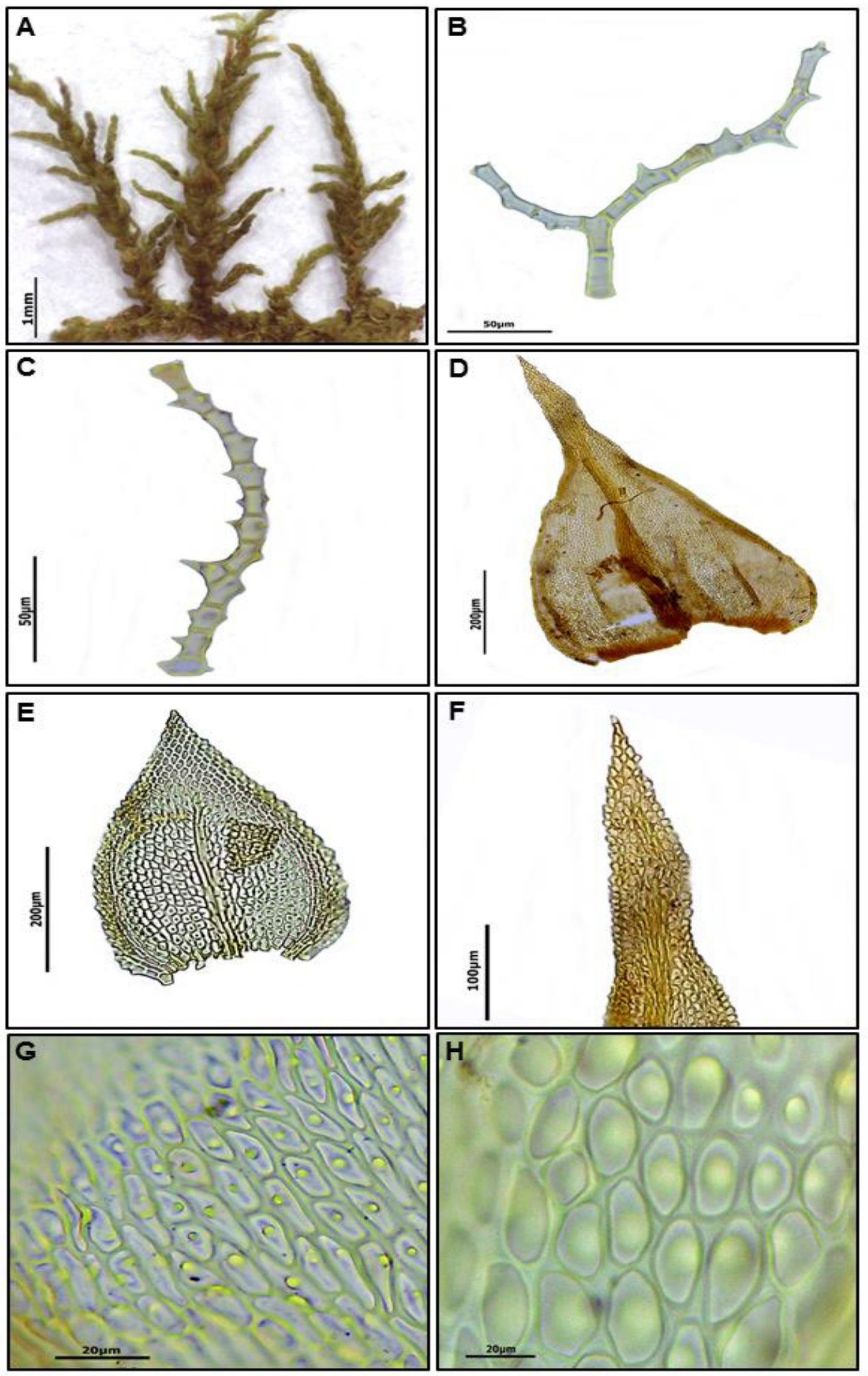

Figura 28: Thuidium delicatulum. A: Gametófito. B e C: Paráfilo. D: Filídio do caulídio. E: Filídio da ramificação. F: Ápice do filídio do caulídio. G: Células unipapilosas do filídio do caulídio. H: Células unipapilosas do filídio do ramo. 
5. Thuidium pseudoprotensum (Müll.Hal.) Mitt., J. Linn. Soc., Bot.12: 578. 1869. Hypnum pseudoprotensum Müll. Hal., Bot. Zeitung (Berlin) 6: 779. 1848. - Tipo: VENEZUELA. Merida, Funck et Schlim 992 (isotypes: NY!, PC!).

Hypnum subdelicatulum Hampe, Vidensk. Meddel. Dansk Naturhist. Foren. Kjøbenhavn 1: 156. 1879. Thuidium subdelicatulum (Hampe) Broth., Acta Soc. Sci. Fenn. 19(5): 27. 1891. - Tipo: BRASIL. Rio de Janeiro, Glaziou 2792 (isotype: PC!).

Fig. 29 e Fig. 30.

Plantas medianas a robustas, $14-18 \mathrm{~cm}$ compr., verde-amareladas. Caulídios ascendentes, 2 a 3-pinado, ramificações com 12-18mm compr.; paráfilos abundantes,

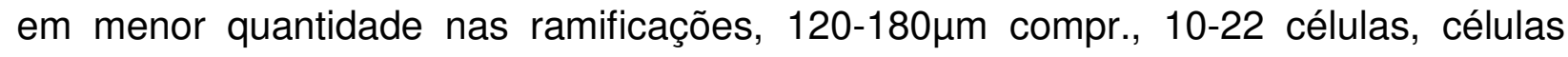
medianas pequenas, subquadradas, ca. de 1:1, 10-14 $\mu$ m compr., papilosas, com 1-2 papilas por células, células apicais truncadas. Filídios dos caulídios ereto-patentes quando secos, patentes quando úmidos, deltóides, 1,4-2×0,8-1,1 mm, acuminados a longo-acuminados, frequentemente com os ápices falcados, côncavos, plicados; margens crenulada-papilosas, recurvadas; costas sub-percurrentes, ca. de 4/5 do tamanho dos filídios, faces abaxiais proeminentes, rugosas na metade inferior; células medianas isodiamétricas, ovais ou curto-retangulares, 1-2:1, ca. de 15-20 $\mu \mathrm{m}$ compr., unipapilosas, papilas retas, às vezes recurvadas, paredes celulares incrassadas; células apicais agudas ou truncadas. Fílidos das ramificações secundárias eretos quando secos, patentes quando úmidos, ovado-deltóides, 0,4-0,7×0,2-0,3mm, agudos, côncavos; margens crenulada-papilosas, planas; costas com ca. de 1/2 a 2/3 do tamanho dos filídios, frequentemente bifurcada no ápice; células medianas ovais, 1-2:1,

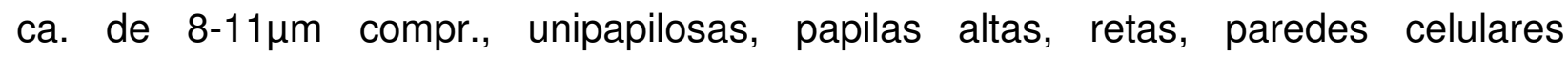
incrassadas; células apicais truncadas. Periquécios lanceolados, ca. de $4 \mathrm{~mm}$ compr., filiformes, plicados; margens serruladas, planas; costas sub-percurrentes; células longo-retangulares, lisas. Setas ca. de $2,5 \mathrm{~cm}$ compr.; cápsulas horizontais, ca. de $3 \mathrm{~mm}$ compr., cilíndricas; células dos exotécios retangulares, incrassadas; opérculos rostrados. Peristômios avermelhados, exostômios bordeados, estriados abaixo, papilosos acima, trabeculados; endostômios lanceolados, quilhados, estritamentes

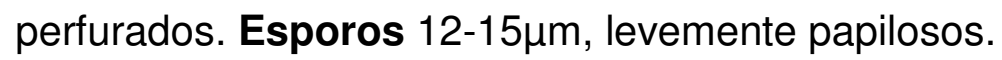

Pode ser confundida com $T$. delicatulum e $T$. brasiliense, diferindo por apresentar paráfilos com células pequenas, subquadradas e filídios dos caulídios maiores e 
robustos, com o ápice frequentemente falcado, características que são usadas para definir a espécie.

Apresenta distribuição restrita as regiões Sul e Sudeste. Ocorrem em diversas áreas inseridas dentro de unidades de conservação, somente no domínio Mata Atlântica. Foi considerada Quase Ameaçada (NT), pois ao ser avaliada pelos critérios da IUCN (2001), não se qualifica em nenhuma das categorias de ameaça, mas está perto da qualificação devido a sua distribuição restita.

Crescem em ambientes florestais, sobre rochas e troncos mortos, em locais sombreados ou expostos, geralmente em altitudes medianas a elevadas, 900-1400m alt.

Ocorrem na América do Sul, Central e do Norte.

Distribuição geográfica: ES, MG, PR, RJ, RS, SC e SP.

Domínios Fitogeográficos: Mata Atlântica.

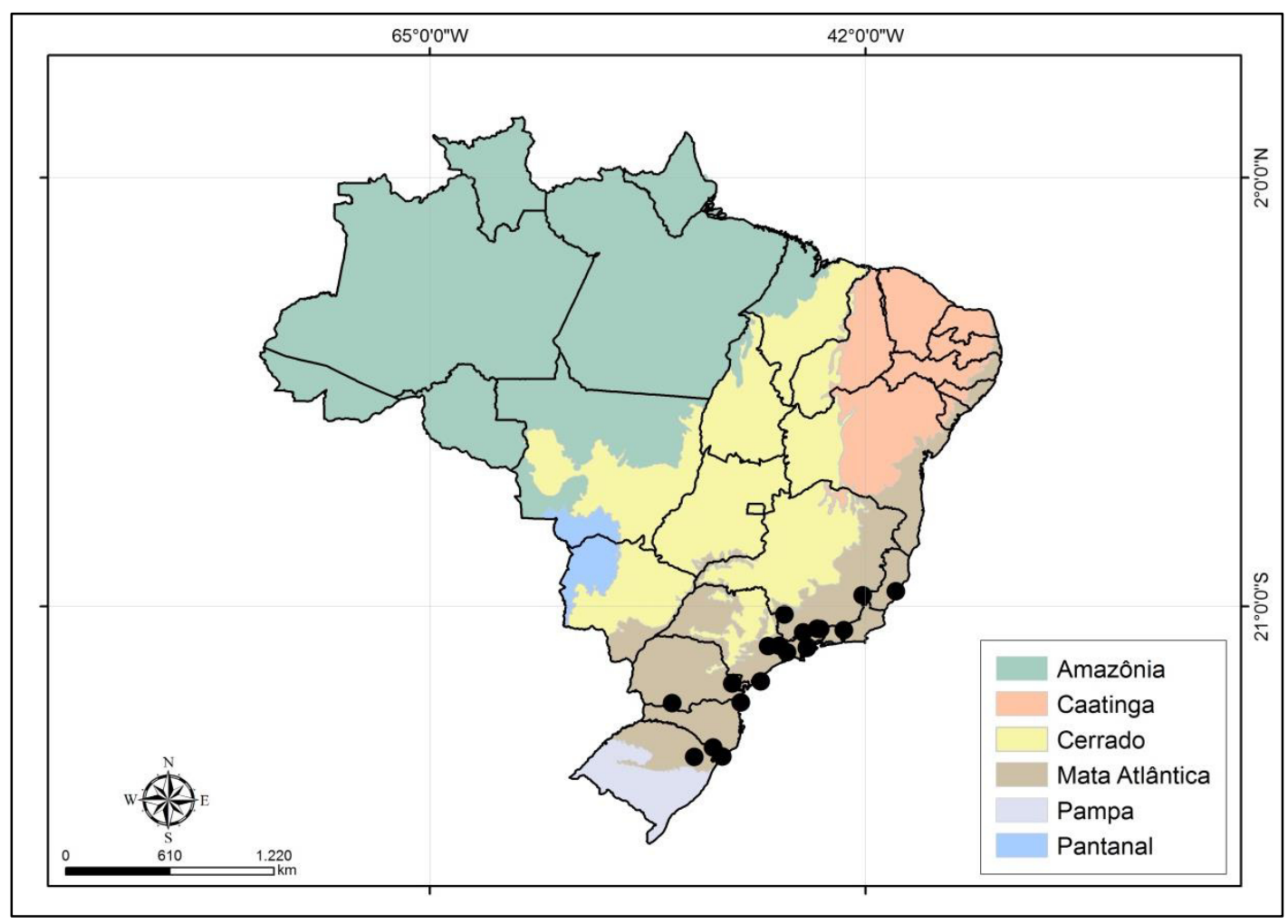

Figura 29: Mapa de distribuição de Thuidium pseudoprotensum no Brasil.

Material Analisado: Espírito Santo: Domingos Martins, Yano 4931 (SP). Minas Gerais: Fervedouro, Costa 4151 (SP); Passa Quatro, Zikan 283 (SP); Poços de Caldas, Vital 158 (SP). Paraná: Campina Grande do Sul, Schwartsburd 1233 (SP); Clevelândia, Sehnem 6677 (PACA). Rio de Janeiro: Parque Nacional do Itatiaia, 
Oliveira 2595 (RB); Petrópolis, Sucre 645 (RB). Rio Grande do Sul: Ana Rech, Wasum s.n. (HUCS 6161); Cambará do Sul, Wasum et al. s.n. (ALCB 18154); Caxias do Sul, Sehnem 1974 (SP). Santa Catarina: Joinvile, Grossmann s.n. (JE); Serra Geral, Ule 191 (JE). São Paulo: Campos do Jordão, Peralta 9916 (SP); Cananéia, Peralta 1280 (SP); Itú, Hoehne 646 (JE); Jundiai, Puiggari 404 (SP); Natividade da Serra, Peralta 9169 (SP); Paranapiacaba, Landrum 2778 (SP); São Luís do Paraitinga, Peralta 9052 (SP). 

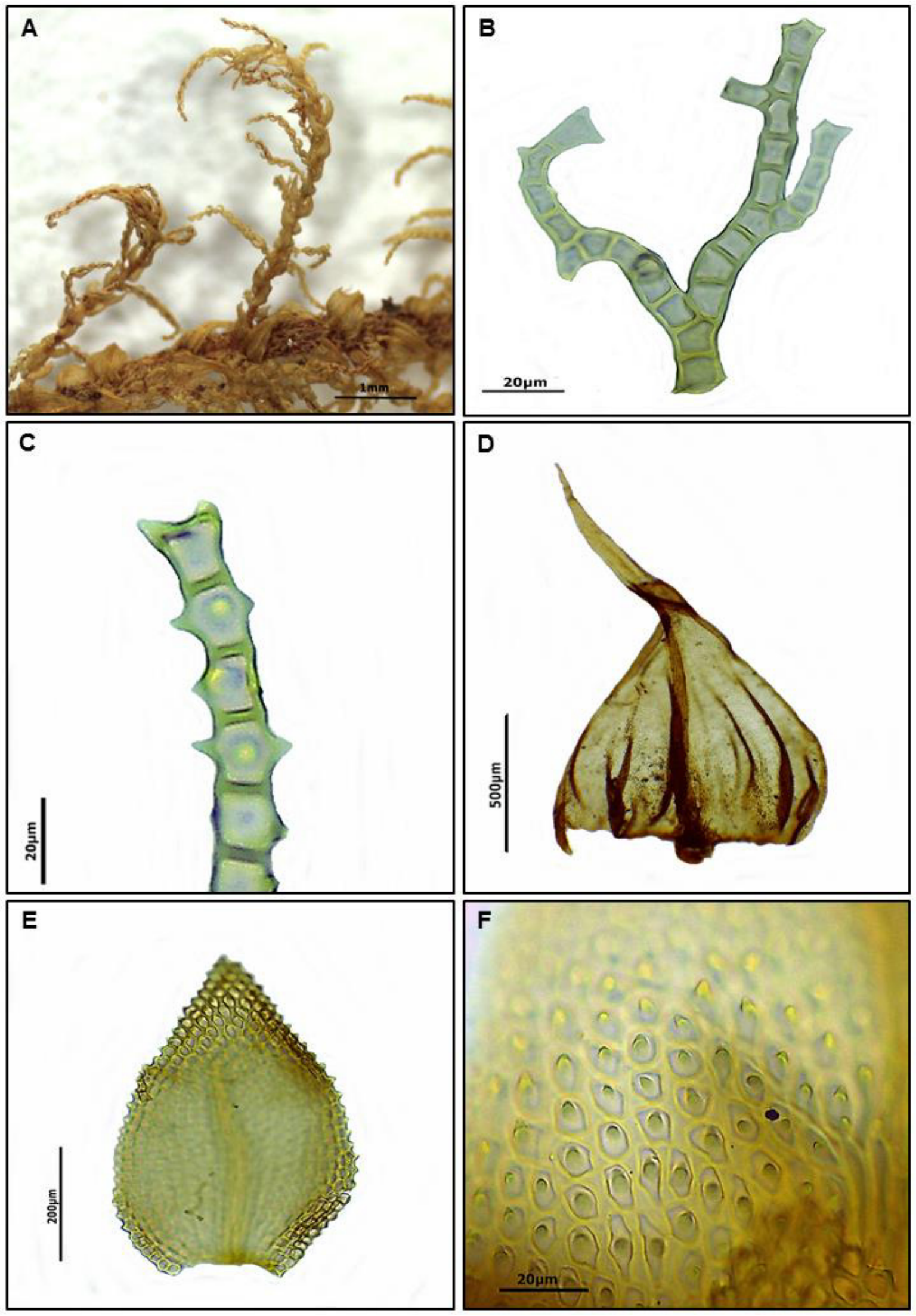

Figura 30: Thuidium pseudoprotensum. A: Gametófito. B e C: Paráfilo. D: Filídio do caulídio. E: Filídio da ramificação. F: Células unipapilosas do filídio do ramo. 
6. Thuidium tamariscinum (Hedw.) Schimp., Bryol. Euro 5: 163. 482, 483 (fasc. $49--51$ Mon. 7. 2, 3.). 1852. Hypnum tamariscinum Hedw., Sp Musc. Frond. 261. 67 f. 1 -5. 1801. Leskea tamariscina (Hedw.) Mitt., J. Proc. Linn. Soc., Bot. 8: 8. 1864. Pterygophyllum tamariscinum (Hedw.) Brid., Muscol. Recent. Suppl. 4: 151. 1819 [1818]. - Tipo: sine loco, in truncis humique passim, sine leg (isotype: BM!).

Fig. 31 e Fig. 32.

Plantas medianas, $10-15 \mathrm{~cm}$ compr., verde-amareladas. Caulídios ascendentes, 2-pinado, menos frequentemente 3-pinado, ramificações com 12-18mm compr.; paráfilos abundantes, em menor quantidade nas ramificações, 170-250 $\mu \mathrm{m}$ compr., 10-

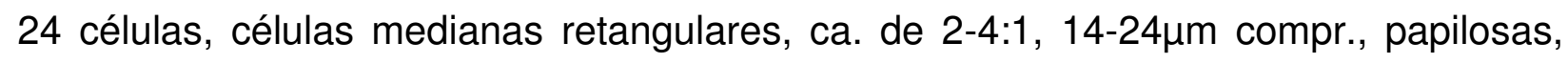
com 1-2 papilas por células, células apicais truncadas. Filídios dos caulídios adpressos a eretos quando secos, ereto-patentes ou patentes quando úmidos, deltóides ou ovado-deltóides, 1,2-1,8×0,0,9-1,1 mm, acuminados a longo-acuminados, côncavos, plicados; margens crenulada-papilosas, recurvadas; costas sub-percurrentes, ca. de 4/5 do tamanho dos filídios, faces abaxiais proeminentes, às vezes levemente rugosas na metade inferior; células medianas isodiamétricas, ovais ou curto-retangulares, 1-3:1, ca. de 10-20 $\mathrm{mm}$ compr., unipapilosas, papilas robustas, retas, às vezes recurvadas, paredes celulares delgadas; células apicais agudas. Filídios das ramificações secundárias eretos quando secos, patentes quando úmidos, ovados, 0,4-0,7×0,20,3mm, agudos, côncavos; margens crenulada-papilosas, planas; costas ca. de 1/2 a 2/3 do tamanho dos filídios, frequentemente bifurcadas no ápice; células medianas ovais, 1-2:1, ca. de 6-10 $\mathrm{m}$ compr., unipapilosas, papilas altas, retas ou recurvadas, paredes celulares incrassadas; células apicais agudas, pontudas, lisas. Periquécios lanceolados, ca. de 5mm compr., filiformes, plicados; margens serruladas acima, inteiras abaixo, fortemente ciliadas, planas; costas sub-percurrentes; células longoretangulares, lisas. Setas ca. de $3 \mathrm{~cm}$ compr.; cápsulas horizontais, ca. de $3 \mathrm{~mm}$ compr., cilíndricas; células dos exotécios retangulares, incrassadas; opérculos rostrados. Peristômios avermelhados, exostômios bordeados, estriados abaixo, papilosos acima, trabeculados; endostômios lanceolados, quilhados, estritamente perfurados. Esporos 12-14 $\mu$ m, levemente papilosos.

Thuidium tamariscinum caracteriza-se por apresentar paráfilos com células retangulares, longas e principalmente por apresentar os filídios da ramificação com a 
célula apical aguda, pontuda e lisa, sendo esta a principal característica usada para separar T. tamariscinum de T. delicatulum.

Apresenta distribuição restrita as regiões Sul e Sudeste, em áreas de Mata Atlântica. Muitas de suas localidades de ocorrência estão inseridas dentro de unidades de conservação. Foi considerada Quase Ameaçada (NT), pois ao ser avaliada pelos critérios da IUCN (2001), não se qualifica em nenhuma das categorias de ameaça, mas está perto da qualificação devido a sua distribuição restita.

Crescem sobre rochas, solo e troncos mortos, em ambientes florestais, sombreados e úmidos na Mata Atlântica, 600-1200m alt.

Ocorrem na Europa, Ásia, América do Sul, Central e América do Norte.

Distribuição geográfica: MG, PR, RJ, RS, SC e SP.

Domínios Fitogeográficos: Mata Atlântica.

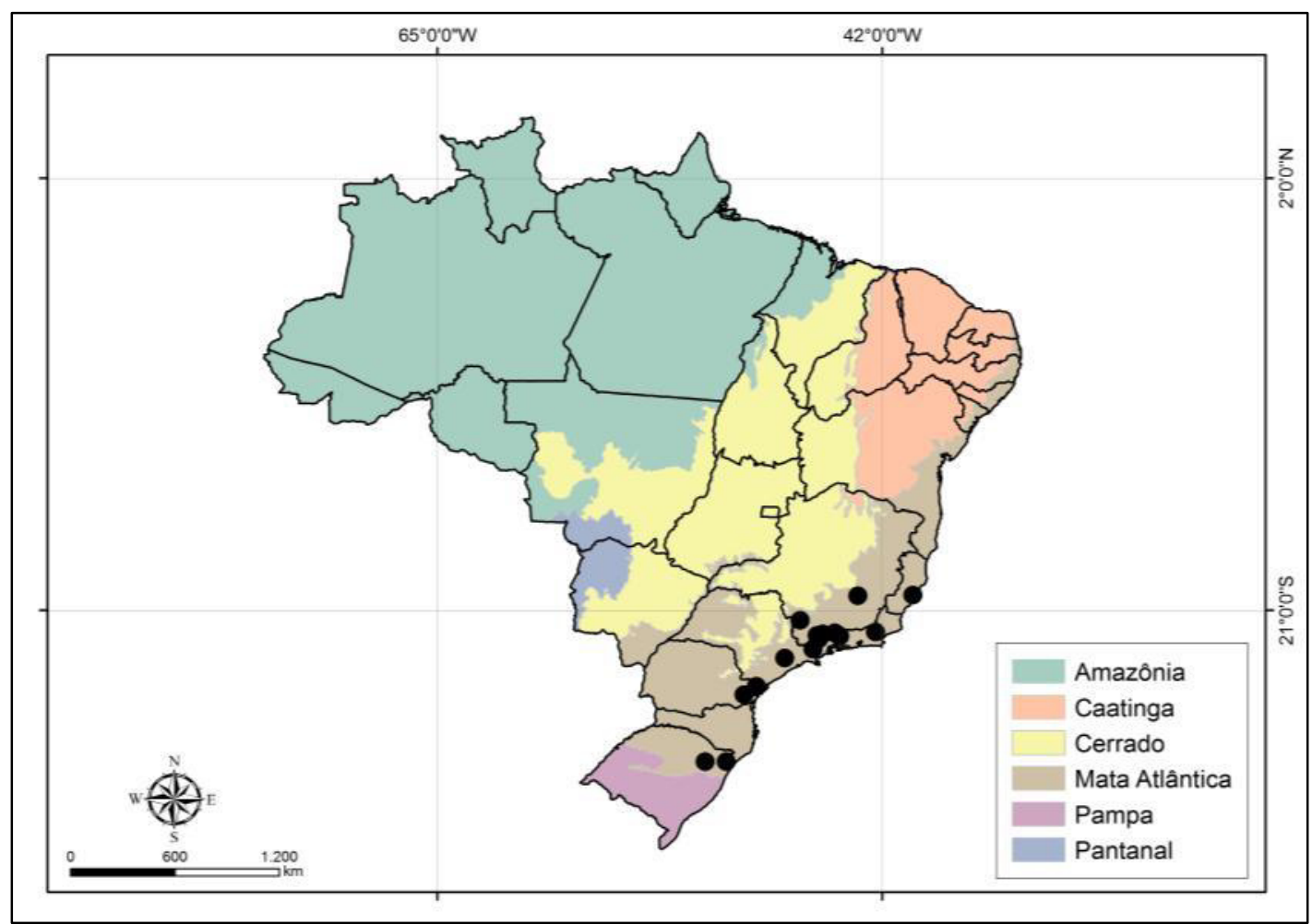

Figura 31: Mapa de distribuição de Thuidium tamariscinum no Brasil.

Material Analisado: Minas Gerais: Caldas, Mosen 363 (SP); Itacolumi, Damazio 2101 (RB); Parque Nacional do Itatiaia, Vital 19483 (SP). Paraná: Quatro Barras, Peralta \& Schafer-Verwimp 12846 (SP); Tijucas do Sul, Shirata 4003 (SP). Rio de Janeiro: Itatiaia, Mizoguchi 1272 (SP); Nova Friburgo, Costa et al. 856 (RB). Rio Grande do Sul: Cambará do Sul, Jeno-Michel 2679 (SP); Caxias do Sul, Wasum et al. 
s.n. (MO). Santa Catarina: Parque Nacional de São Joaquim, Peralta 7721 (SP). São Paulo: Bananal, Esteves 2628 (SP); Campos do Jordão, Buck 26267 (SP); Juquitiba, Colletes 170 (SP); Pindamonhangaba, Visnadi 2380 (SP); Piquete, Peralta 4331 (SP) e São José dos Campos, Yano 32854 (SP). 


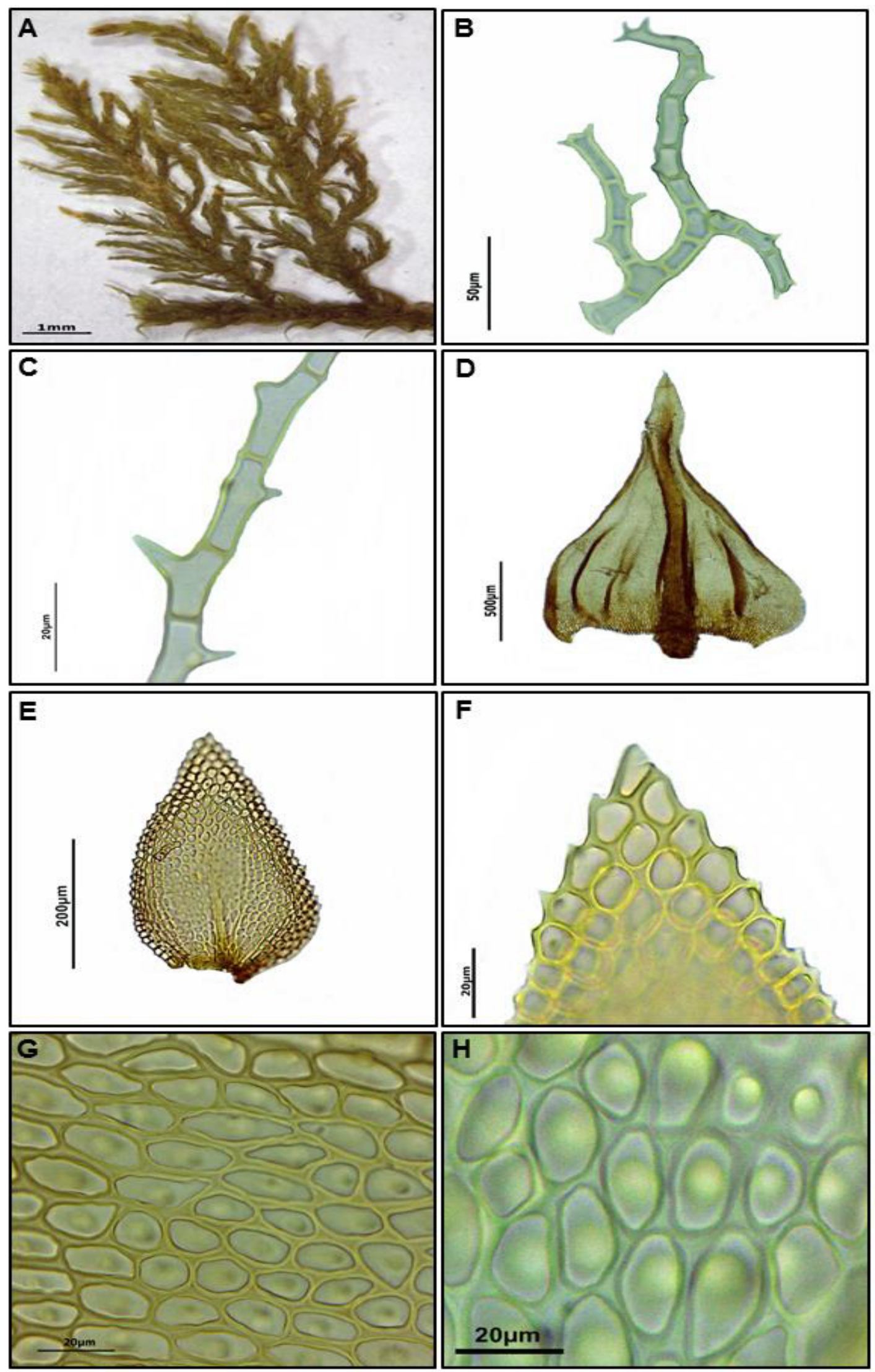

Figura 32: Thuidium tamariscinum. A: Gametófito. B e C: Paráfilo. D: Filídio do caulídio. E: Filídio da ramificação. F: Ápice e célula apical aguda do filídio da ramificação. G: Células unipapilosas do filídio do caulídio. $\mathrm{H}$ : Células unipapilosas do filídio do ramo. 
7. Thuidium tomentosum Schimp., Mém. Soc. Sci. Nat. Math. Cherbourg 16: 237. 1872. - Tipo: MÉXICO. Orizaba, F. Muller 2263a (isotype: NY!).

Thuidium mattogrossense Broth., Bih. Kongl. Svenska Vetensk.-Akad. Handl. 3(7): 55. 1900. - Tipo: BRASIL. Mato Grosso, Lindman 3613 (holotype: H!, isotype: R!). syn. nov.

Thuidium antillarum Besch., Ann. Sci. Nat., Bot., sér. 6, 3: 244. 1876. Tamariscella antillarum (Besch.) Müll. Hal., Hedwigia 37: 262. 1898. - Tipo: GUADALUPE. Riviére Saint-Loius, Husnot 188 (lectotype designated here: PC!, isolectotype: NY!). Beaupertuis s.n. (isosyntype: PC!). L'Herminier 25 (isosyntype: PC?). MARTINICA. sine loco, Husnot 88 (isosyntype: PC!).

Thuidium tamariscinum var. mexicanum Schimp., Mém. Soc. Sci. Nat. Math. Cherbourg 16: 236. 1872. - Tipo: MÉXICO. Mirador, F. Sartorius s.n. (isotype: NY!).

Fig. 33 e Fig. 34.

Plantas medianas, $8-13 \mathrm{~cm}$ compr., verdes a verde-amareladas. Caulídios arqueados ou ascendentes, 2-3-pinado, ramificações com 5-9mm compr.; paráfilos abundantes, em menor quantidade ou ausente nas ramificações, 110-220 $\mu \mathrm{m}$ compr., 718 células, células medianas quadradas, pequenas, ca. de 1-2:1, 5-15 $\mu \mathrm{m}$ compr., papilosas, 1-2 papilas por célula, células apicais truncadas. Filídios dos caulídios adpressos quando secos, ereto-patentes quando úmidos, deltóides ou ovado-deltóides, 0,6-1,1 x0,2-0,5mm, acuminados, côncavos; margens crenulada-papilosas, recurvadas; costas sub-percurrentes, ca. de $4 / 5$ do tamanho dos filídios, faces abaxiais proeminentes, levemente rugosas na metade inferior; células medianas ovais ou subquadradas, 1-2:1, ca. de 6-10 $\mu \mathrm{m}$ compr., pluripapilosas, 2-3(-4) papilas localizadas no centro do lúmen celular, ambos os lados, inconspícuas nas faces adaxiais, paredes celulares delgadas; células apicais agudas ou truncadas, às vezes lisas. Filídios das ramificações secundárias eretos quando secos, patentes quando úmidos, ovadolanceolados, 0,3-0,4×0,15-0,2mm, agudos, côncavos; margens crenulada-papilosas, planas; costa com ca. de $1 / 2$ a 2/3 do tamanho dos filídios, às vezes bifurcada nos ápices, proeminentes nas faces abaxiais; células medianas ovais ou isodiamétricas, 1:1, ca. de 3-8 $4 \mathrm{~m}$ compr., pluripapilosas, 2-3(-4) papilas localizadas no centro do lúmen celular, papilas pequenas, retas, inconspícuas nas faces adaxiais, paredes celulares delgadas; células apicais truncadas com 2-4 papilas. Periquécios lanceolados, ca. de 
$4 \mathrm{~mm}$ compr., filiformes; margens serruladas acima, lisas abaixo, ciliadas na metade superior, planas; costas sub-percurrentes; células retangulares, lisas. Setas ca. de 2$3 \mathrm{~cm}$ compr., cápsulas horizontais, ca. de $2 \mathrm{~mm}$ compr., cilíndricas; células dos exotécios sub-quadradas; opérculos rostrados. Peristômios vermelho-amarelados, exostômios bordeados, estriados abaixo, levemente papilosos acima, trabeculados; endostômios lanceolados, quilhados, estritamente perfurados. Esporos 10-14 $\mu \mathrm{m}$, levemente papilosos.

Caracteriza-se principalmente por apresentar células pluripapilosas com as papilas localizadas no centro do lúmen celular. De acordo com Buck (1998), T. tomentosum talvez seja o único representate do gênero com células pluripapilosas na América tropical. Apresenta ampla distribuição no Brasil, sendo encontrada com facilidade em todas as regiões e nos principais biomas brasileiros.

Sua amplitude latitudinal e altitudinal, aliada a ampla área de ocorrência, muitas destas inseridas dentro de unidades de conservação, faz com que T. tomentosum seja considerada Pouco Preocupante (LC) de acordo com os critérios da IUCN (2001).

Crescem sobre rochas, solos e troncos em decomposição, em locais sombreados e úmidos no interior de áreas florestais ou áreas parcialmente expostas ao sol, geralmente próximos ao curso d’água, 200-1.500m alt.

Ocorrem na América do Sul, Central e do Norte.

Distribuição geográfica: AL, AM, AP, BA, ES, GO, MG, MS, MT, PA, PE, PR, RJ, RO, RR, RS, SC e SP.

Domínios Fitogeográficos: Amazônia, Caatinga, Cerrado e Mata Atlântica. 


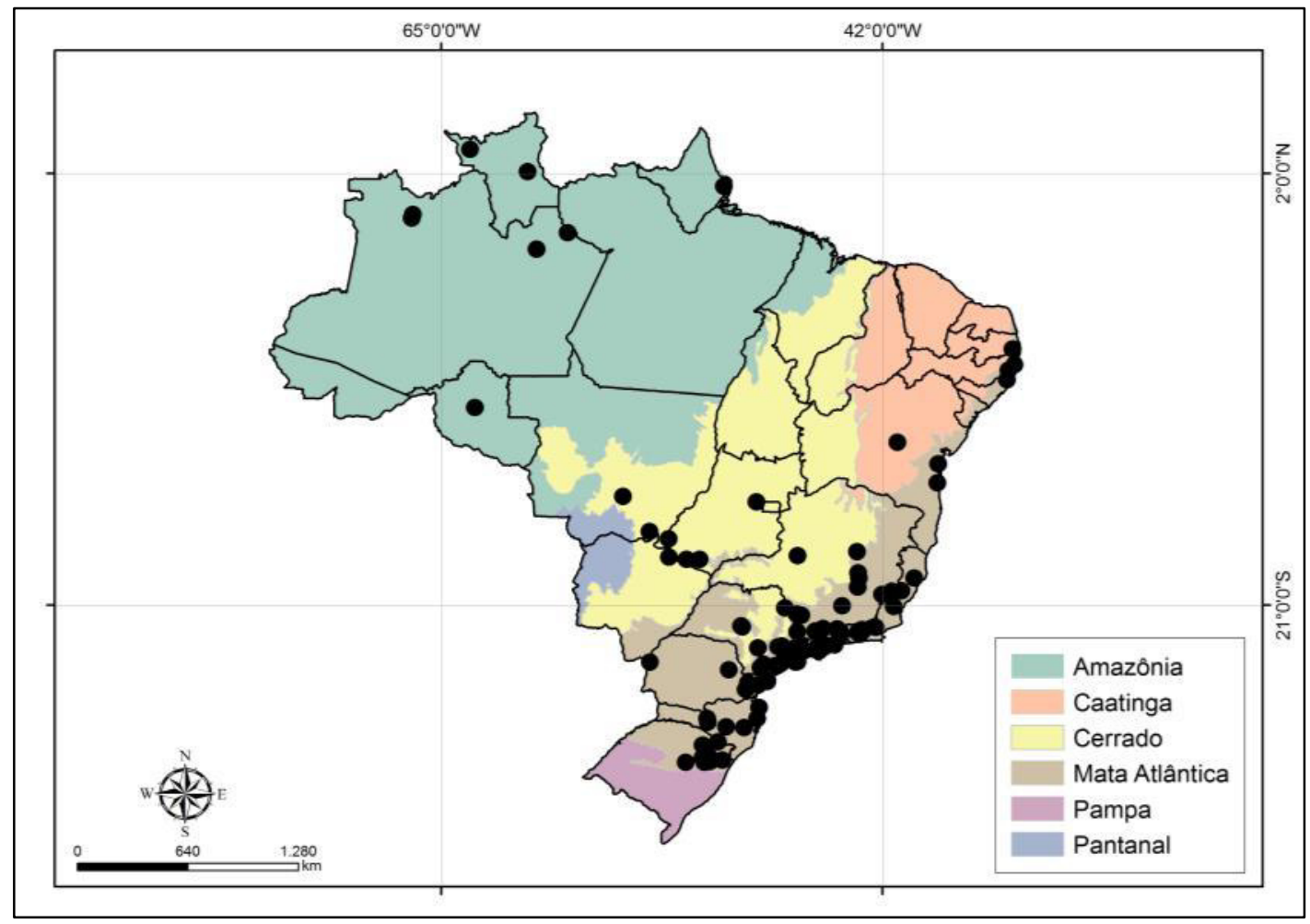

Figura 33: Mapa de distribuição de Thuidium tomentosum no Brasil.

Material Analisado: Alagoas: Ibateguara, Pietrobom et al. 4724 (RB). Amapá: Reserva Biológica do Lago Piratuba, Pietrobom 6146 (SP). Amazonas: Presidente Figueiredo, Ribeiro 2780 (SP); São Gabriel, Buck 2498 (NY); Serra Curicuriari, Yano 1858 (SP). Bahia: Igrapiúna, Bôas-Bastos 1882 (ALCB); Ilhéus, Mexia 5009 (MO, NY); Lençois, Stradmann et al. 34 (ALCB). Espírito Santo: Domingos Martins, SchaferVerwimp 10196 (NY); Reserva Florestal Pedra Azul, Schafer-Verwimp 10068 (NY); Santa Teresa, Yano 3626 (SP). Goiás: Aporé, Windisch 6934 (SP); Pirenópolis, Yano 28742 (SP). Mato Grosso: Alto Taquari, Pietrobom 3014 (SP); Chapada dos Guimarães, Yano 12159 (SP); Itiquira, Windisch 8028 (SP). Mato Grosso do Sul: Costa Rica, Pietrobom 2976 (SP); Indaiá do Sul, Pietrobom 2938 (SP). Minas Gerais: Alto Caparaó, Visnadi 2658 (SP); Caldas, Mosén s.n. (W); Caparaó, Vital \& Buck 11669 (NY); Carangola, Leoni 1904 (SP); Catas Altas, Peralta 6562 (SP); Diamantina, Pirani et al. 5860 (SP); Gonçalves, Peralta 259 (SP); Itabira, Câmara 2544 (UB); Marmelópolis, Peralta 3583 (SP); Patos de Minas, Soares et al. 1511 (UB); Santa Bárbara, Hoehne 160 (JE); Tiradentes, Alves 1157 (SP). Pará: Oriximiná, Pietrobom 7827 (SP). Paraná: Campina Grande do Sul, Cordeiro et al. 1802 (SP); Castro, Kuniyoshi s.n. (SP); Guaira, Vital 8763 (SP); Morretes, Ristow 2877 (SP); Tijucas do Sul, Shirata 3695 (SP). Pernambuco: Escada, Yano 2653 (SP); Igarapeba, Sehnem 
9149 (PACA); Timbaúba, Pietrobom 4663 (RB); São Vicente Ferrer, Pietrobom 4450 (SP). Rio de Janeiro: Angra dos Reis, Vital 983 (SP); Magé, Costa 147 (RB); Nova Friburgo, Costa et al. 1158 (RB); Nova Iguaçu, Costa 4055 (RB); Paraty, Costa 1454 (RB); Parque Nacional do Itatiaia, Soares et al. 1811 (NY, UB); Parque Nacional da Tijuca, Costa 18 (RB); Petrópolis, Sucre 2585 (MO); Resende, Eiten et al. 7382 (NY, RB); Serra de Itatiaia, Schafer-Verwimp 8359 (NY). Rio Grande do Sul: Bom Jesus, Sehnem 291 (NY); Caxias do Sul, Wasum 4590 (MO); Farroupilha, Sehnem 6614 (PACA); Flores da Cunha, Guerra et al. s.n. (HUCS 138, NY); Garibaldi, Wasum et al. s.n. (MO); Marcorama, Wasum s.n. (HUCS 3515, NY); Montenegro, Sehnem 378 (PACA); Nova Prata, Wasum s.n. (HUCS 2883, NY); Nova Roma do Sul, Wasum 4610 (SP); Santa Cruz do Sul, Sehnem 2405 (PACA); São Francisco de Paula, Sehnem 4593 (PACA); Sapiranga, Wasum et al. s.n. (HUCS 5971, NY); Tupandi, Sehnem 378 (SP); Vacaria, Vital 9344 (SP). Rondônia: Boca da Mata, Buck et al. 2002 (MO). Roraima: Serra da Lua, Prance 9351 (NY); Serra Parima, Griffin III (SP). Santa Catarina: Anita Garibaldi, Reitz 15475 (SP); Brusque, Reitz 2223 (MO, SP); Campo dos Padres, Reitz 2428 (JE); Campos Novos, Reitz 15035 (SP); Lages, Reitz 15534 (SP); Penha, Yano 2418 (SP); Tangará, Carl 152 (JE). São Paulo: Amparo, Vital 491 (SP); Apiaí, Peralta 4473 (SP); Atibaia, Peralta 5644 (SP); Bananal, Yano 1234 (SP); Barueri, Vital 6609 (MO, SP); Campos do Jordão, Vital 9736 (SP); Cananéia, Yano 8931 (SP); Cássia dos Coqueiros, Martinez s.n. (SP 418628); Gália, Yano 3434 (SP); Garça, Yano 370 (SP); Guapiara, Vital s.n. (SP); Ilha do Cardoso, Vital 9736 (SP); Ilha Bela, Yano 858 (SP); Ilha de São Sebastião, Schafer-Verwimp 11663 (NY); Iperó, Yano 32262 (SP); Itanhaém, Vital 1584 (SP); Iporanga, Vital 12587 (SP); Itapera, Hoehne s.n. (JE); Itú, Hoehne s.n. (SP 8911); Juquitiba, Colletes 146 (SP); Miracatu, Yano 872 (SP); Mogi das Cruzes, Peralta 7164 (SP); Mongaguá, Vitt 20665 (SP); Morro Grande, Decker 830 (JE); Pai Matias, Baranov s.n. (SP 136203); Paraibuna, Vital 8763 (SP); Parque Estadual da Serra do Mar, Peralta 3767 (SP); São José dos Barreiros, Yano 1307 (SP); São Luíz do Paraitinga, Yano 4291 (SP); São Roque da Fartura, Pietrobom 1889 (SP); São Sebastião, Yano 7884 (SP); Serra da Mantiqueira, Silva 1889 (MO); Sete Barras, Yano 786 (SP) e Ubatuba Visnadi 4025 (SP). 

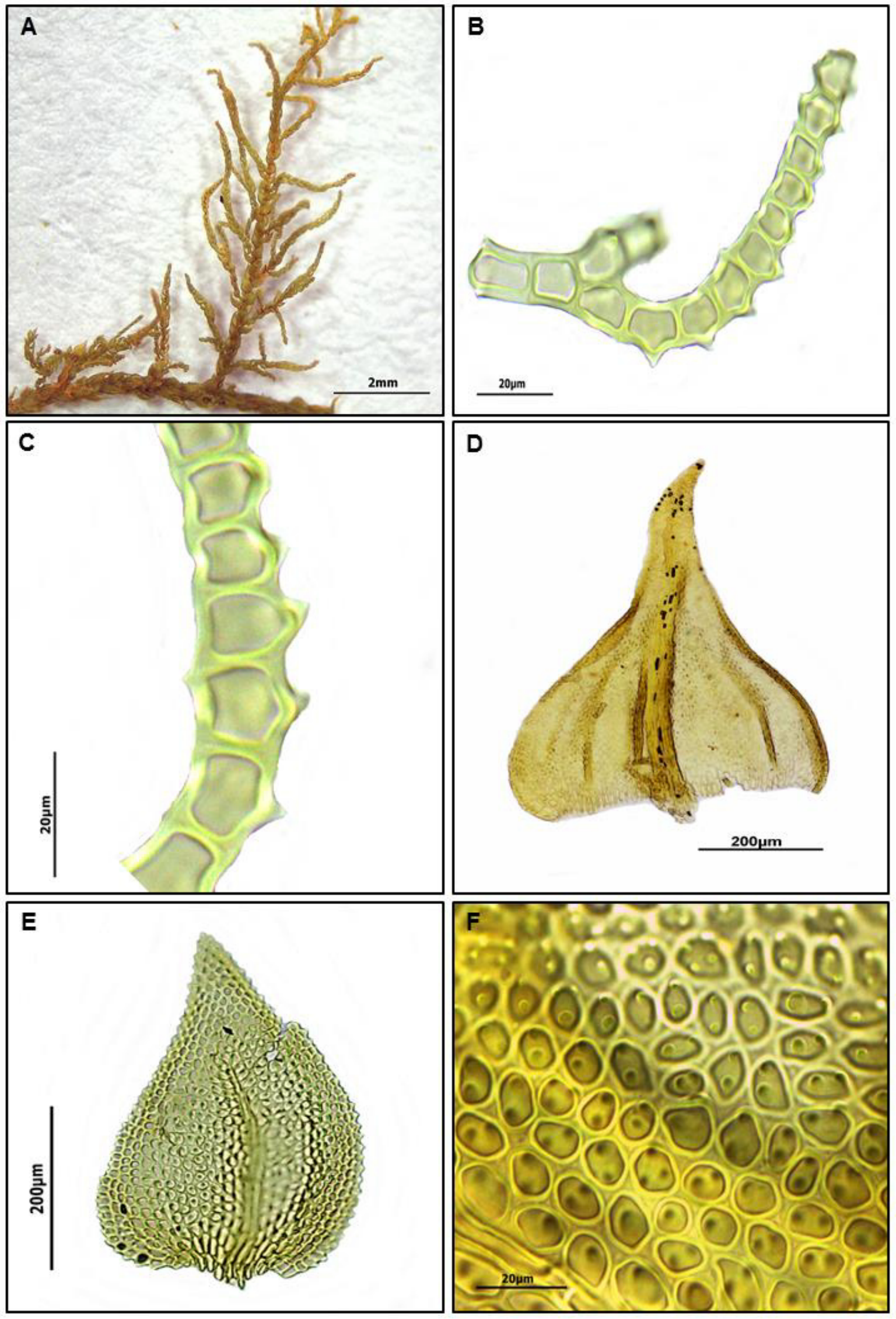

Figura 34: Thuidium tomentosum. A: Gametófito. B e C: Paráfilo. D: Filídio do caulídio. E: Filídio da ramificação. F: Células pluripapilosas do filídio do ramo. 
8. Thuidium urceolatum Lorentz., Moosstudien 167. 1864. - Tipo: JAMAICA. Nazareth, Wullschlaegel 1849 (isotype: NY!).

Hypnum pseudorecognitum Hampe., Vidensk. Meddel. Dansk Naturhist. Foren. Kjøbenhavn 1: 157. 1879. Thuidium pseudorecognitum (Hampe) Kindb., Enum. Bryin. Exot., suppl. 2, 104. 1891. - Tipo: BRASIL. Rio de Janeiro, Glaziou 3542 (holotype: BM!).

Thuidium acuminatum Mitt., J. Linn. Soc., Bot.12: 579. 1869. - Tipo: JAMAICA. sine loco, M'Nab 579 (lectotype designated here: NY!, isolectotype: BM!). March s.n. (isosyntype: NY!), Wilson 814 (isosyntype: NY!), Wilds s.n. (isosyntype: NY!), Heward s.n. (isosyntype: NY!).

Thuidium perrigidum Müll. Hal., Bull. Herb. Boissier 5: 567. 1897. - Tipo: JAMAICA. Morces Pass, W. Harris, s.n. (isotypes: BM!, NY!).

Fig. 35 e Fig. 36.

Plantas medianas a robustas, $15-20 \mathrm{~cm}$ compr., verde-amareladas. Caulídios arqueados, 2 a 3-pinado, ramificações com 12-18mm compr.; paráfilos abundantes, em menor quantidade ou ausente nas ramificações, 140-225 $\mu \mathrm{m}$ compr., 7-22 células, células medianas quadradas a curto-retangulares, ca. de 1-2:1, 6-12 $\mu \mathrm{m}$ compr., papilosas, com 1-2 papilas por células, células apicais truncadas. Filídios dos caulídios ereto-patentes quando secos, patentes quando úmidos, deltóides, 1,2-1,5×0,6-0,9mm, acuminados ou longo-acuminados, côncavos, plicados; margens crenulada-papilosas, planas, às vezes levemente recurvadas abaixo; costa percurrente, preenchendo os ápices dos filídios, faces abaxiais proeminentes, levemente rugosas na metade inferior; células medianas isodiamétricas ou curto-retangulares, 2-3:1, ca. de 14-20 $\mu \mathrm{m}$ compr., unipapilosas, papilas pequenas, paredes celulares delgadas; células apicais truncadas. Filídios das ramificações secundárias e terciárias eretos quando secos, patentes quando úmidos, ovados, 0,2-0,4×0,1-0,3mm, agudos, côncavos; margens crenuladapapilosas, planas; costa ca. de 5/6 do tamanho dos filídios; células medianas ovais ou subquadradas, 1-2:1, ca. de 7-11 $\mu \mathrm{m}$ compr., unipapilosas, papilas pequenas, paredes celulares incrassadas; células apicais truncadas, com 2-4 papilas. Periquécio, Seta, Peristômio e Esporos não foram observados.

Apresenta distribuição restrita, sendo conhecidos poucos exemplares. Caracteriza-se por apresentar paráfilos com células pequenas, quadradas e 
principalmente pelos filídios do caulídio que possuem costa percurrente, preenchendo o ápice.

Possui distribuição geográfica restrita, ocorrendo apenas em oito localidades, fazendo com que seu status de conservação, de acordo com os critérios da IUCN (2001), seja classificado como Vulnerável - VU (B1a,b(i, ii)).

Crescem sobre rochas e troncos em decomposição, em ambientes mésicos e úmidos, 300-1400m alt.

Ocorrem na América do Sul e Central.

Distribuição geográfica: AM, MG, RJ, RS e SP.

Domínios Fitogeográficos: Amazônia e Mata Atlântica.

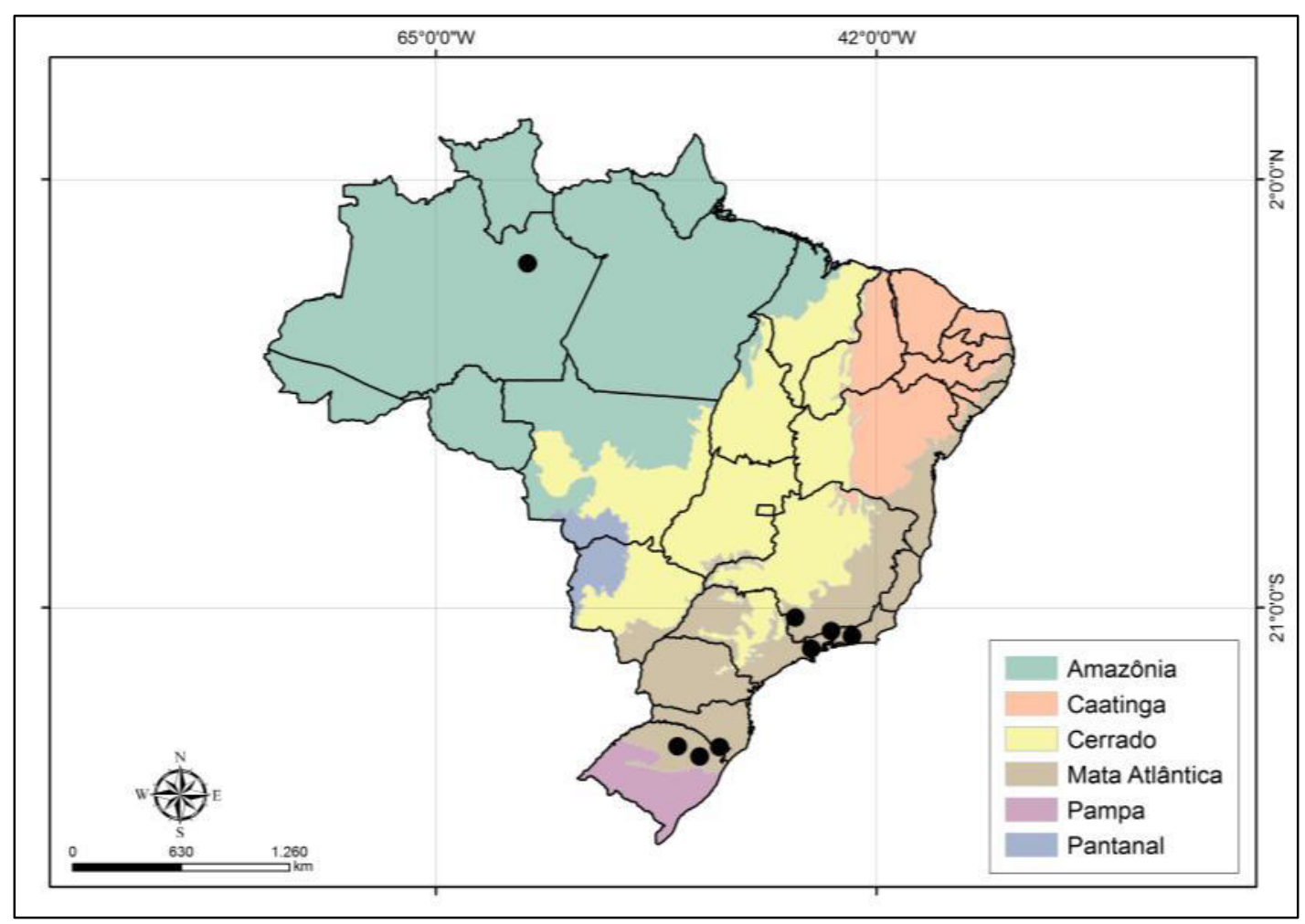

Figura 35: Mapa de distribuição de Thuidium urceolatum no Brasil.

Material Analisado: BRASIL: Amazonas: Rio Negro, Prance 16077 (NY). Minas Gerais: Caldas, Regnell s.n. (NY). Rio de Janeiro: Itatiaia, Vaughan s.n. (RB166916); Rio de Janeiro, Glaziou 9215 (NY). Rio Grande do Sul: Jaquirana, Wasum et al. 753 (NY); Nova Prata, Wasum et al. s.n. (HUCS 5332, NY); Nova Roma do Sul, Peralta 10473 (SP). São Paulo: Paraibuna, Vital 8763 (NY). 


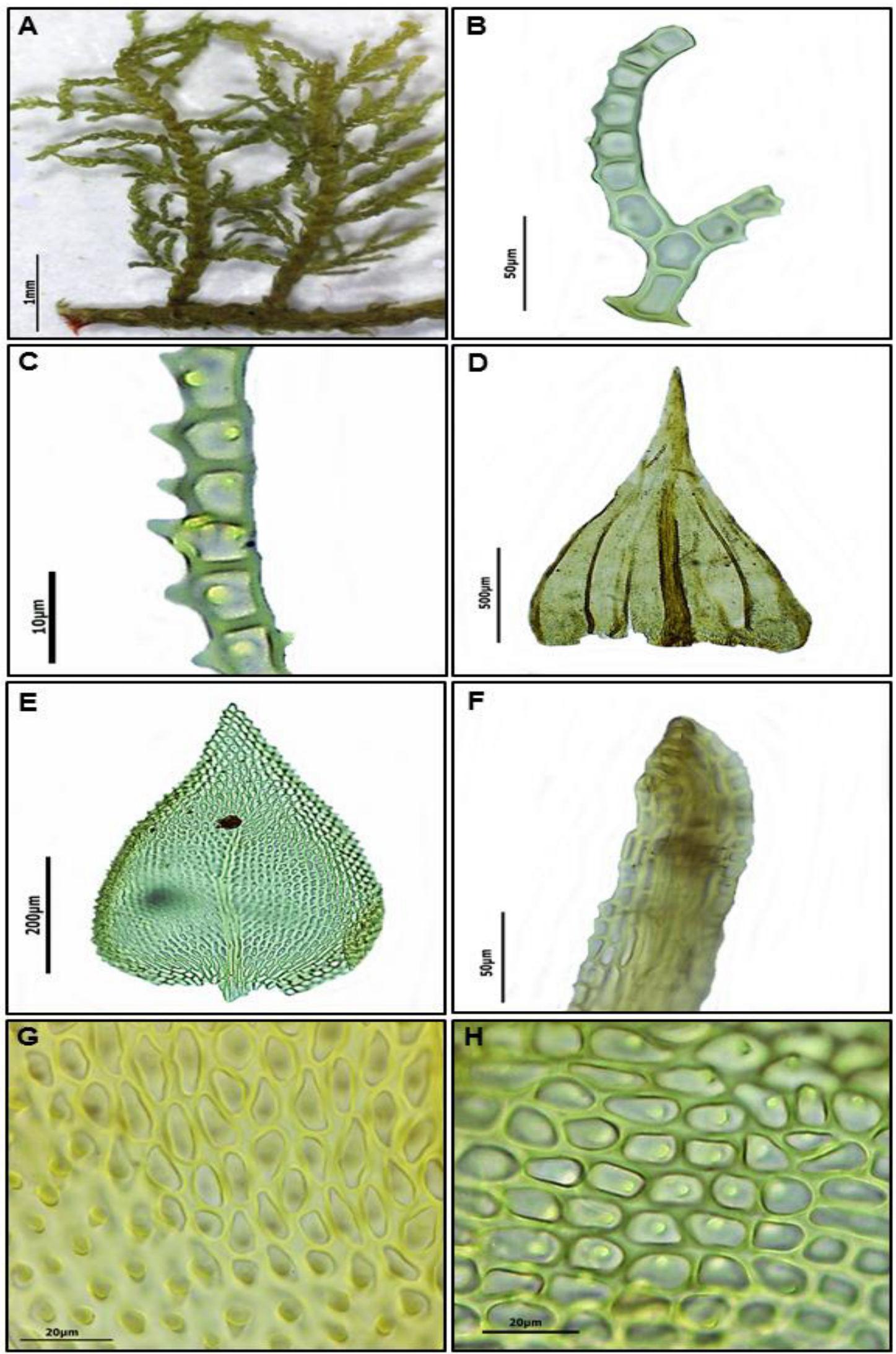

Figura 36: Thuidium urceolatum. A: Gametófito. B e C: Paráfilo. D: Filídio do caulídio. E: Filídio da ramificação. F: Ápice do filídio do caulídio preenchendo o ápice. G: Células unipapilosas do filídio do ramo. $\mathrm{H}$ : Células unipapilosas do filídio do caulídio. 


\section{Tipos não localizados e excluídos do estudo}

Thuidium granulatum (Hampe) A. Jaeger, Ber. Thätigk. St. Gallischen Naturwiss. Ges., 1877-78: 511 (Gen. Sp. Musc. 2: 775). 1880. Hypnum granulatum Hampe,

Vidensk. Meddel. Dansk Naturhist. Foren. Kjøbenhavn ser. 3, 10: 273. 1878. Tipo: BRAZIL. São Paulo, Rio Preto, Glaziou 9078 (PC?, BM?, LE?).

Conhecida somente pela espécie-tipo coletada por Glaziou em Rio Preto. O tipo foi localizado nos herbários BM, PC e LE, porém todas as exsicatas coletadas por Glaziou como o número 9078 tratavam-se de Dicranum subarctocarpum Hampe. Todavia, Hampe comenta na obra princeps que descreve Hypnum granulatum, que a mesma foi coletada juntamente com Dicranum. A espécie deve ter sido coletada em pequenas quantidades devido ao pouco material disponível em campo, o que fez com que a mesma se perde-se com o passar do anos e o excesso de uso da exsicata.

Thuidium serricola (Müll.Hal.) Paris, Index Bryol. Suppl. 321. 1900. Haplocladium serricola Müll. Hal., Bull. Herb. Boissier 6: 125. 1898. - Tipo: BRASIL. Santa Catarina, E. Ule 488. (B?, BM?, G?, H?, HBG?, NY?, PC?).

Conhecida somente pela espécie-tipo coletada por Ule em Santa Catarina. O tipo não foi localizado nos herbários visitados/estudados e não foram localizadas amostras nos herbários e nas coletas de campo realizadas. De acordo com a descrição original do tipo, a espécie aparentemente trata-se de um indivíduo de Haplocladium pertencente a família Leskeaceae, desta forma optou-se pela exclusão da mesma.

Thuidium subtamariscinum (Hampe) Broth., Acta Soc. Sci. Fenn. 19(5): 27. 1891. Hypnum subtamariscinum Hampe, Vidensk. Meddel. Dansk Naturhist. Foren. Kjøbenhavn ser. 4, 1: 157. 1879. - Tipo: BRASIL. sine loco, Reinhardt s.n.(BM?, NY?).

Conhecida somente pelo material tipo coletado no Brasil, sem localidade específica. Brotherus (1925) comentou que possivelmente $T$. subtamariscinum tratavase de um sinônimo de Thuidium brasiliense Mitt., toda via, ele acreditava que não era capaz de resolver a questão naquele momento. 
Thuidium costaricense Broth. \& Thér., Recueil Publ. Soc. Havraise Études Diverses 88: 314. 8. 1921. - Tipo: COSTA RICA, La Palma, C. Werkle s.n. (holotype: H?).

Não foi localizada nos herbários visitados e também nos herbários onde foram solicitados os empréstimos.

Cyrto-hypnum montei Hedenäs, Bryophyt. Biblioth. 44: 71. f. 19. 1992. - Tipo: ILHA DA MADEIRA. Barreto s.n. (syntype: MADS?).

Não foi localizada nos herbários visitados e também nos herbários onde foram solicitados os empréstimos. 


\section{Referências Bibliográficas}

Anderson, L.E. Hoyer's Solutionas a rapid mounting médium for bryophytes. The Bryologist 57: 242-244.

Bartram, E. B. 1939. Mosses of the Philippines.Philippine Journal of Science 68: 1-437.

Bartram, E. B. 1949. Mosses of Guatemala. Fieldiana, Botany 25: 1-442.

Breen, R. S. 1963. Mosses Florida. University Presses of Florida, Gainesville.

Brotherus, V. F. 1891. Contribution à la Flore bryologique du Brasil. Acta Societatis Scientiarum Fennicae 19(5): 27.

Brotherus, V. F. 1908. Bryales. 977-1019. In: A. Engler \& K. Prantl (eds.). Die naturlichen Pflanzenfamilien Part I(3), Engelmann, Leipzig.

Brotherus, V. F. 1925. Musci (Laubmoose). 2. Halfte. 1-542. In A. Engler (ed.), Die naturlichen Pflanzenfamilien, Zweite Auflage. 11. Duncker \& Humblot, Berlin.

Buck, W. R. 1998. Pleurocarpous mosses of the West Indies. Memoirs of the New York Botanical Garden 82: 1-400.

Buck, W. R. \& H. Crum. 1990. An evaluation of familial limits among the genera traditionally aligned with the Thuidiaceae and Leskeaceae. Contributions of the University of Michigan Herbarium 17: 55-69.

Buck, W. R. \& D. H. Vitt. 1986. Suggestionsfor a new familial classification of pleurocarpous mosses. Taxon 35: 21.

Costa, D. P. 2009. Briófitas. p. 13-17. In: J. R. Stehmann, R. C. Forzza, A. Salino, M. Cabral, D.P. Costa \& L. H. Y. Kamino (eds.). Plantas da Floresta Atlântica. Instituto de Pesquisas Jardim Botânico do Rio de Janeiro, Rio de Janeiro.

Costa, D.P. \& A. E. R. Soares. 2015. Thuidiaceae. In Lista de Espécies da Flora do Brasil. Jardim Botânico do Rio de Janeiro. Disponível em: <http://www.floradobrasil.jbrj.gov.br/jabot/floradobrasil>. Acesso: 10/1/2015.

Churchill, S. P. \& E. L. Linares. 1995. Prodromus bryologiae Novo-Granatensis: introducción a la flora de musgos de Colombia. Parte 2: Grimmiaceae a Trachypodaceae. Biblioteca José Jerónimo Triana 12(2): 831-843. 
Crum, H. 1973. Mosses of the Great Lakes forest. Contr. Univ. Michigan Herb.10: 1404.

Crum, H. A. \& L. E. Anderson. 1981. Mosses of EasternNorth America. 1. Columbia University Press, New York.

Crum, H. \& W. C. Steere.1957. The mosses of Porto Rico and the Virgin Islands. Sci. Surv. Porto Rico \& Virgin Islands 7(4a): 396-599.

Fleischer, M. 1922. Thuidiaceae. Die Musci der Flora von Buitenzorg 4: 1494-1533.

Gier, L. J. 1980. A preliminary study of the Thuidiaceae (Musci) of Latin America. Journal of Bryology 11: 253-309.

Gradstein, S. R., S. P. Churchill, N. Salazar-Allen. 2001. Guide to the Bryophytes of Tropical America. Memoirs of The New York Botanical Garden 86: 1-577.

Grout, A. J. 1932. Leskea and Pseudoleskea. pp. 185-196. In: Grout, A. J. (ed.), Moss Flora of North America v. 3. Newfane, Vermon.

Hedenäs, L. 1997. An Evaluation of Phylogenetic Relationships among the Thuidiaceae, the Amblystegiaceae, and the Temperate Members of the Hypnaceae. Lindbergia 22(3): 101-133.

IUCN. 2001. IUCN Red List Categories and Criteria: Version 3.1. IUCN Species Survival Commission. IUCN, Gland, Switzerland and Cambridge, UK.

Kindberg, N. C. 1897. Laubmoose aus dem Umanakdistrickt. Bibliotheca Botanica 87(A): 64-68.

Luizi-Ponzo, A. P., C. J. P. Bastos, D. P. Costa, K. C. Pôrto, P. E. A. S. Câmara, R. C. L. Lisboa, S. V. Bôas-Bastos. 2006. Glossarium Polyglottum Bryologiae: Versão Brasileira do Glossário Briológico. UFJF, Juiz de Fora.

Mitten, W. 1869. Musci austro-americana. Journal of the Linnean Society, Botany.12: $1-659$.

Schimper, W. P. 1852. Thedenia, Anisodon, Pseudoleskea, Heterocladium, Thuidium, Hylocomium, Thamnium, Rhynchostegium. Bryologia Europaea 49-51.

Schimper, W. P. 1860. Synopsis muscorum europaeorum. E. Schweizerbart, Stuttgart.

Schimper, W. P. 1876. Synopsis muscorum europaeorum praemissa introductione de elementis bryologicis tractante. Ed. 2. E. Schweizerbart, Stuttgart.

Spruce, R. 1867. Catalogus muscorum fere omnium quos in terris Amazonicis et Andinis legit Ricardius Sprucus per annos 1849-1860. London. 
Stehmann, J. R; R. C. Forzza, A. Salino, M. Sobral, D. P. Costa, D.P. \& L. H. Y. Kamino. Diversidade Taxonômica na Floresta Atlântica. In: Stehmann J. R., R. C. Forzza, A. Salino, M. Cabral, D. P. Costa \& L. H. Y. Kamino (eds.). Plantas da Floresta Atlântica. Instituto de Pesquisas Jardim Botânico do Rio de Janeiro, Rio de Janeiro.

Touw, A.2001a. A review of Thuidiaceae (Musci) and a realignment of taxa traditionally accommodated in Thuidium sensu amplo (Thuidium Schimp., Thuidiopsis (Broth.) M. Fleisch, and Pelekium Mitt.) including Aequatoriella gen. nov. and Indothuidium gen. nov. Journal of the Hattori Botanical Laboratory 90: 167-209.

Touw, A. 2001b. A Taxonomic Revisionof the Thuidiaceae (Musci) of Tropical Asia, the Western Pacific, and Hawaii. Journal of the Hattori Botanical Laboratory 91: 1-136.

Warnstorf, C. 1904-1906. Kryptogamenflora der Mark Brandenburg, Laubmoose 5. Gebrüder Borntraeger, Leipzig.

Watanabe, R. 1972. A revision of the family Thuidiaceae in Japan and adjacent areas. Journal of the Hattori Botanical Laboratory 36: 171-320.

Yano, O. 2011. Catálogo de musgos brasileiros: literatura original, basiônimo, localidade-tipo e distribuição geográfica. Instituto de Botânica: São Paulo. 